\title{
Physical Oceanographic Processes at Candidate Dredged-Material Disposal Sites B1B and 1M Offshore San Francisco
}

Volume 2: Appendixes
C. R. Sherwood
D. W. Denbo
D. A. Coats
J. P. Downing

October 1990

Prepared for

U.S. Army Corps of Engineers - San Francisco District under a Related Services Agreement

with the U.S. Department of Energy

Contract DE-AC06-76RLO 1830

Pacific Northwest Laboratory Operated for the U.S. Department of Energy

by Battelle Memorial Institute 


\title{
DISCLAIMER
}

This report was prepared as an account of work sponsored by an agency of the United States Government. Neither the United States Government nor any agency thereof, nor Battelle Mernorial Institute, nor any of their employees, makes any warranty, expressed or implied, or assumes any legal liability or responsibility for the accuracy, completeness, or usefulness of any information, apparatus, product, or process disclosed, or represents that its wse would not infringe privately owned rights. Reference herein to any specific commercial product, process, or service by trade name, trademark, manufacturer, or otherwise, does not necessarily constitute or imply its endorsement, recommendation, or favoring by the United States Govemment or any agency thereof, or Battelle Mernorial Institute. The views and opinions of authors expressed herein do not necessarily state or reflect those of the United States Government or any agency thereof.

\author{
PACIFIC NORTHWEST LABORATORY \\ operated by \\ BATTELLE MEMORIAL INSTITUTE \\ for the \\ UNITED STATES DEPARTMENT OF ENERGY \\ under Contract DE-ACO6-76RLO 1830
}

Printed in the United States of America

Availabie to DOE and DOE contractors from the

Office of Scientific and Terbnical Information, P.O. Box 62, Oak Ridge, TN 37831; prices available from (615) 576-8401. FTS 626-8401.

Available to the public from the National Technical Information Service,

U.S. Deparinent of Commerce, 5285 Porr Royal Rd., Springfield, VA 22161.

NTIS Price Cindes, Misrofiche A01

Printed Copy

\begin{tabular}{ccccc}
\hline Price Code & Page Range & & Price Code & Page Range \\
\cline { 5 - 5 } & & & A15 & $326-350$ \\
A02 & $1-10$ & & A16 & $351-375$ \\
A03 & $11-50$ & & A17 & $376-400$ \\
A04 & $51-75$ & & A18 & $401-425$ \\
A0S & $76-100$ & & A19 & $426-450$ \\
A06 & $101-125$ & & A20 & $451-475$ \\
A07 & $126-150$ & & A21 & $476-500$ \\
A08 & $151-175$ & & A22 & $501-525$ \\
A09 & $176-200$ & & A23 & $526-550$ \\
A10 & $201-225$ & & A24 & $551-575$ \\
A11 & $226-250$ & & A25 & $576-600$ \\
A12 & $251-275$ & & & $601-U P$ \\
A13 & $276-300$ & $301-325$ & &
\end{tabular}


PNL-7553 VoT. 2

UC -603

PHYSICAL OCEANOGRAPHIC PROCESSES AT

CANDIDATE DREDGED-MATERIAL DISPOSAL

SITES BIB AND IM

OFFSHORE SAN FRANCISCO

Volume 2: Appendixes

C. R. Sherwood

D. A. Coats $(a)$

D. W. Denbo

J. P. Downing

Battelle/Marine Sciences Laboratory

Sequim, Washington

October 1990

Prepared for

U.S. Army Corps of Engineers-San Francisco District under a Related Service Agreement

with the U.S. Department of Energy

Contract DE-AC06-76RL0 1830

Pacific Northwest Laboratory

Richland, Washington 99352

(a) Marine Research Specialists

3639 Harbour Boulevard, Suite 208 


\section{PREFACE TO VOLUME 2}

This is volume 2 of a two-volume report that presents information gathered during a study of two candidate dredged-material disposal sites located offshore San Francisco. Volume 1 contains project background, summary of methods, results, discussion, and conclusions; this volume contains several appendixes that provide details of the data analyses and full presentations of data and results. 


\section{.}

$\checkmark$ 


\section{SUMMARY}

The U.S. Army Corps of Engineers (USACE), San Francisco District, has identified two candidate sites for ocean disposal of material from several dredging projects in San Francisco Bay. The disposal site is to be designated under Section 103 of the Ocean Dumping Act. One of the specific criteria in the Ocean Dumping Act is that the physical environments of the candidate sites be considered. Toward this goal, the USACE requested that the Pacific Northwest Laboratory ${ }^{(a)}$ conduct studies of physical oceanographic and sediment transport processes at the candidate sites. Details of the methods and complete listing or graphical representation of the results are contained in this second volume of the two-volume report.

Appendix $A$ describes the methods and results of a pre-disposal bathymetric survey of Site BIB, and provides an analysis of the accuracy and precision of the survey. Appendix $B$ describes the moorings and instruments used to obtain physical oceanographic data at the candidate sites, and also discusses other sources of data used in the analyses. Techniques used to analyze the information, processed data, and complete results of various analyses are provided in tabular and graphical form. Appendix $C$ provides details of the sediment transport calculations. Appendix $D$ describes the format of the archived current meter data, which is available through the National Oceanographic Data Center.

(a) Pacific Northwest Laboratory is operated for the U.S. Department of Energy Battelle Memorial Institute under Contract DE-AC06-76RL0 1830. 
- 


\section{CONTENTS}

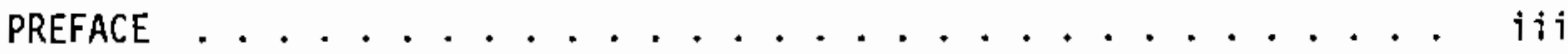

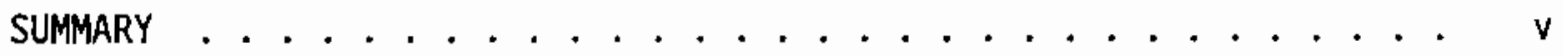

APPENDIX A - BATHMETRIC DATA REPORT, PRE-DISPOSAL SURVEY, SITE BIB . . A.1

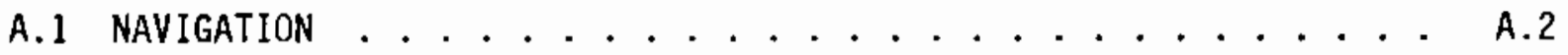

A.2 BATHYMETRY . . . . . . . . . . . . . A.4

A.3 DATA PROCESSING . . . . . . . . . . . . . . . A.6

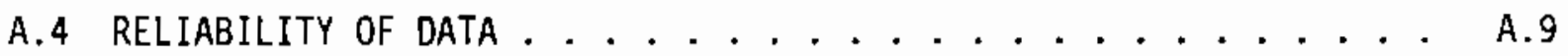

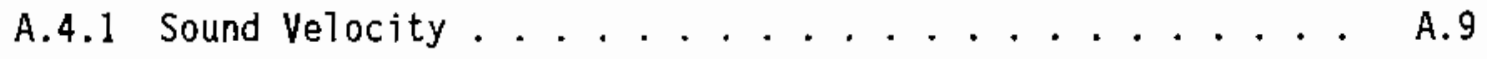

A.4.2 Heave/Pitch/Roll .................... Al

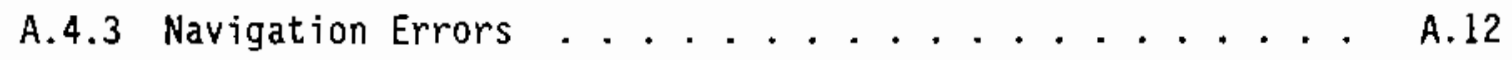

A.4.4 Waves and Swe11 .................... A.12

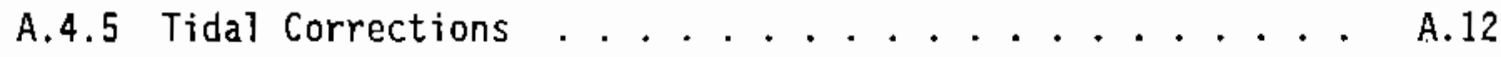

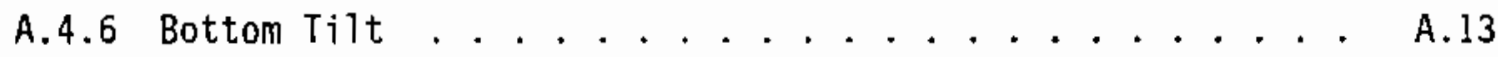

A.4.7 Combined Effects of A11 Sources of Error........ A.13

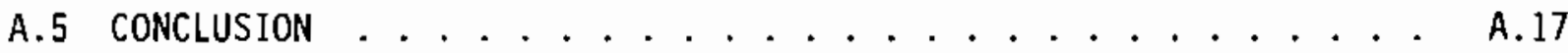

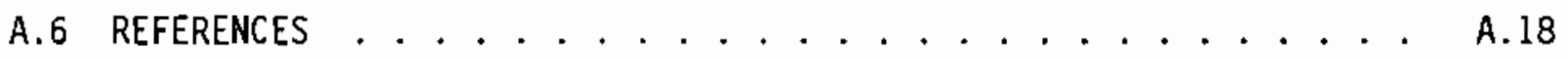

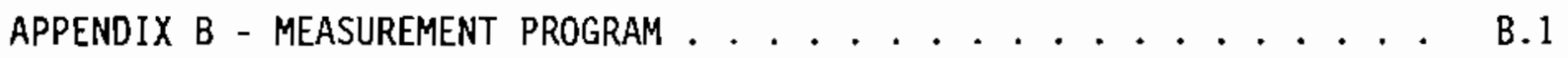

B.I MOORINGS AND INSTRUMENTS ............ B.2

B.1.1 Acoustic Current Meter . . . . . . . . . B.2

B.1.2 Electromagnetic Wave Current Meter . . . . . . B.2

B.1.3 Optical Backscatter Sensors ............ B.3

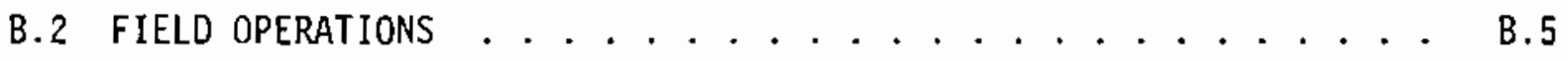

B.2.1 First Deployment . . . . . . . . . B.5 
B.2.2 Second Deployment . . . . . . . . . . . B.6

B.2.3 Third Deployment . . . . . . . . . . B.7

B.2.4 Fourth Deployment ............ B.8

B.2.5 Deployment Problems ............. B.9

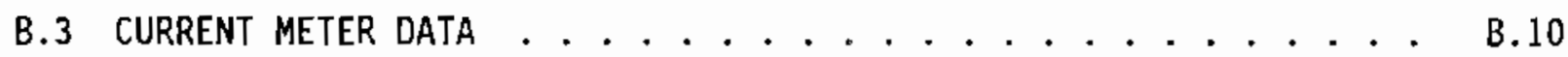

B.3.1 Processing ........................ B. .

B.3.2 Filtering ......................... B.

8.3.3 Spectral Anatysis ............... B.1I

B.3.4 Principal Components Analysis .......... B.13

B.3.5 Tidat Anatysis . . . . . . . . . . . . B.13

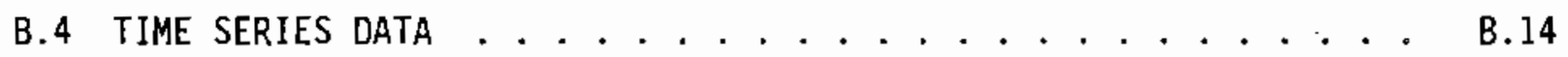

B.4.1 Winds ............................ B.

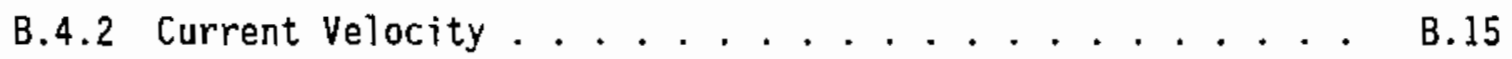

B.4.3 Water Temperature .................... B. .

B.4.4 Waves at Montara .............. B.16

B.4.5 Suspended Sediment .............. B.17

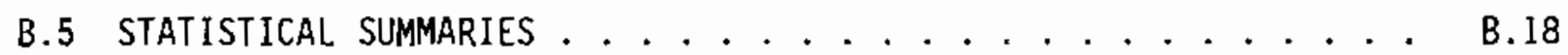

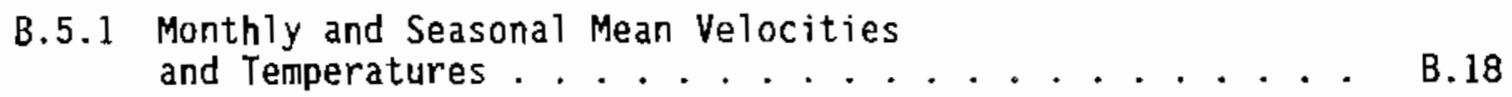

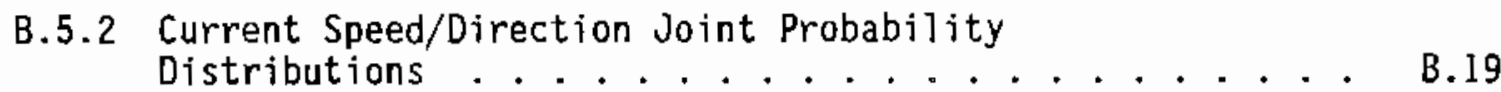

B.5.3 Principal Components ................... B. . .

B.6 SPECTRAL AND TIDAL HARMONIC ANALYSES OF CURRENTS ....... B.20

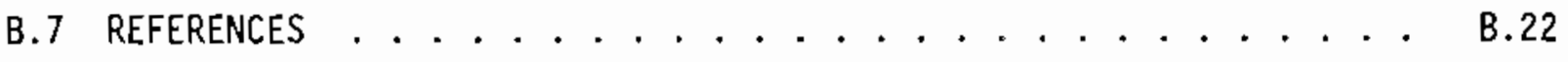

APPENDIX C - SEDIMENT TRANSPORT CALCULATIONS . . . . . . . . c.l

C.1 WAVE-CURRENT BOUNDARY LAYER MODEL ........... C.2 


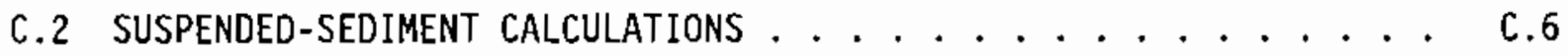

C.3 INPUT FOR SEDIMENT-TRANSPORT CALCULATIONS .......... . . . .

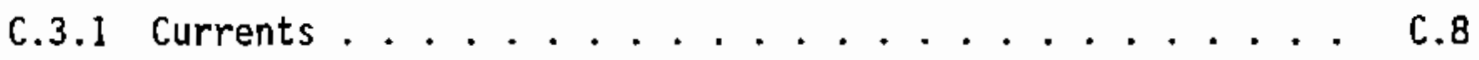

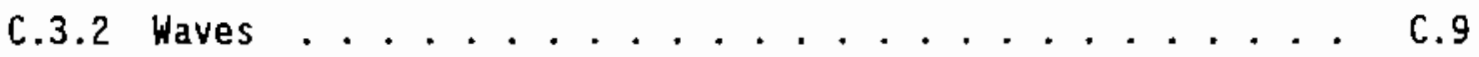

C.3.3 Bottom-Sediment Parameters ............ C.11

C.4 RESULTS AND DISCUSSION . . . . . . . . . . . . . c.11

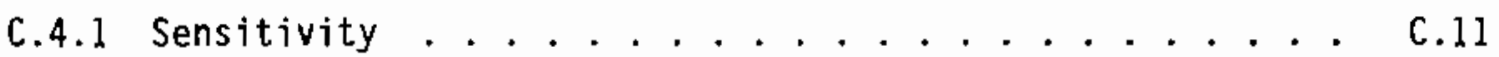

C.4.2 Calculated Sediment Transport .......... C.16

C.4.3 Comparison with Optical Backscatterance Data . . . . . . c.19

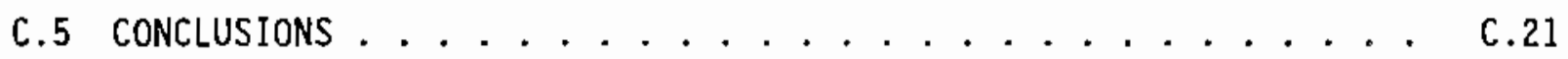

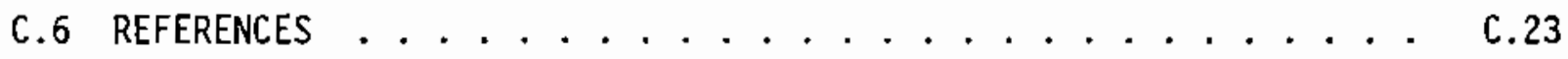

APPENDIX 0 - CURRENT METER DATA FILE FORMAT $\ldots \ldots \ldots . \ldots . \ldots . \ldots$

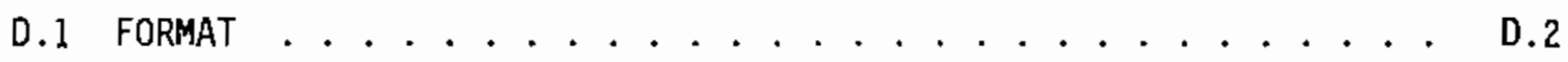

D.1.1 Disk Format . . . . . . . . . . . 0.2

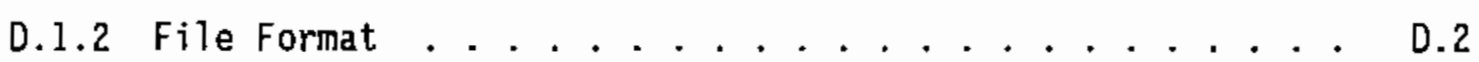

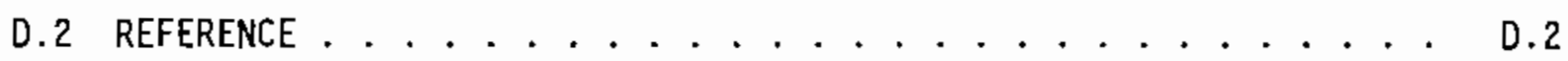




\section{FIGURES}

A.1 Chart of the Gulf of the Farallones Including Proposed

Dredged-Material Disposal Site B1B ............ A.3

A.2 Chart of Track Lines Followed During Bathymetric Survey at Site BlB ..................... A.5

A.3 Tidal Heights Used to Correct Bathymetric Data During the Survey ...................

A.4 Depth Data from a Typical Track Line Before and After Smoothing ................. A.8

A.5 Final Bathymetric Map Contoured from 200-ft Grid . . . . . . A.10

A.6a Contour Map of the Difference Found by Subtracting Depth Grid Based on Even-Numbered Primary Track Lines from Grid Based on Odd-Numbered Primary Track Lines . . . . . . . . . . . . . .

A.6b Contour Map of the Difference Found by Subtracting Depth Grid Based on Even-Numbered Primary Track Lines from Grid Based on Secondary Track Lines . . . . . . . . . . . . . . .

A.6c Contour Map of the Difference Found by Subtracting Depth Grid Based on Odd-Numbered Primary Track Lines from Grid Based on Secondary Track Lines

B.1 Map of the Study Area Showing Locations of CurrentMeter Moorings, Wave Gage, and Meteorological Buoy

B.2 Configuration of Mooring Deployed at Site B1B . . . . . B.26

B.3 Configuration of Mooring Deployed at Site 1M ...... B.27

B.4 Sediment Grain Size Distribution and Cumulative Size Curves . . B.28

B.5 Calibration Curves for DBS Sensor S/N 67 Before and

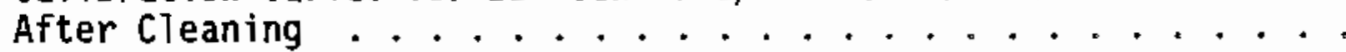

B.6 Calibration Curves for OBS Sensor S/N 68 Before and After Cleaning

B.7 Calibration Curves for OBS Sensor $S / N$ 88 Before Deployment 4 at Site BlB. .............

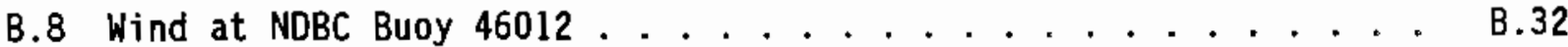


B.9 Vector Plot of 40-h Low-Pass Filtered

Current Velocity at Site BlB ............. B.32

B.10 Vector Plot of 40-h Low-Pass Filtered

Current Velocity at Site 1M ............. B.33

B.11 Alongshore Component of 40-h Low-Pass Filtered

Current Velocity at Site BlB ............. B.33

B.12 Alongshore Component of 40-h Low-Pass Filtered

Current Velocity at Site $1 M \ldots . \ldots . . . . . . .3 .34$

B.13 Cross-Shelf Components of 40-h Low-Pass Filtered

Current Velocity at Site BIB ............. B.34

B. 14 Cross-Shelf Component of 40-h Low-Pass Filtered

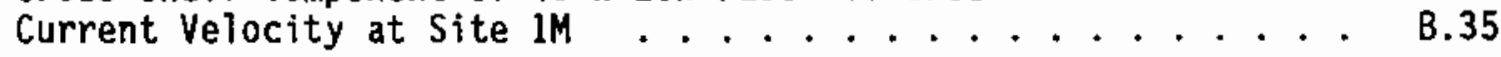

B.15 Time Series of Monthly Mean Alongshore Velocity Components

for Sites B1B, IM, and SuperCODE Mooring H3 . . ...... B.36

B.16 Time Series of Monthly Mean Cross-Shelf Velocity

Component for Sites B1B and IM ............ B.37

B.17 Time Series of 40-h Low-Pass Filtered Water Temperature

from Current Meters at Sites $\mathrm{BIB}$ and $\mathrm{IM}$........... B.38

B.18 Time Series of Monthly Mean Water Temperature

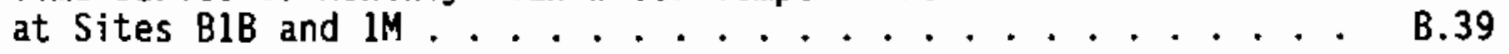

B.19 Time Series of Significant Wave Height and Dominant Period

Recorded at Montara Pressure Gage Array . . . . . . . . B.40

B.20 Cumulative Frequency Distributions of Significant Wave Height and Dominant Period Record at Montara Pressure

Gage Array.

B.21 Examples of Raw OBS Data, Despiked and Filtered Output

Showing Baseline Trend, and Concentrations Estimated

with the Detrended Data and the Calibration Coefficients. . . B.42

B.22 Time Series of Raw OBS Output Voltage and Estimated Sediment

Concentration for Complete Record at Site B1B . . . . . . . B.43

B.23 Time Series of Raw OBS Output Voltage and Estimated Sediment

Concentration for Complete Record at Site 1M . . . . . . . B.44

B.24 Scatter Plots, Principal Component Axes, and Joint Probability of Occurrence Contours for $40-\mathrm{h}$ Low-Pass Filtered Current Velocity at Site B1B. 
B.25 Scatter Plots, Principal Component Axes, and Joint Probability of Occurrence Contours for 40-h Low-Pass Fi7tered Current

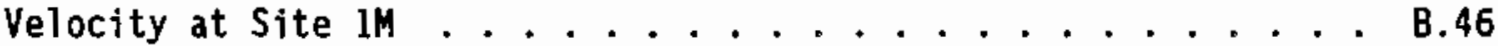

B.26 Autospectra of Components of Current Velocity for the Entire Records ... . . . . . . . . . . B.47

B.27 Autospectra of Water Temperature for the Entire Records . . . . B.48

B.28 Coherence and Phase Spectra of Components from Cross-Spectral Analysis of Pairs of Current Velocity

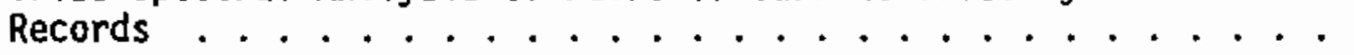

B.29 Coherence and Phase Spectra of Components from CrossSpectral Analysis Between Current Velocity at Site BlB and Wind at Buoy 46012 for the Entire Records . . . . . . . . B. B0

B.30 Computed Tidal Current Ellipses for M2 and K1 Tidal

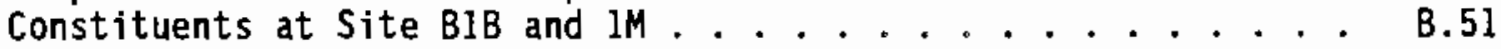

C.1 Representative Velocity Profile, Suspended-Sediment Profile, and Flux Profile Calculated for High ShearStress Conditions at Site B1B ............ C.26

C.2 Bottom Shear Stresses Computed Using the Grant-Madsen Model . . C.27

C.3 Plot of the Nikuradse Bottom Roughness $\left(\mathrm{z}_{\mathrm{oN}}\right)$ Function ..... C.28

C.4 Input Time Series for Sediment Transport Calculations...... C.29

C.5 Schematic Illustration of Significant Orbital-Velocity Amplitude Calculation From Surface Wave Spectrum ....... C.30

C.6 Sediment Grain-Size Distribution Histograms and Cumulative Frequency Plots for Bottom-Grab Samples ......... C.31

C.7 Cumulative Frequency Distributions for Combined Shear

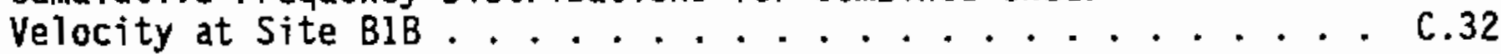

C.8 Cumulative Frequency Distributions for Combined Shear Velocity at Site $1 M \ldots . \ldots . . . . . . . . . .33$

C.9 Progressive Vector Diagrams for Currents at Site B1B . . . . . C.34

C.10 Progressive Vector Diagrams for Currents at Site 1M ..... C.35

C.11 Time Series of Calculated Combined Shear Velocity and Calculated Suspended Sediment Concentrations at Site B1B and Site $1 M$ 
C.12 Calculated Cumulative Erosion Depths at Sites B1B and 1M.... C.37

C.13 Time Series of Calculated Alongshore and Cross-Shelf Sediment Flux, and Cumulative Alongshore and Cross-Shelf

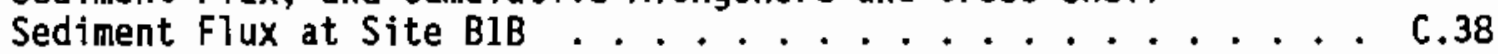

C.14 Time Series of Calculated Alongshore and Cross-Shelf Sediment Flux, and Cumulative Alongshore and Cross-Shelf

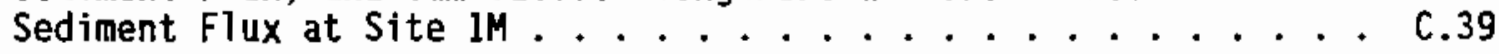

C.15 Time Series of Sediment Concentrations at $36 \mathrm{~cm}$ Above the Bed Estimated from Optical Backscatterance Data ........ . C.40

C.16 Principal Axes and Means of Sediment Flux and Near-Bottom Currents at Sites BIB and IM ................... 


\section{IABLES}

A.1 List of Shore Reference Locations Used . . . . . . . A.4

A.2 Estimates of Errors Associated with Depth, and Controls Used to Reduce Contributions from Each Error Source in the

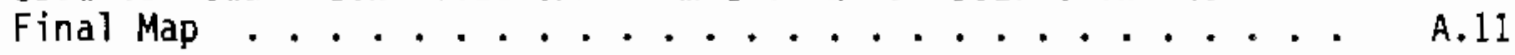

A.3 Differences Between Three Independent Maps of the Bathymetry

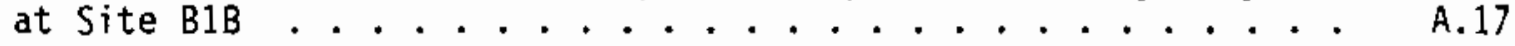

B.1 Summary of Current Meter and Suspended Sediment Measurement Program .................. B.52

B.2 Specifications of Instruments Deployed at Site B1B ..... B.54

B.3 Regression Coefficients from Optical Backscatterance Sensor Calibrations ...................... B.54

B.4 Tidal Constituent Names and Frequencies .......... B.55

B.5 Tidal Analysis Results in Current Ellipse Form for Site B1B $(21 \mathrm{~m}) \ldots \ldots . \ldots . \ldots . . \ldots . . \ldots 66$

B.6 Tidal Analysis Results in Current Ellipse Form for

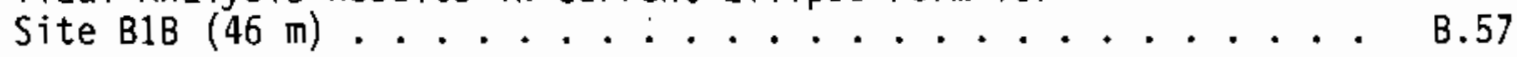

B.7 Tidal Analysis Results in Current Ellipse Form for

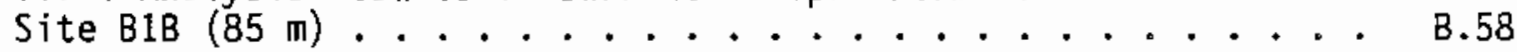

B.8 Tidal Anatysis Results in Current Ellipse Form for

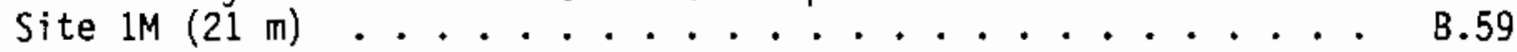

B.9 Tidal Analysis Results in Current Ellipse Form for

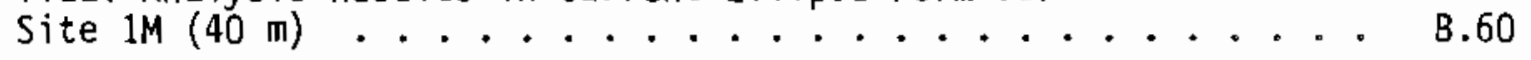

B.10 Joint Probability Distribution of Significant Wave Height and Period at Montara ................... B.61

B.11 Monthly Means and Standard Deviations of Alongshore Velocity for site B1B $(21 \mathrm{~m}) \ldots \ldots \ldots . \ldots \ldots$. . . . . . . . .

B.12 Monthly Means and Standard Deviations of Cross-Shelf Velocity for site B1B $(21 \mathrm{~m}) \ldots \ldots \ldots . . \ldots$

B.13 Monthly Means and Standard Deviations of Alongshore Velocity for Site B1B $(46 \mathrm{~m}) \ldots \ldots \ldots$ 
B.14 Monthly Means and Standard Deviations of Cross-Shelf Velocity for site B1B $(46 \mathrm{~m}) \ldots \ldots \ldots . \ldots . \ldots . \ldots . \ldots$

B.15 Monthly Means and Standard Deviations of Alongshore Velocity for Site B1B $(85 \mathrm{~m}) \ldots \ldots \ldots . \ldots \ldots$

B.16 Monthly Means and Standard Deviations of Cross-Shelf Velocity

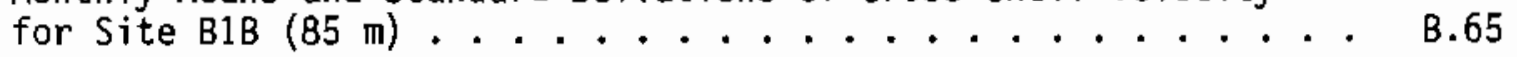

B.17 Monthly Means and Standard Deviations of Alongshore Velocity for site $1 M(21 \mathrm{~m}) \ldots \ldots . \ldots . \ldots . . \ldots$. . . . . . . . .

B.18 Monthly Means and Standard Deviations of Cross-Shelf Velocity

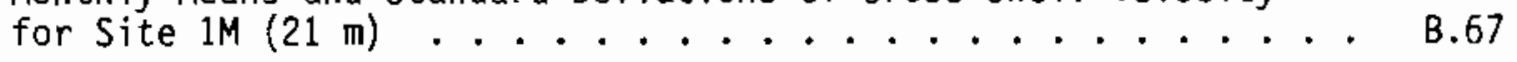

B.19 Monthly Means and Standard Deviations of Alongshore Velocity

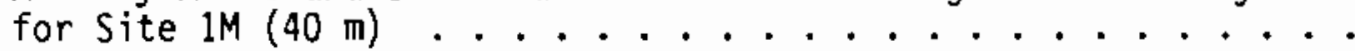

B.20 Monthly Means and Standard Deviations of Cross-Shelf Velocity

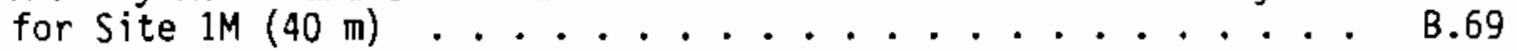

B.21 Monthly Means and Standard Deviations of Temperature for

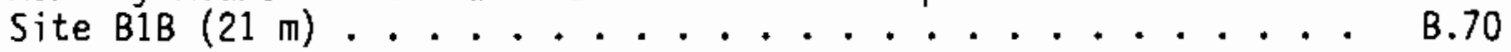

B.22 Monthly Means and Standard Deviations of Temperature for Site B1B $(46 \mathrm{~m}) \ldots \ldots \ldots \ldots . \ldots . \ldots$

B.23 Monthly Means and Standard Deviations of Temperature for Site B1B $(85 \mathrm{~m}) \ldots \ldots \ldots \ldots$

B.24 Monthly Means and Standard Deviations of Temperature for Site $1 \mathrm{M}(21 \mathrm{~m}) \ldots \ldots \ldots \ldots . . \ldots$

B.25 Monthly Means and Standard Deviations of Temperature for Site $1 \mathrm{M}(40 \mathrm{~m}) \ldots \ldots \ldots \ldots$

B.26 Seasonal Means and Standard Deviations of Alongshore Velocity..

B.27 Mean and Standard Deviations of All Stations and Variables for the Complete Record ...............

B.28 Joint Probability Distribution of Site B1B $(21 \mathrm{~m})$ for Spring/Summer .......................... B

B.29 Joint Probability Distribution of Site B1B (21 m)

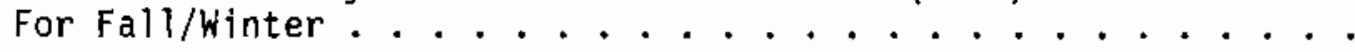

B.30 Joint Probability Distribution of Complete Record for Site B1B $(21 \mathrm{~m}) \ldots \ldots \ldots$ 
B.31 Joint Probability Distribution of Site B1B (46 m)

for Spring/Surmer ................

B.32 Joint Probability Distribution of Site B1B (46 m)

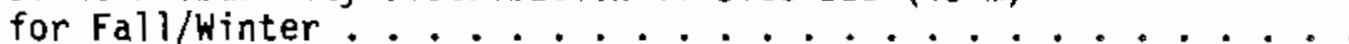

B.33 Joint Probability Distribution of Complete Record for Site B1B $(46 \mathrm{~m}) \ldots \ldots \ldots . \ldots . \ldots . \ldots . . \ldots$

B.34 Joint Probability Distribution of Site B1B (85 m) for Spring/Summer $\ldots \ldots \ldots \ldots$

B.35 Joint Probability Distribution of Site B1B ( $85 \mathrm{~m})$ for Fall/winter..................

B.36 Joint Probability Distribution of Site B1B (85 m)

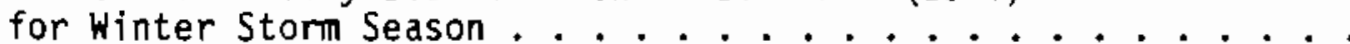

B.37 Joint Probability Distribution of Complete Record for Site BlB $(85 \mathrm{~m}) \ldots \ldots \ldots$

B.38 Joint Probability Distribution of Site 1 M (21 m) for Spring/Sumner .................

B.39 Joint Probability Distribution of Site $1 \mathrm{M}(21 \mathrm{~m})$

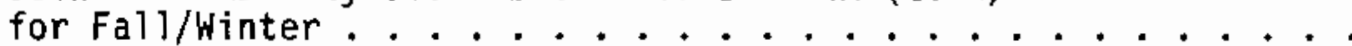

B.40 Joint Probability Distribution of Complete Record for site $1 \mathrm{M}(21 \mathrm{~m}) \ldots \ldots \ldots$

B.41 Joint Probability Distribution of Site $1 M(40 \mathrm{~m})$ for Spring/Summer ................

B.42 Joint Probability Distribution of Site $1 M(40 \mathrm{~m})$

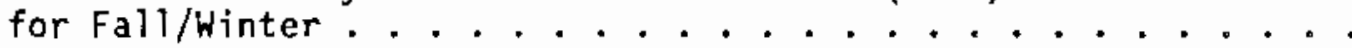

B.43 Joint Probability Distribution of Site $1 M(40 \mathrm{~m})$

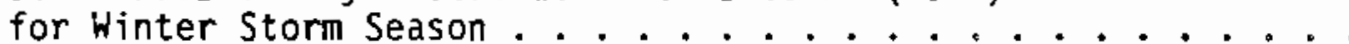

B.44 Joint Probability Distribution of Complete Record for Site $1 M(40 \mathrm{~m}) \ldots \ldots \ldots$

B.45 Principal Components of Current Meters for Complete Record . . . B.91

B.46 Principal Components of Current Meters for Spring/Sunmer and Fall/Winter Seasons ...............

B.47 Average Percentage of Alongshore Variance by Frequency Band . . . 
C.1 Distribution Statistics for Wave Height and Period

at Montara, and Wave-Orbital Velocity Aplitude and Period

at Sites B1B and $1 M$................ C.42

C.2 Joint-Probability Distribution of Wave Orbital

Velocity Amplitude and Period at Site $1 M$. . . . . . . . C.42

C.3 Joint Probability Distribution of Wave Orbital

Velocity Amplitude and Period at Site B1B . . . . . . . . C.43

C.4 Bottom Sediment Characteristics Used In Transport

Calculations ................. c.... . . . . . . . .

C.5 Summary of Parameters Varied in Transport Calculations. . . . . C.43

D.1 Sumnary of Current-Meter Data Files in NODC Format . . . . . D.3

D.2 NODC File Format . . . . . . . . . . . . . 0.4

D.3 NODC File Sample . . . . . . . . . . . . . . D.6 


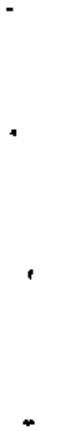


APPENDIX A

BATHYMETRIC DATA REPORT PRE-DISPOSAL SURVEY SITE BIB 
APPENDIX A

\section{BATHYMETRIC DATA REPORT PRE-DISPDSAL SURVEY SITE BIB}

This appendix was initially prepared as a data report for the U.S. Army Corps of Engineers (USACE), San Francisco District, by the Pacific Northwest Laboratory (PNL), as part of the 0akland Inner Harbor Dredged Material Disposal Monitoring Project. The report described results of an initial bathymetric survey performed at candidate dredged material disposal Site BlB before any disposal operations. The survey provides coverage of a circular area with a radius of 1 nautical mile ( $\mathrm{nmi}$ ), centered at $37^{\circ} 29^{\prime} 00^{\prime \prime} \mathrm{N}$ latitude, $122^{\circ} 48^{\prime} 00^{\prime \prime} \mathrm{W}$ longitude, on the continental shelf approximately $12 \mathrm{nmi}$ west of Half Moon Bay. This survey is intended to serve as a baseline for comparison with later, post-disposal surveys. No subsequent surveys have yet been performed, because dredging operations were suspended.

The bathymetric survey was performed from the vessel $\underline{R} / \mathrm{V}$ David Johnston, on charter from the Institute of Marine Science at University of California, Santa Cruz, on April 26-28, 1988. The vessel was operated by Gordon Smith. The scientific party was directed by Chris Sherwood of PNL and included subcontractors from Battelle Ocean Sciences (Ventura Operations), Williamson and Associates (Seattle, Washington), and Chris Ransome and Associates (CRA; Houston, Texas). Williamson and Associates were responsible for all equipment and data collection; their subcontractor (CRA) provided navigation equipment and services.

Survey operations were mobilized from Pillar Point Harbor, Half Moon Bay, California. Initial survey lines were run beginning at 2215 PST on Monday, Apri1 25. The survey was suspended at 0700 on Tuesday, April 26, because of poor reception from the Point Bonita shore reference station. Work resumed at 0315 on Wednesday, April 27, and was completed at 1422 on Thursday, April 28. The $\mathrm{R} / \mathrm{V}$ David Johnston was demobilized and released Thursday evening. 


\section{A. 1 NAVIGATION}

Navigation data were obtained using a Del Norte 545 UHF $^{\circ}$ microwaveranging system with a ship transceiver and four shore transponders. Primary shore reference stations were located on U.S. Geological Survey (USGS) monument "Ridge," located on Mt. Tamalpais and USGS monument "San," just north of San Gregorio State Park. Secondary stations were located at U.S. Coast Guard-maintained lighthouses on Points Bonita and Montara. These locations are shown in Figure A.1, and coordinates of shore reference stations are listed in Table A.l. The navigation equipment was calibrated on a measured 7-mile over-water range on Monday, April 20. Additional shore station calibrations were performed on Tuesday, April 21, and Wednesday, April 22. An onboard computer with custom software acquired range information from the UHF transceiver and depth recorder, performed calculations to generate navigation fixes in state $p l$ ane coordinates, logged all data on 3.5-in. disks, provided real-time track-line display to the helmsman, and generated real-time track-line plots. Error ellipses were available to the navigator, and the optimal number of shore stations was determined and used. Because intersection angles were nearly $90^{\circ}$ and reception of the shore stations was very good, two shore reference stations were normally used. When shore reference station reception was momentarily interrupted for any reason, the on-board computer generated a dead-reckoning position for the helmsman every 15 seconds. The dead-reckoned fixes were replaced with interpolated positions in post-processing. Less than $1 \%$ of the fixes were interpolated.

Track-1ine orientation was dictated by the dominant swell direction. Primary track lines were oriented NW-SE $\left(315^{\circ}\right.$ to $\left.135^{\circ} \mathrm{T}\right)$ and run with line spacing of $165 \mathrm{ft}$. Cross lines were run perpendicular to the primary lines $\left(45^{\circ}\right.$ to $\left.225^{\circ} \mathrm{T}\right)$ with line spacing of $660 \mathrm{ft}$. A total of 74 primary 1 ines and 19 secondary (cross) lines were run, amounting to approximately 185 nautical survey miles. Odd-numbered lines were run first to obtain rapid areal

- Del Norte 545 UHF is a registered tradename of Del Norte Technology, Inc., Euless, Texas. 


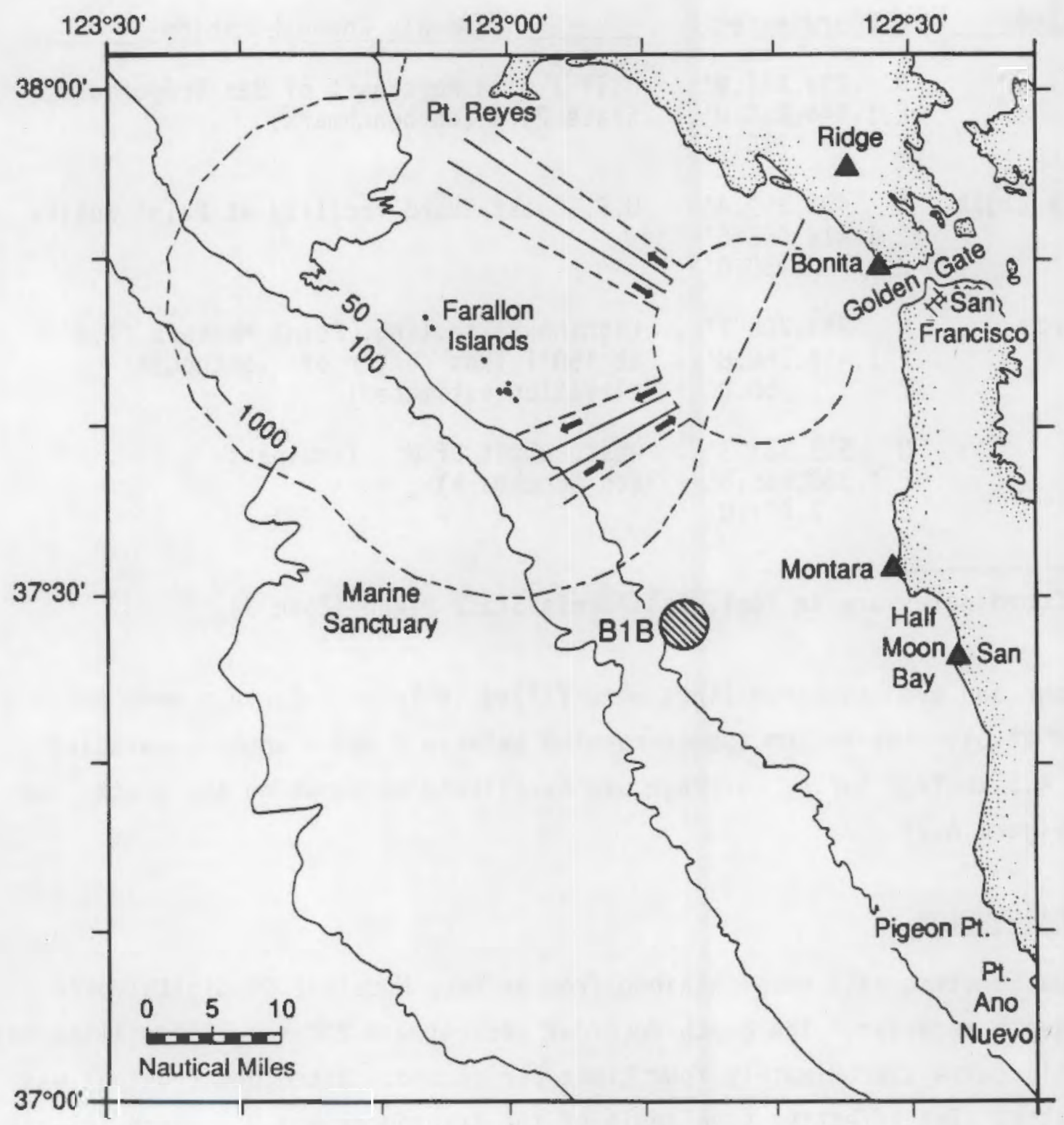

FIGURE A.1. Chart of the Gulf of the Farallones Including Proposed Dredged-Material Disposal Site BlB (Stippled Circle). Depth contours are in meters. Locations of navigation shore reference stations are marked with triangles. 
TABLE A.1. List of Shore Reference Locations Used (a)

\begin{tabular}{|c|c|c|}
\hline Name & Coordinates & Commonly Known Location \\
\hline San & $\begin{array}{lr}N & 299,661.9^{\prime} \\
\mathrm{E} & 1,446,855.0^{\prime} \\
\mathrm{Z} & 210.0^{\prime}\end{array}$ & $\begin{array}{l}\text { Hill 1 mile northeast of San Gregorio } \\
\text { State Park (on benchmark) }\end{array}$ \\
\hline Bonita Light & $\begin{array}{lr}N & 485,399.4^{\prime} \\
E & 1,414,068.6^{\prime} \\
Z & 150.0^{\prime}\end{array}$ & U.S. Coast Guard facility at Point Bonita \\
\hline Montara & $\begin{array}{lr}N & 383,705.7^{\prime} \\
E & 1,414,860.8^{\prime} \\
Z & 50.0^{\prime}\end{array}$ & $\begin{array}{l}\text { Lighthouse railing, Point Montara }\left(7.5^{\prime}\right. \\
\text { at } 150^{\circ} \mathrm{T} \text { from center of lighthouse; } \\
\text { elevation estimated) }\end{array}$ \\
\hline Ridge & $\begin{array}{lr}\mathrm{N} & 519,321 \cdot 3^{\prime} \\
\mathrm{E} & 1,388,635 \cdot 5^{\prime} \\
\mathrm{Z} & 2,071 \cdot 0^{\prime}\end{array}$ & $\begin{array}{l}\text { West summit of Mt. Tamalpais } \\
\text { (on benchmark) }\end{array}$ \\
\hline
\end{tabular}

(a) Coordinates are in feet, California State Plane (Zone 3).

coverage and even-numbered lines were filled in later. Surveys were performed at over-the-bottom speeds ranging between 2 and 7 knots, averaging about 4.5 knots. Survey coverage was excellent, as shown on the track-1ine map (Figure A.2).

\section{A.2 BATHYMETRY}

Bathymetric data were obtained from an Odem Model $3200^{\circledR}$ digital precision depth recorder. The depth recorder generated a $200-\mathrm{KHz}, 0.2 \mathrm{mill}$ isecond acoustic pulse approximately four times per second. Rated power output was 200 watts. The effective cone angle of the transducer was $9^{\circ}$, which insonified a circular area on the bottom with a radius of about $22 \mathrm{ft}$ (assuming a flat bottom and depth of $280 \mathrm{ft}$ ). Depth recorders such as this are typically accurate to within about $1 \%$ of the total water depth. Bar-check calibrations of the bathymetric equipment, which are made by lowering an acoustically reflective metal plate to a known depth to obtain a reading, were performed on three occasions during the survey. Bar checks were made to depths of

(B) Odem Model 3200 is a registered tradename. 


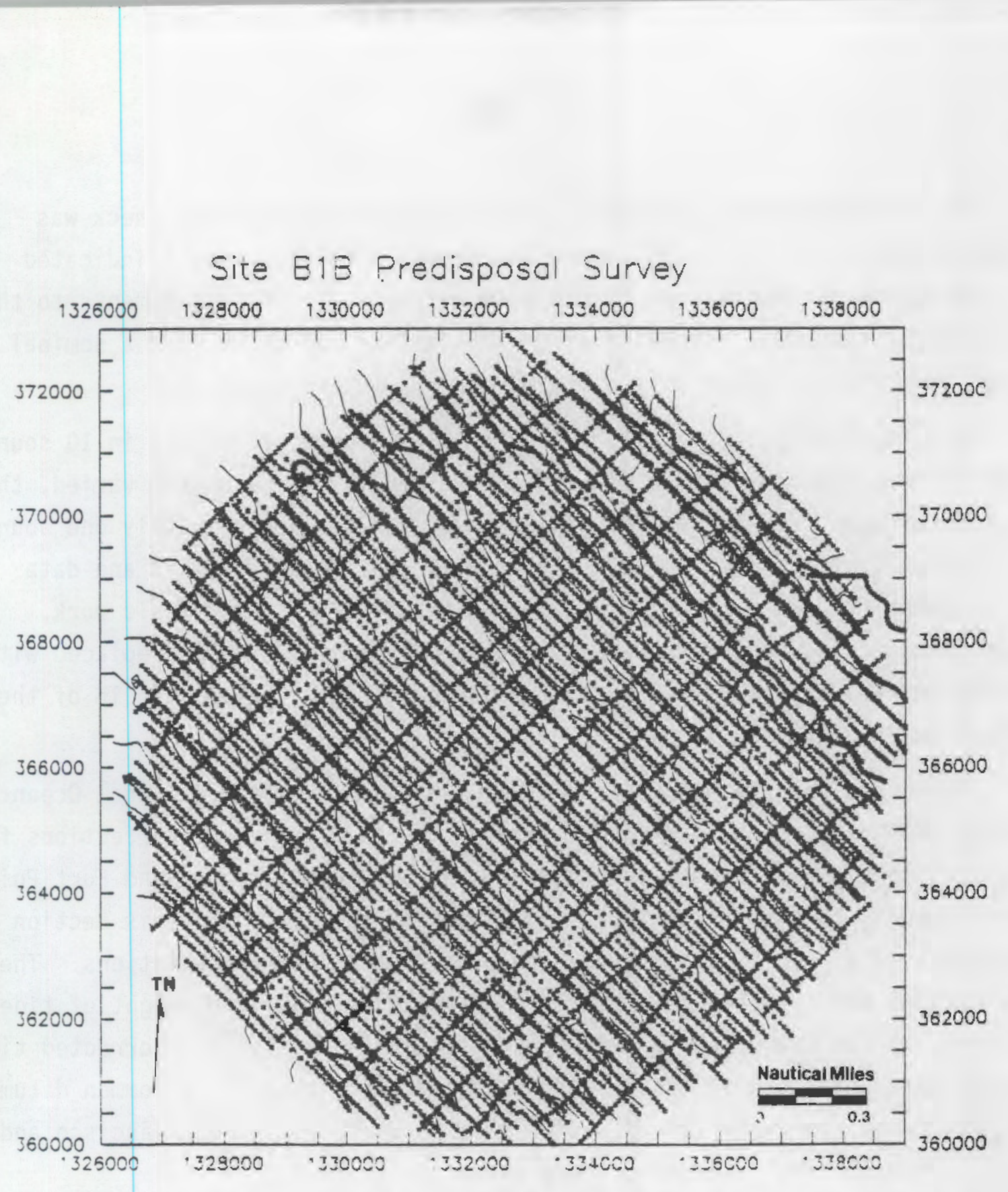

FIGURE A.2. Chart of Track Lines Followed During Bathymetric Survey at Site BIB. Each asterisk indicates the position of a data point used to make the final grid. Original data density was five times greater; the 10,000 points shown are weighted averages of the complete data set resulting from the smoothing and decimation procedures. Coordinates are Northings and Eastings in feet, California State Plane (Zone 3 ). 
$100 \mathrm{ft}$ at the beginning and middle of the survey. A final bar check was made to $200 \mathrm{ft}$ at the completion of the survey. All bar checks indicated that depth measurements were accurate to within $1 \mathrm{ft}$. No adjustments to the bathymetric equipment were made after the initial bar check, and a nominal sound velocity of $4870 \mathrm{ft} \cdot \mathrm{s}^{-1}$ was used for the entire survey.

Bathymetric data were recorded every 1.5 seconds, resulting in 10 soundings between each navigation fix. Because speed over the bottom varied, the spacing of data over the bottom varied, but averaged approximately one sounding every $20 \mathrm{ft}$. Soundings were digitized by the depth recorder and data were stored on disk with the navigation data. Following the field work, soundings were edited by CRA and obviously erroneous data were replaced with values interpolated linearly from neighboring values. Fewer than $1 \%$ of the data were interpolated.

Tide data for the survey period were obtained from the National Ocean Survey (NOS) tide gage located at Fort Point, San Francisco. Corrections for amplitude and phase changes in the tidal wave between Site B1B and Fort Point were based on the numerical tidal model used by the Tidal Analysis Section of NOS, Rockville, Maryland, in preparing published NOS tide predictions. The corrections are the inverse of those used to adjust time and height of tides measured at San Francisco to Half Moon Bay values (NOS 1987). Corrected tide height data were used in adjusting the bathymetric survey to a common datum at Mean Lower Low Water (MLLW). Tide heights measured in San Francisco and used in making tidal corrections are shown in Figure A.3.

\section{A.3 DATA PROCESSING}

Range data were used to compute fix locations in California state plane coordinates (Zone 3 ). A least-squares error algorithm was employed whenever more than two shore reference stations were acquired, and missed fixes were interpolated from surrounding data. These navigation data and the edited bathymetric data were corrected to MLLW using the tidal data shown in Figure A.3 and the corrections specified above. The depth data were smoothed using a 17-point weighted moving-average filter. The filter weights produced the best fit (in a least-squares sense) of a quadratic equation to the data 


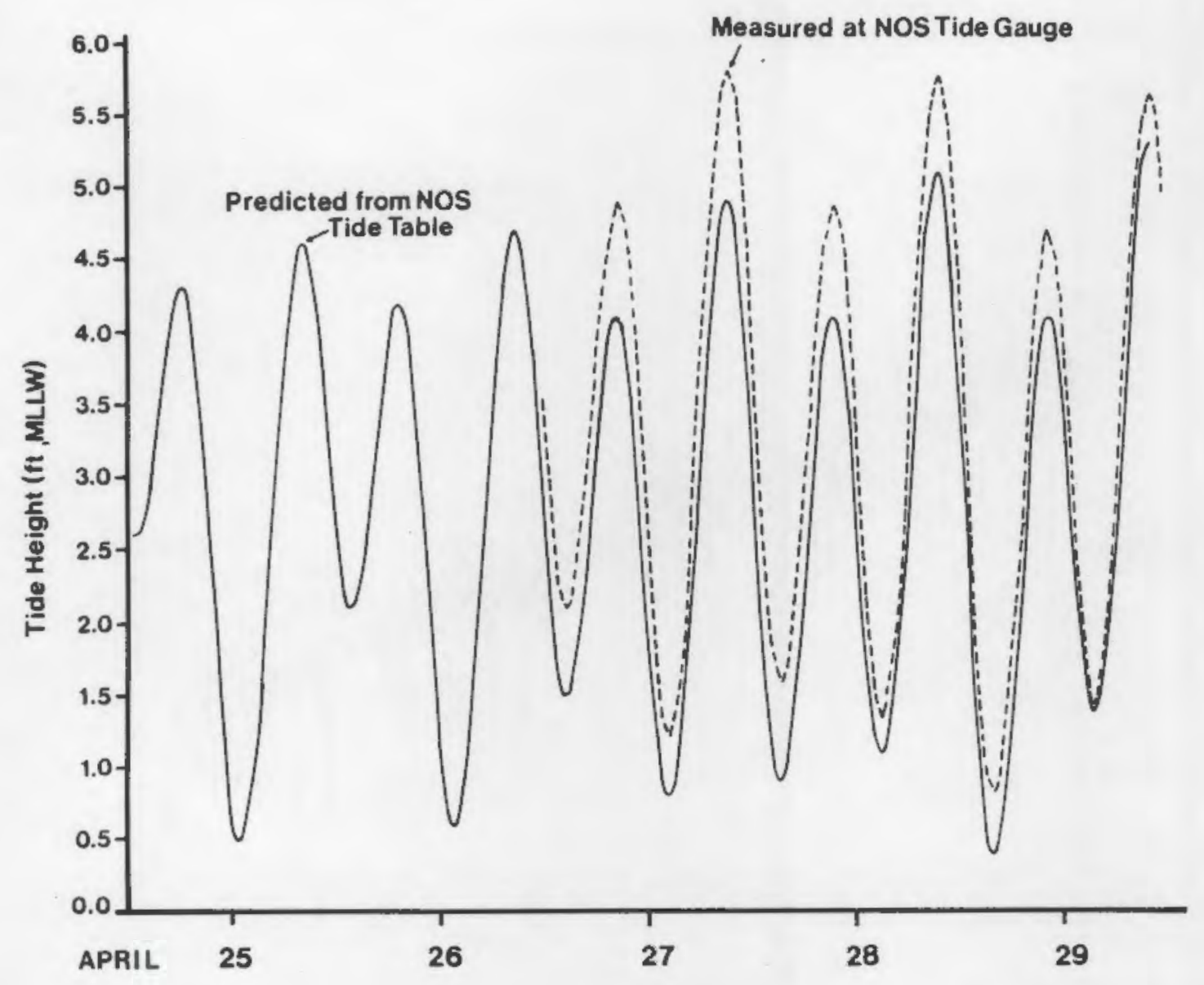

FIGURE A.3. Tide Heights Used to Correct Bathymetric Data During the Survey. Heights were recorded at the NOS gage at Fort Point, San Francisco. Time and height corrections were made to represent tides at the study area.

(Davis 1986). The filter was used to provide smoothed estimates at every fifth fix, corresponding to along-track-line spacings of about $100 \mathrm{ft}$. Deviation from the specified track line was calculated for each fix location and all data exceeding three standard deviations around the track-line average were flagged and removed. The same criteria were used to remove potentially erroneous depth data before filtering. These editing and smoothing procedures reduced the data set to slightly less than 10,000 points located along the track lines (Figure A.2). Data from a typical track line are shown before and after smoothing in Figure A.4. 


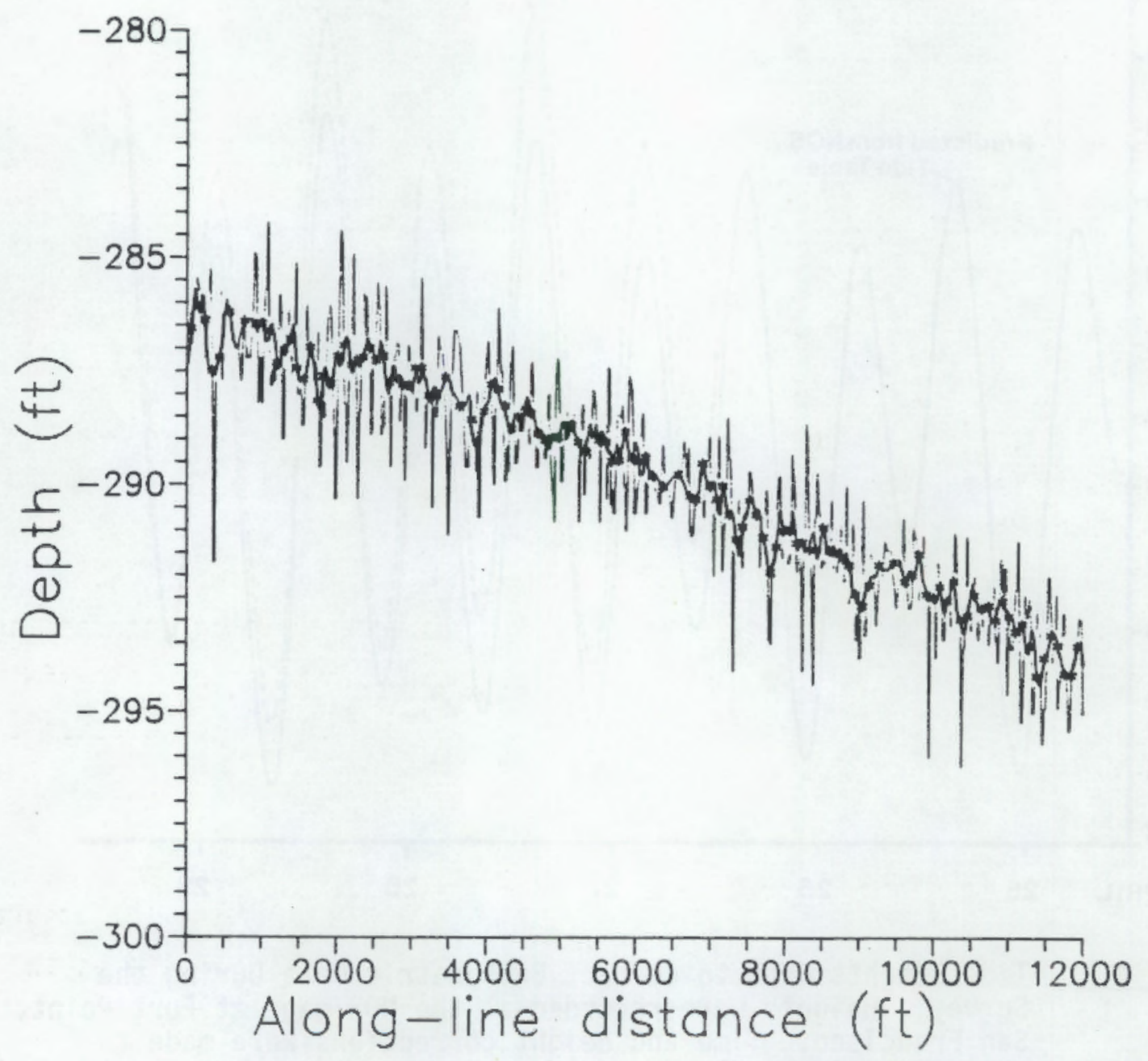

FIGURE A.4. Depth Data from a Typical Track Line Before and After Smoothing. Asterisks mark the smoothed points

(Figure A.2) used in generating the final grid.

The irregularly spaced data were interpolated onto a regular $200-\mathrm{ft}$ grid using a commercial contouring package. A quadrant-search algorithm was employed to select the closest points (up to a maximum of six) within each of the four quadrants surrounding each grid location. Only points within a radius of $800 \mathrm{ft}$ from each grid location were considered. An inversedistance weighting scheme was used to increase the influence of data points. near the grid location. The combined effect of the quadrant search algorithm and the inverse-distance weighting scheme was to reduce biases resulting from 
the track-line orientation and regional slope while providing some additional smoothing in the final depth estimate at the grid location. The final contour map was produced from the gridded data with a $1-\mathrm{ft}$ contour interval (Figure A.5).

\section{A.4 RELIABILITY OF DATA}

The bathymetric data are intended to be compared with subsequent surveys to determine the volume of dredged material at the disposal site. Bathymetric change measurements are commonly made in shallow water (depths typically less than $65 \mathrm{ft}$ ). The potential for errors associated with the greater depths involved in this study reduce the reliability of this approach. For this reason, estimates of the errors involved in preparation of the gridded data were made. The magnitude of potential errors (Table A.2) associated with 1) variations in sound velocity, 2) heave/pitch/roll of the survey vesse1, 3) navigation errors, 4) waves and swel1, 5) tidal corrections, and 6) bottom tilt, were estimated. Steps were taken to minimize loss of accuracy and precision from these sources of error. Each will be discussed briefly below.

\section{A.4.1 Sound Velocity}

Systematic errors in the sound velocity may have affected the accuracy of the survey. The bar-check calibration procedure ensured that the depth recorder was accurate to within $\pm 1 \mathrm{ft}$ at $200 \mathrm{ft}$. Because large changes in the average sound velocity are unlikely to occur in the bottom $100 \mathrm{ft}$, systematic errors in the measured depths are probably small. Errors in the accuracy could tend in either direction, but because the sound velocity in the lower third of the water column is likely to be higher than the depth-averaged velocity, accuracy errors arising from sound velocity errors may range from $2 \mathrm{ft}$ to $+1 \mathrm{ft}$ (positive errors indicate that the true depths are greater than the measured depths).

Spatial or temporal variations in the depth-averaged sound velocity also had the potential to degrade the precision of the survey. Changes in sound velocity may have occurred because of changes in temperature or salinity during the study. No evidence of this was observed when the three bar-check 


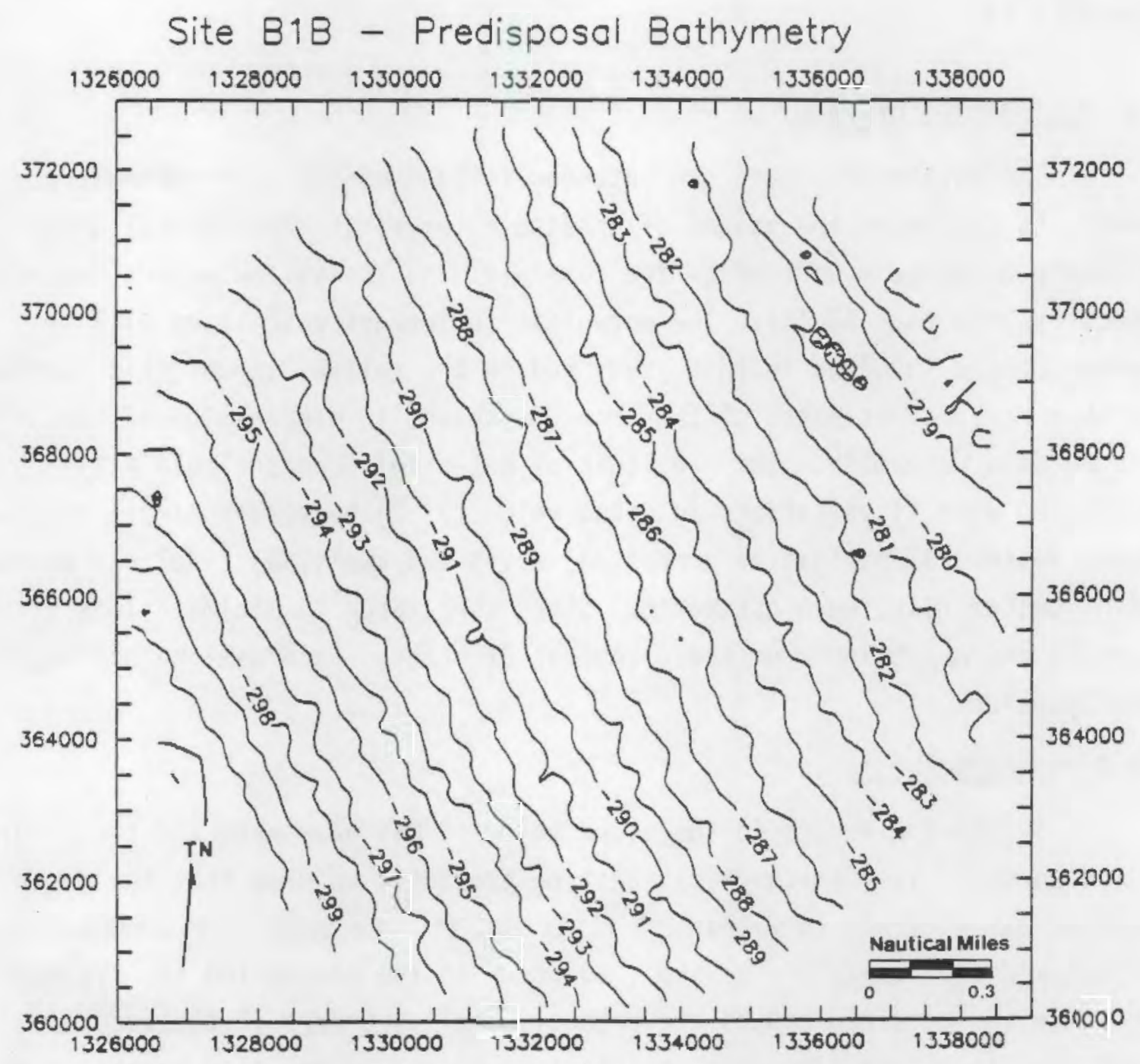

FIGURE A.5. Final Bathymetric Map Contoured from 200-ft Grid. Contours are in feet below mean lower low water; contour interval is $1 \mathrm{ft}$. Vertical precision is approximately $\pm 1.5 \mathrm{ft}$. Bathymetric features are significantly smoothed over horizontal scales of approximately $400 \mathrm{ft}$. 
TABLE A.2. Estimates of Errors Associated with Depth and Controls Used to Reduce Contributions from Each Error Source in the Final Map

\begin{tabular}{|c|c|c|c|}
\hline Source & Accuracy & Precision & Control \\
\hline Sound Velocity & $-2 \mathrm{ft}$ to $+1 \mathrm{ft}$ & $\pm 1 \mathrm{ft}$ & Bar check \\
\hline Heave/Pitch/Roll & 0 to $-2 \mathrm{ft}$ & 0 to $-6 \mathrm{ft}$ & Smoothing \\
\hline Navigation & $< \pm 0.5 \mathrm{ft}$ & $< \pm 0.5 \mathrm{ft}$ & Gridding \\
\hline Waves/Swe11 & $-0 \mathrm{ft}$ & $\pm 5 \mathrm{ft}$ & Smoothing \\
\hline Tidal Correction & $\pm 1.5 \mathrm{ft}$ & $\pm 1.5 \mathrm{ft}$ & Survey plan \\
\hline Bottom Tilt & $< \pm 0.5 \mathrm{ft}$ & $< \pm 0.5 \mathrm{ft}$ & Gridding, survey plan \\
\hline
\end{tabular}

calibration results were compared. Reasonable estimates of temperature- or salinity-induced velocity fluctuations suggest that the errors related to such changes are $< \pm 0.5 \%$, or $< \pm 1.5 \mathrm{ft}$. Evidence from the bar-check calibration suggests that even better precision was likely. The pattern and timing of the survey prevented any slow changes in the sound velocity from systematically changing depth estimates.

\section{A.4.2 Heave/Pitch/Roll}

The effect of boat motion combined with the conical 1istening volume of the acoustic transducer can result in an overestimate of the water depth when the boat motion exceeds the half-angle of the conical listening volume. Estimates of the errors associated with boat motion over a gently sloping bottom were made using the geometrical relationships. Assuming maximum heave/pitch/roll angles of $15^{\circ}$, and using a bottom slope of $0.5^{\circ}$ (high compared to the average over the survey area of $0.15^{\circ}$ ), potential errors of -3 to $-7 \mathrm{ft}$ were calculated. Because the vessel and transducer were typically within $4.5^{\circ}$ of vertical, these error estimates represent the worst case. However, because heave/pitch/roll errors consistently result in overestimates of the depth, they may have introduced a systematic overestimate of the depth on the order of 0 to $-2 \mathrm{ft}$. 


\section{A.4.3 Navigation Errors}

Nominal precision of the navigation ranges was $\pm 6 \mathrm{ft}$. Allowing for various errors, it is likely that the final fix location is accurate to within $\pm 20 \mathrm{ft}$ in values of Northing and Easting. Because of the gently sloping and featureless bottom, errors in navigation are unlikely to introduce much, if any, additional error to the final depth map.

\section{A.4.4 Waves and Swell}

Combined heights of waves and swell occasionally exceeded $12 \mathrm{ft}$ during the survey. Waves and swell, therefore, represent the largest single source of error in individual soundings. However, because the soundings were filtered to remove some of the wave/swell noise and then spatially averaged to construct the regularly-spaced depth grid, the errors in final bathymetry resulting from waves and swell is expected to be small. Errors in accuracy should be negligible, and errors in precision are probably less than $\pm 0.5 \mathrm{ft}$ in the final map.

\section{A.4.5 Tidal Corrections}

Tidal data were not collected at the survey site, so errors may have been introduced when estimating tidal heights at the site from tidal records recorded in San Francisco. In addition to datum errors at the tide gage, errors in estimating the phase and magnitude of the tidal wave are possible, as are errors introduced by local meteorological effects at the site or at the San Francisco tide gage. An inadvertent experiment in estimating the magnitude of potential tidal correction errors was performed when the sign of the time correction was reversed. A tidal correction that was approximately 2 hours out of phase was applied, resulting in errors of up to $6 \mathrm{ft}$ in individual soundings. A contour map constructed from these erroneous data differs from the final map (with true tidal corrections) by less than $2 \mathrm{ft}$ in all areas. With the tidal correction estimates suggested by the Tidal Analysis Section at NOS, it is unlikely that individual sounding errors larger than $\pm 0.5 \mathrm{ft}$ could have occurred. Because of the timing of the survey and the track-line pattern, any tidal correction errors would be at least partially averaged out, resulting in an even smaller error in the final map. 


\section{A.4.6 Bottom Tilt}

Errors introduced by the mean slope of the sea floor at Site BlB were estimated from the final bathymetric chart; these errors were found to be $< \pm 0.5 \mathrm{ft}$.

\section{A.4.7 Combined Effects of All Sources of Error}

Lack of independently measured data precludes a formal analysis of the errors caused by each of the phenomena discussed. However, a statistical estimate of all sources of error was made by comparing final maps based on independent subsets of the survey track lines. To make this estimate, three sets of survey track lines (even-numbered primary lines, odd-numbered primary lines, and secondary lines) were considered separate surveys. Bathymetric maps for each were prepared, and the final maps were quantitatively compared by differencing at the grid points. Contour maps of the differences were prepared to identify systematic errors (Figures A.6a, b, and c). The largest difference found when comparing the three maps was $3.2 \mathrm{ft}$. The median difference between maps ranged from 0.19 to $0.51 \mathrm{ft}$, and the mean of the mean differences between maps was $0.39 \mathrm{ft}$ with a $95 \%$ confidence interval of \pm 0.53 . Table A.3 summarizes the differences between the three maps. The 1 argest differences occurred in the northeast portion of the study area where some track lines were run 2 days before the bulk of the survey. This suggests that changes in conditions, which ultimately introduced changes in depth measurements or tidal corrections, occurred between the two portions of the survey. Even the largest of these errors is relatively small, amounting to $1 \%$ of the measured depth. Over most of the survey area, the independent maps vary by less than $1 \mathrm{ft}$.

This error estimation technique is especially useful because it is analogous to the differencing process that will be performed when postdisposal surveys are conducted. The error estimates suggest that the combination of survey coverage and data processing procedures used in this study has resulted in a bathymetric map with a precision of, at best, $\pm 0.5 \mathrm{ft}$ and, at worst, $\pm 1.5 \mathrm{ft}$, suggesting that post-disposal studies will be able to identify mounds with relief greater than $3 \mathrm{ft}$. The smoothing required to remove wave and vessel motion noise from the bathymetric data has resulted in 


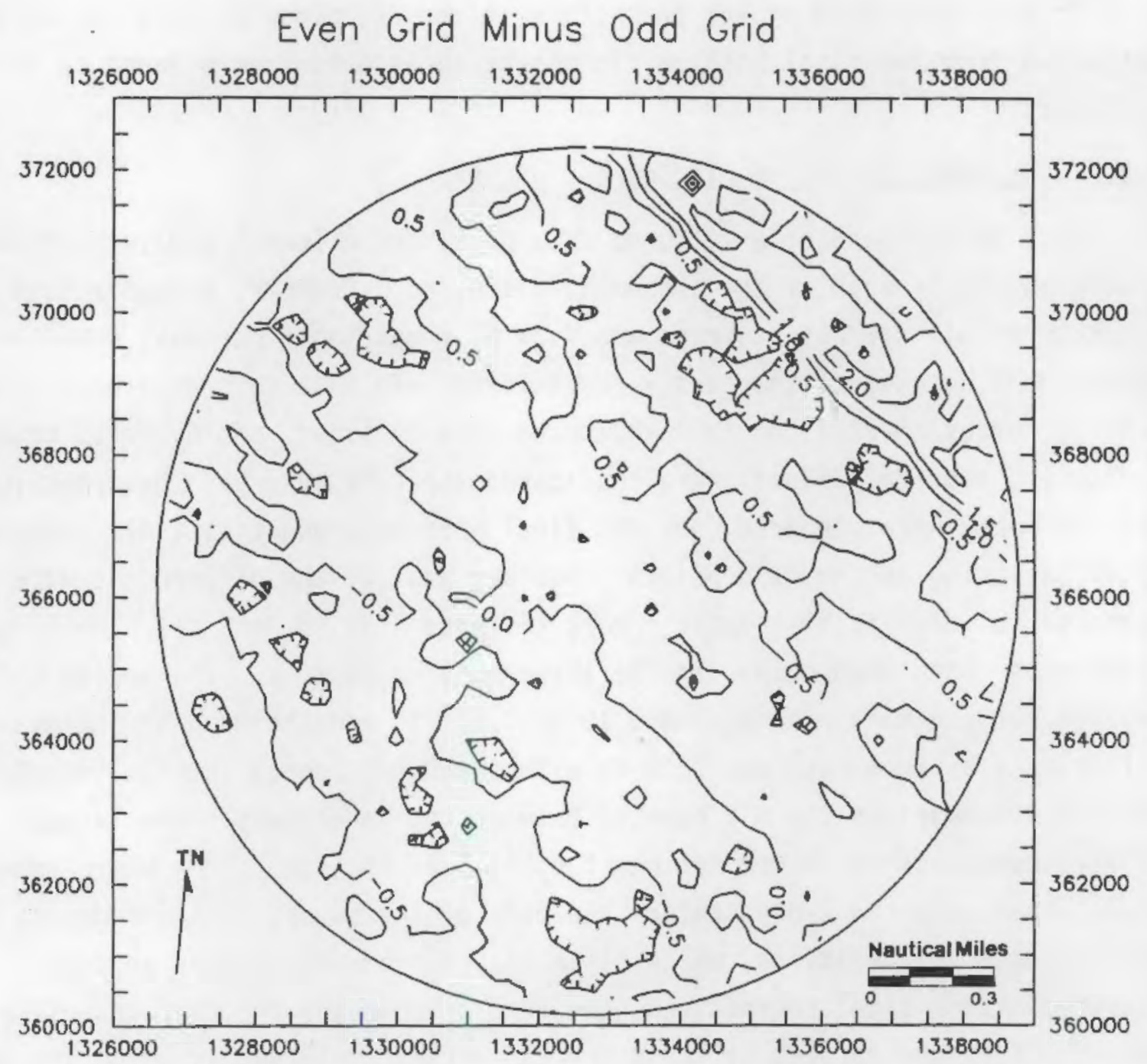

FIGURE A.6a. Contour Map of the Difference Found by Subtracting Depth Grid Based on Even-Numbered Primary Track Lines from Grid Based on Odd-Numbered Primary Track Lines. Contour interval is $0.5 \mathrm{ft}$. 


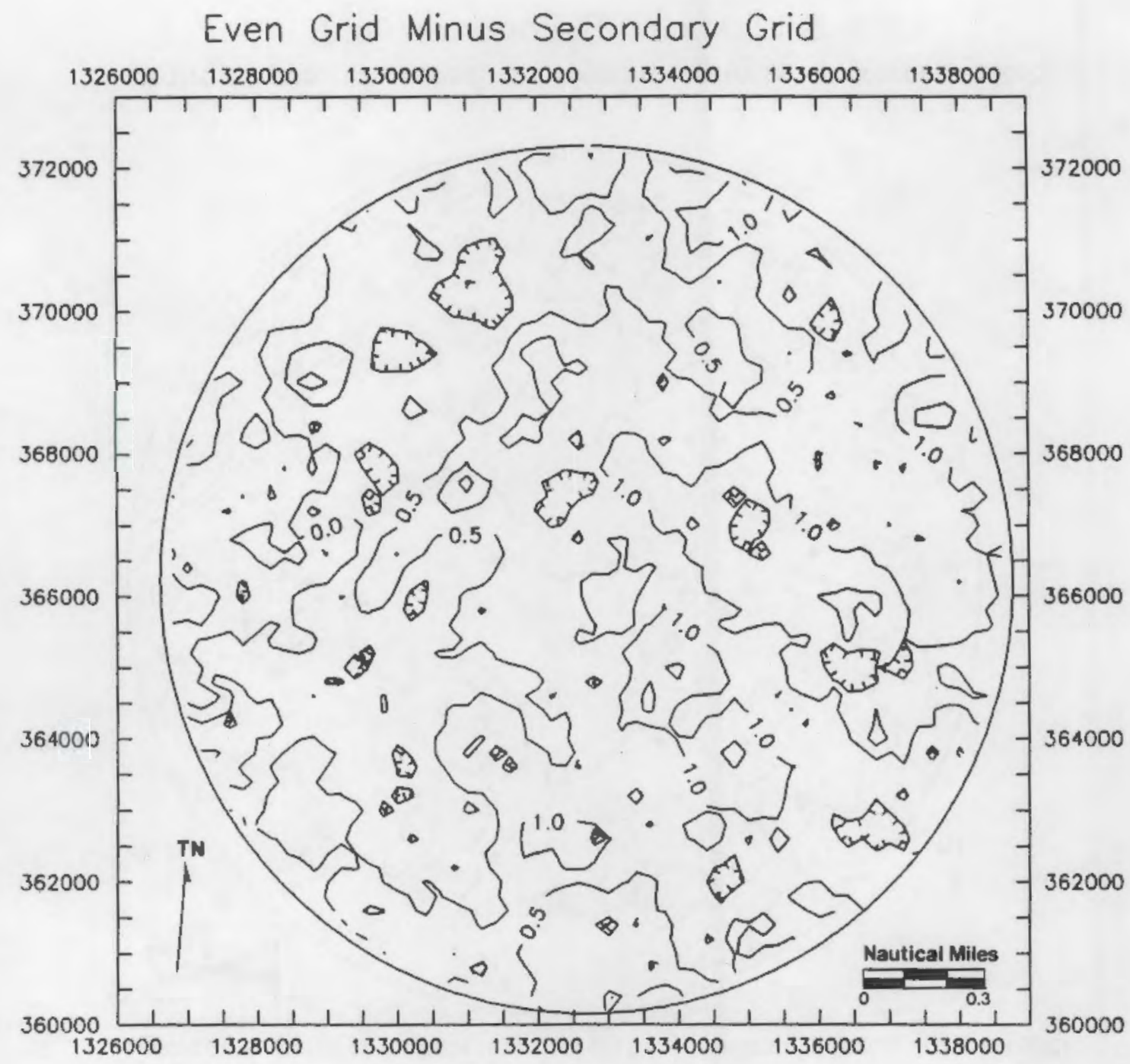

FIGURE A.6b. Contour Map of the Difference Found by Subtracting Depth Grid Based on Even-Numbered Primary Track Lines from Grid Based on Secondary Track Lines. Contour interval is $0.5 \mathrm{ft}$. 
Odd Grid. Minus Secondary Grid

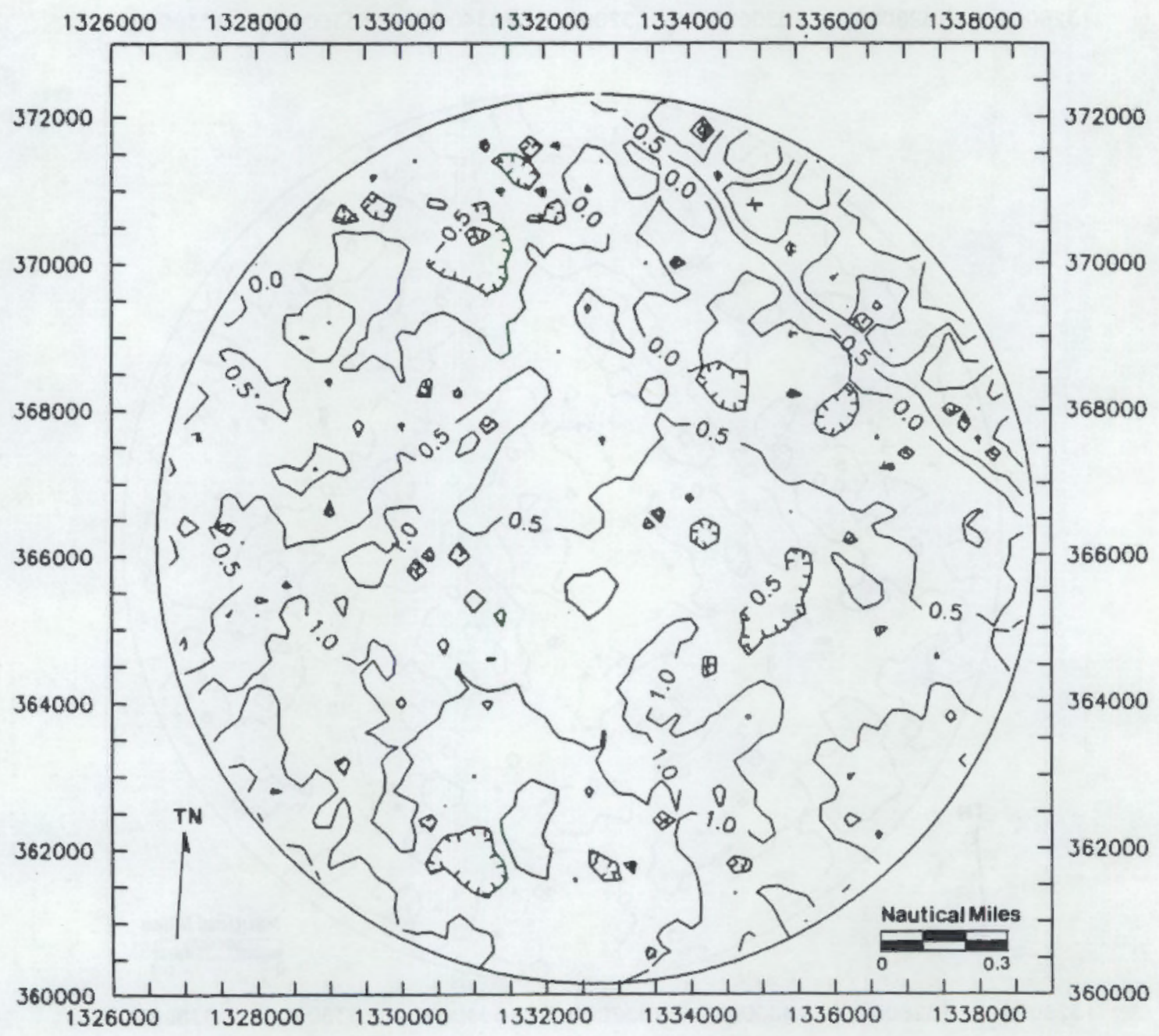

FIGURE A.6c. Contour Map of the Difference Found by Subtracting Depth Grid Based on Odd-Numbered Primary Track Lines from Grid Based on Secondary Track Lines. Contour interval is $0.5 \mathrm{ft}$. 
IABLE A.3. Differences Between Three Independent Maps of the Bathymetry at Site B1B Based on Even-Numbered Primary Track Lines, Odd-Numbered Primary Track Lines, and Secondary (Cross) Track Lines

\begin{tabular}{|c|c|c|c|}
\hline Statistic & Even - Odd & Even - Cross & Odd -cross \\
\hline Number & 2898 & 2898 & 2898 \\
\hline Arithmetic Mean & $0.16 \mathrm{ft}$ & $0.58 \mathrm{ft}$ & $0.42 \mathrm{ft}$ \\
\hline Standard Deviation & 0.53 & 0.19 & 0.41 \\
\hline Minimum & -1.42 & -1.11 & -2.43 \\
\hline 10 percentile & -0.71 & -0.02 & -0.42 \\
\hline Median & 0.19 & 0.61 & 0.51 \\
\hline 90 percentile & 0.87 & 1.10 & 1.13 \\
\hline Maximum & 3.16 & 1.82 & 1.86 \\
\hline
\end{tabular}

spatial blurring over horizontal scales of 400 to $800 \mathrm{ft}$. Objects or disposal mounds with smaller diameters are unlikely to be resolved in a similar survey. It is unlikely that a surface survey without 1) heave/pitch/roll corrections applied to the individual soundings, 2) local tidal measurements, 3) frequent acoustic velocity measurements, and 4) ideal weather conditions, will produce significantly more precise bathymetric maps. Significantly better data could be obtained using deep-towed instruments, but at higher survey costs.

\section{A.5 CONCLUSIONS}

The bathymetric survey performed at Site B1B obtained excellent coverage of the area. Survey 1 ines were spaced $165 \mathrm{ft}$ apart, and cross 1 ines were run at a 660-ft spacing. Navigation and depth recording equipment functioned well and provided consistent data with very few questionable fixes or soundings. Post-processing of the data to remove noise caused by sea, swell, and vessel motion was successful in producing a smoothed bathymetric map with an estimated error of $\pm 1.5 \mathrm{ft}$. Post-disposal surveys will be able to successfully determine the thickness of mounds with relief of $>3 \mathrm{ft}$ and diameters $>800 \mathrm{ft}$, with similar precision. More sophisticated and costly survey tech- 
niques would be required to achieve higher-precision estimates of mound volume based on bathymetric differencing techniques in these water depths.

\section{A. 6 REFERENCES}

Davis, J. C. 1986. Statistics and Data Analysis in Geology. John Wiley and Sons, New York, New York.

NOS (National Ocean Survey). 1987. Tide Tables 1988; High and Low Water Predictions: West Coast of North and South America including the Hawai ian Is 7 ands. Nationa 7 Oceanic and Atmospheric Administration, U. S. Department of Commerce, Rockville, Maryland. 
APPENDIX B

MEASUREMENT PROGRAM 


\section{APPENDIX B}

\section{MEASUREMENT PROGRAM}

This appendix describes the measurement program and other oceanographic data obtained during a study of physical and sediment transport processes at candidate dredged-material disposal Sites $B 1 B$ and IM offshore San Francisco. The measurement program was conducted for the U.S. Army Corps of Engineers (USACE), San Francisco District, by the Pacific Northwest Laboratory (PNL). The objective of the measurenent program was to obtain site-specific current and suspended-sediment data for 1) physical characterization of the sites, and 2) use as input in sediment transport calculations. The measurement program consisted of four deployments of moorings with current meters and optical suspended-sediment sensors over a 13-month period between April 1988 and May 1989. The instruments and moorings were maintained by Kinetics Laboratories, Inc. (KLI) of Santa Cruz, California, under the supervision of Battelle, Ocean Sciences Division, Ventura Operations, of Ventura, California, and, later, under the supervision of Marine Resource Specialists, Inc. (MRS), also of Ventura, California. Data were analyzed by MRS and PNL. To aid in interpretation of the current-meter.data, wind data were obtained from the National Data Buoy Center (NOBC). Wave data were obtained from the Coastal Data Information Program (CDIP) for use in sediment transport calculations.

The locations of the moorings and locations where other data used in this study were collected are shown in Figure B.1. Table B.1 summarizes the schedule of field operations, mooring locations, sensor depths, sampling rates, and record lengths. Sections B.1 and B.2 describe the equipment, sensors, and chronology of the field operations for the four deployments. The data analyses and time series of winds, currents, suspended sediment, and water temperature are discussed in Sections B.3 and B.4. Statistics and results of frequency-domain and tidal harmonic analyses are developed in Sections B.5 and B.6. References are contained in Section B.7. Figures and Tables are located at the back of this appendix. 


\section{B.1 MOORINGS AND INSTRUMENTS}

Two moorings were maintained from April 1988 to May 1989, one located near the edge of candidate disposal Site B1B and one at Site 1M. The moorings were deployed four times and produced a data set containing nearly 13 months of temperature and current data from five current meters. Mooring configurations are shown in Figures B.2 and B.3. At Site B1B (water depth $86 \mathrm{~m})$, current meters were moored at 21, 46, and $85 \mathrm{~m}$, and the suspended sediment sensor was mounted $0.36 \mathrm{~m}$ above the bottom. At Site $1 \mathrm{M}$ (water depth $42 \mathrm{~m})$, the meter depths were 21 and $40 \mathrm{~m}$, and the sediment sensor was mounted $0.36 \mathrm{~m}$ above the bottom.

\section{B.1.1 Acoustic Current Meters}

Neil Brown Smart Acoustic Current Meters (SACMs) were used to make most of the velocity measurements. They measure velocity by detecting the phase shift in acoustic pulses traveling through a small volume of water enclosed by four piezo-electric transducers and a flat acoustic mirror. Direction reference is provided by an internal flux gate compass mounted with the velocity and temperature sensors. The SACM is a true vector-averaging system that internally corrects for the effects of temperature fluctuations on sound velocity. SACMs vector-average the current over a fixed sampling interval by computing the sum of a large number of vector components measured periodically over the interval and normalizing the resultant vector by the sample interval. The velocity and temperature sensors were factory-calibrated, and the coefficients from the manufacturer were used in converting binary data to physical units. Table B.2 gives the specifications of the SACM.

\section{B.1.2 Electromagnetic Wave Current Meter}

The Sea Data Model 621 directional wave current meter (DWCM) was used during the fourth deployment with the intent of measuring wave-orbital

- Neil Brown Smart Acoustic Current Meter is a registered tradename of Neil Brown Instrument Systems, Cataumet Massachusetts.

B Sea Data is a registered tradename of the Pacer Systems Company, Newton, Massachusetts. 
velocities and the steady current simultaneously. These data were to be used for sediment transport calculations and to verify the procedure used to estimate wave-orbital velocities from surface wave spectra measured at Montara (Volume 2, Appendix C).

The DWCM measures velocity with an electromagnetic sensor, which has a predictable response in hydraulic regimes where an oscillatory flow is superimposed on a steady current (Aubrey and Trowbridge 1985). Electromagnetic flow sensors measure velocity by sensing the voltage induced when sea water, a conductor, moves relative to a magnetic field generated by the sensor. By Faraday's Law, the induced voltage is directly proportional to the water velocity component perpendicular to the pair of sensing electrodes. The DWCM uses two orthogonal pairs to measure two components of flow velocity. Conversion from voltage to velocity is made with coefficients obtained from the manufacturer's tow tank calibrations. Specifications for the Model 621 current meter are given in Table B.2.

\section{B.1.3 Optical Backscatter Sensors}

The optical backscatter $\left(O \mathrm{BS}^{\circ}\right)$ sensor was selected to measure suspended sediment concentration because of its small size and linear response over a wide concentration range (Downing 1983). OBS sensors detect suspended particles by sensing infrared light scattered from them. The sensor consists of an infrared light source surrounded by four silicon PIN photodiodes and a sma1] circuit board. Specifications for the OBS sensor are listed in Table B.2. The OBS circuit boards were housed in an Aanderaa pressure case with batteries and a Campbell Scientific $C R-10^{\circ}$ programable datalogger. The OBS sensors were programmed to warm up for $2 \mathrm{~s}$ and then measure 20 samples at $1 \mathrm{~Hz}$ every $15 \mathrm{~min}$ synchronously with the current meters. All 20 samples were stored when a predetermined OBS response threshold was exceeded; otherwise, the mean of the samples was stored. The program was altered to store the

B OBS is a registered trademark of D\&A Instruments, Port Townsend, Washington.

* Aanderaa is a registered tradename of Aanderaa Instruments, Bergen, Norway.

- CR-10 is a registered tradename of Campbell Scientific, Inc., Logan, Utah. 
standard deviation of all samples after the second deployment to provide information about the variability of sediment concentration associated with the sample means.

Before the first deployment, gain of the OBS sensors (ratio of output voltage to sediment concentration) was checked using suspensions of Santa Cruz Bay mud. After the third deployment, sensors were calibrated with sediment obtained in grab samples from Sites B1B and $1 M$. Grain-size data from sediment at each site are displayed in Figure B.4. The OBS was calibrated in the University of Washington calibration tank (Downing and Beach 1989). Each instrument was calibrated over a range of suspended sediment concentrations up to $3.5 \mathrm{~g} \cdot 1^{-1}$. Because biofouling of the sensors occurred, the sensors were calibrated before and after the optical surfaces were cleaned. Laboratory studies conducted by Ludwig and Hanes (1989) suggest that the response of OBS sensors to background water clarity can vary significantly without affecting the gain of the sensor, which is determined by the slope of a calibration curve (D\&A Instruments 1988, 1989). Calibration results are shown in Figures B.5 through B.7. Weighted least-squares linear regression was performed to determine the common slope (reduced model with separate $y$ intercepts) and the two separate slopes (full model) for the calibration before and after cleaning. Weights equal to the inverse-square of the standard deviation of voltage response were used to de-emphasize the points with greater variance. At the $95 \%$ confidence level, the full model with separate slopes was not significantly different from the reduced model (common slope with separate intercepts). The regression coefficients are summarized in Table B.3. The calibrations provide reassurance that, while the baseline output may drift in response to biofouling of the sensors and slow changes in background water clarity, the gain does not appear to be affected. The calibrations also confirm resuits of laboratory studies by Ludwig and Hanes (1989). Output voltage was converted to sediment concentration with common regression slopes from the laboratory calibrations after offsets resulting from changes in background water clarity and biofouling were removed by detrending the time series as discussed in Section B.4.5. The combined error in the estimates of sediment concentration attributed to 
calibration errors and sensor nonlinearity, given by the maximum standard error of the estimate from the three calibration curves, is approximately $\pm 5 \%$.

\section{B.2 FIELD OPERATIONS}

This section describes significant aspects of the mooring program and instrument performance. The schedule of field operations, mooring locations, sensor depths, sampling rates, and record lengths are summarized in Table B.1.

\section{B.2.1 First Deployment}

The first deployment was successful, in both the instrument performance and the amount of data recovered. On recovery, all instruments were found to be operational except the bottom current meter on the Site $1 M$ mooring, which stopped because the lithium battery failed 4 days before recovery. Except for this 4-day loss of data from one meter, a complete set of data was recovered from all 17 sensors (5 temperature sensors, 2 OBS sensors, and 10 sensors for velocity components). Because of the good condition of the moorings, all instruments were expeditiously serviced and redeployed.

The Site B1B mooring was deployed at $37^{\circ} 28^{\prime} 5.5^{\prime \prime} \mathrm{N}$ latitude, $122^{\circ} 47^{\prime} 9.2^{\prime \prime} \mathrm{W}^{-}$ longitude at a depth of $86 \mathrm{~m}$. The mooring configuration, shown in Figure B.2, included a primary array of two SACMs at shallow and mid-depths and a secondary mooring with a single SACM and OBS sensor mounted $1.42 \mathrm{~m}$ and $0.36 \mathrm{~m}$ above the bottom, respectively. The moorings at B1B were connected by $200 \mathrm{ft}$ of 5/8-in. polypropylene ground 1 ine, and each mooring was equipped with an acoustic release. The Site B1B mooring was in position at 0401 Greenwich mean time (GMT) on April 27, 1988. Recovery took place at 2231 GMT on June 7, 1988. Calm sea and wind conditions facilitated recovery, and no damage to the equipment occurred. There was no evidence of damage by vessels or fishing gear. No biofouling was observed, and the zinc anodes were moderately expended on the current meters. The instrumentation was serviced and tested immediately after recovery and redeployed in the same configuration.

The site $1 \mathrm{M}$ mooring was deployed at $37^{\circ} 38^{\prime} 49.8^{\prime \prime} \mathrm{N}$ latitude, $122^{\circ} 42^{\prime} 1.3^{\prime \prime} \mathrm{W}$ Tongitude at a depth of $42 \mathrm{~m}$. Figure B.3 shows the mooring configuration. 
It consisted of a SACM at $21 \mathrm{~m}$ attached by a $200-\mathrm{m} 1$ ine to a second mooring with a SACM and OBS sensor mounted 1.56 and $0.36 \mathrm{~m}$ above the bottom. This mooring was similar to the mooring at Site B1B except that the secondary mooring was equipped with a $25-\mathrm{kHz}$ pinger as an aid for recovery.

The Site 1 M mooring was in position at 0204 GMT on May 28, 1988. Recovery was completed at 2103 GMT on June 7,1988 , with all mooring components and instrumentation in good condition. Biofouling was minimal with moderate to low zinc anode erosion. There was a large amount of silt on top of the bottom-mounted acoustic release, OBS sensor, and on the horizontal surfaces of the bottom mount and outer edges of the o-ring seals. This is noteworthy because of the complete lack of any visible sediments on the other components of the Site IM mooring or on any components of the Site B1B mooring, and provides supporting evidence for the large number of suspension events observed in the Site $1 \mathrm{M}$ OBS data relative to the Site B1B data described below.

\section{B.2.2 Second 0eployment}

The second deployment was successful despite substantial difficulty in the recovery of the Site BiB mooring. The difficulty arose because the mooring was dragged off station at some point during the deployment period. Nevertheless, all instruments were operational on recovery. Some data loss from the OBS sensors occurred when approximately 10 days of data at Site $1 M$ and 21 days of data at Site B1B were overwritten because the data logger storage capacity was exceeded. Otherwise, a complete set of data from all 17 sensors was recovered.

The mooring configurations were identical to those of the initial deployment. The Site B1B mooring was deployed at $37^{\circ} 28^{\prime} 13.2^{\prime \prime} \mathrm{N}, 122^{\circ} 47^{\prime} 3.1^{\prime \prime} \mathrm{W}$ at 1012 GMT on June 8, 1988. Three recoveries were attempted before the mooring was finally located. On September 1, acoustic transmissions from the release were weak, and the primary anchor would not respond to release commands. No contact was made with the pinger or release on the secondary array, and pinger-tracking/dragging-operations were unsuccessful. On

September 5, a second recovery was attempted but was discontinued because of rapidly deteriorating weather conditions. On September 9, the steel float of 
the primary array was sighted enroute to the original mooring position. It was determined that the mooring had been dragged off station, and the ground line had fouled the release mechanism. Except for some chafe of the meter housings and sediment on half of the upper surface of the anchor, the mooring components were in generally good condition. Components were reconditioned, and the mooring was redeployed at 0453 GMT on September 13.

The Site $1 M$ mooring was deployed at $37^{\circ} 38^{\prime} 42.6^{\prime \prime} \mathrm{N}, 122^{\circ} 42^{\prime} 16.0^{\prime \prime} \mathrm{W}$ at 0500 GMT on June 9, 1988, and recovered at 0058 GMT on September 1, 1988. On recovery, moderate zinc anode corrosion and low levels of biofouling were noted. No evidence of sediment deposition was apparent on the mooring components, as had occurred during the initial deployment, and the OBS sensor was clean. Before redeployment, all mooring components and instruments were serviced and tested, and the OBS data acquisition program was configured without burst sampling, to economize memory for an extended deployment.

\section{B.2.3 Third Deployment}

The third deployment of moorings was the longest of the study and was highly successfut, resulting in the recovery of a data set totaling over 250,000 observations from all 17 sensors. Records from the 17 sensors each contain up to 13,000 data points covering 136 days. Although weather conditions delayed the recovery of the moorings and some OBS data were lost because the data storage capacity of the logger was exceeded, all instruments were operational on recovery. Approximately 8 days of OBS data from the Site $I M$ and 28 days from Site BIB were overwritten by the data logger at the beginning of the records. Current-meter data loss ( 3 days at Site B1B and 4 days at Site $1 M$ ) occurred at the end of the records because data storage capacity was exceeded.

The mooring configurations were identical to those of the first and second deployments. The Site B1B mooring was deployed at $37^{\circ} 28^{\prime} 14.7^{\prime \prime} \mathrm{N}$, $122^{\circ} 46^{\prime} 43.2^{\prime \prime} \mathrm{W}$ at 1818 GMT on September 15, 1988, and recovered at 2030 GMT on January 20, 1989. Recovery occurred without incident, and equipment was found to be in generally good condition except that approximately $30^{\circ}$ of the OBS senșor face was fouled with barnacles. Fortunately, the infrared emitter 
was clear of fouling. The OBS sensor was replaced with a calibrated one before redeployment. The recovered OBS sensor was sent to the University of Washington for post-calibration.

The Site $1 M$ mooring was deployed at $37^{\circ} 38^{\prime} 38.8^{\prime \prime} \mathrm{N}, 122^{\circ} 42^{\prime} 19.0^{\prime \prime} \mathrm{W}$ at 2017 GMT on September 2, 1988. The primary mooring at Site 1M was recovered at 1910 GMT on January 21, 1989, and the secondary mooring was retrieved 9 days later at 2010 GMT on January 30, 1989. The instruments were in good condition with little biofouling observed. Bad weather and the need to remobilize with a larger vessel to pull out the anchor that had been buried in the mud caused a 9-day delay in the recovery of the secondary mooring equipment. The OBS sensor was replaced with a calibrated one, and the mooring components and instruments were serviced, tested, and redeployed in the previous configuration. A grab sample of ambient sediments was also collected for use in post-calibration of the OBS instrument. The recovered OBS sensor and sediment samples were transported to the University of Washington for post-calibration.

\section{B.2.4 Fourth Deployment}

The configurations of the primary and secondary moorings at Site IM were the same as previously deployed. The site B1B secondary mooring consisted of a DWCM attached to a quad-mount for improved measurement of flow velocities in the benthic boundary layer. An OBS sensor and CR-10 datalogger were also placed on the quad-mount, and the CR-10 was reconfigured with expanded memory storage to accommodate burst sampling of suspended sediment concentrations.

The Site B1B mooring was deployed at $37^{\circ} 28^{\prime} 13.2^{\prime \prime} \mathrm{N}$ latitude, $122^{\circ} 47^{\prime} 3.1^{\prime \prime} \mathrm{W}$ longitude at 1825 GMT on February 1, 1989, and recovered at 2120 GMT on June 2, 1989. Recovery occurred without incident, and the equipment was found to be in good condition. Biofouling on the OBS sensor was limited to a thin film of material on the sensor face. Although the condition of the DWCM appeared excellent, preliminary data processing revealed that the burstsampling current meter recorded only one component of current velocity. Therefore, neither current direction or magnitude could be determined with the data and no analysis was performed on them. The Site BIB OBS recorder acquired about $97 \%$ of the data for the 4-month deployment period. Only 
3 days of missing data resulted from overwrite of initial data in the CR-10 memory as a result of the extended deployment duration. 0verwriting resulted in a data gap of approximately 3 days around 1988 Day 143. Otherwise, the OBS data form the longest continuous record, with over 11,000 individual observations, recovered in this study. As in previous deployments, there was a monotonic increase in sensor output over time. This was caused by the growth of biogenous film on the OBS sensor face.

The Site $1 M$ mooring was deployed at $37^{\circ} 38^{\prime} 42.6^{\prime \prime} \mathrm{N}$ latitude, $122^{\circ} 42^{\prime} 16.0^{\prime \prime} \mathrm{W}$ longitude at 2210 GMT on January 20, 1989, and was recovered at 0003 GMT on June 3, 1989. The instruments were in good condition, except for a defective lithium battery pack in the OBS sensor package. Despite careful predeployment bench testing, the battery voltage dropped to about $1.8 \mathrm{~V}$ (normally $13.5 \mathrm{~V}$ ) within $6 \mathrm{~h}$ of sealing the recorder canister. The CR-10 data logger made an accurate recording of the OBS battery failure.

The success of the field operations is measured by the data recovery record, which, in this case, was excellent. A data set representing nearly 13 months of temperature and current data from five current meters yielding 880,000 usable data points was produced. At Site B1B, current data in the upper water column were collected over 402 days with $93.6 \%$ of the possible parameter values being recovered. At Site $1 \mathrm{M}$, current data were collected over a period of 367 days with $95 \%$ of the possible values recovered. The two OBS sensors performed well and provided 432,000 observations during the field program.

\section{B.2.5 Deployment Problems}

There were some logistical and instrumentation problems that are noteworthy. These are summarized below.

- Seventy-seven days of OBS sensor data, about $10 \%$ of a possible 767 days, were not recovered either because the CR-10 logger overwrote early records when its memory capacity was exceeded during long deployments or when the lithium batteries failed. Biofouling by barnacles during the third deployment was extensive and nearly made the sensor inoperable.

- Seven days of current meter data $(1 \%)$ were not recorded because the SACM storage capacity was exceeded during the third deployment. The DWCM provided by Coastal Leasing, Inc., logged only one channel 
of flow sensor and therefore none of the data were usable for computing wave-orbital velocities because the reference direction was unknown.

- Gaps in the processed data resulting from a variety of other difficulties constitute $15 \%$ of the record for Site $B 1 B$ and $4.5 \%$ of the record for Site $1 M$.

- Bad weather, acoustic release problems, and problems with deck equipment during recovery of moorings resulted in schedule disruptions totalling about 17 days.

However, considering prior experience with moored equipment in Alaska and Washington, this was a very successful field program.

\section{B.3 CURRENT-METER DATA}

\section{B.3.1 Processing}

Before analysis, the complete data set was processed to truncate preand postdeployment data and to remove outliers (despiking) in the temperature records. After truncation and despiking, current-meter observations were preprocessed by filtering with a 3-h low-pass filter (described below) and decimated to an hourly sampling interval.

The reference coordinates for the components of current velocity were rotated into alignment with the regional trend of bathymetric contours: that is, the alongshore $(v)$ axis points toward $328^{\circ} \mathrm{T}$, northward is positive; the cross-shelf (u) axis points toward $58^{\circ} \mathrm{T}$, eastward (shoreward) is positive. The general trend of depth contours at Sites $B 1 B$ and $1 M$, as determined from the NOAA navigation chart No. 18645, appears similar and parallels the regional coastline and bathymetry at Site $B I B$ determined by the survey made in April 1989 (Volume 2, Appendix A). The $328^{\circ}$ orientation differs from the axis determined by principal components analyses of the current data, as discussed in Section B.5.3. Current variation is presented on scatter plots, which consist of dot patterns on $x-y$ coordinate grids. Each dot represents the head of a current vector with its tail located at the origin. The dots on the 3-h low-pass scatter plots represent hourly current vectors; the 40-h low-pass scatter plots are 6-h current vectors. Current directions are shown by the vector azimuth, and the radial displacement of the dots from the 
origin represents current speed. A dark pattern of dots indicates a group of current speeds and directions that occurred frequently. Light dot patterns indicate current velocities that occurred infrequently.

Another way to interpret scatter diagrams is to consider a continuous release of discrete tracer particles from the current-meter location, one every hour for the 3-h low-pass data and one every $6 \mathrm{~h}$ for the $40-\mathrm{h}$ low-pass data. The dots then represent the destinations of the particles, 1 or $6 \mathrm{~h}$ after release. In this way, the scatter plots represent expected trajectories of water particles near the current meter. This analogy should not be extended more than about a kilometer away from the mooring location, because currents there may be different. Changes in currents across the shelf are discussed further under the topic of spatial coherence in Volume 1, Section 3.0. In addition to the scatter plots, the joint probability distribution of unrotated $u$ and $v$ components of velocity were contoured and plotted for each deployment and for the entire data set. These plots provide a visual representation of the likelihood of observing a velocity with a vector corresponding to the $u$ and $v$ components associated with the coordinates of the plot.

\section{B.3.2 Filtering}

Current velocity components and temperature data were filtered using 3-h and 40-h Fourier-transform, low-pass filters with three-point (frequency-domain) tapers beginning at the nominal cutoff frequencies of $0.333 \mathrm{~h}-1$ and $0.025 \mathrm{~h}-1$ (Elgar 1988; Forbes 1988; Rabiner, Gold, and McGonegal 1975). The 3-h low-pass filter was used primarily to remove smallscale turbulence and prevent aliasing before decimation of the 15-min samples to hour intervals. The 40-h low-low-pass filter effectively removed tidal and inertial oscillations to permit examination of long-period variation in the data.

\section{B.3.3 Spectral Analysis}

Spectral analysis, via the fast Fourier transform (FFT), is an efficient approach for assessing the variance (estimator of the kinetic energy of the flow available for dispersion of sediment particle and dissolved materials) as well as the strength and direction of mass transport on various time 
scales and for interpreting the data when most of the variance is contained within a few narrow frequency bands. The analyses of separate scales of flow can be addressed by filtering time series into physically meaningful spectral energy bands. Thus, the local flow field can be described in terms of the statistics of the fluctuations whereby the flow field can be separated into functions of duration or persistence over time. The low frequency bands are the interannual (years), seasonal (months), weather or subinertial (days), and the tidal frequencies (hours) and high frequencies (<hours).

Autospectra provide an indication of the relative importance (in terms of contribution to the total variance of the time series) of oscillations with different periods. Autospectra are calculated from a single time series (such as the alongshore component of current velocity) and provide an estimate of the "power" contained in narrow frequency bands corresponding to periods ranging from half the length of a segment of the time series (low frequency) to half the sampling interval (high frequency). Cross-spectra are calculated from two time series and provide estimates of the common variance of fluctuations in each of the frequency bands. Cross-spectral calculations include estimation of the coherence (formally, the coherence squared). When coherence is high, it implies that the two time series contain oscillations within the same frequency band. Amplitude and phase of coherent oscillations at each frequency may vary between two time series; these are expressed in terms of a transfer function.

Autospectral estimates of the current-meter data were computed using the Blackman-Tukey method (Jenkins 1961; Rabiner and Gold 1975). Autocorrelation estimates were calculated from time-series segmented into appropriate lengths of 512, 1024, 2048, or 8196 points. A Bartlett window was applied to the autocorrelation function, from which spectral estimates were derived using an FFT. Estimates of the $95 \%$ confidence interval around the autospectra were calculated assuming a chi-squared distribution with $n$ degrees of freedom, where $n$ was determined by the length of the time series segment and adjusted for the effects of the window. Confidence limits and frequency-bin width vary for each deployment, depending on the length of data. 
Cross-spectral estimates were performed in a similar manner using, instead of autocorrelation, the cross-correlation function. The coherence (squared) was calculated as the square of the cross-spectra normalized by the product of the two autospectra in each frequency band. An estimate of the level for which the coherence is significant at the $95 \%$ confidence level was calculated as prescribed in Jenkins and Watts (1963). Estimates of the phase and magnitude of the transfer functions should be disregarded whenever the coherence falls below this level.

\section{B.3.4 Principal Components Analysis}

The principal axes of variation in current velocity data from each instrument were computed for each deployment, for the entire data set, and for each of the two oceanographic seasons using the principal components analysis procedure described in Davis (1976). The component axes were rotated such that covariance between the two velocity components is zero. Rotation to principal component axes has the same effect as choosing a reference coordinate in which a maximum amount of the total variance is contained in the primary axis, and the remaining variance is contained in the secondary axis. This is done to minimize the amount of energy (variance) from the alongshore current that is included in the cross-shore component. The analysis permits a clearer interpretation of the physical mechanisms that drive the shelf circulation, because the dynamics associated with alongshore and cross-shelf flows are usually different.

\section{B.3.5 Tidal Analysis}

Harmonic analysis of the 3 -h low-pass filtered, hourly current-meter records was carried out using a computer program called TIDEl, developed by the Canadian government. The analysis technique and use of the program are described by Foreman (1978). The program calculates, by a least-squares method, amplitudes and phases of the tidal constituents appropriate to the length of the velocity record. Phases are in degrees of longitude relative to Greenwich; amplitudes are in units of $\mathrm{cm} \cdot \mathrm{s}-1$, and the results are plotted in the form of ellipses.

The tidal analyses of the current data are reported for the 69 tidal constituents listed in Table B.4. Results of the analyses include major and 
minor axes of the tidal current velocity ellipses, inclination, and three phase angles. The major and minor axes indicate the maximum and minimum magnitudes of tidal current velocity associated with each constituent. In a narrow tidal channel, tidal currents oscillate along the major axis with very little motion along the minor axis. This gives rise to a very thin tidal ellipse and a period in the cycle when the velocity of the constituent is nearly zero. On the mid-continental shelf, there is no coastline to constrain the tidal currents and they are rotary with fatter ellipses. The timing of tidal constituents is specified by a direction called inclination (INC) and three phase angles, G, G+, and G-. Given these parameters and the others shown in Tables B.5 through B.9, it is possible to predict/hindcast tidal currents at all future/past times for the location represented by the parameters. Although prediction of tidal currents is not an objective of this study, the computed tidal parameters are provided to complete the data description and because they may be useful at some later date for estimating tidal current at Sites B1B and $1 M$.

\subsection{TIME SERIES DATA}

\section{B.4.1 Winds}

Wind velocity and meteorological data from NDBC Buoy 46012 were obtained from the National Oceanographic Oata Center (NOOC) to investigate coupling of the wind and currents at the two sites. Buoy data are telemetered in near-real time to the NOBC for processing and redistribution. The data cover the entire 13-month deployment period, although the anemometer was not operational for approximately 40 days at the beginning of 1989 . Wind vectors, plotted at $6-\mathrm{h}$ intervals for the monitoring period, are shown in Figure B.8.

The height of the meteorological package, as well as the entire buoy payload, was changed in September 1988. Consequently, as part of the wind analysis, wind speeds were adjusted to a common 10-m level above sea surface to conform to the standard frequently used in nondimensionalization of wind parameters. The formalism applied follows that of Liu and Schwab (1987) where the wind speed at a level $z$ above the sea surface is given by 


$$
u=\left(u_{\star} / x\right)\left[\ln \left(z / z_{0}\right)-\phi_{m}\right]
$$

where $x$ is von Karman's constant $(\cong 0.4), z_{0}$ is the surface roughness length, and $\phi_{m}$ is related to the Monin-Obukhov stability length. The latter parameter is computed from a bulk atmospheric flux iteration described by Liu, Katsaros, and Businger (1979) and implemented in a FORTRAN program by Liu and Blanc (1984). Wind stress $\left(\tau_{W}\right)$ is then defined to be

$$
\tau_{W}=\sigma C_{D} W|\mathbf{H}|
$$

where $\sigma$ is the air density; $C_{D}$ is the wind-stress drag coefficient, which increases as a function of wind strength as specified by Wu (1980), and $W$ is the wind vector. The alongshore component of the calculated wind stress is also shown in Figure B.8.

\section{B.4.2 Current Velocity}

The rotated velocity time series are presented as vector plots in Figures B.9 and B.10. Vector plots represent 40-h low-low-pass currents, at 6-h intervals, as a line originating on the $x$ axis with length proportional to speed and oriented in the direction toward which the current flows. The reference coordinates for all wind and current velocities (y axis) were rotated so that the alongshore $(v)$ axis bears $328^{\circ} \mathrm{T}$ and is positive northward. Separate plots of the $u$ and $v$ components for each velocity record are presented in Figures B.11 through B.14. The entire record, comprising data from four deployments, is shown for each current meter. Data gaps are indicated by an absence of piotted data. At Site BIB, data were not recovered at $83 \mathrm{~m}$ for the period from day 15, 1989, until the end of the program. There are gaps in the current records from the top- and mid-water meters in the periods from day 245 to 260,1988 , and 15 to 30,1989 . The current time series from Site $1 M$ have very few gaps; the longest one is between days 20 and 30, 1989 .

The velocity time series from Site $81 B$ indicate that the alongshore component of velocity dominates the cross-shelf component and becomes stronger toward the surface. Near the bottom, the flow is more aligned with the bathymetric contours than it is higher in the water column, but the

\section{B. 15}


dominant near-bottom fluctuations are rotated slightly offshore from the $328^{\circ} \mathrm{T}$ reference axis. The current directions at Site $1 \mathrm{M}$ (Figure B.10) appear to be less aligned with the bottom contours than those at Site B1B, and there is considerable variability from top to bottom during most of the record. Two episodes of strong alongshore flow occurred during the study, one centered on day 160, 1988, and the other on day 215, 1988. The episode of strong flow centered on day 160 included a cross-shelf component as well. Strong along-shore flow occurred in the upper water column between days 300 and 320 and days 110 and 130 at Site B1B. The monthly mean alongshore and cross-shelf velocity components at Site $B 1 B$ and $1 M$ are shown in Figures $B .15$ and $B .16$, respectively.

\section{B.4.3 Water Temperature}

Time series of water temperature are shown for Site B1B and $1 \mathrm{M}$ in Figure B.17. At Site B1B, the water column is thermally stratified during most of the measurement period. There was a nearly $1.5^{\circ} \mathrm{C}$ temperature gradient in the upper water column most of time. During February and early March 1989, thermal stratification in the upper water column broke down and the water column was thermally well mixed. At Site $1 \mathrm{M}$, the water appeared well mixed during more of the year and was generally colder than that at Site B1B by about $0.5^{\circ} \mathrm{C}$ to $1.0^{\circ} \mathrm{C}$. Gaps in the temperature records generally correspond to the gaps in velocity data discussed above. The monthly mean temperatures are shown in Figure B.18. Warming of the upper water column in June and July 1988, followed by deepening of the mixed layer in November and December, is very apparent in the monthly averages.

\section{B.4.4 Waves at Montara}

Wave data were obtained from a four-gage array of bottom-mounted pressure transducers located at a 15-m depth in the nearshore zone off Montara, California (Figure B.1). The array is maintained by the ocean Engineering Research Group at Scripps Institution of Oceanography, under CDIP, and provides estimates of significant height $\left(H_{S}\right)$, period $(T)$, and wave-energy spectra at approximately $6-h$ intervals. In addition to the time series of 
$\mathrm{H}_{5}, \mathrm{~T}$, and energy spectra, CDIP provided estimates of wave-orbital velocity for depths of $42 \mathrm{~m}$ and $86 \mathrm{~m}$, calculated from $H_{s}$ and $T$ using linear wave theory (a).

Figure B.19 shows time series of significant wave height and dominant period during the study. The joint probability distribution of significant wave height and period for the Montara wave record is given in Table B.10. Figure B.20 shows the cumulative frequency distribution of significant wave height and dominant wave period. The dominant wave period is most frequently in the range from $B$ to $10 \mathrm{~s}$, and the significant wave height exceeded $1 \mathrm{~m}$ about $50 \%$ of the time and exceeded $2 \mathrm{~m}$ about $10 \%$ of the time. The record is typical of a mild year in terms of storm frequency and intensity.

\section{B.4.5 Suspended Sediment}

The voltage output of the OBS sensor for the third deployment at site $B 1 B$ is shown in Figure B.21. The recorded signal consists of numerous events of sharply rising output riding on a baseline ambient signal that increases steadily throughout the deployment. During the 100-day record, the frequency and amplitude of the events relative to the baseline vary with time but do not appear correlated with background water clarity. To recover the signais of suspension events so they could be related to the current and wave observations, the raw voltages were despiked to remove values outside the reasonable expected range (very large positive values as well as all negative values) and filtered with the 3-h low-pass filter described in Section B.3.2. The resulting time series was detrended to remove the effect of changes in background water clarity and biofouling of the sensor. Detrending was accomplished by dividing the record into 5-day segments and subtracting the minimum value in each segment from all values in the segment. The inherent assumptions of the detrending procedure are that the high-frequency variation in suspended sediment is related to the near-bottom current conditions, the low-frequency signal is noise, and the high- and the low-frequency signals

(a) J. Thomas, Scripps Institution of Oceanography, La Jolla, California; personal communication with $C$. Sherwood, PNL, Sequim, Washington, Apri i 4, 1989. 
are not correlated. Estimated sediment concentrations for the despiked, filtered, and detrended OBS record are shown on the bottom panel of Figure B.21. The complete record (Figure B.22) shows an increase in high sediment concentration events during the fall/winter that is well correlated with the larger wave heights and periods measured during that time.

The OBS data from the other deployments were processed as shown in the example above. Complete records for Sites $B 1 B$ and $1 M$ are shown in Figures B.22 and B.23. The records from both sites indicate that suspension events are most frequent in the winter months and that relatively few events occur in the summer. A complete interpretation of the causes of the annual cycle are developed with the aid of dynamically based sediment transport calculations discussed in Volume 2, Appendix $C$.

\section{B.5 STATISTICAL SUMMARIES}

\section{B.5.1 Monthly and Seasonal Mean Velocities and Temperatures}

Velocity mean values and standard deviations were calculated to provide estimates of temporal trends in the current regimes over month to month, seasonal, and annual periods, and for comparisons of current records at different depths and between the two sites. Tables B.11 through B.20 report the monthly mean and standard deviations of the velocities for each current meter. The monthly mean and standard deviations of water temperature are reported in Tables B.21 through B.25. Seasonal and total record means and standard deviations are given in Tables $\mathrm{B} .26$ and $\mathrm{B} .27$, respectively. At Site $B 1 B$ the strongest monthly mean currents occurred in the surface layer and were toward the south in the spring and early summer. The observed mean velocities range from 0.0 to $\sim 17 \mathrm{~cm} \cdot \mathrm{s}^{-1}$, and the variability was very constant despite the large differences in record length from month to month. The monthly mean currents in the winter at the surface were weak and variable and showed no strong seasonal direction. The bottom currents, however, were southerly throughout the measurement period with the exception of March 1989 when weak northerly flow occurred. The seasonal trend at Site $1 M$ is more evident in the monthly means. Weak northward flow occurred during most of the winter months, and southward flow occurred in the summer months. The 
mean current speeds were lower at Site IM than at Site B1B. A complete interpretation of the monthiy and seasonal velocity and temperature statistics is developed in volume 1 , Section 3.0 .

\section{B.5.2 Current Speed/Direction Probability Distributions}

Joint probability distributions indicate the percentage of time that a particular range of current velocities occurred during the measurement period. Joint probabilities were calculated for seasonal segments as well as for the entire study period. A description of the oceanographic seasons and reasons for selecting them is provided in Volume 1, Section 1.0. Briefiy, spring/sumer is characterized by southward wind that exerts a southward wind stress along the coast and offshore Ekman transport of surface water. Ekman transport refers to the current associated with the balance between wind stress at the surface and the Coriolis force resulting from the earth's rotation. Along the west coast, the surface water is transported offshore and upwelling occurs. During the fall/winter season, the winds are more erratic and storms track through the region more frequently than during summer. Under these conditions, upwelling stops and northward flowing currents predominate, especially in the surface layer.

Tables B.28 through B.44 give the joint probability statistics for the two seasons and the total record for each current meter. Unfiltered 15-min current velocities were included in the joint probability analyses. For Site B1B, the current speeds are slightly higher on average during the fall/ winter season than during spring/summer. The seasonal trend in current speed is more evident in the surface and botton waters than at mid-depth. There is no obvious seasonal trend in the distribution of current directions at Site B1B. At Site 1M, the seasonal trend appears opposite to what was observed at Site B1B (i.e., the lower speeds occur more frequently during the winter). Unlike at Site B1B, there is a pronounced seasonal shift in dominant current direction from southeast to north at Site 1M. The explanations for these trends are fully developed in Volume 1, Section 3.0.

\section{B.5.3 Principal Components}

The results of the principal components analyses are summarized in Tables B.45 and B.46, and the orientation of the calculated axes with respect 
to the measured current vectors, depicted on scatter plots, are shown in Figures B.24 and B.25. Principal component analyses indicate that rotation of the reference axes for the current velocities to $328^{\circ} \mathrm{T}$ was not sufficient to maximize the variance of the currents on one axis. They also indicate that there is substantial variance of the currents across the local depth contours. At Site B1B, the principal component of variance is oriented about $334^{\circ} \mathrm{T}$ at mid-depths and about $312^{\circ} \mathrm{T}$ near the bottom, and the seasonal variation was less than $3^{\circ}$. In the upper water column, the principal axes ranged from $355^{\circ} \mathrm{T}$ to $340^{\circ} \mathrm{T}$ from summer to winter. At Site $1 M$, the seasonal trend in surface current variance opposed the observations at Site $B 1 B$ and ranged from $342^{\circ} \mathrm{T}$ to $353^{\circ} \mathrm{T}$. Near the bottom, the variance in winter was similar to the observations at Site B1B, whereas in sumer the principal axes oriented more toward the west than at Site B1B. A complete discussion of the dynamic implications of the principal components analyses is given in Volume 1, Section 3.1.1.

\section{B.6 SPECTRAL AND TIDAL HARMONIC ANALYSES OF CURRENTS}

The autospectra of current velocity and temperature for each of the current meters are shown in Figures $B .26$ and $B .27$, respectively. Figure B.26 displays separate spectra for the $u$ and $v$ components of velocity for each current-meter record. For frequencies below the $\mathrm{k} 1$ tide (period $=24.8 \mathrm{~h}$ ), there is significantly more energy (variance per $\mathrm{Hz}$ ) in the alongshore component of the current than in the cross-shelf component. The lower two meters recorded nearly an order of magnitude more alongshore energy at $0.002 \mathrm{~h}^{-1}$ than cross-shelf energy. This is an underestimate of the relative difference, however, because the coordinate axis rotation was about $15^{\circ}$ to $20^{\circ}$ less than it should have been, according to the principal component analysis near the bottom. At tidal and higher frequencies, there is little difference between the spectra of $u$ - and v-veiocity components at the $95 \%$ confidence level. The exception to this is near the bottom, where there is substantially more energy in the $K 1 \vee$ component. This is also evident in the tidal analyses results discussed below.

The other notable feature of the autospectra is that variance at the inertial frequency is apparent primarily near the surface at Site B1B. 
Although the spectral peak at the inertial frequency is not significant at the $95 \%$ confidence level, it suggests that inertial currents do not impinge much further onshore than at Site B1B. Also, there is increased energy in the tidal currents relative to other oscillatory components of the circulation as the coast is approached. Table B.47 shows these trends quite clearly. The table gives the percentage of alongshore variance in the currents contained in three frequency bands: $10 \mathrm{w}(<0.6 \mathrm{~d}-1)$, diurnal $(0.91$ to $1.3 \mathrm{~d}^{-1}$ ), and semidiurnal ( 1.9 to $2.1 \mathrm{~d}-1$ ). At Site $1 \mathrm{M}$, nearly $67 \%$ of the variance is in the diurnal and semidiurnal frequency bands, whereas at Site $B 1 B$, only $53 \%$ of the variance is in these bands.

Autospectra for temperature, Figure B.27, indicate a strong dominance of variance in the low frequencies, less than $0.07 \mathrm{~h}-1$, and a sharp peak at the M2 tidal frequency. Near the bottom at both sites, the variations in water temperature are, for a11 purposes, low frequency. There is a weak M2 peak at Site $1 \mathrm{M}$ but it contains less than $10 \%$ of the energy at $0.01 \mathrm{~h}-1$. The implication is that changes in water temperature are seasonal and influence broad areas of the shelf. Further discussion of changes in the temperature regimes at the sites and their relation to upwelling are presented in volume 1, Section 3.1.1.

Coherence and phase spectra are shown for pairs of current meters in Figure B.28. All plots show the spectra of both the $u$ and $v$ components of velocity. The coherence and phase spectra provide a picture of the similarity, band-for-band in the frequency domain, of the variance in the current at two locations. High coherence at a particular frequency indicates that there is a common variation in the current at that frequency at both sites. The variation, however, does not necessarily occur in phase, and the phase spectrum contains the latter sort of information. Phases near zero indicate variations are synchronized in time at the two locations. Large positive (negative) phase angles indicate that coherent variations in the currents at one location lead $(1 \mathrm{ag})$ the variations at the other location. As shown on the spectra, the greatest coherence, like oscillations at both meter locations, is in the $K 1$ and $M 2$ tidal constituents and at frequencies less than $0.01 \mathrm{~d}-1$. The phase differences among meter pairs.(i.e., top to bottom and bottom to bottom) are small at low frequencies, suggesting that the flow 
reversals and changes in direction occur at the same time at both locations. These general conclusions are obvious in the time series plots of velocity for the sites. Further discussion of the dynamic bases for these derived spectral quantities is provided in volume 1, Section 3.1.1.

The coherence of the currents with the winds at NDBC buoy 46012 is generally low in comparison with the tidal signal discussed above. Examples of the wind-current coherence for near-surface and bottom flow are shown in Figure B.29. In general, coherence is low, but significant at the $95 \%$ confidence level, across the spectra. This suggests that measurements of the winds at one location, even though it may be close by, do not predict the majority of the variation in the shelf currents. Previous studies of largescale circulation reached the same conclusion, and winds from a relatively large area must be included in the calculations to account for a large fraction of the variation in the shelf currents.

Tables B.5 through B.9 give the amplitudes, in $\mathrm{cm} \cdot \mathrm{s}^{-1}$, and phases, in degrees relative to GMT, for the five current meter records. The four largest constituents are $M 2, K 1,01$, and $S A_{;}$the first two readily apparent in the velocity spectra. These four constituents are dominant at most midshelf sites along the central California and Oregon coasts. The phase and relative magnitudes of the $M 2$ and $K 1$ constituents at sites $B 1 B$ and $1 M$ are shown in Figure B.30. There is considerable phase shift in the $M 2$ constituent, top to bottom, at both sites and larger tidal excursions at Site $1 \mathrm{M}$. The physical explanation for these features of the tidal wave as recorded at the sites is given in volume 1, Section 3.1.1.

\section{B.7 REFERENCES}

Aubrey, D. G. and J. H. Trowbridge. 1985. "Kinematic and Dynamic Estimates from Electromagnetic Current Meter Data." Journal of Geophysical Research 90 (C5) : $9137-9146$.

Davis, J. C. 1976. Statistics and Data Analysis in Geology. John Wiley and Sons, New York.

Downing, J. P. 1983. "An Optical Instrument for Monitoring Suspended Particles in Ocean and Laboratory." In Proceedings of OCEANS '83, pp. 199202, Institute of Electronic and Electrical Engineers and Marine Technology Society, San Francisco. 
Downing, J. P., and R. A. Beach. 1989. "Laboratory Apparatus for Calibrating Optical Suspended Solids Sensors." Marine Geology 86:243-249.

D\&A Instruments. 1988. Optical Backscatterance Turbidity Monitor Instruction Manual. D\&A Instruments, Washington, D.C.

D\&A Instruments. 1989. "Optical Methods for Measuring Turbidjty and Suspended Solids in Water: Some Notes for Users of OBS Sensors." TECHNOTE 3/89, D\&A Instruments, Washington, D.C.

Elgar, S. 1988. Comment on "Fourier Transform Fi]tering: A Cautionary Note," by A. M. G. Forbes. Journal of Geophysical Research 93(C12):15,75515,756 .

Forbes, A. M. G. 1988. "Fourier Transform Filtering: A Cautionary Note." Journal of Geophysical Research 93(C6):6958-6962.

Foreman, M. G. G. 1978. "Manual for Tidal Currents Analys is and Prediction." Pacific Marine Science Report 78-6 (May 1984 Edition). Institute of Ocean Sciences, Sidney, B.C., Canada.

Jenkins, G. M. 1961. "General Consjderations in the Analysis of Spectra." Technometrics 3:133-166.

Jenkins, G. M., and D. G. Watts. 1968. Spectral Analysis and its Applications. Holden-Day, New York.

Liu, P. C., and D. J. Schwab. 1987. "A Comparison of Methods for Estimating $u_{\star}$ From Given $u_{2}$ and Air-Sea Temperature Differences." Journal of Geophysi-: cal Research 92(C6):6488.

Liu, T. W., and T. V. B1 anc. 1984. The Liu, Katsaros, and Businger (1979) Bulk Atmospheric Flux Computationa I Iteration Program in FORTRAN and BASIC. NRL Memorandum Report 5291, Navai Research Laboratory, Washington D.C.

Liu, T. W., K. B. Katsaros, and J. A. Businger. 1979. "BuTk Parameterization of Air-Sea Exchanges of Heat and Water Vapor Including the Molecular Constraints at the Interface." Journal of Atmospheric Science 36:1722.

Ludwig, K. A. and D. M. Hanes. 1989. A Laboratory Investigation into the Behavior of Optical Backscatter Sensors used for the Measurement of Suspended Sediment Concentration. University of Miami Draft Technical Report, Miami, FTorida.

Rabiner, L. R., and B. Gold. 1975. Theory and Application of Diqital Signal Processing. Prentice-Hall, Englewood Cliffs, New Jersey.

Rabiner, L. R., B. Gold, and C. A. McGonegal. 1975. "An Approach to the Approximation Problem for Non-recursive Digital Filters." IEEE Transactions on Audio and Electroacoustics AU-18(2):83-106. 
Wu, J. 1980. "Wind-Stress Coefficients over the Sea Surface Near Neutral Conditions. Journal of Physical Oceanography. 10:727-740. 


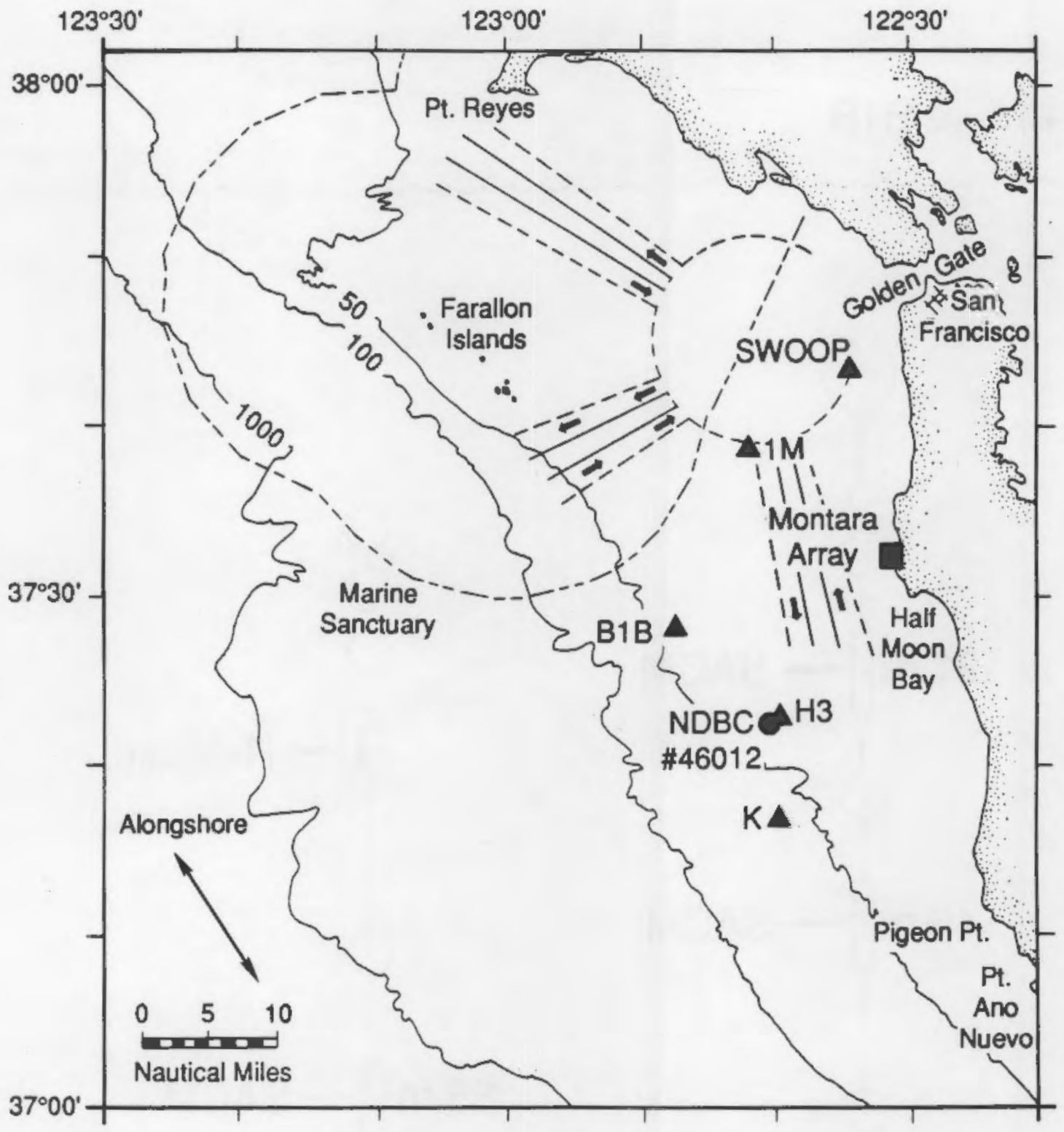

FIGURE B.1. Map of the Study Area Showing Locations of CurrentMeter Moorings, Wave Gage, and Meteorological Buoy 


\section{a) Site $B 1 B$}

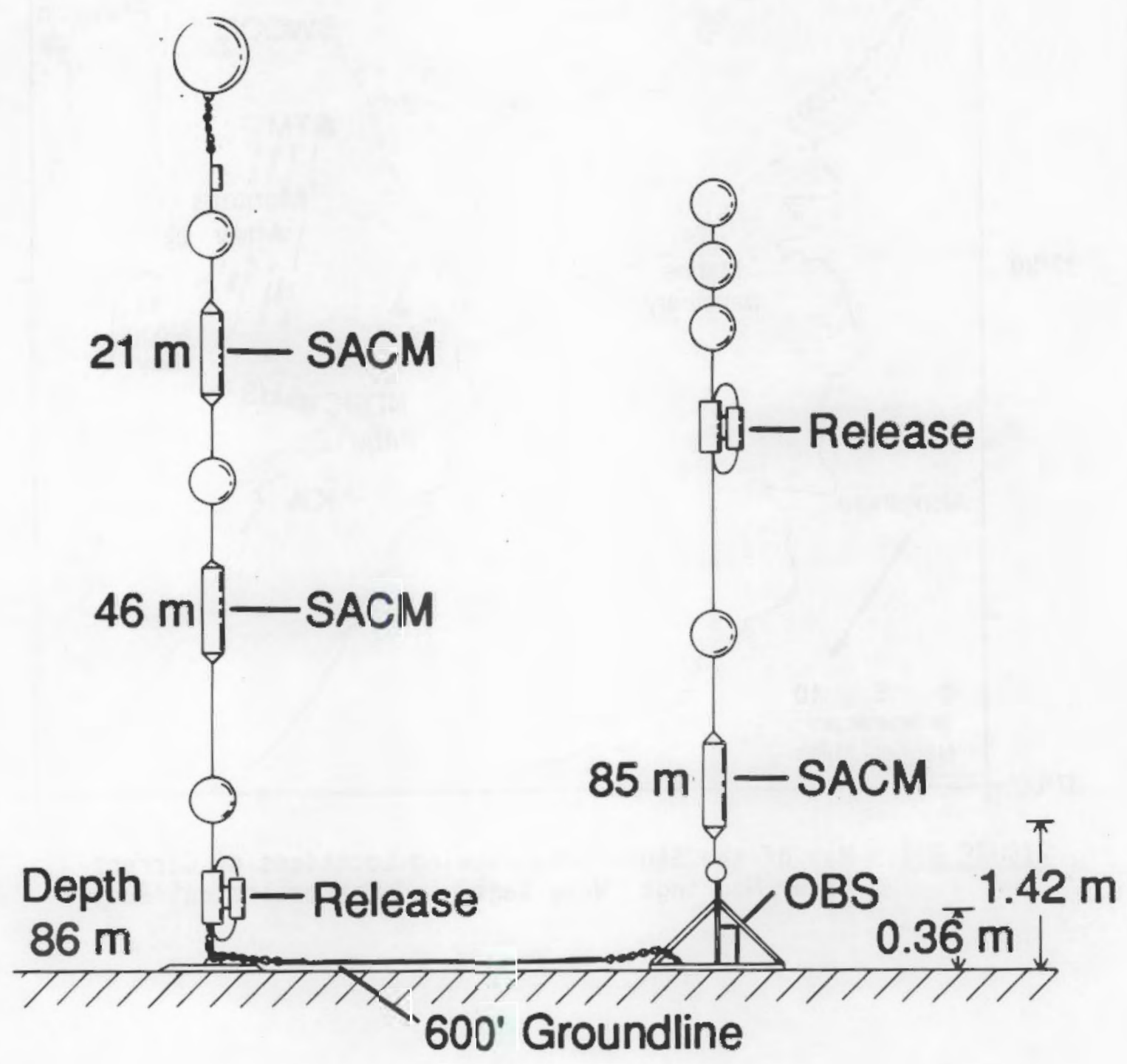

FIGURE B.2. Configuration of Mooring Deployed at Site B1B 
b) Site $1 \mathrm{M}$

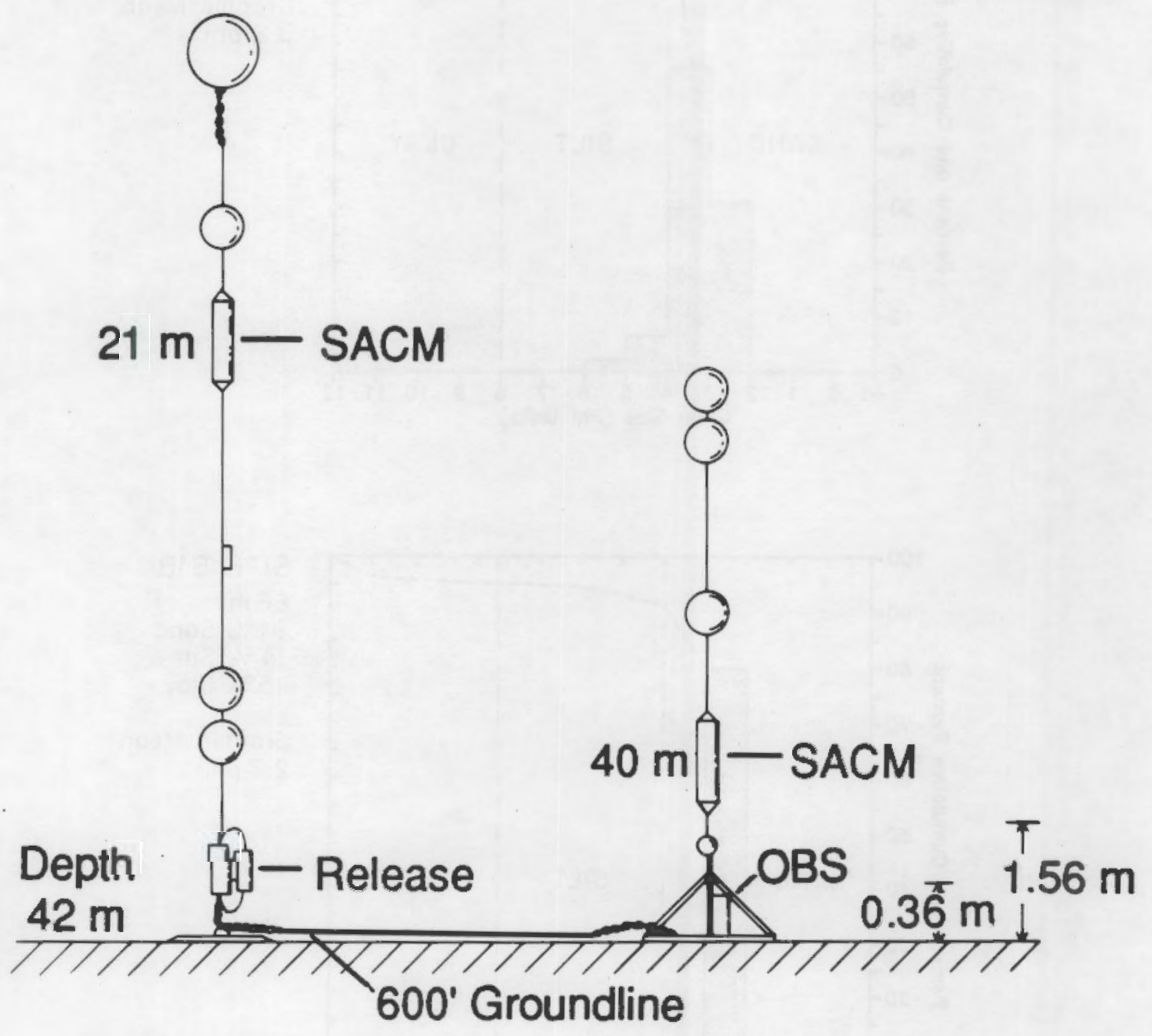

FIGURE B.3. Configuration of Mooring Deployed at Site 1M 


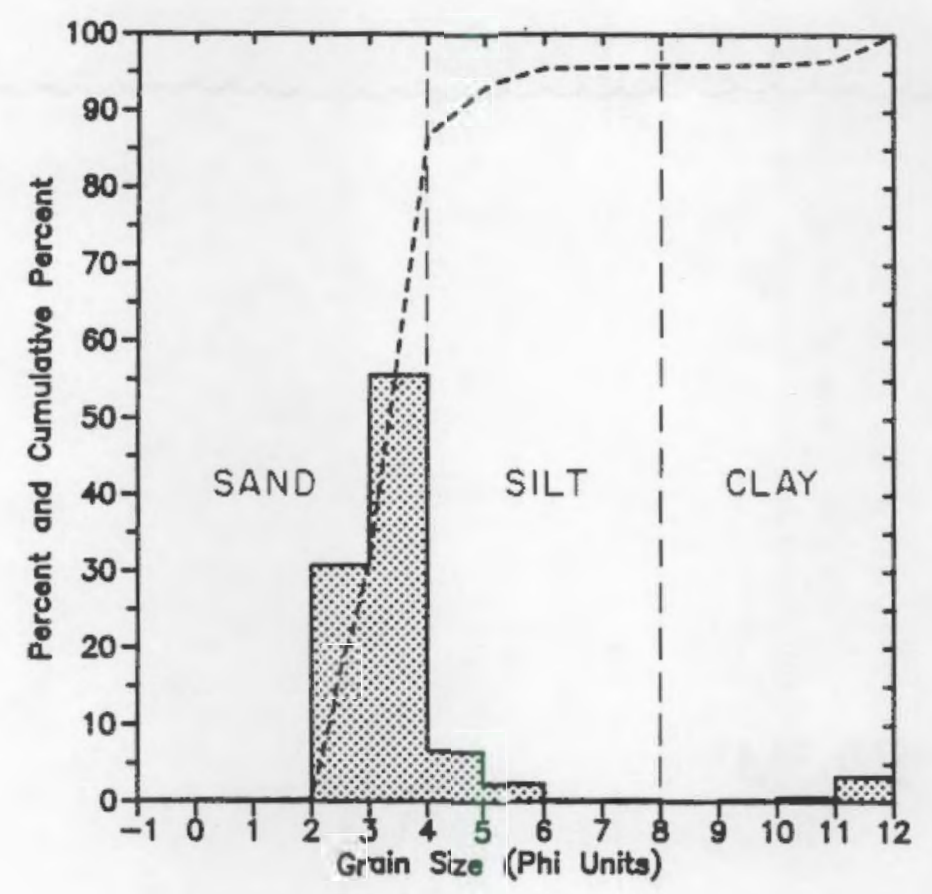

$$
\begin{aligned}
& \text { SITE IM } \\
& 42 \mathrm{~m} \\
& 87 \% \text { Sand } \\
& 9 \% \text { Silt } \\
& 4 \% \text { Clay }
\end{aligned}
$$

Graphic Mean:

$3.2 \mathrm{phi}$

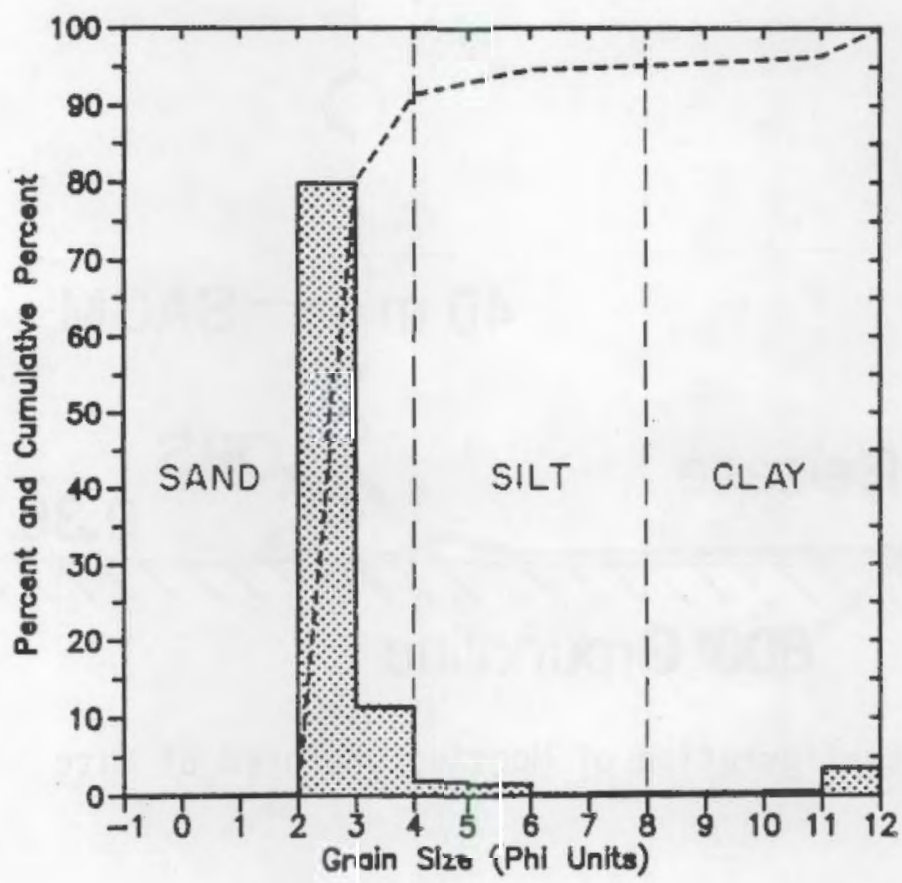

SITE B1B $86 \mathrm{~m}$

$91 \%$ Sand

$4 \%$ Silt

$5 \%$ Clay

Graphic Mean:

2.7 phi

FIGURE B.4. Sediment Grain Size Distribution and Cumulative Size Curves for Grab Sample Taken at a) Site B1B and b) Site 1M. 


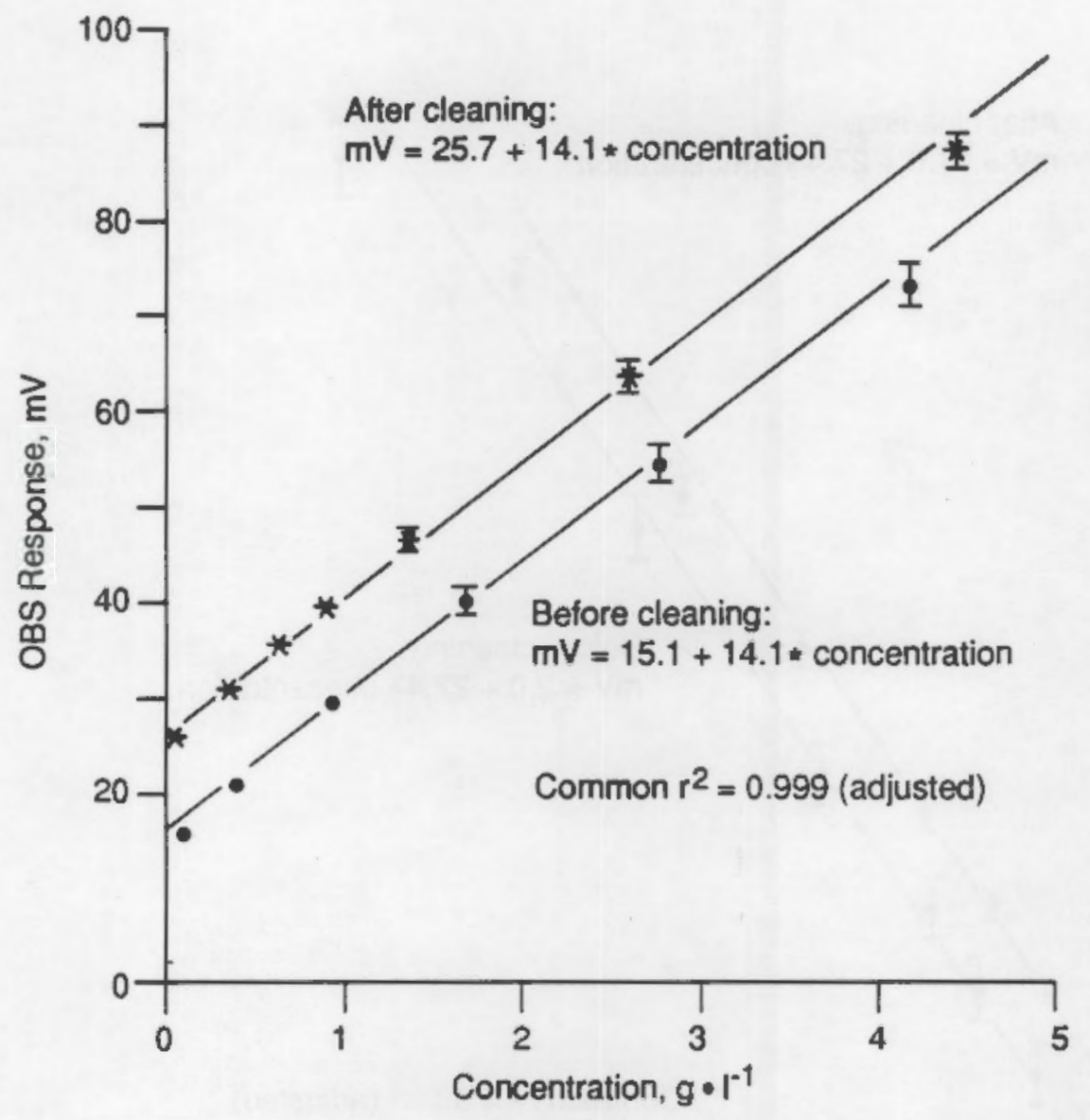

FIGURE B.5. Calibration Curves for OBS Sensor S/N 67 Before and After Cleaning. Plots show output voltage in $\mathrm{mV}$ versus sediment concentration in $\mathrm{g} \cdot \mathrm{f}^{-1}$. Error bars indicate standard deviation in output voltage. Solid line is fit from weighted least-squares regression using common slope. 


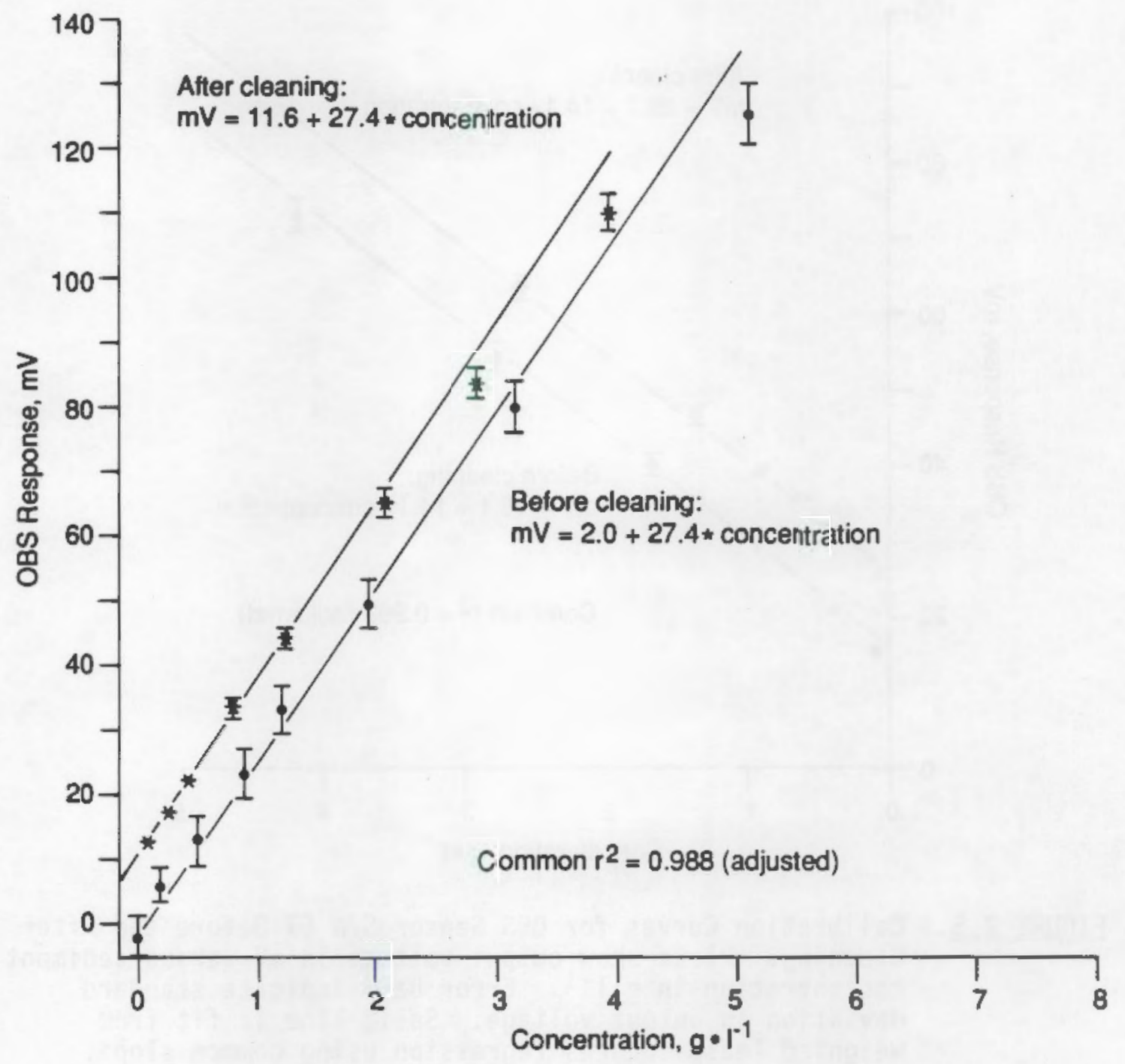

FIGURE B.6. Calibration Curves for OBS Sensor S/N 68 Before and After Cleaning. Plots show output voltage in $\mathrm{mV}$ versus sediment concentration in $g^{-1}$. Error bars indicate standard deviation in output voltage. Solid lines are fit from weighted least-squares regression using common slope. 


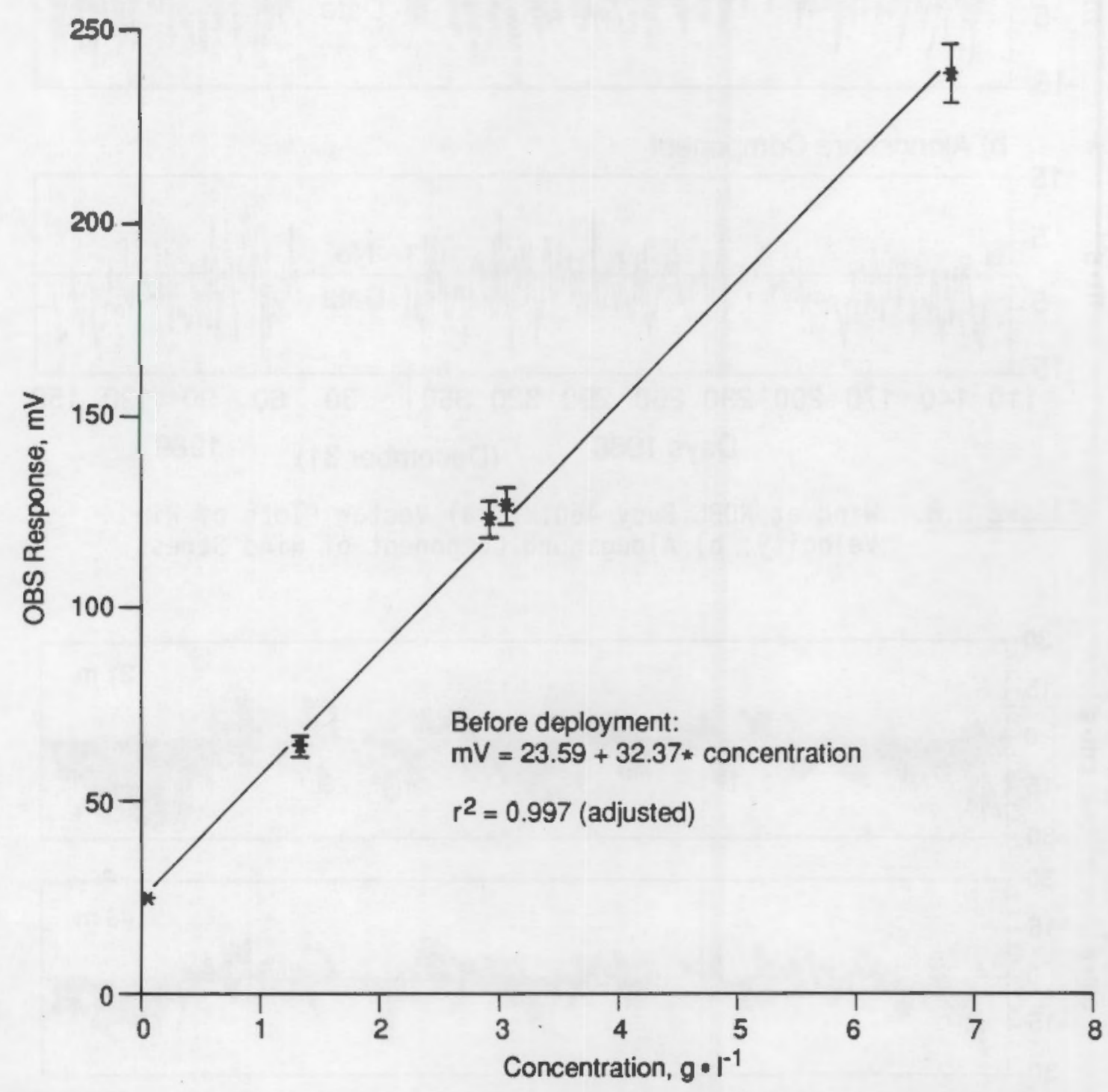

FIGURE B.7. Calibration Curve for OBS Sensor S/N 88 Before Deployment 4 at Site B1B. Plots show output voltage in $\mathrm{ml}$ versus sediment concentration in $\mathrm{g} \cdot \mathrm{l}^{-1}$. Error bars indicate standard deviation of output voltage. Solid line is fit using weighted leastsquares regression. 
a) Wind Vectors

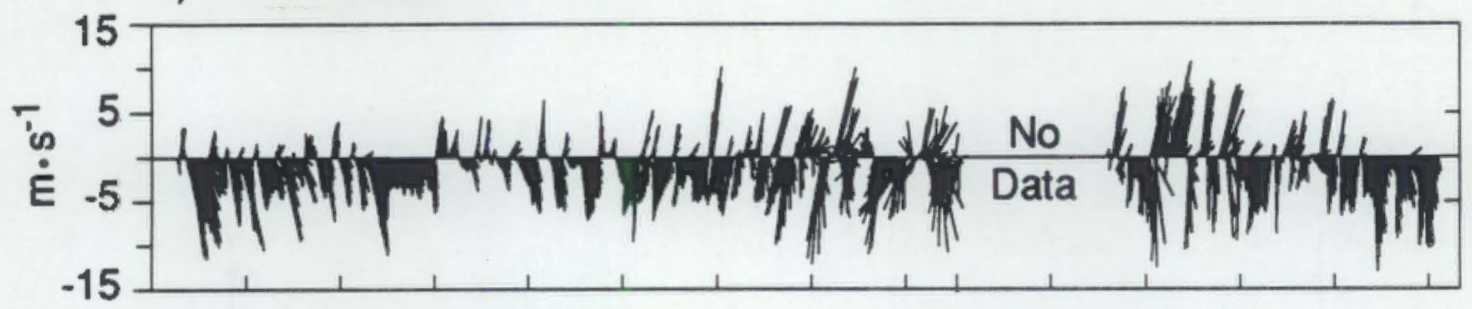

b) Alongshore Component

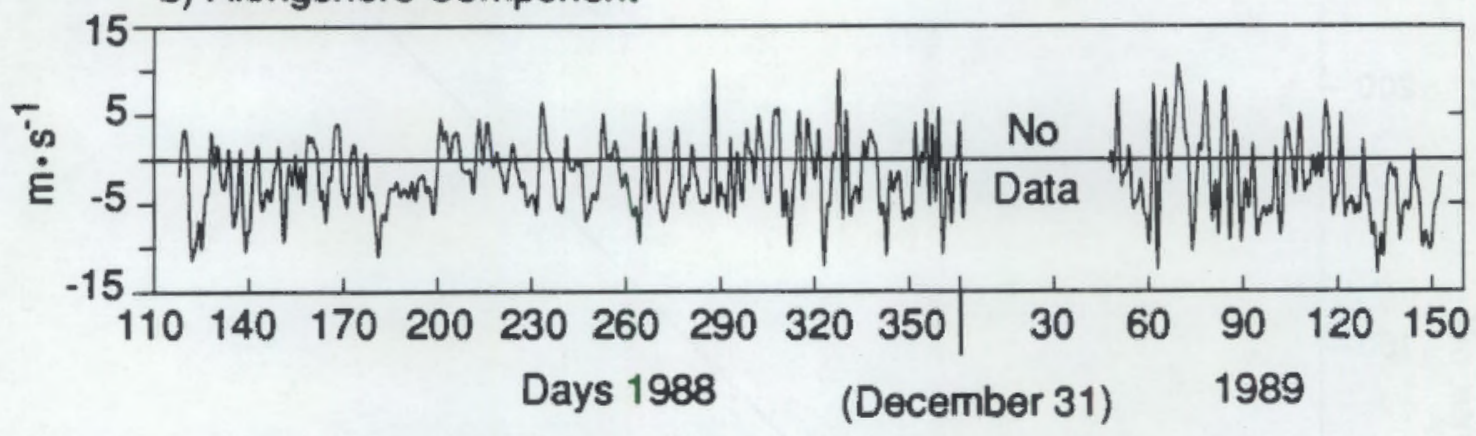

FIGURE B.8. Wind at NDBC Buoy 46012: a) Vector Plots of Wind Velocity, b) Alongshore Component of Wind Stress
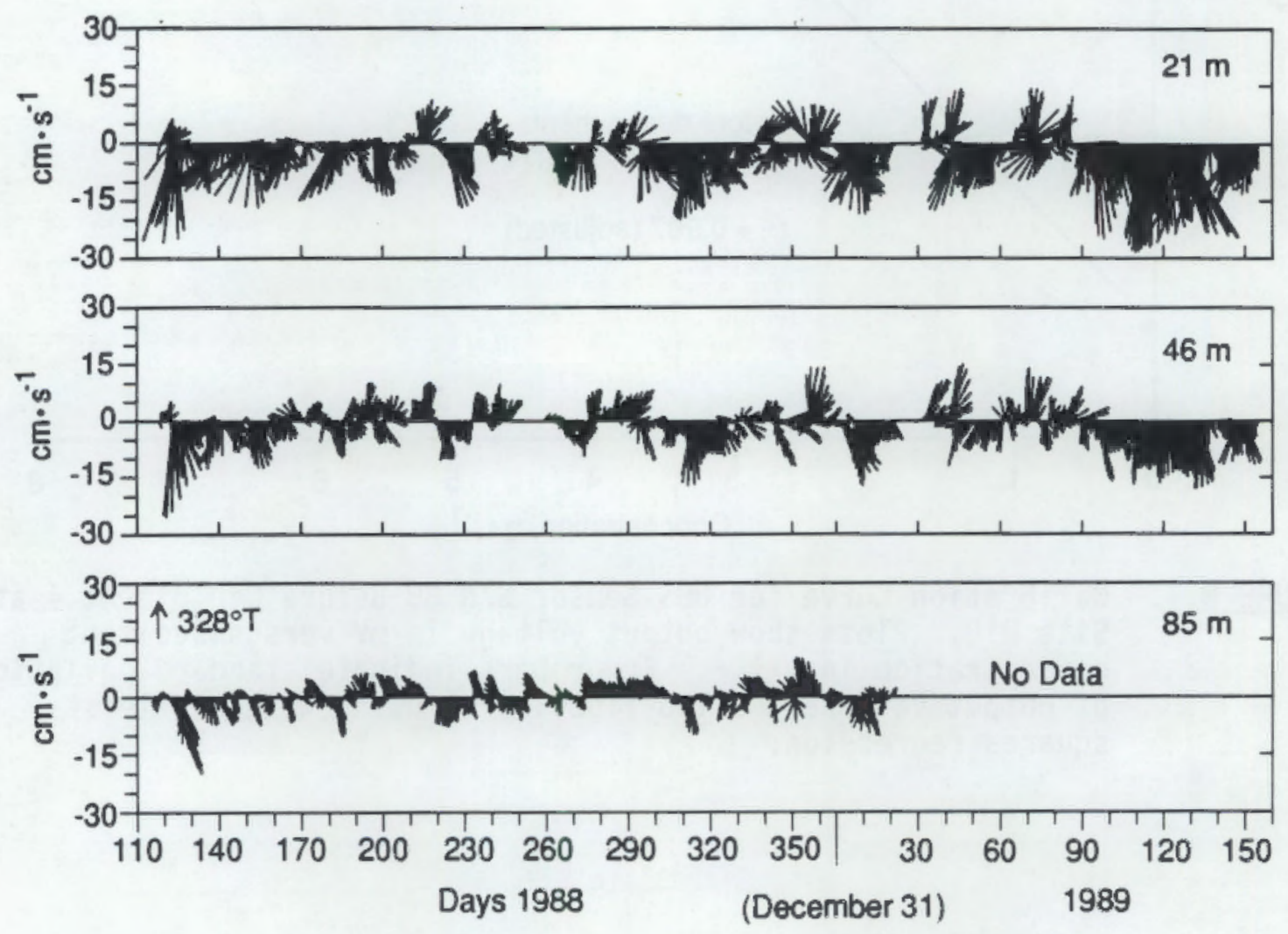

FIGURE B.9. Vector Plot of 40-h Low-Pass Filtered Current Velocity at Site B1B 

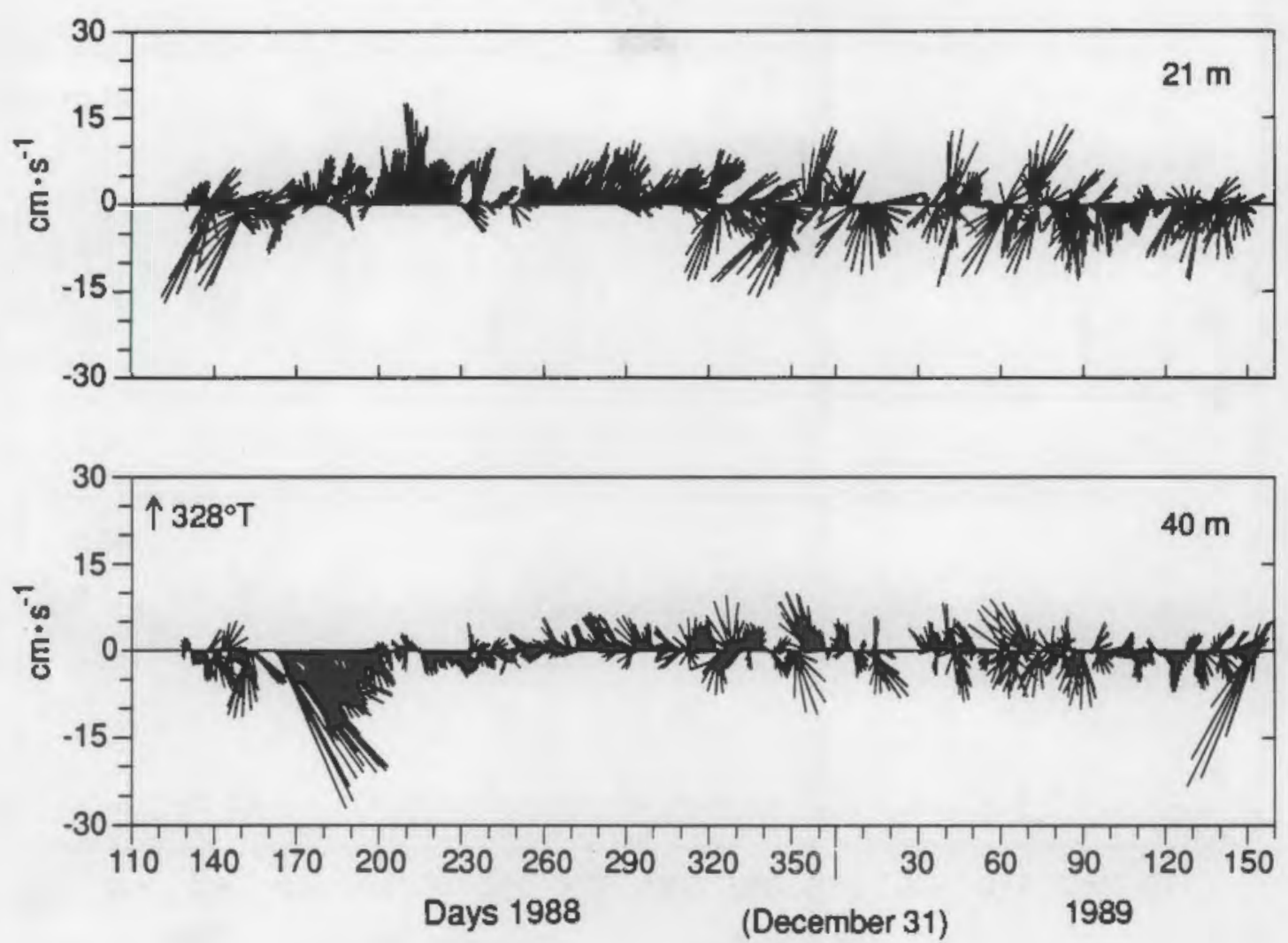

FIGURE B.10. Vector Plot of 40-h Low-Pass Filtered Current Velocity at Site IM
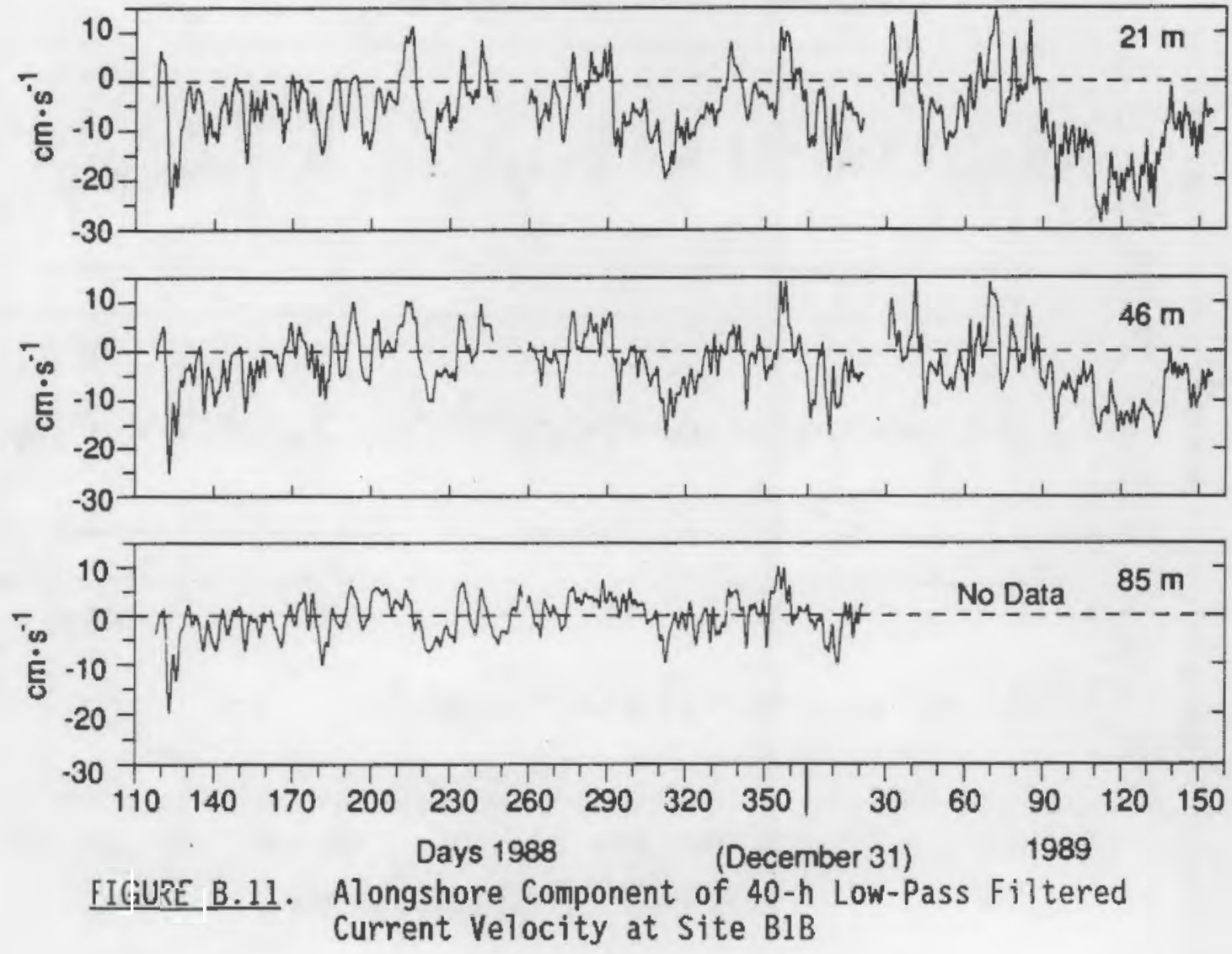

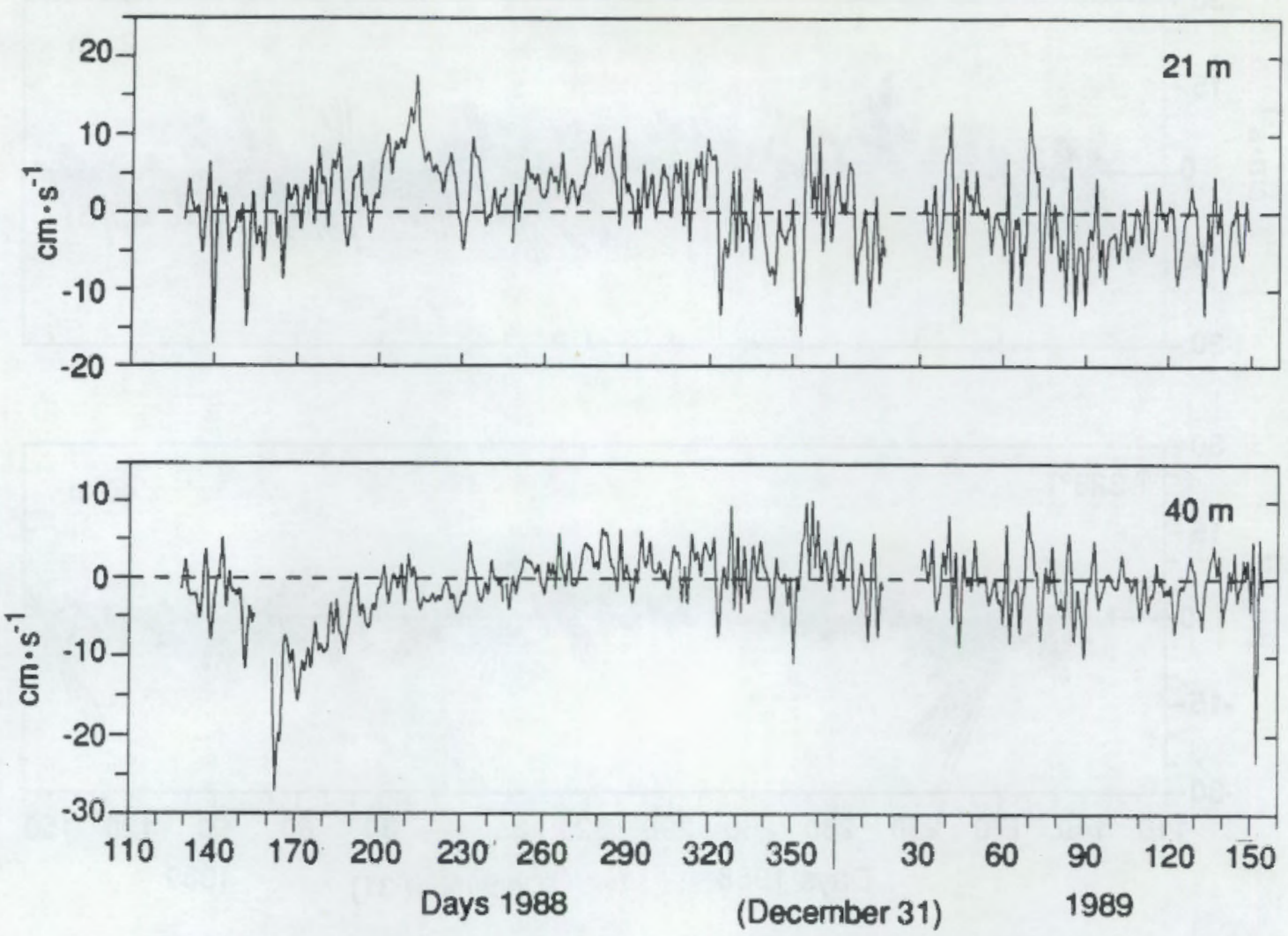

FIGURE B.12. Alongshore Component of 40-h Low-Pass Filtered Current Velocity at Site $1 \mathrm{M}$
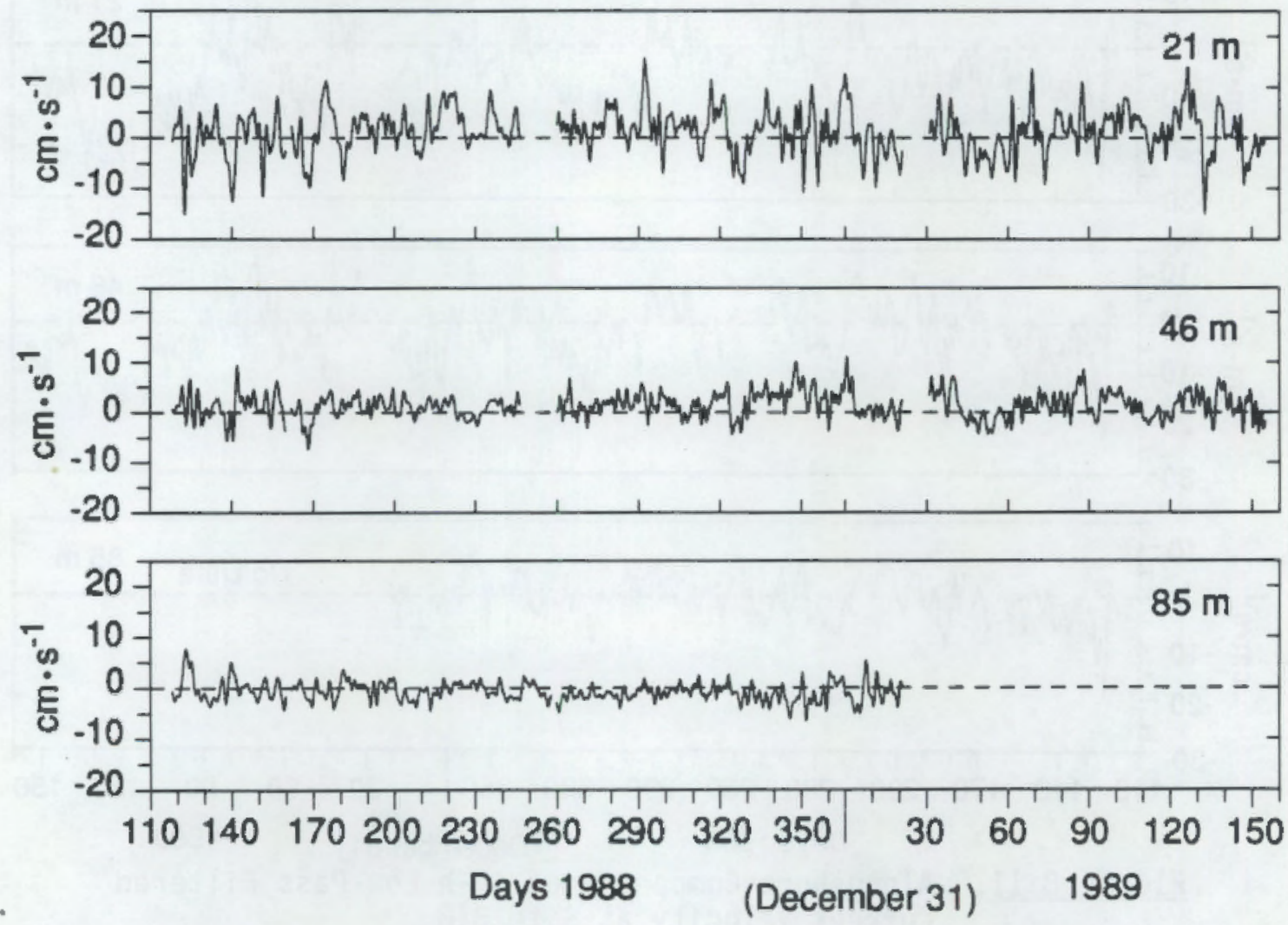

FIGURE B.13. Cross-Shelf Components of 40-h Low-Pass Filtered Current Velocity at Site B1B 

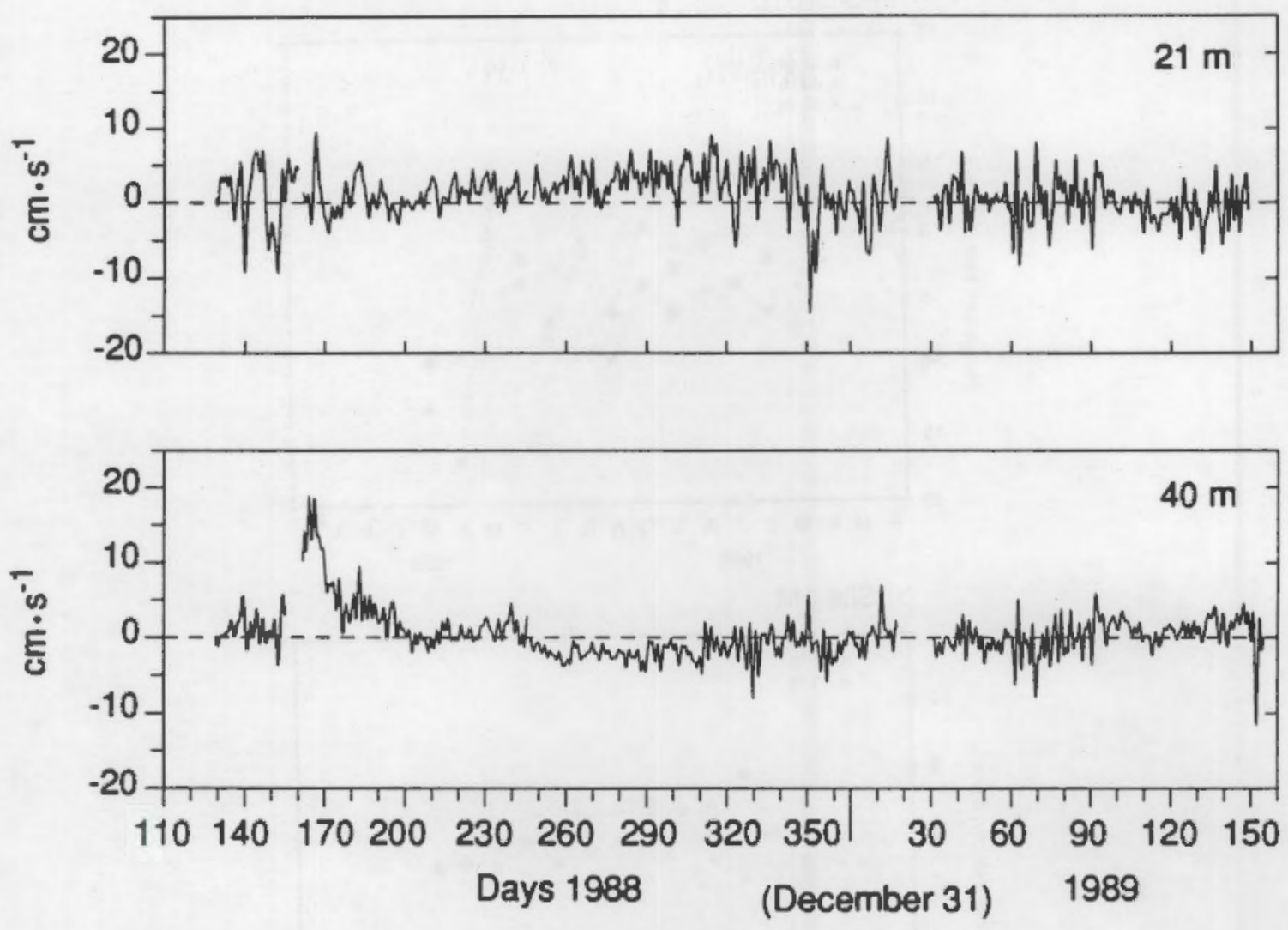

FIGURE B.14. Cross-Shelf Components of 40-h Low-Pass Filtered Current Velocity at Site $1 M$ 
a) Site B1B

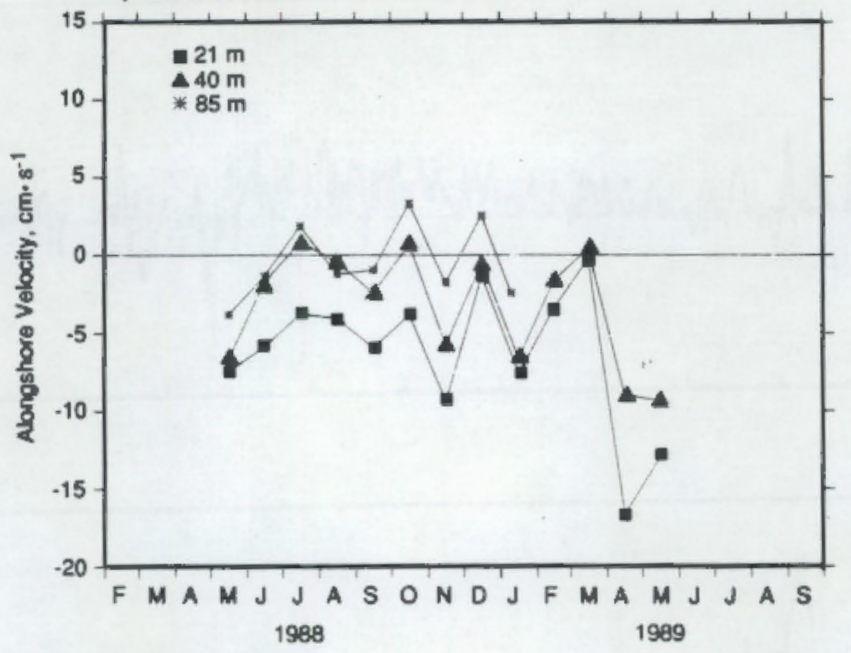

b) Site $1 M$

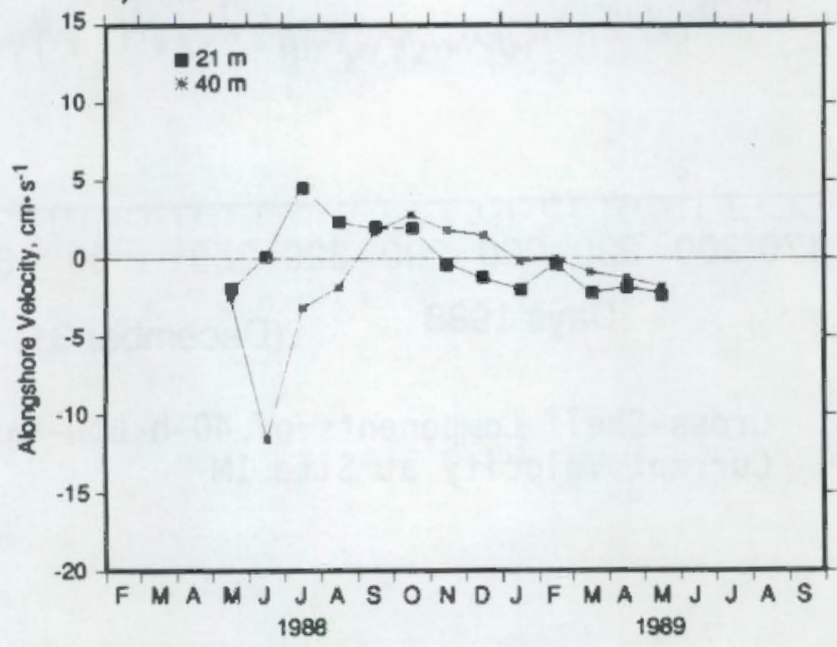

c) H3 Mooring (SuperCODE)

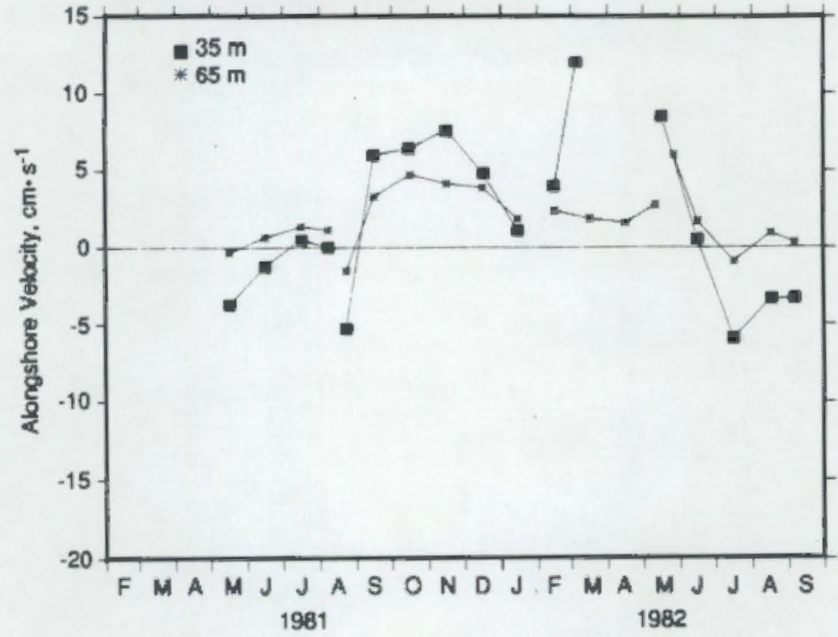

FIGURE B.15. Time Series of Monthly Mean Alongshore Velocity Components for a) Site BlB, b) Site 1M, and

c) SuperCODE Mooring $\mathrm{H} 3$ 

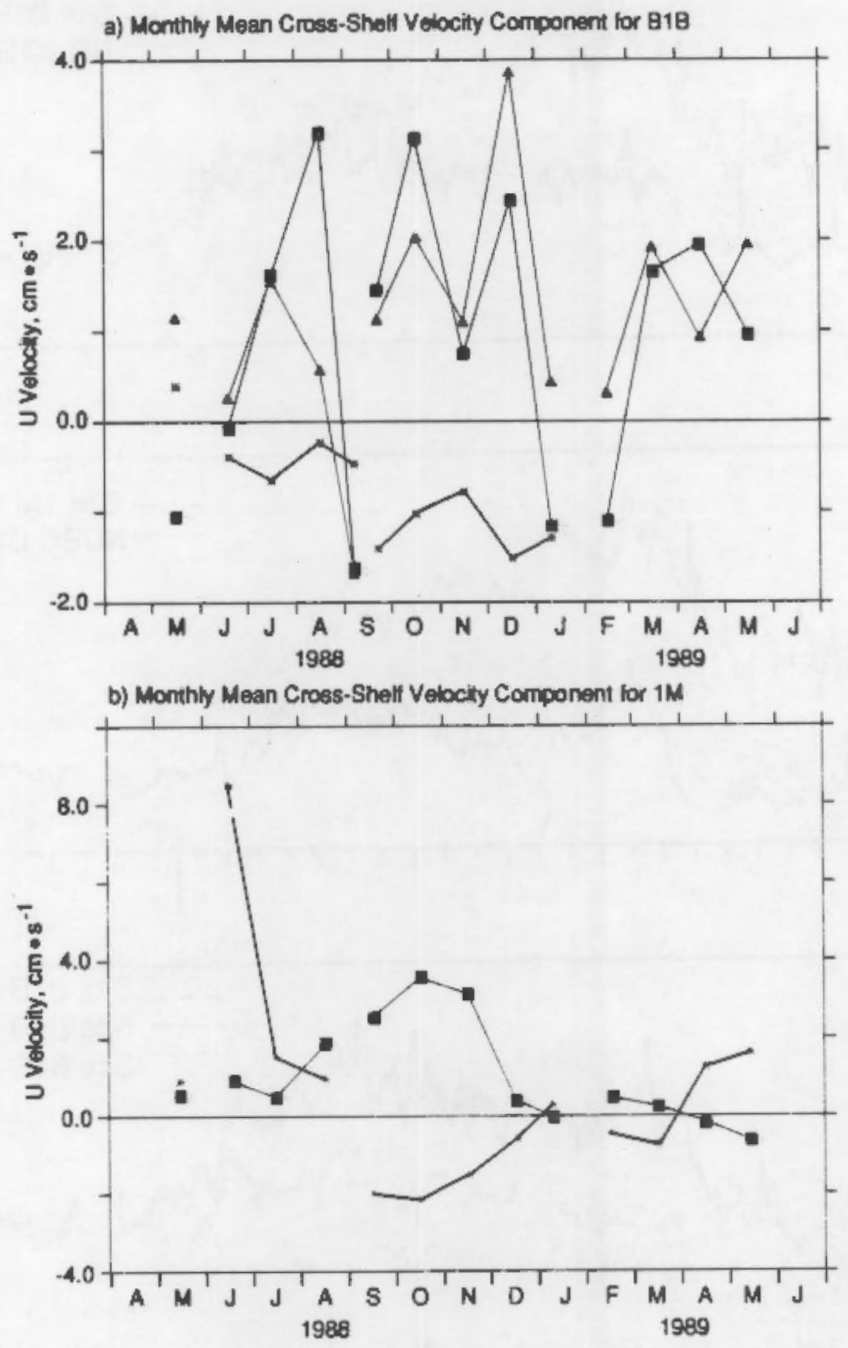

FIGURE B.16. Time Series of Monthly Mean Cross-Shelf Velocity Components for a) Site B1B and b) Site $1 M$ 

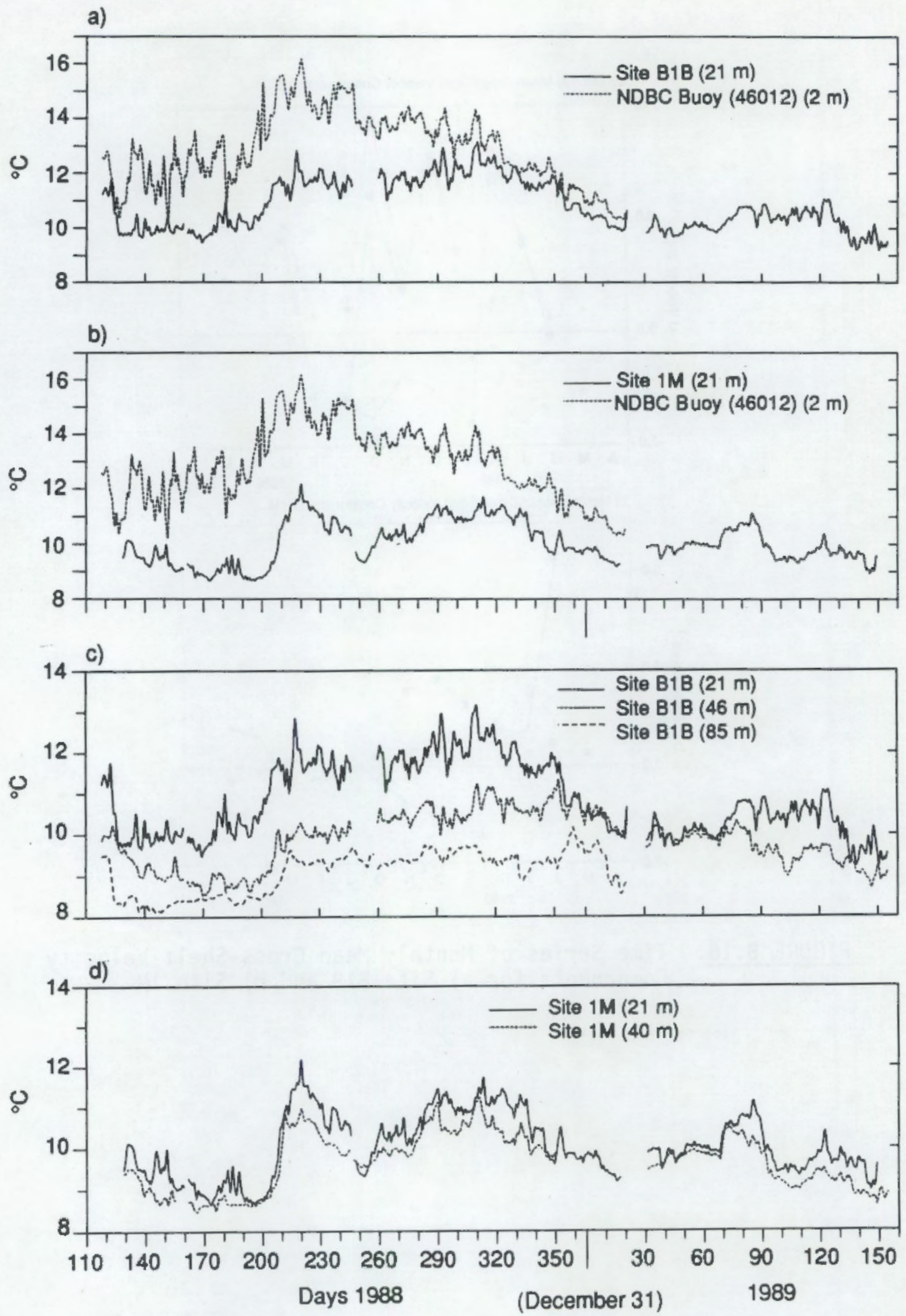

FIGURE B.17. Time Series of 40-h Low-Pass Filtered Water Temperature From Current Meters at Sites B1B and $1 \mathrm{M}$ 

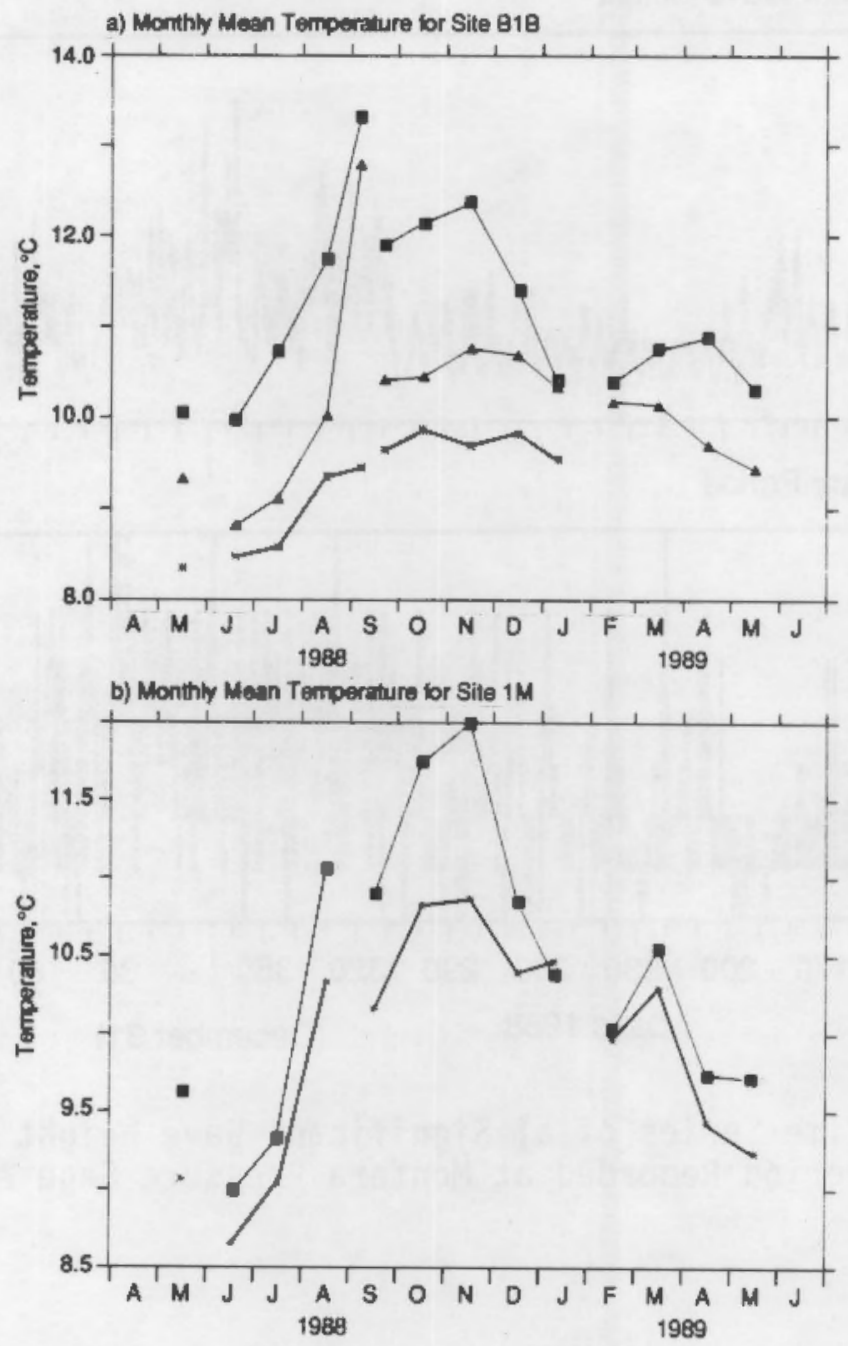

FIGURE B.18. Time Series of Monthly Mean Water Temperature at a) Site $B 1 B$ and b) Site $1 M$ 
a) Significant Wave Height
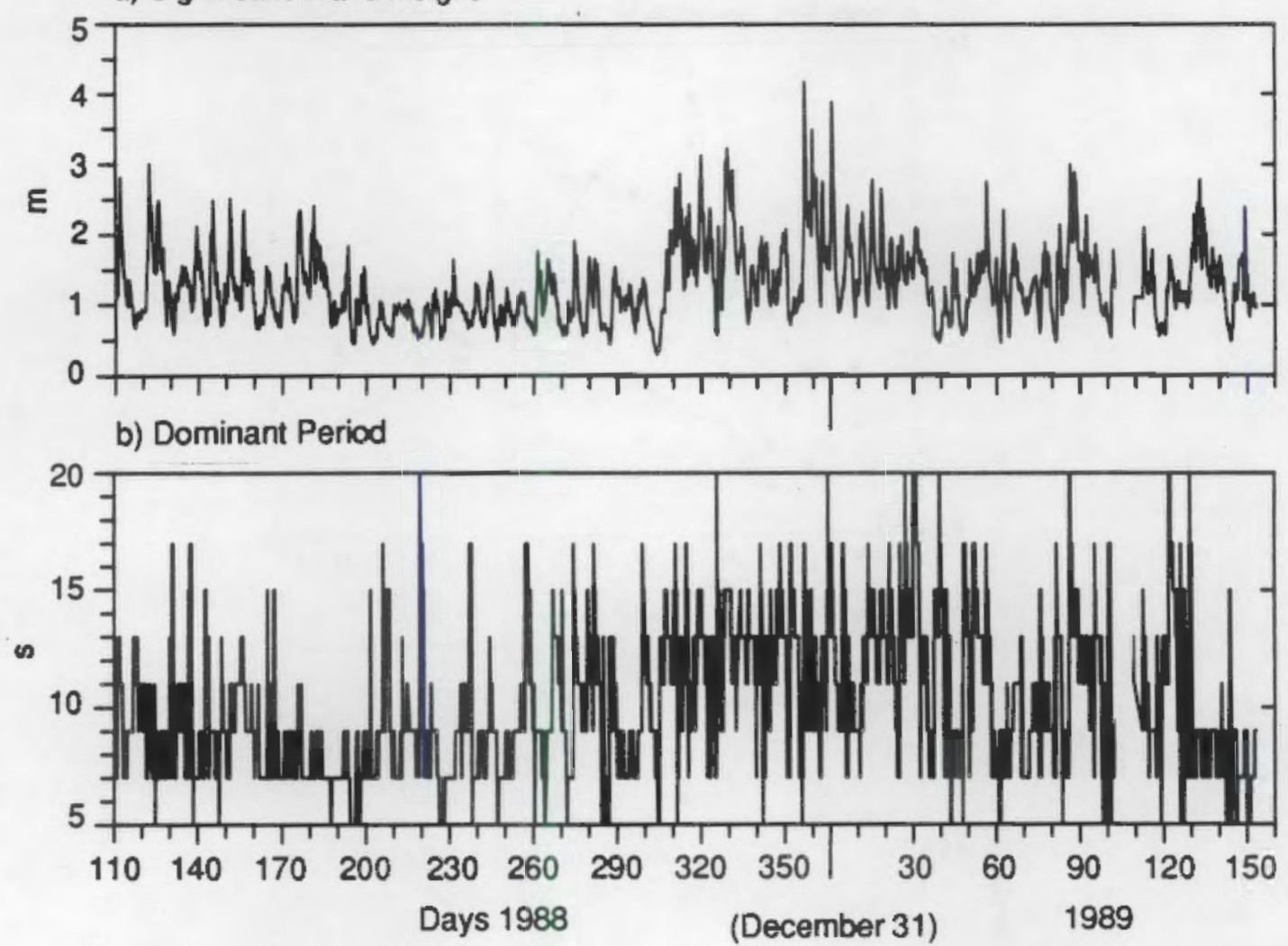

FIGURE B.19. Time Series of a) Significant Wave Height and b) Dominant Period Recorded at Montara Pressure Gage Array 


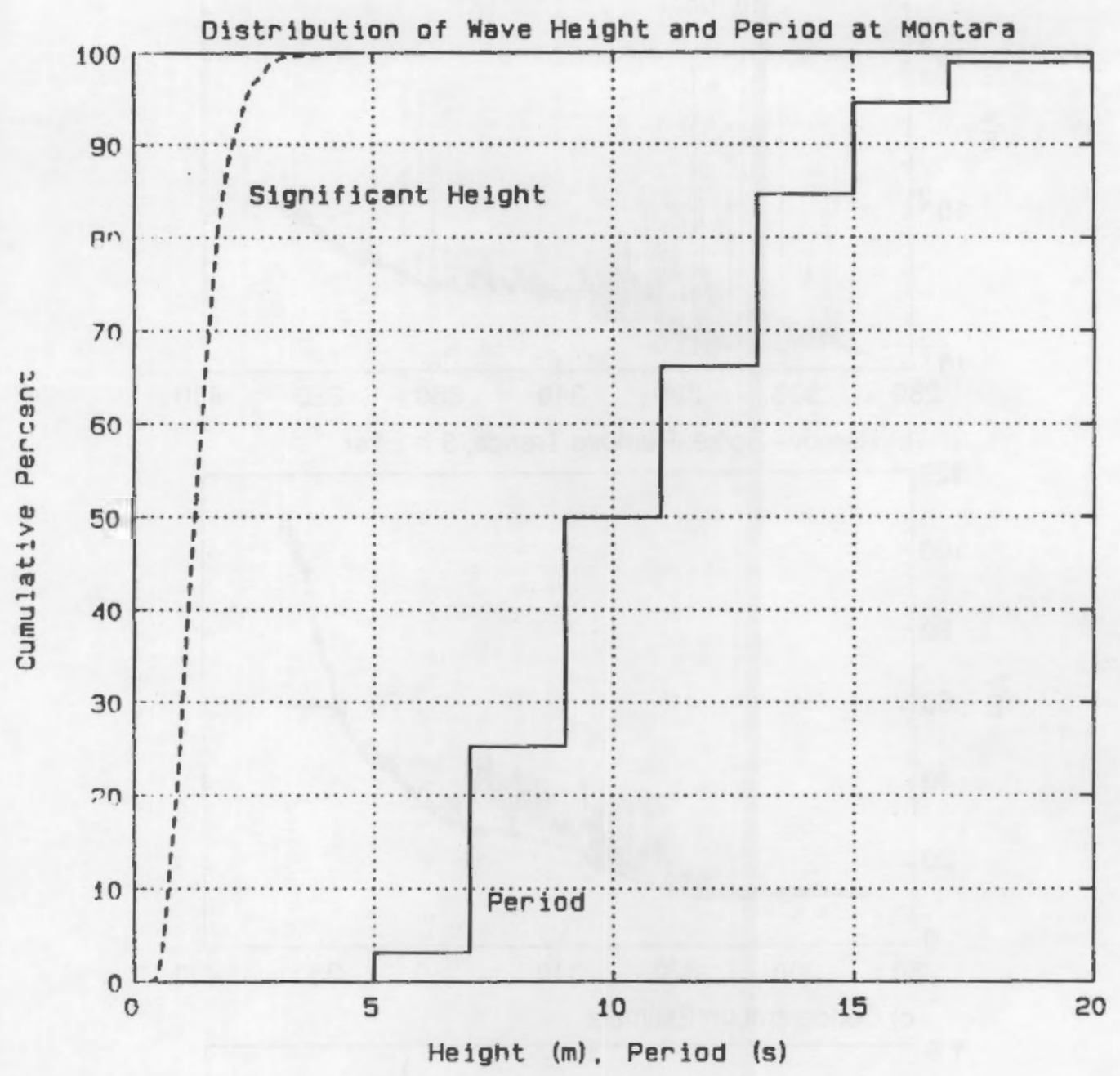

FIGURE B.20. Cumulative Frequency Distributions of Significant Wave Height and Dominant Period Recorded at Montara Pressure Gage Array 
a) Raw OBS Data

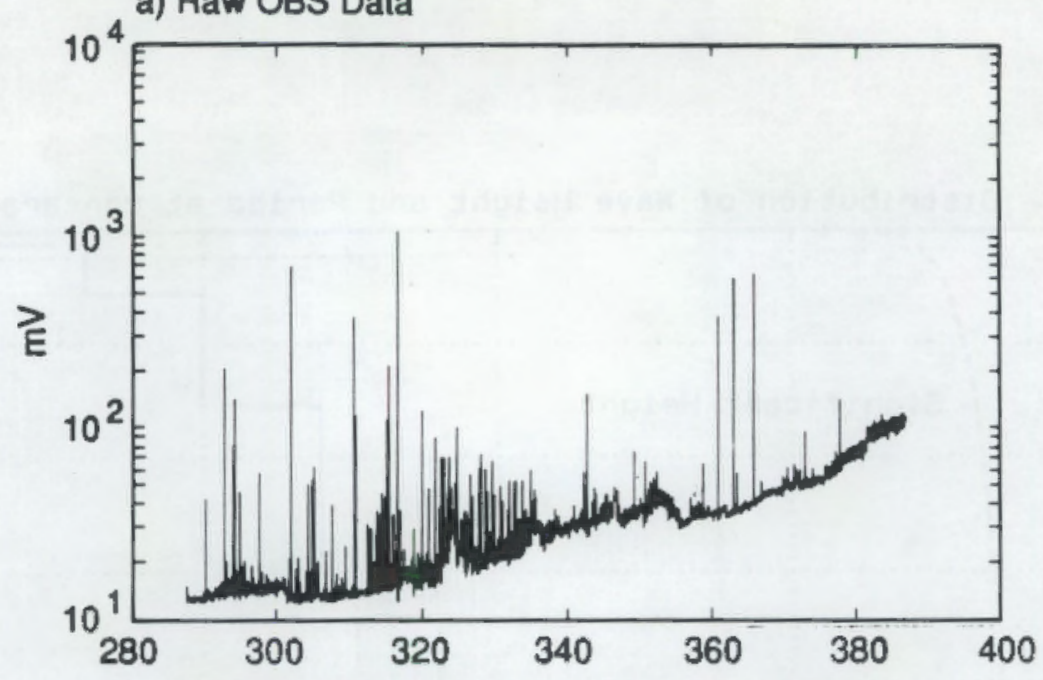

b) Remove Spike, Remove Trends, 3-h Filter

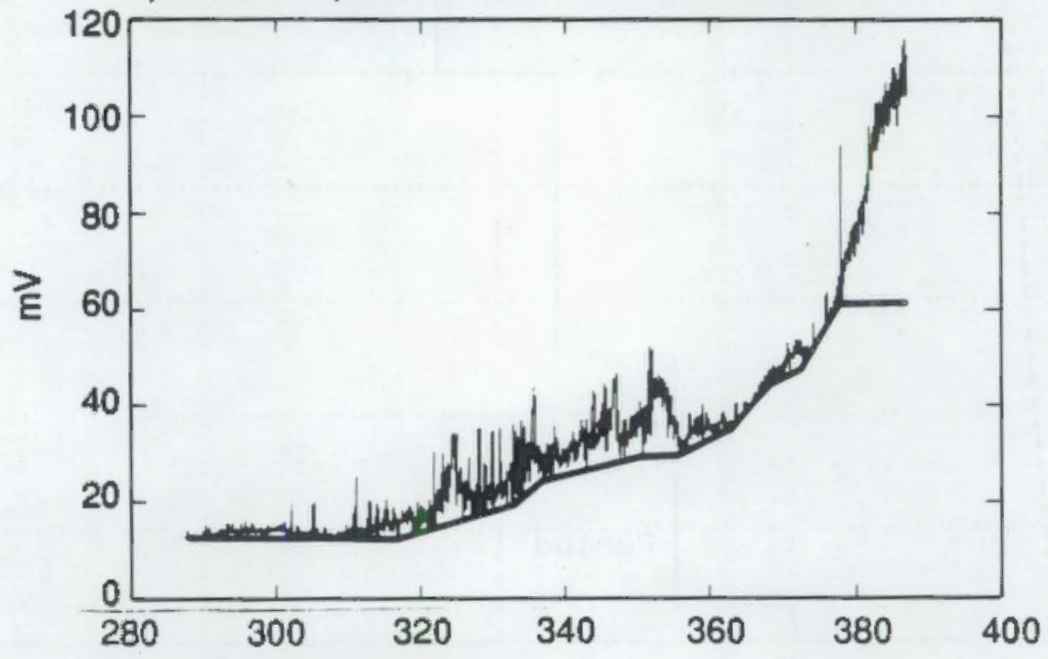

c) Concentration Estimate

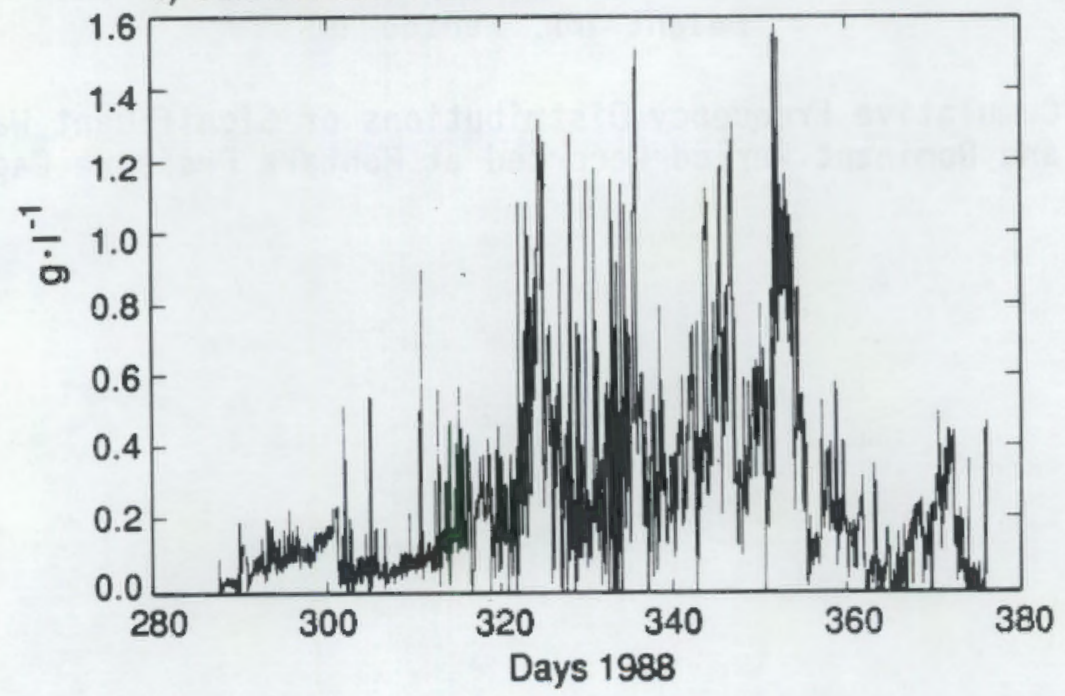

FIGURE B.21. a) Example of Raw OBS Output Voltage, b) Despiked and Filtered Output Showing Baseline Trend, and c) Concentrations Estimated with the Detrended Data and the Calibration Coefficients 

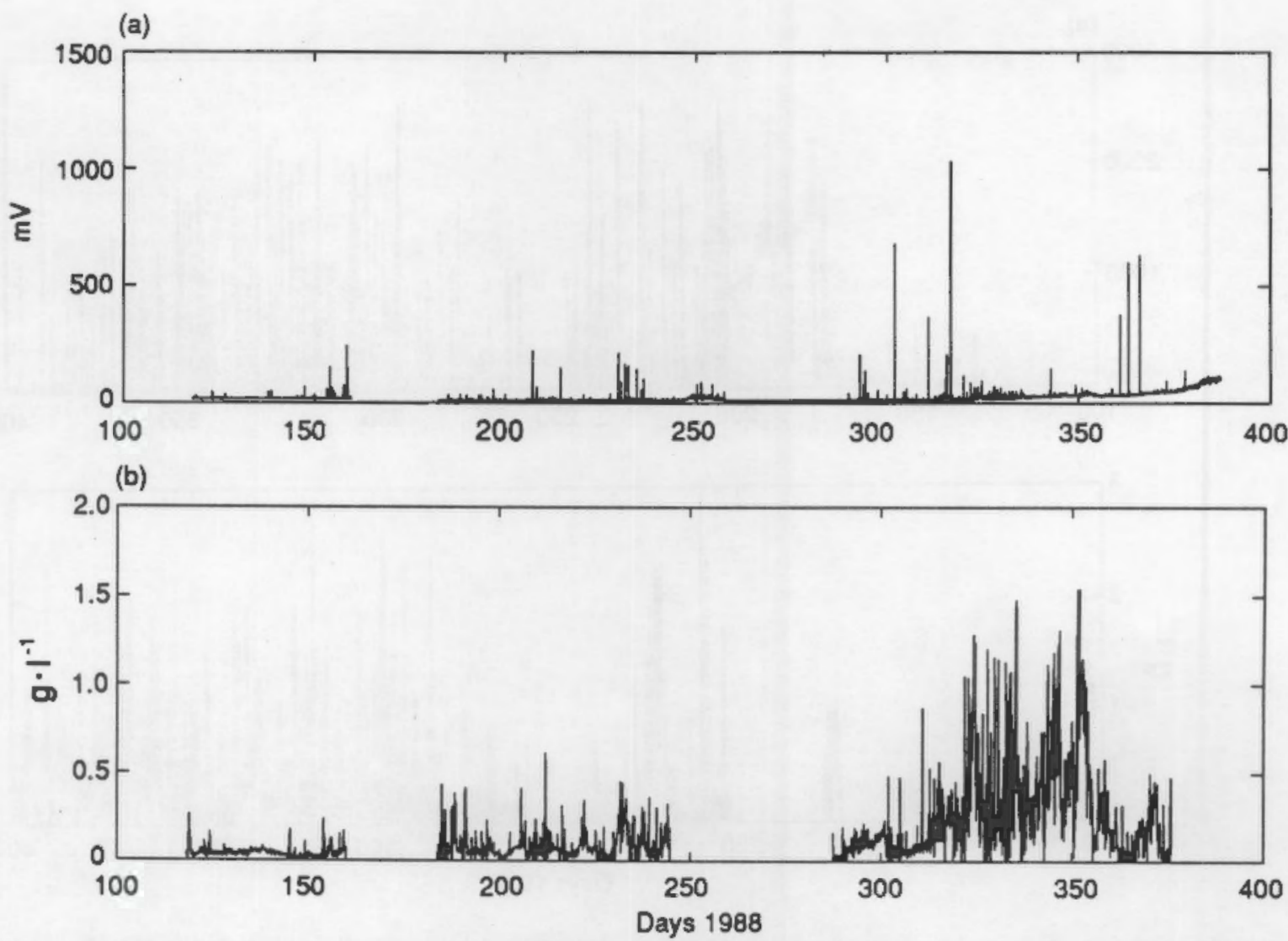

FIGURE B.22. Time Series of a) Raw OBS Output Voltage and b) Estimated Sediment Concentration for Complete Record at Site B1B 

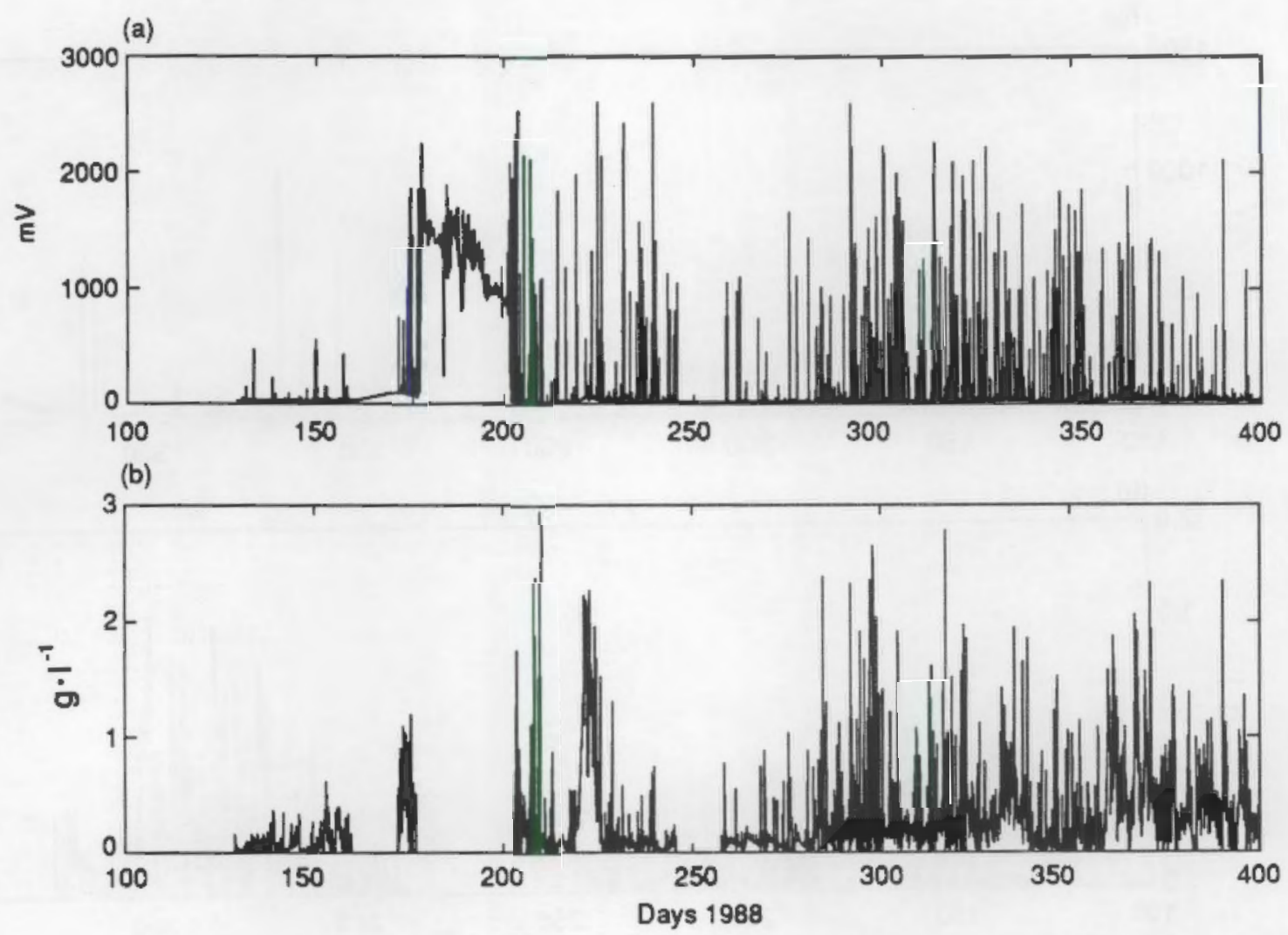

FIGURE B.23. Time Series of a) Raw OBS Output Voltage and b) Estimated Sediment Concentration for Complete Record at Site $1 \mathrm{M}$ 

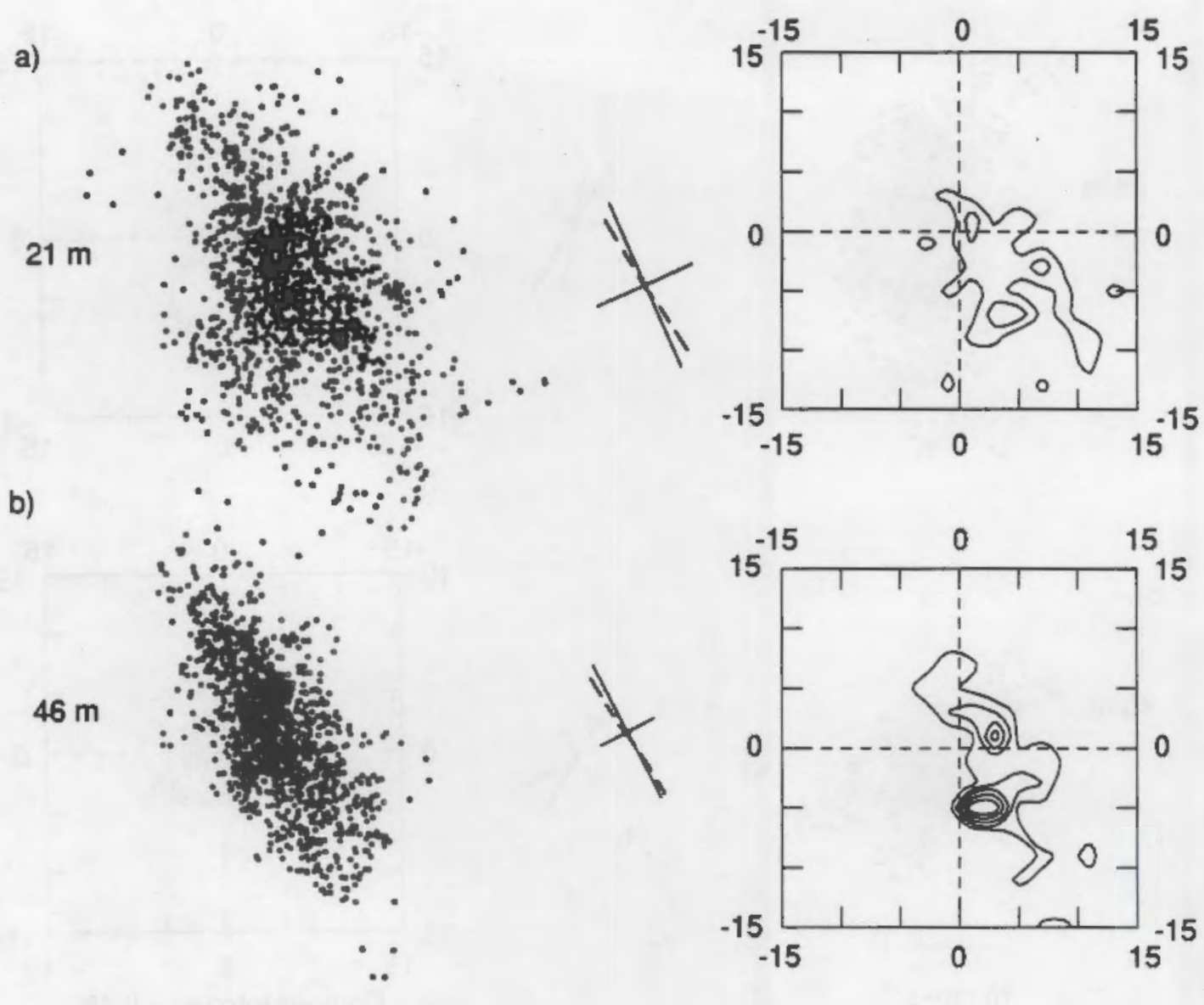

c)
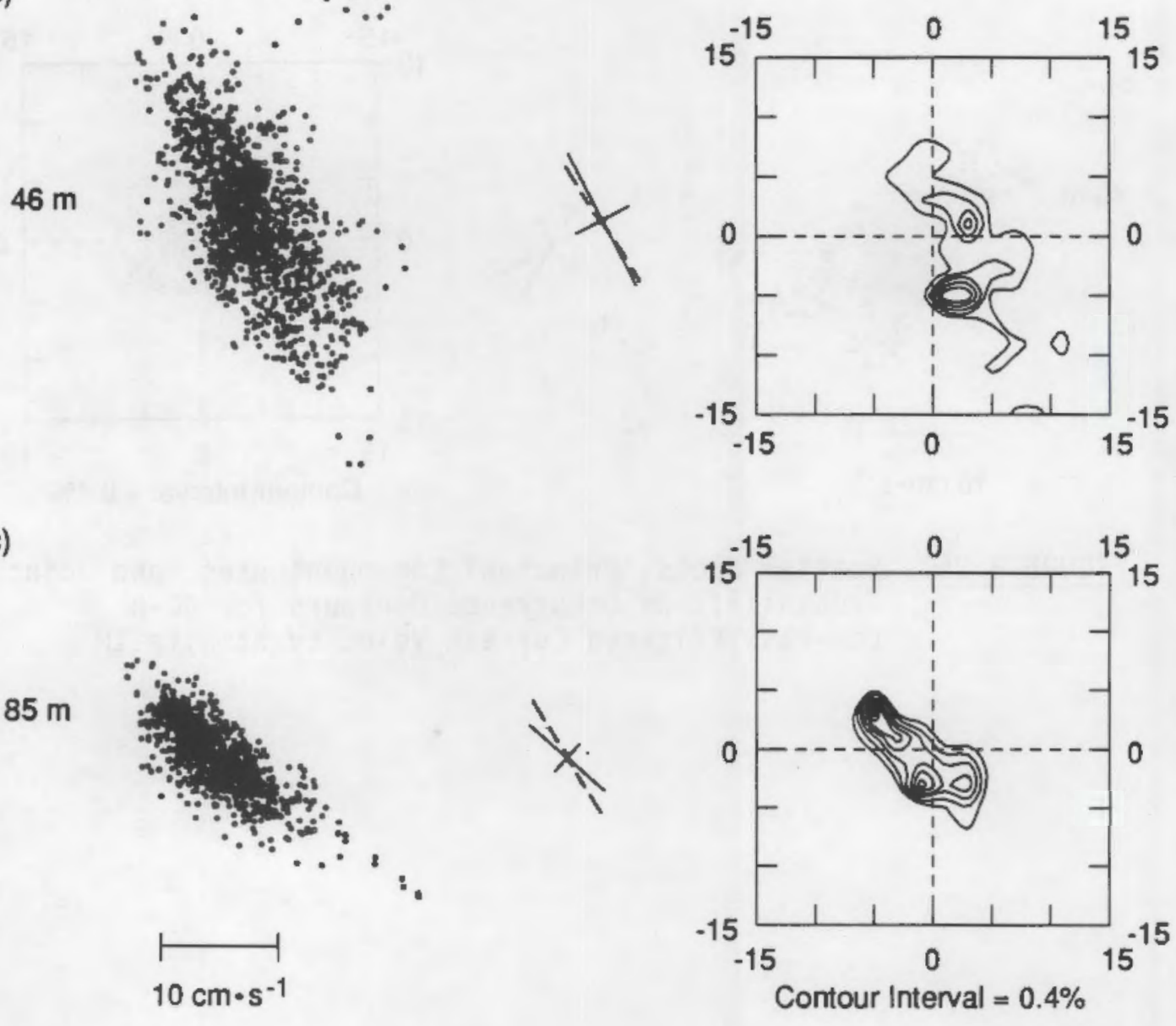

FIGURE B.24. Scatter Plots, Principal Component Axes, and Joint Probability of Occurrence Contours for 40-h LowPass Filtered Current Velocity at Site B1B 
a)
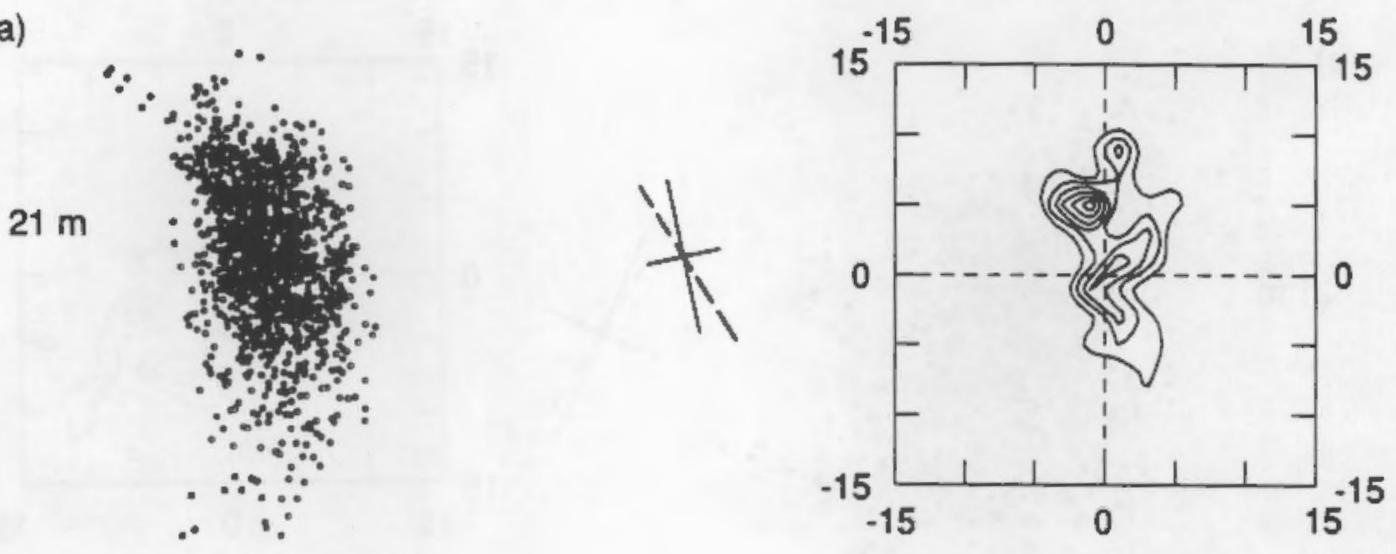

b)
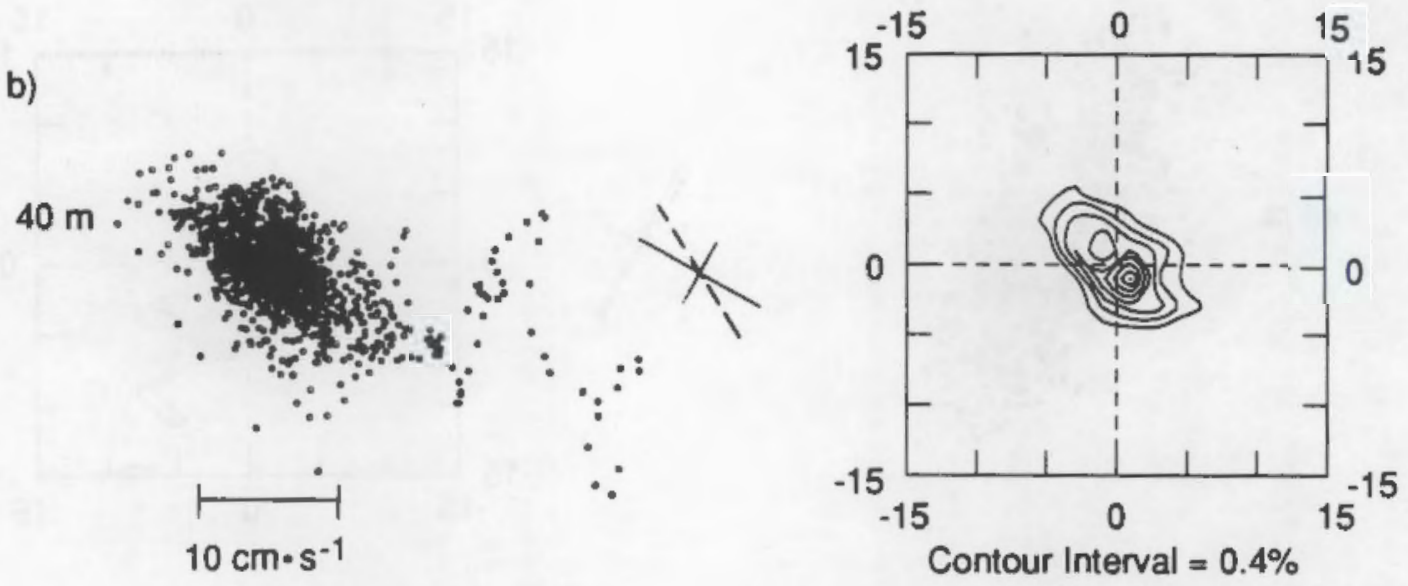

FIGURE B.25. Scatter Plots, Principal Component Axes, and Joint Probability of Occurrence Contours for 40-h Low-Pass Filtered Current Velocity at Site 1M 

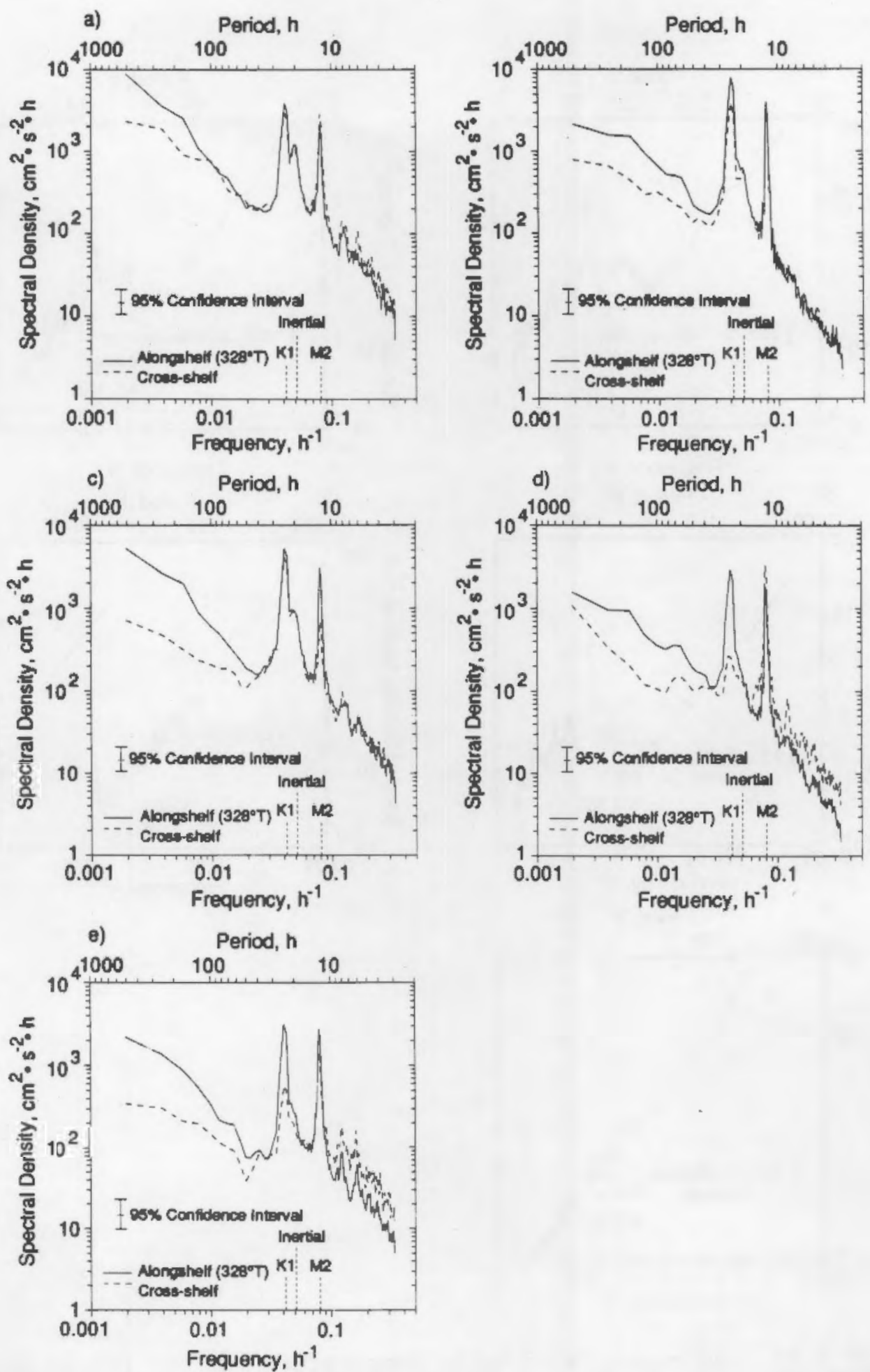

FIGURE B.26. Autospectra of $u(---)$ and $v(-)$ Components of Current Velocity for the Entire Records at a) Site B1B $(21 \mathrm{~m})$, b) Site $1 M(21 \mathrm{~m})$, c) Site B1B $(46 \mathrm{~m})$, d) Site $1 M(39 \mathrm{~m})$, and e) Site B1B (84 m) 

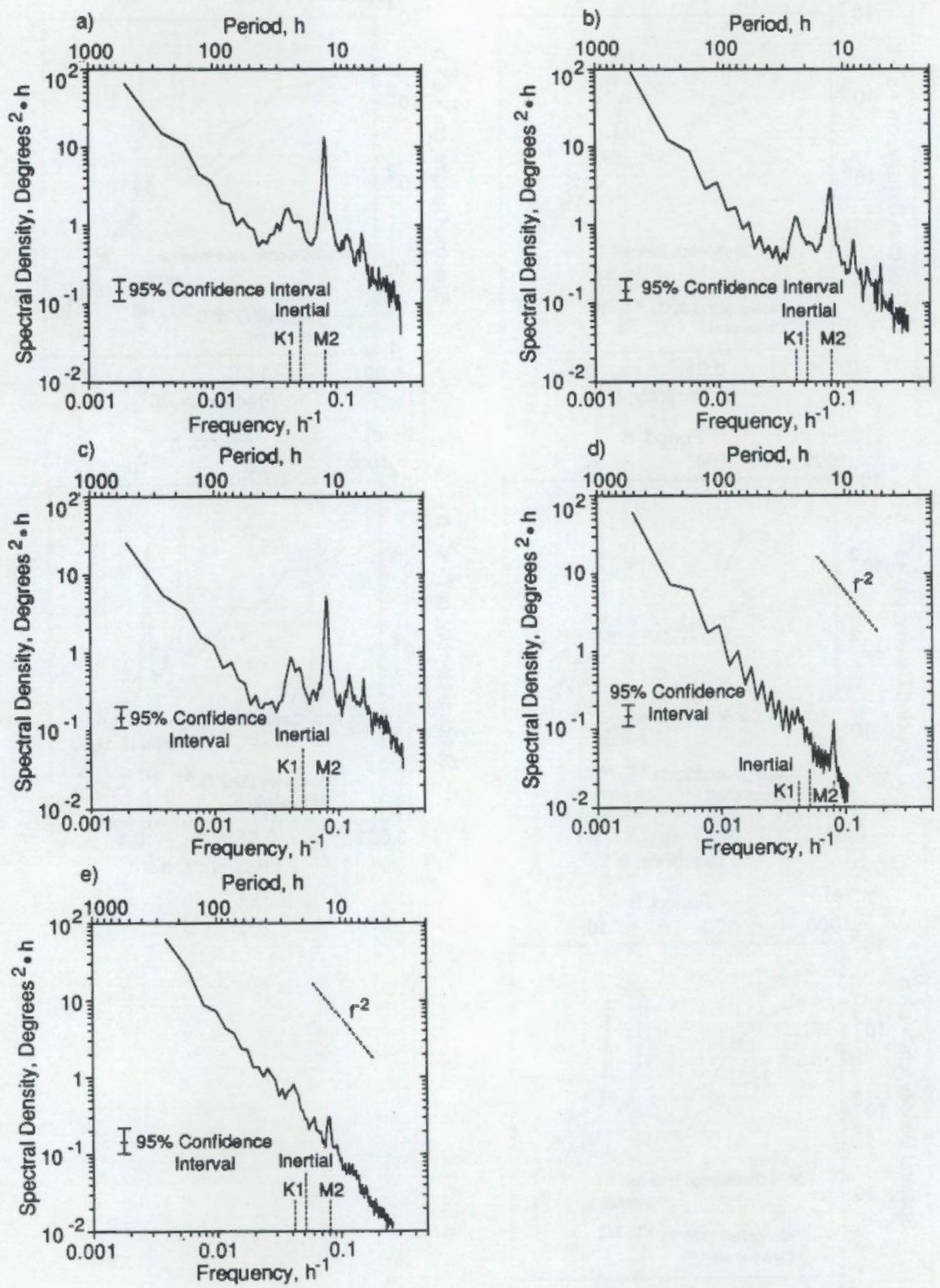

FIGURE B.27. Autospectra of Water Temperature for the Entire Records at a) Site B1B $(21 \mathrm{~m})$, b) Site $1 M(21 \mathrm{~m})$, c) Site B1B $(46 \mathrm{~m}), \mathrm{d})$ Site $1 \mathrm{M}(40 \mathrm{~m})$, and e) Site B1B $(85 \mathrm{~m})$ 

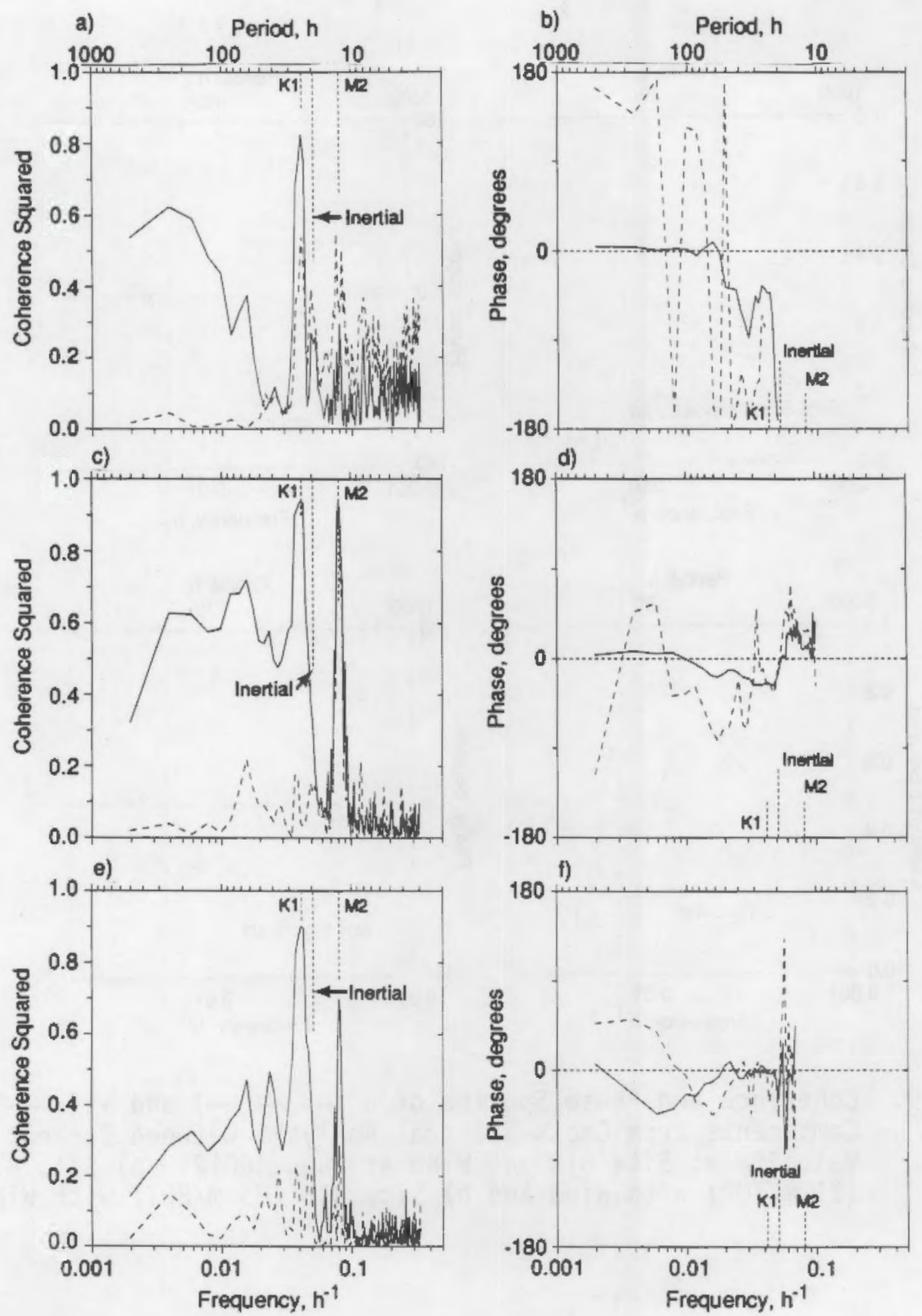

FIGURE B.28. Coherence and Phase Spectra of $u(--\rightarrow)$ and $v(-)$ Components From Cross-Spectral Analys is of Pairs of Current Velocity Records: a) Site B1B (21 m/TOP) with Site B1B $(85 \mathrm{~m} / \mathrm{BOT})$, b) Site $1 \mathrm{M}(21 \mathrm{~m} / \mathrm{TOP})$ with Site $1 \mathrm{M}(40 \mathrm{~m} / \mathrm{BOT})$, and c) Site B1B $(85 \mathrm{~m} / \mathrm{BOT})$ with Site $1 \mathrm{M}(40 \mathrm{~m} / \mathrm{BOT})$ 
a)
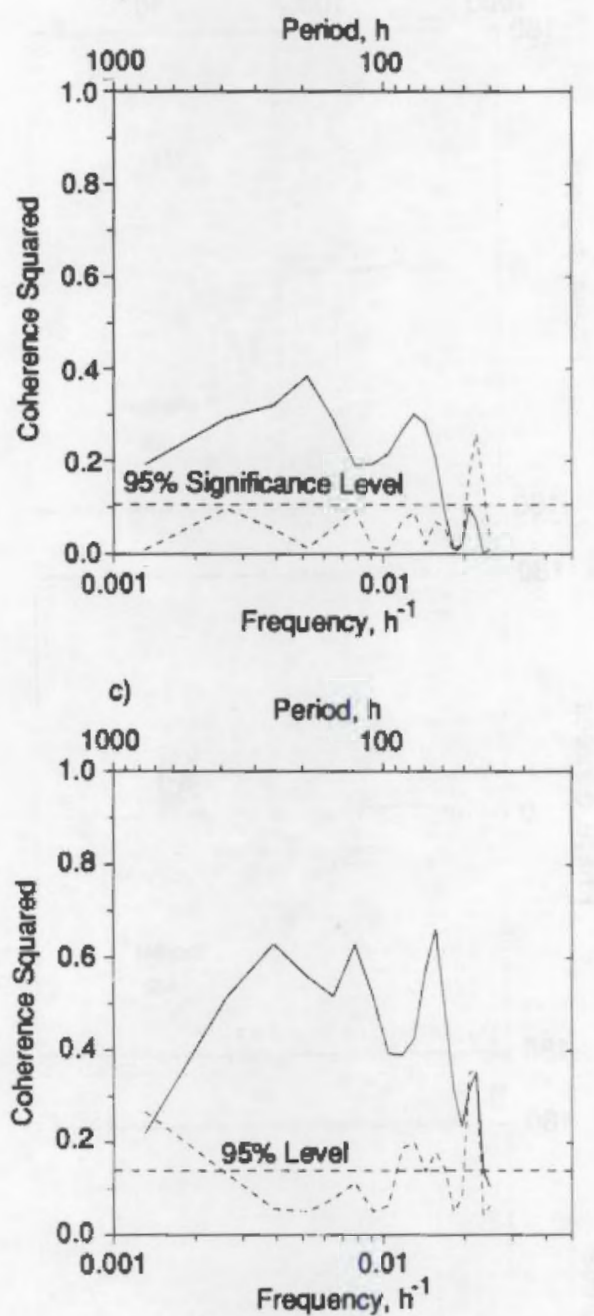

b)
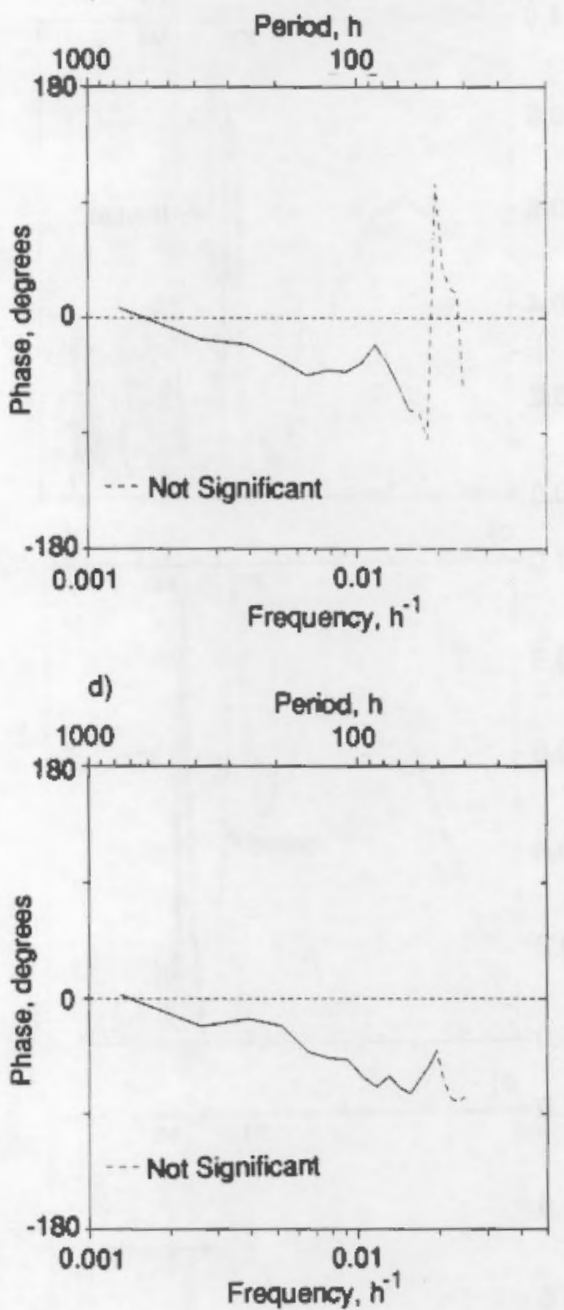

FIGURE B.29. Coherence and Phase Spectra of $\left.u_{(--}-\right)$and $v(-)$ Components From Cros5-Spectral Analys is Between Current Velocity at Site B1B and Wind at Buoy 46012: a) Site B1B $(21 \mathrm{~m} / \mathrm{TOP})$ with Wind and b) Site B1B $(85 \mathrm{~m} / \mathrm{BOT})$ with Wind 
a) M2 Tidal Ellipses, Site B1B

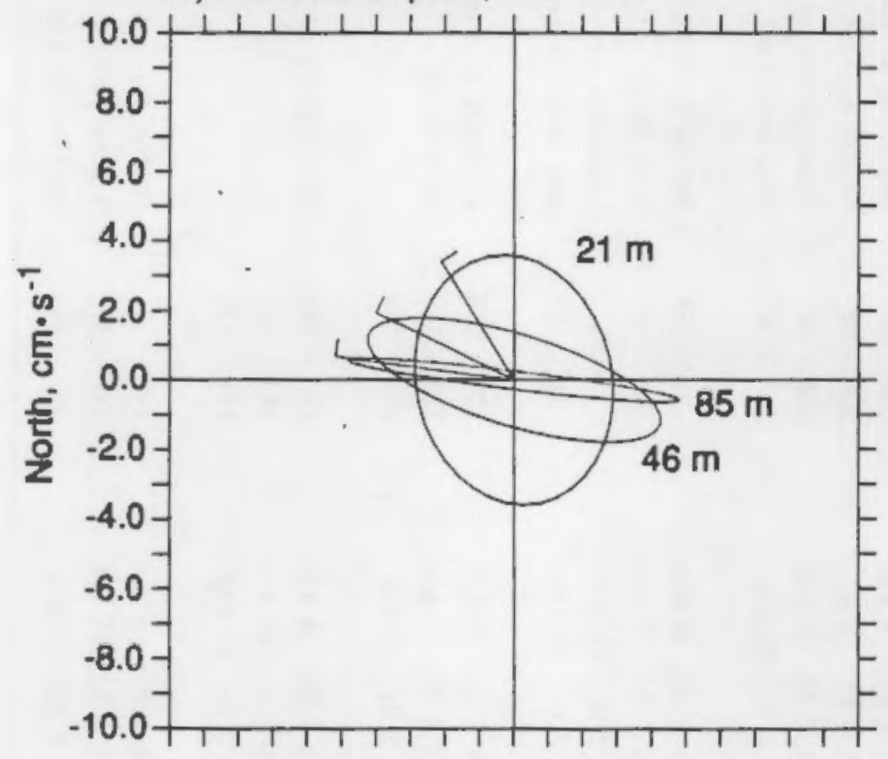

c) K1 Tidal Ellipses, Site B1B

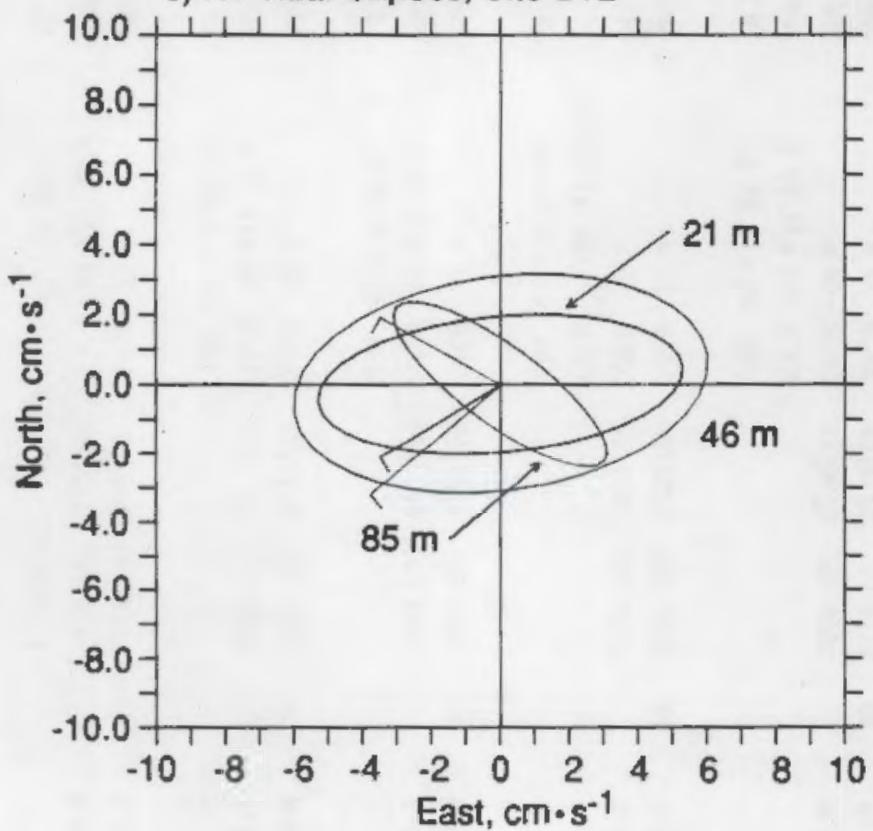

b) M2 Tidal Ellipses, Site $1 \mathrm{M}$

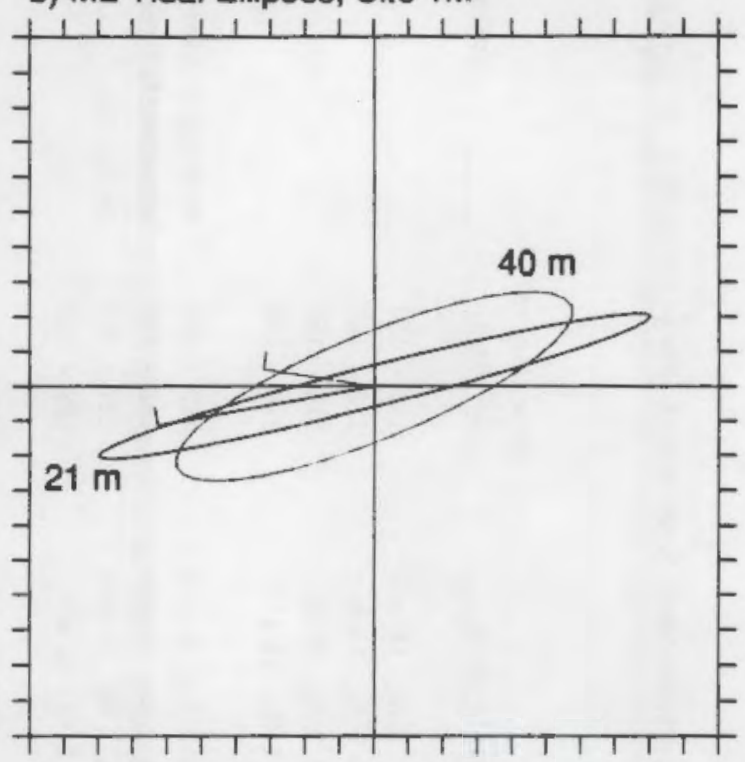

d) K1 Tidal Ellipses, Site 1M

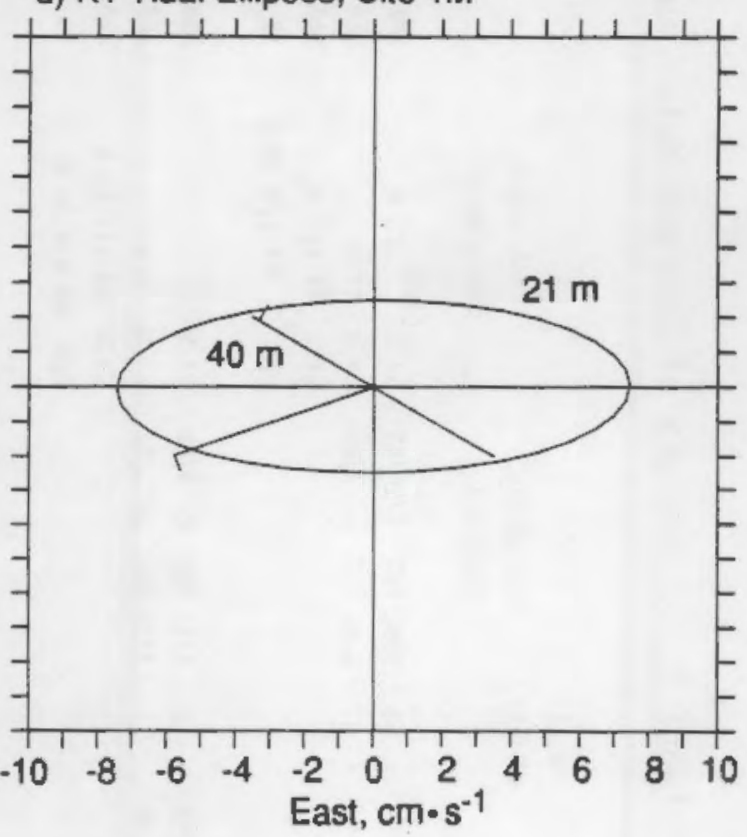

FIGURE B.30. Computed Tidal Current Ellipses for M2 and K1 Tidal Constituents at Sites $\mathrm{BlB}$ and $1 M$. The angles between the y axis and the radials indicate the phase of rotation relative to GMT and the barbs (—) indicate direction of rotation. 
IABLE B.1. Summary of Current Meter and Suspended Sediment Measurement Program

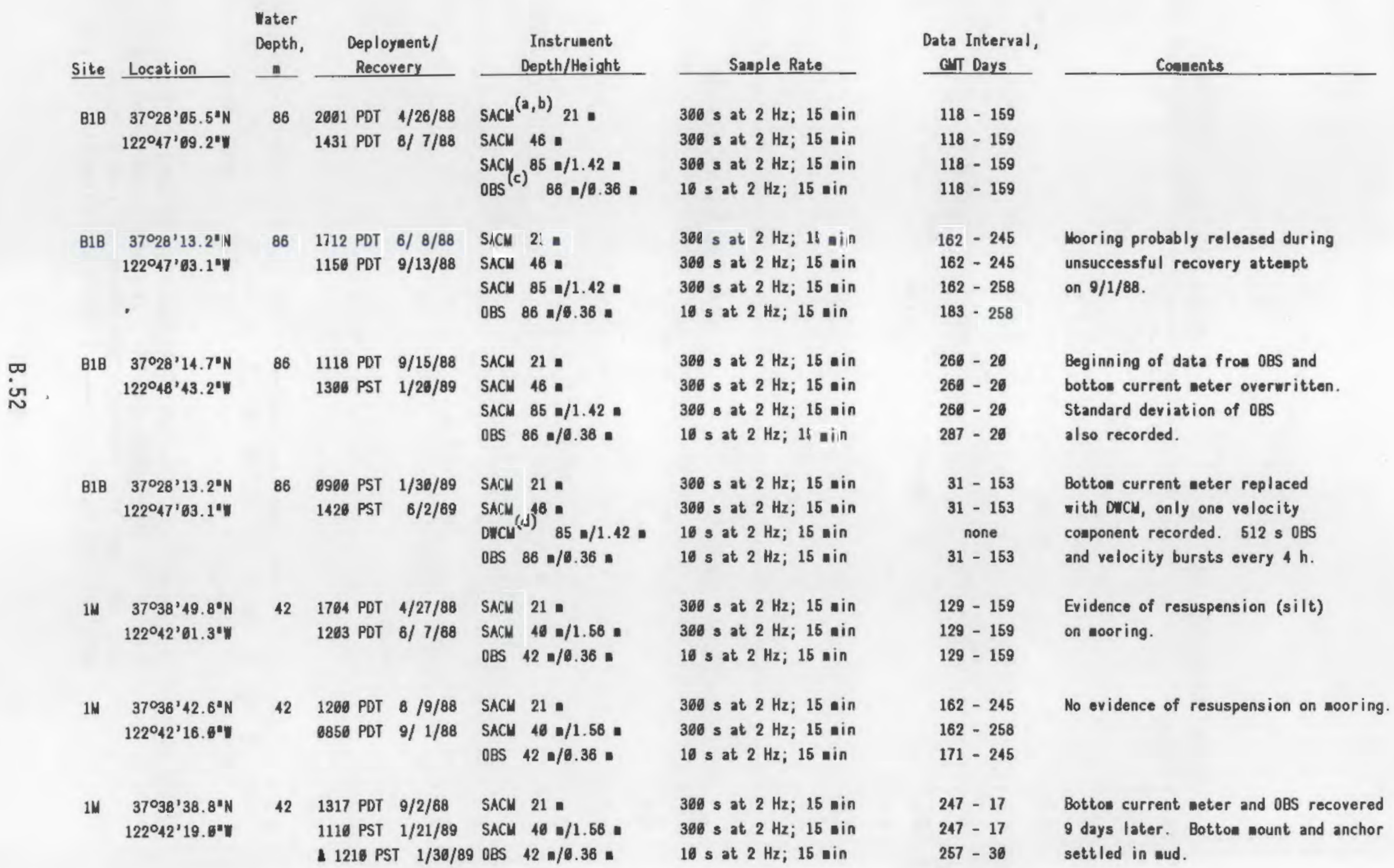


IABLE B.1. (Continued)

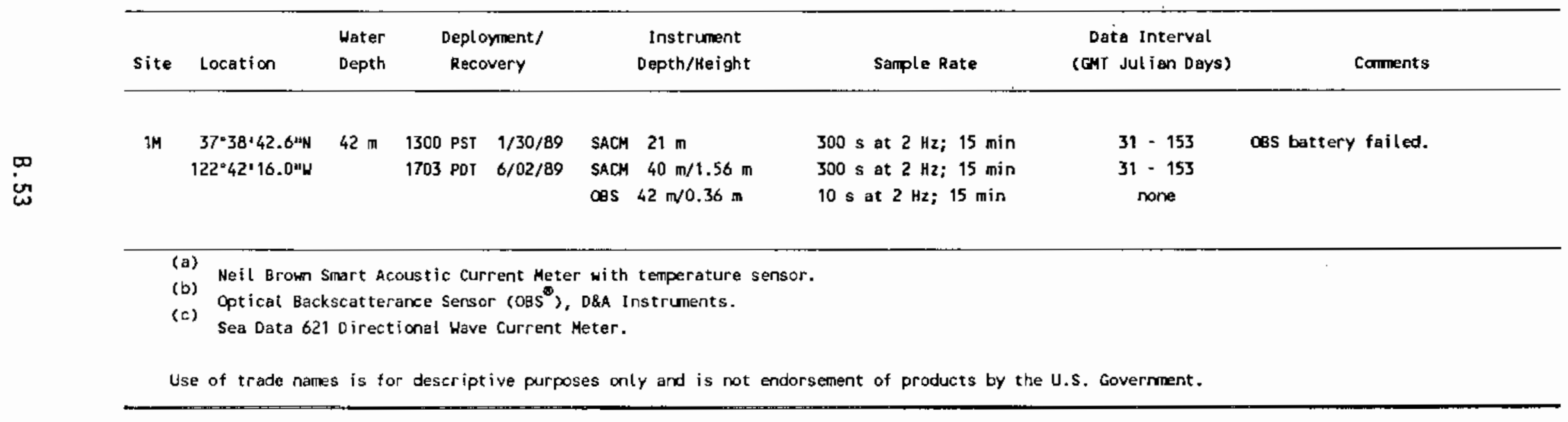


IABLE B.2. Specifications of Instruments Deployed at Sites BlB and $1 M$ Smart Acoustic Current Meter (SACM), EG\&G-NBIS

$\begin{array}{lll}\text { Parameter } & \text { Accuracy } & \text { Range } \\ \text { Sensor Type } & 2 \text {-component acoustic flow sensor } \\ \text { Speed } & \pm 1.0 \mathrm{~cm} \cdot \mathrm{s}^{-1}( \pm 5 \%) & 0.300 \mathrm{~cm} \cdot \mathrm{s}^{-1} \\ \text { Direction } & \left.5.0^{\circ}\right)^{\circ} & 0 .-360^{\circ} \mathrm{C} \\ \text { Temperature } & \pm 0.05^{\circ} \mathrm{C} & -2-+30^{\circ} \mathrm{C} \\ \text { Data Logger Capacity } & & 30,00012-\text { bit values }\end{array}$

Directional Wave Current Meter (DWCM), Sea Data Model 621

$\begin{array}{lll}\text { Sensor Type } & 2 \text {-component electromagnetic flow sensor } \\ \text { Speed } & \pm 1.0^{\circ} \mathrm{cm} \cdot \mathrm{s}^{-1}( \pm 5 \%)(\text { a) } & 0-300 \mathrm{~cm} \cdot \mathrm{s}^{-1} \\ \text { Direction } & 5.0^{\circ} & 0 .-360^{\circ} \\ \text { Temperature } & \pm 0.05^{\circ} \mathrm{C} & -2-+30^{\circ} \mathrm{C} \\ \text { Data Logger Capacity } & & 400,000 \mathrm{scans}\end{array}$

Optical Backscatter (OBS) Sensor, D\&A Instruments Model OBS-1

Range

Threshold

Linearity

Drift

$5000 \mathrm{mg} ; 7^{-1}$

$5 \mathrm{mg} \cdot \mathrm{1}^{-1}$

$2 \%$

$-3.5 \%$ per 1000 hours or $0.05 \%$ per ${ }^{\circ} \mathrm{C}(a)$

(a) Whichever is larger.

TABLE B.3. Regression Coefficients From Optical Backscatterance Sensor (OBS) Calibrations

\begin{tabular}{|c|c|c|c|c|c|c|c|}
\hline $\begin{array}{l}\text { Serial } \\
\text { Number }\end{array}$ & Location & Deployment & Regression $(a)$ & $\begin{array}{l}\text { Nunber of } \\
\text { Points }\end{array}$ & $\begin{array}{c}\text { Gain, } \\
m^{*} g^{-1} \cdot !\end{array}$ & $\begin{array}{c}\text { Adjusted. } \\
\mathrm{mV}\end{array}$ & $r^{2(b)}$ \\
\hline 67 & B18 & $1,2,3$ & Cormon fit, before cleaning & 8 & 14.14 & 25.68 & 0.999 \\
\hline 67 & B1B & $1,2,3$ & Cormon fit, after cleaning & 7 & 14.14 & 15.11 & 0.999 \\
\hline 68 & IM & $1,2,3$ & Cormon fit, before cleaning & 8 & 27.41 & -2.00 & 0.988 \\
\hline 68 & 1M & $1,2,3$ & Common fit, after cleaning & 8 & 27.41 & 11.55 & 0.988 \\
\hline 88 & $81 \mathrm{~B}$ & 4 & Individual fit, before deployment & 5 & 32.37 & 23.59 & 0.997 \\
\hline
\end{tabular}

(a) Weighted least-squares regression was used in all cases; weights were $1 / \sigma$, where $\sigma$ is the standard deviation about the mean response.

(b) Correlation coefficient $r^{2}$ was adjusted for the reduced degrees of freedon in the cormon slope and weighted least-squares models. 
TABLE B.4. Tidal Constituent Names and Frequencies

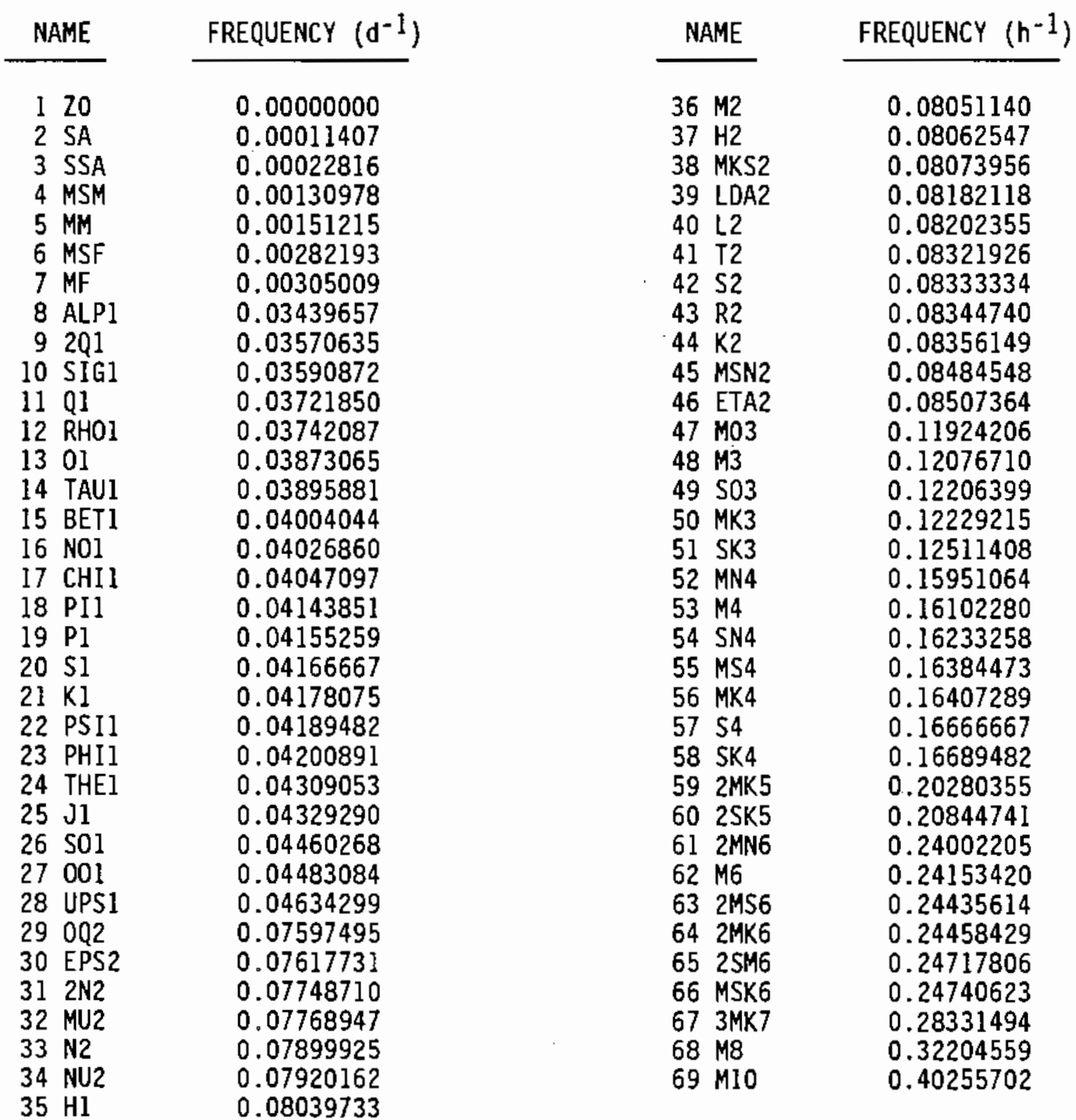


IABLE B.5. Tida] Analysis Results in Current Ellipse Form for Site B1B (21 m), Apri1 27, 1988, 1600 through June 2, 1989, 2400.

(Greenwich Phases are for Time Zone GMT.)

\begin{tabular}{|c|c|c|c|c|c|c|c|c|c|c|c|c|c|}
\hline AME & $\mathrm{JOR}$ & INOR & INC & G & $G+$ & $\mathrm{G}-$ & NAME & MAJOR & INOR & NC & $\mathbf{G}$ & G+ & G- \\
\hline $1 z 0$ & 5.597 & 0.000 & 136.7 & 360.0 & 223.3 & 136.7 & $36 \mathrm{M} 2$ & 3.627 & -2.862 & 102.6 & 23.8 & 281.2 & 126.3 \\
\hline $25 A$ & 2.179 & -0.595 & 163.0 & 120.9 & 317.9 & 283.9 & $37 \mathrm{H} 2$ & 1.209 & 0.358 & 82.8 & 3.7 & 281.0 & 86.5 \\
\hline 3 SSA & 3.575 & 0.484 & 143.1 & 83.9 & 300.8 & 227.0 & 38 MKS2 & 0.689 & -0.108 & $\$ 1.0$ & 15.6 & 4.6 & 26.5 \\
\hline $4 \mathrm{MSM}$ & 226 & 0.018 & 10.0 & 22.7 & 12.8 & 32.7 & 39 DA2 & 1.379 & 0.107 & 149.3 & 315.7 & 166.4 & 105.0 \\
\hline $5 \mathrm{N1}$ & 0.399 & -0.101 & 54.7 & 243.6 & 188.9 & 298.4 & $40 \mathrm{LZ}$ & .483 & 0.352 & 25.0 & 35.7 & 10.7 & 60.7 \\
\hline $6 \mathrm{MSF}$ & 1.116 & 0.451 & 69.9 & 201.6 & 131.7 & 271.4 & $41 \mathrm{T2}$ & .675 & 0.429 & 175.6 & 190.8 & 15.2 & 6.4 \\
\hline $7 \mathrm{MF}$ & 1.447 & -0.091 & 1.0 & 355.4 & 354.4 & 356.3 & $42 \mathrm{s2}$ & 1.541 & -0.997 & 102.3 & 49.0 & 306.7 & 151.4 \\
\hline 8 ALP1 & 0.186 & 0.006 & 13.8 & 216.2 & 202.4 & 230.0 & $43 R 2$ & .488 & -0.194 & 78.9 & 239.2 & 960.3 & 318.1 \\
\hline 9201 & 212 & 0.074 & 169.4 & 176.7 & 7.3 & 346.0 & $44 \mathrm{~K} 2$ & 395 & -0.116 & 9.8 & 147.2 & 107.4 & 127.0 \\
\hline T0 SIG1 & 0.297 & -0.099 & 19.2 & 46.6 & 27.4 & 65.8 & 45 MSN2 & 0.258 & -0.151 & 53.0 & 243.8 & 190.8 & 296.9 \\
\hline 1101 & 0.525 & 0.108 & 1.1 & 35.8 & 34.7 & 36.8 & 46 ETA2 & 0.208 & -0.021 & 112.1 & 139.9 & 27.8 & 252.0 \\
\hline 12 RHO1 & 0.575 & 0.340 & 172.6 & 205.5 & 32.9 & 18.1 & 47103 & .230 & -0.087 & 99.3 & 22.3 & 283.0 & 129.6 \\
\hline$\$ 301$ & 2.985 & 1.535 & 11.5 & 89.1 & 77.6 & 100.7 & $48 \mathrm{NB}$ & .116 & 0.011 & 124.1 & 272.9 & 148.8 & 37.0 \\
\hline 34 TAUT & 0.752 & 0.236 & 169.9 & 281.5 & 121.6 & 101.3 & $49 \mathrm{SO} 3$ & 0.085 & 0.000 & 29.8 & 143.7 & 113.9 & 73.5 \\
\hline 15 BET1 & 0.354 & 0.146 & 80.4 & 241.7 & 161.3 & 322.1 & 50 MK3 & 0.220 & 0.019 & 78.8 & 259.7 & 180.9 & 38.5 \\
\hline 16 No1 & 0.261 & 0.209 & 9.2 & 204.5 & 105.4 & 303.7 & 51 SK3 & 0.343 & 0.083 & 144.9 & 317.0 & 172.1 & 101.9 \\
\hline $17 \mathrm{CHI} 1$ & 0.324 & 0.155 & 3.2 & 337.5 & 334.4 & 340.7 & 52 MN4 & 0.202 & -0.004 & 32.5 & 204.4 & 172.0 & 236.9 \\
\hline 18 PI 1 & 0.759 & 0.116 & 178.0 & 293.0 & 115.0 & 111.0 & $53 \mathrm{M}$ & 0.152 & 0.026 & 50.1 & 228.5 & 178.4 & 278.6 \\
\hline $19 P 1$ & 1.742 & & 12.4 & $\uparrow 48.4$ & 135.9 & 160.8 & 54 SN4 & 0.134 & 0.045 & 129.3 & 67.9 & & 197.3 \\
\hline 2051 & 1.638 & 0.408 & 170.0 & 158.6 & 348.6 & 328.6 & 55 MS4 & 0.263 & 0.154 & 17.6 & 322.8 & 305.2 & 340.3 \\
\hline $21 \mathrm{KI}$ & 5.319 & 1.955 & 5.3 & 127.3 & 122.0 & 132.6 & 56 MK4 & 0.198 & 0.085 & 67.5 & 24.5 & 317.1 & 92.0 \\
\hline 22 PSI1 & 0.509 & 0.181 & 163.2 & 223.6 & 60.4 & 26.8 & $57 \mathrm{S4}$ & 0.084 & -0.002 & 176.6 & 130.6 & 314.0 & 307.2 \\
\hline 23 PH!1 & 0.652 & 0.260 & 147.0 & 200.7 & 53.7 & 347.6 & 58 SK4 & & 0.013 & 179.9 & 20.6 & & 200.5 \\
\hline 24 THE1 & 0.649 & 0.425 & 168.0 & 270.4 & 102.4 & 78.4 & 59 24K5 & 0.190 & 0.050 & 70.7 & 269.5 & 198.8 & 340.2 \\
\hline $25 \mathrm{~d} 1$ & 0.399 & -0.069 & 47.2 & 144.2 & 97.0 & 191.5 & $602 \$ \times 5$ & 0.121 & 0.092 & 68.1 & 74.7 & 6.7 & 142.8 \\
\hline $26 \mathrm{SO} 1$ & 0.502 & 0.291 & 33.5 & 140.8 & 107.3 & 174.2 & 61 LNNS & 0.074 & -0.003 & 63.9 & 57.8 & 353.9 & $12 i .7$ \\
\hline $27 \infty 1$ & 0.249 & 0.146 & 144.2 & 359.3 & 215.1 & 143.6 & $62 \mathrm{Mb}$ & 0.060 & 0.020 & 29.2 & 95.3 & 66.1 & 124.5 \\
\hline 28 UPS1 & 0.116 & -0.064 & 69.3 & 221.9 & 152.7 & 291.2 & $632 M S 6$ & 0.065 & 0.033 & $\$ 15.1$ & 64.2 & 309.1 & 179.2 \\
\hline 29002 & 0.358 & 0.116 & 43.8 & 236.1 & 192.3 & 279.9 & $6421 \times 1 \times 6$ & 0.044 & -0.018 & 99.7 & 88.8 & 349.1 & 188.4 \\
\hline 30 EPS2 & 0.361 & 0.104 & 33.7 & 218.1 & 184.5 & 251.8 & 65 2SH6 & 0.087 & $0.06 t$ & 129.9 & 330.1 & 200.2 & 100.0 \\
\hline $3 \div 2 \mathrm{~N} 2$ & 0.551 & 0.084 & 68.8 & 22.6 & 313.8 & 91.4 & 66 MSKS & 0.050 & -0.002 & 107.3 & 333.1 & 225.8 & 80.4 \\
\hline 32 me & 0.355 & 0.133 & 14.1 & 155.3 & 141.3 & 169.4 & $673 \times 1 \times 7$ & 0.108 & 0.026 & 57.1 & 310.4 & 253.3 & 7.5 \\
\hline 33 N2 & 0.966 & -0.610 & 93.8 & 8.6 & 274.8 & 102.4 & $68 \mathrm{MB}$ & 0.135 & -0.019 & 76.2 & 180.6 & 104.4 & 256.8 \\
\hline 34 NU2 & 0.894 & 0.209 & 75.1 & 21.4 & 306.3 & 96.5 & $69 \mathrm{M10}$ & 0.023 & -0.007 & 166.1 & 106.7 & 300.6 & 272.9 \\
\hline 35 н1 & 1.238 & -0.455 & 21.4 & 96.9 & 75.6 & 118.3 & & & & & & & \\
\hline
\end{tabular}


IABLE B.6. Tidal Analysis Results in Current Ellipse Form for Site BIB (46 m), Apri1 27, 1988, 1600 through June 2, 1989, 2400. (Greenwich Phases are for Time Zone GMT.)

\begin{tabular}{|c|c|c|c|c|c|c|c|c|c|c|c|c|c|}
\hline NAME & MAJOR & MINOS & INC & G & G* & G. & NAME & MA.JOR & MINOR & INC & G & G+ & G- \\
\hline 120 & 651 & 0.000 & 118.7 & 60.0 & 241.3 & 118.7 & $36 \mathrm{M} 2$ & 4.445 & -1.319 & 163.4 & 331.6 & 168.2 & 134.9 \\
\hline $2 \mathrm{sa}$ & 2.019 & 0.556 & 150.3 & 96.7 & 306.5 & 247.0 & $37 \mathrm{H2}$ & 0.639 & 0.254 & 137.7 & 330.9 & 193.3 & 108.6 \\
\hline 3 SSA & 2.962 & -0.442 & 138.8 & 93.4 & 314.6 & 232.2 & 38 mKS2 & 0.451 & -0.196 & 175.7 & 197.4 & 21.8 & 13.1 \\
\hline 4, MSI & 0.978 & 0.456 & 11.4 & 7.8 & 356.4 & 19.2 & 39 DA2 & 0.395 & 0.171 & 80.6 & 60.2 & 339.6 & 140.8 \\
\hline $5 \mathrm{~m}$ & 0.699 & -0.157 & 93.2 & 281.4 & 188.2 & 14.6 & $40 \mathrm{~L} 2$ & 0.711 & 0.245 & 6.7 & 316.7 & 310.1 & 323.4 \\
\hline $6 \mathrm{MSF}$ & 0.533 & 0.236 & 18.3 & 115.8 & 97.5 & 134.2 & $41 \mathrm{~T} 2$ & $0.6 \%$ & 0.402 & 147.8 & 177.9 & 30.1 & 325.7 \\
\hline $7 \mathrm{MF}$ & 0.782 & -0.114 & 165.1 & 213.4 & 48.2 & 18.5 & 4252 & 1.902 & -0.180 & 136.4 & 10.3 & 233.9 & 146.8 \\
\hline 8 ALP1 & 0.169 & 0.027 & 60.6 & 97.6 & 37.0 & 158.1 & $43 \mathrm{R} 2$ & 0.552 & 0.133 & 106.4 & 169.5 & 3.1 & 335.8 \\
\hline 201 & 0.287 & -0.051 & 167.5 & 329.0 & 161.4 & 136.5 & $44 K 2$ & .442 & -0.004 & 03.0 & 335.1 & 232.1 & 78.1 \\
\hline 10 SIG1 & 0.177 & 0.076 & 142.4 & 69.0 & 286.5 & 211.4 & 45 MSN2 & 0.270 & -0.027 & 5.3 & 216.1 & 210.8 & 221.3 \\
\hline 11 Q & 0.465 & 0.092 & 31.1 & 81.3 & 50.1 & 112.4 & 46 ETAZ & 0.139 & 0.077 & 165.8 & 306.5 & 140.7 & $\$ 12.4$ \\
\hline 12 RHD1 & 0.135 & 0.046 & 35.9 & 102.3 & 66.4 & 138.1 & $47 \mathrm{mos}$ & 0.123 & 0.050 & 8.9 & 322.9 & 314.0 & 331.8 \\
\hline 2301 & 3.241 & 1.522 & 13.9 & 82.6 & 68.8 & 9.5 & $48 \mathrm{nz}$ & 0.232 & 0.129 & 130.4 & 166.9 & 36.5 & 297.4 \\
\hline 14 TAU1 & 0.731 & 0.286 & 11.3 & 125.2 & 113.9 & 136.5 & $49 \operatorname{sos}$ & 0.076 & 0.041 & 50.1 & 191.4 & 41.2 & 341.5 \\
\hline 15 BETi & 0.393 & 0.145 & 152.1 & 303.6 & 151.5 & 95.7 & 50 NK3 & 0.043 & -0.023 & 164.9 & 19.2 & 274.3 & 184.2 \\
\hline 16 N01 & 0.299 & 0.175 & 48.9 & 74.6 & 25.7 & 123.5 & 51 SK3 & 0.204 & 0.107 & 159.3 & 141.9 & 342.7 & 301.2 \\
\hline $17 \mathrm{CHII}$ & 0.270 & 0.109 & 122.9 & 246.1 & 123.2 & 9.0 & 52 MN4 & 0.150 & 0.130 & 61.7 & 13.7 & 312.0 & 75.4 \\
\hline $18 \mathrm{PII}$ & 0.601 & 0.580 & 84.5 & 189.0 & 104.5 & 273.5 & $53 \mathrm{H4}$ & 0.059 & 0.037 & 12.8 & 345.7 & 332.9 & 358.5 \\
\hline $19 p 1$ & 9.535 & 0.866 & 179.0 & 324.6 & 145.6 & 143.5 & 54 5N4 & 0.297 & 0.174 & 945.5 & 224.5 & 79.0 & 10.0 \\
\hline $20 s 1$ & 2.076 & 1.306 & 132.1 & 966.0 & 33.9 & 298.1 & 55 MS4 & 0.194 & 0.062 & 88.7 & 110.4 & 21.7 & 199.1 \\
\hline $21 \mathrm{~K} 1$ & 6.052 & 3.088 & 7.5 & 128.3 & 120.9 & 135.8 & 56 MK4 & 0.066 & 0.021 & 134.7 & 273.0 & 138.3 & 47.8 \\
\hline 22 PSII & 0.748 & 0.586 & 163.2 & 197.0 & 33.8 & 0.2 & $57 \$ 4$ & 0.172 & 0.040 & 150.8 & 242.2 & 99.4 & 33.0 \\
\hline 23 PHII & 1.103 & 0.811 & 25.9 & 355.2 & 329.3 & 21.1 & 58 sK4 & 0.083 & -0.016 & 105.0 & 322.4 & 217.5 & 67.4 \\
\hline 24 THE1 & 0.416 & 0.223 & 97.8 & 152.3 & 54.5 & 250.1 & 59 2MKS & 0.091 & -0.007 & 32.1 & 57.9 & 25.8 & 90.0 \\
\hline $25 \mathrm{~J} 1$ & 0.545 & 0.439 & 6.9 & 131.0 & 124.1 & 138.0 & $602 S K 5$ & 0.069 & 0.025 & 28.6 & 255.7 & 227.1 & 284.3 \\
\hline $26 \mathrm{SO} 1$ & 0.356 & 0.160 & 86.0 & 315.9 & 229.8 & 41.9 & 61 ZNA6 & 0.142 & 0.065 & 116.8 & 298.2 & 181.4 & 55.0 \\
\hline $27 \infty 1$ & 0.235 & 0.077 & 18.0 & 119.9 & 101.9 & 137.9 & $62 M 6$ & 0.110 & 0.043 & 157.2 & 356.1 & 198.9 & 153.3 \\
\hline 28 UPS1 & 0.128 & -0.062 & 170.0 & 308.5 & 138.5 & 118.5 & 63 2MSS & 0.064 & -0.022 & 73.3 & 298.2 & 224.9 & 11.6 \\
\hline $29 \infty 2$ & 0.161 & 0.039 & 167.3 & 34.0 & 226.8 & 201.3 & $6424 \times 6$ & 0.110 & 0.027 & 167.7 & 323.4 & 155.7 & 131.0 \\
\hline 30 EPS2 & 0.122 & -0.054 & 48.5 & 335.5 & 286.9 & 24.0 & $652 \mathrm{sm} 6$ & 0.079 & 0.038 & 22.4 & 71.4 & 49.0 & 93.9 \\
\hline 31 2N2 & 0.528 & 0.188 & 104.0 & 306.5 & 200.5 & 48.5 & OS MSKO & 0.078 & -0.006 & 64.5 & $120 . i$ & 55.5 & 184.6 \\
\hline $32 \mathrm{mu2}$ & 0.390 & 0.198 & 40.0 & 308.2 & 268.2 & 348.3 & 67 3MK7 & 0.098 & 0.013 & 78.8 & 78.3 & 359.6 & 157.1 \\
\hline 33 N2 & 0.923 & -0.213 & 173.7 & 306.7 & 133.0 & $\uparrow 20.4$ & $68 \mathrm{MB}$ & 0.103 & -0.016 & 170.5 & 142.4 & 331.9 & 312.9 \\
\hline 34 NU2 & 0.603 & 0.258 & 132.7 & 285.1 & 152.4 & 57.8 & $69 \times 10$ & 0.025 & 0.003 & 80.1 & 6.6 & 286.5 & 86.7 \\
\hline $35 \mathrm{H1}$ & 1.416 & 0.016 & 172.6 & 310.0 & 137.4 & 122.6 & & & & & & & \\
\hline
\end{tabular}


TABLE B.7. Tidal Analysis Results in Current Ellipse Form for Site B1B (85 m), Apri1 27, 1988, 1600 through January 20, 1989, 2400. (Greenwich Phases are for Time Zone GMT.)

\begin{tabular}{|c|c|c|c|c|c|c|c|c|c|c|c|c|c|}
\hline MAME & MA JOR & MINOR & INC & G & $\mathrm{G}+$ & G- & MAME & A.JOR & MINOR & INC & $\mathbf{G}$ & $G+$ & G- \\
\hline 120 & 0.766 & 0.000 & 34.5 & 180.0 & 145.5 & 214.5 & $31 \mathrm{M2}$ & 4.842 & -0.284 & 173.2 & 347.8 & 174.6 & 161.0 \\
\hline 2 SSA & 0.557 & 0.027 & 148.8 & 135.9 & 347.1 & 284.7 & 32 MKS2 & 0.976 & 0.270 & 165.8 & 18.8 & 213.1 & 184.6 \\
\hline 3 HSH & 1.499 & -0.130 & 138.5 & 120.6 & 342.1 & 20.1 & 33 LAZ & 0.210 & 0.049 & 138.4 & 213.0 & 74.7 & 351.4 \\
\hline $4 \mathrm{~m}$ & 0.344 & -0.062 & 78.6 & 158.4 & 79.8 & 237.0 & $34 \mathrm{~L} 2$ & 0.731 & 0.363 & 20.4 & 260.2 & 239.8 & 200.7 \\
\hline 5 MSF & 1.116 & -0.268 & 129.1 & 36.5 & 267.4 & 165.5 & $35 \mathrm{~s} 2$ & 1.727 & 0.248 & 148.4 & 16.1 & 227.7 & 164.4 \\
\hline $6 \mathrm{MF}$ & 0.714 & -0.095 & 121.3 & 204.4 & 83.2 & 325.7 & $36 \mathrm{~K} 2$ & 0.561 & 0.002 & 112.3 & 64.4 & 312.1 & 176.7 \\
\hline 7 ALP1 & 0.071 & 0.041 & 37.7 & 127.5 & 89.9 & 165.2 & 37 MSN2 & 0.117 & 0.016 & 34.1 & 75.3 & 41.2 & 109.4 \\
\hline 8201 & 0.161 & -0.066 & 2.1 & 135.3 & 133.2 & 137.4 & 38 ETA2 & 0.083 & 0.002 & 167.8 & 273.5 & 105.7 & 81.3 \\
\hline 9 SIG1 & 0.171 & 0.093 & 135.4 & 314.0 & 178.6 & 89.4 & $39 \mathrm{mo3}$ & 0.291 & 0.187 & 33.8 & 49.2 & 15.4 & 83.0 \\
\hline 1001 & 0.197 & 0.115 & 168.8 & 271.9 & 103.0 & 80.7 & $40 \mathrm{MB}$ & 0.145 & 0.058 & 30.9 & 100.6 & 69.7 & 131.5 \\
\hline 11 RHO1 & 0.236 & 0.207 & 150.2 & 255.2 & 105.0 & 45.5 & 41503 & 0.177 & 0.071 & 174.9 & 178.8 & 3.9 & 353.7 \\
\hline 1201 & 2.230 & 0.882 & 156.6 & 289.6 & 132.9 & 86.2 & $42 \mathrm{MK} 3$ & 0.373 & 0.147 & 68.8 & 72.9 & 4.1 & 141.7 \\
\hline 13 TAU1 & 0.393 & 0.295 & 149.1 & 79.8 & 290.6 & 228.9 & 43 SK3 & 0.261 & 0.162 & 48.7 & 55.9 & 7.2 & 104.6 \\
\hline 14 BET1 & 0.190 & 0.059 & 80.7 & 337.0 & 256.3 & 57.6 & 44 MN4 & 0.294 & 0.134 & 80.8 & 77.8 & 357.0 & 158.5 \\
\hline 15 Not & 0.117 & -0.019 & 154.3 & 285.4 & 131.2 & 79.7 & $45 \mathrm{~m}$ & 0.413 & 0.186 & 73.3 & 118.0 & 44.7 & 191.3 \\
\hline $16 \mathrm{CH} ! 1$ & 0.438 & 0.287 & 150.1 & 285.6 & 135.5 & 75.7 & 46 SN4 & 0.057 & 0.010 & 61.0 & 141.1 & 80.0 & 202.1 \\
\hline 17 P1 & 1.405 & 0.555 & 138.9 & 341.4 & 202.4 & 120.3 & 47 MS4 & 0.106 & -0.058 & 5.3 & 323.8 & 318.5 & 329.1 \\
\hline $18 \mathrm{k} 1$ & 3.749 & 1.121 & 244.1 & 337.7 & 193.6 & 121.8 & $48 \times 1 K 4$ & 0.262 & 0.054 & 169.7 & 125.0 & 315.3 & 294.7 \\
\hline 19 PHI & 0.389 & 0.148 & 127.0 & 356.3 & 229.3 & 123.3 & 495 & 0.230 & 0.093 & 30.1 & 351.2 & 321.1 & 21.3 \\
\hline 20 THE $\uparrow$ & 0.139 & 0.046 & 106.8 & 307.3 & 200.5 & 54.1 & $50 \mathrm{s \times 4}$ & 0.108 & 0.025 & 100.6 & 184.4 & 83.9 & 285.0 \\
\hline $21 \downarrow 1$ & 0.359 & 0.162 & 130.2 & 336.2 & 206.0 & 106.3 & 51 2MKS & 0.132 & 0.007 & 113.7 & 316.2 & 202.4 & 69.9 \\
\hline $22 \mathrm{so1}$ & 0.323 & 0.169 & 50.6 & 349.8 & 299.2 & 40.4 & 52 2sK5 & 0.108 & -0.038 & 87.8 & 179.8 & 92.0 & 267.6 \\
\hline $23 \infty 01$ & 0.080 & 0.067 & 28.0 & 285.9 & 257.9 & 313.8 & 53 2MNO & 0.116 & -0.055 & 33.8 & 339.4 & 305.5 & 13.2 \\
\hline 24 UPS1 & 0.169 & 0.085 & 125.8 & 37.9 & 272.2 & 163.7 & $54 \mathrm{Mb}$ & 0.067 & -0.039 & 33.5 & 10.7 & 337.2 & 44.2 \\
\hline 25002 & 0.375 & 0.302 & 25.8 & 121.6 & 95.9 & 147.4 & 552 ZMS6 & 0.131 & 0.007 & 37.7 & 106.1 & 68.4 & 143.8 \\
\hline 26 EPS2 & 0.536 & 0.140 & 128.4 & 256.6 & 128.3 & 25.0 & $5624 K 6$ & 0.058 & 0.019 & 79.6 & 223.0 & 143.5 & 302.6 \\
\hline 27 2N2 & 0.384 & 0.126 & 23.1 & 159.8 & 136.7 & 182.9 & 572546 & 0.109 & -0.012 & 48.6 & 90.7 & 42.1 & 139.3 \\
\hline $28 \mathrm{mu}$ & 0.371 & 0.045 & 85.9 & 332.6 & 246.7 & 58.5 & 58 MSK6 & 0.037 & 0.000 & 171.5 & 257.2 & 85.7 & 68.7 \\
\hline 29 N2 & 0.982 & -0.133 & 164.3 & 340.8 & 176.5 & 145.2 & 59 3MK7 & 0.109 & 0.046 & 53.9 & 14.9 & 321.0 & 68.8 \\
\hline \multirow[t]{2}{*}{30 NU2 } & 0.359 & $=0.149$ & 4.5 & 157.8 & 153.3 & 162.3 & $60 \mathrm{MB}$ & 0.082 & -0.065 & 0.8 & 353.9 & 353.1 & 354.7 \\
\hline & & & & & & & $61 M 10$ & 0.038 & 0.013 & 69.8 & 183.0 & 113.2 & 252.8 \\
\hline
\end{tabular}


TABLE B.8. Tidal Analysis Results in Current Elipse Form for Site $1 M$ (21 m), May 8, 1988, 1300 through May 27, 1989, 1700.

(Greenwich Phases are for Time Zone GMT.)

\begin{tabular}{|c|c|c|c|c|c|c|c|c|c|c|c|c|c|}
\hline NAME & MANOR & MINOR & INC & $\mathrm{G}$ & $\mathrm{G}+$ & G- & NAME & MA.JOR & MIMOR & INC & G & $\mathrm{G}+$ & G. \\
\hline 120 & 1.351 & 0.000 & 24.2 & 360.0 & 335.8 & 24.2 & $36 \mathrm{ML}$ & 8.265 & -0.581 & 14.2 & 135.3 & $\uparrow 21.1$ & 149.5 \\
\hline $2 \mathrm{SA}$ & 3.820 & 0.668 & 168.9 & 66.2 & 257.3 & 235.2 & 37 H2 & 1.324 & -0.002 & 14.1 & 95.0 & 80.9 & 109.1 \\
\hline 3 SSA & 1.517 & 0.653 & 134.4 & 102.8 & 328.5 & 237.2 & $38 \mathrm{~m} \times 52$ & 0.646 & -0.207 & 23.8 & 13.7 & 349.9 & 37.5 \\
\hline 4 MSH & 0.665 & 0.144 & 156.3 & 213.7 & 57.6 & 10.1 & 39 LOA2 & 0.159 & 0.079 & 0.5 & 349.9 & 349.6 & 350.4 \\
\hline $5 \mathbf{~ m ~}$ & 0.359 & -0.003 & 161.6 & 326.8 & 165.2 & 128.4 & 4012 & 0.517 & -0.049 & 41.7 & 107.5 & 65.8 & 149.2 \\
\hline 6 nSF & 0.130 & 0.000 & 169.6 & 275.1 & 105.5 & 84.7 & $41 T 2$ & 0.378 & 0.052 & 0.2 & 42.9 & 62.8 & 43.1 \\
\hline $7 \mathrm{MF}$ & 0.347 & 0.303 & 149.6 & 35.5 & 245.9 & 185.1 & $42 \mathrm{~s} 2$ & 2.215 & -0.502 & 0.6 & 159.2 & 158.6 & 159.9 \\
\hline 8 ALP1 & 0.352 & 0.180 & 158.8 & 346.9 & 188.0 & 145.7 & $43 R 2$ & 0.207 & -0.016 & 66.5 & 129.3 & 322.8 & 295.8 \\
\hline 9201 & 0.278 & 0.049 & 29.2 & 68.2 & 39.0 & 97.4 & $44 \times 2$ & 0.605 & -0.156 & 1.3 & 129.9 & 128.5 & $13 t .2$ \\
\hline $105 I G 1$ & 0.156 & 0.077 & 69.7 & 268.1 & 198.4 & 337.9 & 45 MSN2 & 0.129 & 0.004 & 165.9 & 214.9 & 49.1 & 20.8 \\
\hline 11 11 & 0.740 & 0.375 & 12.2 & 84,0 & 71.8 & 96.2 & 46 ETA2 & 0.096 & 0.065 & 58.7 & 85.5 & 26.8 & 144.2 \\
\hline 12 RHOI & 0.217 & 0.086 & 163.6 & 284.0 & 120.4 & 87.6 & $47 \mathrm{mos}$ & 0.224 & 0.067 & 55.5 & 335.1 & 279.6 & 30.6 \\
\hline 33 ot & 4.525 & 2.148 & 4.1 & 94.8 & 90.7 & 98.8 & $48 \mathrm{kB}$ & 0.167 & 0.057 & 172.2 & 183.9 & 17.7 & 356.0 \\
\hline 14 TAUI & 0.705 & 0.179 & 153.0 & 347.0 & 194.0 & 140.0 & 49503 & 0.174 & 0.075 & 105.6 & 30.1 & 284.5 & 135.6 \\
\hline 15 BET 1 & 0.221 & 0.126 & 174.6 & 276.2 & 101.5 & 90.8 & 50 MK3 & 0.159 & 0.044 & 61.7 & 60.9 & 359.2 & 122.5 \\
\hline 16 NOI & 0.317 & 0.092 & 14.5 & $113 . ?$ & 98.6 & 127.5 & 51 SK3 & 0.044 & 0.009 & 113.8 & 2.7 & 248.9 & 116.6 \\
\hline $17 \mathrm{CH} 1$ & 0.285 & 0.123 & 132.9 & 242.6 & $\uparrow 09.7$ & 15.6 & 52 MN4 & 0.107 & 0.029 & 56.4 & 286.7 & 230.3 & 343.0 \\
\hline $18 \mathrm{P!1}$ & 0.613 & 0.337 & 174.8 & $2 \pi 5.8$ & 101.0 & 90.6 & $53 \mathrm{M} / 4$ & 0.073 & 0.000 & 11.6 & 334.4 & 322.8 & 346.0 \\
\hline $19 P 1$ & 2.524 & 1.257 & 4.2 & 146.5 & 142.3 & 150.7 & 54 SN4 & 0.099 & 0.020 & 102.4 & 177.7 & $\pi .3$ & 280.1 \\
\hline $20 \$ 1$ & 2.881 & 1.558 & 158.9 & 200.6 & 41.7 & 359.5 & 55 MS4 & 0.085 & 0.045 & 83.3 & 38.1 & 314.8 & 121.3 \\
\hline $21 \mathrm{k} 1$ & 7.452 & 2.499 & 0.5 & 135.4 & 134.9 & 135.9 & $56 \mathrm{HK}^{2}$ & 0.084 & 0.035 & 62.7 & 85.3 & 22.5 & 148.0 \\
\hline 22 PSI1 & 1.300 & 0.735 & 62.3 & 224.9 & 62.6 & 27.2 & $57 \$ 4$ & 0.093 & 0.081 & 73.6 & 54.6 & $\$ 41.0$ & 128.2 \\
\hline 23 PHI1 & 0.876 & 0.428 & 171.8 & 217.8 & 45.9 & 29.6 & 58 SK4 & 0.045 & 0.031 & 17.9 & 332.8 & 314.9 & 350.7 \\
\hline 24 THE1 & 0.340 & 0.152 & 1.4 & 151.0 & 149.6 & 952.3 & 59 ح'K5 & 0.097 & 0.021 & 30.6 & 321.6 & 291.0 & 352.3 \\
\hline $25 \mathrm{~d}$ & 0.649 & 0.285 & $\uparrow 70.1$ & 317.0 & 146.9 & 127.1 & $6025 K 5$ & 0.050 & -0.003 & 33.4 & 319.9 & 286.5 & 353.4 \\
\hline 26501 & 0.265 & -0.008 & 71.3 & 83.6 & 12.3 & 154.9 & 61 ZNN6 & 0.070 & -0.007 & 25.9 & 313.6 & 287.8 & 339.5 \\
\hline 27001 & 0.107 & -0.022 & 6.4 & 179.6 & 173.2 & 188.1 & $62 \mathrm{nb}$ & 0.081 & 0.005 & 51.3 & 308.4 & 257.1 & 359.7 \\
\hline 28 UP\$1 & 0.951 & 0.064 & 18.9 & 257.3 & 238.4 & 276.2 & 632456 & 0.068 & -0.003 & 59.2 & 320.9 & 261.7 & 20.1 \\
\hline 29002 & 0.272 & 0.069 & 162.6 & 103.0 & 300.4 & 265.6 & 64 2NK6 & 0.059 & 0.024 & 7.3 & 289.8 & 212.5 & 7.1 \\
\hline 30 EPS2 & 0.298 & 0.201 & 118.2 & 318.0 & 199.7 & 76.2 & 652516 & 0.017 & 0.007 & 102.9 & 223.7 & 120.8 & 326.6 \\
\hline 31 2N2 & 0.210 & 0.077 & 139.6 & 337.1 & 197.5 & $\$ 16.6$ & $\$ \infty$ MSKG & 0.022 & 0.003 & 5.3 & 319.6 & 314.3 & 325.0 \\
\hline $32 \mathrm{~mL}$ & 0.243 & 0.029 & 99.4 & 297.2 & 197.8 & 36.5 & $673 * k 7$ & 0.039 & -0.012 & 90.6 & 146.2 & 55.6 & 236.8 \\
\hline $33 * 2$ & 1.620 & -0.298 & 21.4 & 106.5 & 85.1 & 127.9 & $68 \mathrm{MB}$ & 0.046 & -0.003 & 62.5 & 904.2 & 41.7 & 166.7 \\
\hline 34 NU2 & 0.439 & 0.128 & 4.6 & 108.8 & 104.2 & 193.4 & 69 M10 & 0.014 & 0.005 & 139.7 & 240.2 & 100.6 & 19.9 \\
\hline $35 \mathrm{Ht}$ & 0.894 & 0.140 & 170.4 & 351.5 & 181.1 & 162.0 & & & & & & & \\
\hline
\end{tabular}


TABLE B.9. Tidal Analysis Results in Current Ellipse Form for Site IM $(40 \mathrm{~m})$, May 8, 1988, 1300 through June 2, 1989, 2400.

(Greenwich Phases are for Time Zone GMT.)

\begin{tabular}{|c|c|c|c|c|c|c|c|c|c|c|c|c|c|}
\hline NAHE & MAJOR & MILOR & INC & G & $G+$ & G- & NAME & MA,JCR & MINOR & INC & G & $\mathrm{G+}$ & G. \\
\hline $1 z 0$ & 0.940 & 0.000 & 133.1 & 360.0 & 226.9 & 133.1 & $36 \mathrm{M} 2$ & 6.185 & -1.524 & 22.1 & 112.5 & 90.4 & 134.6 \\
\hline $2 \mathrm{SA}$ & 3.323 & 0.135 & 110.9 & 149.5 & 38.6 & 260.4 & $37 \mathrm{H} 2$ & 0.977 & 0.105 & 9.4 & 106.3 & 96.9 & 115.8 \\
\hline 3 SSA & 2.250 & 0.259 & 106.4 & 199.1 & 92.7 & 305.5 & 38 MKS2 & 0.698 & $-0.05 t$ & 26.0 & 1.8 & 335.8 & 27.8 \\
\hline $4 \mathrm{MSM}$ & 0.571 & -0.068 & 126.8 & 238.7 & 111.9 & 5.5 & 39 एA2 & 0.092 & 0.037 & 91.2 & 93.2 & 2.0 & 184.5 \\
\hline $5 \mathrm{rm}$ & 0.449 & -0.099 & 70.3 & 77.8 & 7.6 & 148.1 & $40 \mathrm{L2}$ & 0.940 & 0.064 & 25.7 & 114.0 & 88.3 & 139.7 \\
\hline $6 \mathrm{MSF}$ & 0.204 & -0.007 & 55.0 & 38.2 & 343.1 & 93.2 & 4172 & 0.516 & 0.086 & 16.6 & 0.3 & 343.7 & 16.9 \\
\hline $7 \mathrm{MF}$ & 0.305 & -0.211 & 11.5 & 259.5 & 248.0 & 271.1 & $42 \$ 2$ & 1.697 & -0.864 & 16.3 & 125.3 & 109.0 & 141.7 \\
\hline 8 ALP1 & 0.101 & -0.004 & 2.3 & 248.0 & 245.7 & 250.3 & $43 \mathrm{R} 2$ & 0.302 & 0.017 & $\$ 28.8$ & 170.4 & 41.6 & 299.1 \\
\hline 9201 & 0.131 & 0.081 & 93.7 & 294.9 & 201.2 & 28.5 & $44 K 2$ & 0.606 & -0.057 & 18.9 & 121.7 & 102.8 & 140.6 \\
\hline $10 \mathrm{sIG}$ & 0.160 & -0.066 & 0.4 & 243.8 & 243.4 & 244.3 & 45 MSN2 & 0.163 & 0.000 & 8.2 & 289.0 & 280.8 & 297.2 \\
\hline 11 Q1 & 0.386 & -0.056 & 176.8 & 273.3 & 96.5 & 90.2 & 46 ETA2 & 0.109 & 0.055 & 79.9 & 74.7 & 354.8 & 154.7 \\
\hline 12 RHOT & 0.236 & 0.052 & 55.7 & 237.6 & 181.9 & 293.4 & $47 \mathrm{N03}$ & 0.197 & 0.045 & 22.1 & 335.8 & 313.8 & 357.9 \\
\hline 1301 & 2.449 & 0.366 & 162.4 & 287.0 & 124.6 & 89.3 & $48 \mathrm{kB}$ & 0.046 & 0.001 & 2.5 & 69.7 & 67.2 & 72.2 \\
\hline 14 TAU1 & 0.346 & -0.168 & 129.6 & 15.7 & 246.1 & 145.4 & 49503 & 0.065 & 0.012 & 10.1 & 122.9 & 112.9 & 133.0 \\
\hline 15 вET1 & 0.287 & 0.109 & 7.5 & 160.1 & 152.7 & 167.6 & $50 \mathrm{MK3}$ & 0.376 & 0.097 & 45.1 & 66.3 & 21.2 & 111.4 \\
\hline $16 \mathrm{~N} 01$ & 0.254 & 0.052 & 14.1 & 40.5 & 26.4 & 54.6 & $515 \times 3$ & 0.106 & 0.073 & 46.1 & 126.2 & 80.1 & 172.4 \\
\hline $17 \mathrm{CHI} 1$ & 0.342 & 0.183 & 9.2 & 189.3 & 180.1 & 198.5 & 52 MN4 & 0.111 & 0.019 & 37.8 & 52.4 & 14.6 & 90.3 \\
\hline 18 PI 1 & 0.181 & 0.014 & 83.5 & 59.1 & 335.6 & 142.7 & $53 \mathrm{MH}$ & 0.120 & -0.027 & 52.0 & 85.8 & 33.8 & 137.8 \\
\hline $19 p 1$ & 0.892 & -0.266 & 142.4 & 334.6 & 192.2 & 117.0 & 54 SN4 & 0.068 & 0.018 & 104.5 & 243.5 & 138.9 & 348.0 \\
\hline $20 s 1$ & 1.451 & 0.872 & 118.9 & 199.5 & 80.6 & 318.5 & 55 MS4 & 0.068 & -0.001 & 59.4 & 213.3 & 161.9 & 264.7 \\
\hline $21 \mathrm{kt}$ & 4.036 & -0.008 & 150.3 & 325.7 & 175.4 & 116.0 & 56 MK4 & 0.089 & -0.034 & 44.8 & 40.1 & 355.4 & 84.9 \\
\hline 22 PS11 & 0.727 & 0.478 & 7.7 & 108.7 & 101.1 & 116.4 & 5754 & 0.088 & 0.071 & 106.8 & 65.0 & 318.2 & 171.8 \\
\hline $23 \mathrm{PHI} 1$ & 0.191 & -0.061 & 39.0 & 342.8 & 303.9 & 21.8 & 58 SK4 & 0.069 & -0.037 & 114.8 & 322.6 & 207.8 & 77.4 \\
\hline 24 THE1 & 0.225 & -0.024 & 113.9 & 325.8 & 212.7 & $\pi .0$ & 59 ZMK5 & 0.164 & 0.014 & 52.6 & 292.2 & 239.5 & 364.8 \\
\hline $25 \mathrm{~J} 1$ & 0.161 & 0.021 & 94.5 & 324.3 & 229.8 & 58.8 & $6025 \times 5$ & 0.042 & -0.009 & 164.1 & 145.0 & 340.9 & 309.2 \\
\hline $26 \$ 01$ & 0.122 & 0.061 & 12.3 & 242.3 & 230.1 & 254.6 & 61 ZUNG & 0.050 & 0.009 & 45.6 & 265.8 & 220.2 & 311.4 \\
\hline 27001 & 0.114 & 0.031 & 41.9 & 65.6 & 23.7 & 107.5 & $62 \mathrm{Mb}$ & 0.168 & 0.030 & 31.5 & 291.6 & 260.1 & 323.2 \\
\hline 28 UPS1 & 0.113 & -0.030 & 68.3 & 92.4 & 24.1 & 160.7 & 632456 & 0.105 & 0.011 & 66.6 & 277.5 & 210.9 & 364.0 \\
\hline 29002 & 0.179 & 0.029 & 46.4 & 273.3 & 226.8 & 319.7 & $642 M 1 K 6$ & 0.024 & -0.007 & 60.3 & 58.3 & 358.9 & 119.6 \\
\hline 30 EPS2 & 0.281 & 0.129 & 19.8 & 189.5 & 169.7 & 209.3 & $652 \mathrm{SHO}$ & $0.03 ?$ & -0.023 & 71.4 & 324.2 & 252.7 & 35.6 \\
\hline $312 \mathrm{~N} 2$ & 0.142 & -0.094 & 83.3 & 323.2 & 240.0 & 46.5 & 66 NSKS & 0.070 & 0.008 & 28.8 & 291.9 & 263.1 & 320.7 \\
\hline 32 MU2 & 0.075 & -0.035 & 49.5 & 187.8 & 138.3 & 237.3 & 67 3HK7 & 0.011 & .0 .003 & 71.1 & 319.8 & 248.7 & 30.9 \\
\hline 33 N2 & 1.217 & -0.415 & 32.9 & 74.7 & 41.8 & 107.5 & $68 \mathrm{Mg}$ & 0.073 & 0.001 & 83.2 & 77.0 & 353.7 & 160.2 \\
\hline 34 NU2 & 0.155 & -0.047 & 76.0 & 28.0 & 312.0 & 104.0 & $69 M 10$ & 0.028 & 0.005 & 146.0 & $i 15.7$ & 329.7 & 261.6 \\
\hline 35 H1 & 0.815 & 0.175 & 27.3 & 120.3 & 93.1 & 147.6 & & & & & & & \\
\hline
\end{tabular}


IABLE B.10. Joint Probability Distribution of Significant Wave Height and Period at Montara

\begin{tabular}{|c|c|c|c|c|c|c|c|c|c|c|}
\hline \multirow[b]{2}{*}{ Hoight, } & \multicolumn{10}{|c|}{ Poriod, } \\
\hline & $<6$ & $8-8$ & $8-10$ & $10-12$ & $12-14$ & $14-16$ & :Q -18 & $18-22$ & 322 & Total \\
\hline$<6.5$ & 0.28 & 0.38 & 6. 28 & & 0.28 & 0.64 & & 0.04 & & 1.28 \\
\hline D. $5-1$ & 2.33 & 7.79 & 8.86 & 3.91 & 3.38 & 2.21 & 1.42 & 0.12 & & 27.94 \\
\hline $1-1.5$ & 0.47 & 8.77 & 11.23 & 6.52 & 6.13 & 2.17 & 1.42 & G. 26 & & 36.92 \\
\hline $1.5-2$ & & 4.19 & 3.87 & 4.51 & B.61 & 2.88 & 0.83 & 6. 32 & & 22.81 \\
\hline $2-2.5$ & 0.94 & 0.99 & 2,13 & 1.63 & 1.94 & 1.15 & 0.47 & б.18 & & 7.91 \\
\hline $2.5-3$ & & 0.04 & 6. 32 & 9.24 & 6. 63 & 1.11 & 6.12 & 8.12 & & 2.57 \\
\hline $3-3.5$ & & & 6.34 & 8.04 & 0.12 & 0.28 & 0.04 & & & 0.61 \\
\hline 3. $5-4$ & & & & & & 0.08 & 6.68 & 6.94 & & 0.28 \\
\hline $4-4.5$ & & & & & & & 6.68 & & & 0.68 \\
\hline$>4.5$ & & & & & & & & & & 0.00 \\
\hline Tota I & 3.12 & 22.13 & 24.08 & 18.25 & 18.48 & 9.92 & 4.47 & 1. 99 & 0.80 & 100.00 \\
\hline
\end{tabular}

TABLE B.11. Monthly Means and Standard Deviations of Alongshore Velocity $\left(\mathrm{cm} \cdot \mathrm{s}^{-1}\right)$ for Site B1B $(21 \mathrm{~m})$

\begin{tabular}{|c|c|c|c|}
\hline Date & $\operatorname{Mean}(a)$ & Standard Deviation & Days \\
\hline $\begin{array}{l}\text { Apri1 } 1988 \\
\text { May } \\
\text { June }\end{array}$ & $\begin{array}{r}2.92 \\
-8.06 \\
-5.41\end{array}$ & $\begin{array}{r}8.59 \\
10.11 \\
8.21\end{array}$ & $\begin{array}{r}3 \\
31 \\
7\end{array}$ \\
\hline $\begin{array}{l}\text { June } \\
\text { July } \\
\text { August } \\
\text { September }\end{array}$ & $\begin{array}{l}-5.84 \\
-3.37 \\
-3.30 \\
-5.51\end{array}$ & $\begin{array}{r}9.60 \\
9.29 \\
10.10 \\
10.57\end{array}$ & $\begin{array}{l}21 \\
31 \\
31 \\
12\end{array}$ \\
\hline $\begin{array}{l}\text { September } \\
\text { October } \\
\text { November } \\
\text { December } \\
\text { January }\end{array}$ & $\begin{array}{l}-5.86 \\
-3.04 \\
-9.55 \\
-0.68 \\
-8.19\end{array}$ & $\begin{array}{r}8.28 \\
9.41 \\
8.53 \\
10.24 \\
8.15\end{array}$ & $\begin{array}{l}15 \\
31 \\
30 \\
31 \\
19\end{array}$ \\
\hline $\begin{array}{l}\text { January } 1989 \\
\text { February } \\
\text { March } \\
\text { April } \\
\text { May } \\
\text { June }\end{array}$ & $\begin{array}{r}9.98 \\
-3.90 \\
0.29 \\
-16.90 \\
-13.18 \\
-5.92\end{array}$ & $\begin{array}{l}8.78 \\
9.59 \\
9.92 \\
9.58 \\
9.82 \\
5.55\end{array}$ & $\begin{array}{r}1 \\
28 \\
31 \\
30 \\
31 \\
1\end{array}$ \\
\hline
\end{tabular}

(a) Positive toward $328^{\circ} \mathrm{T}$. 
IABLE B.12. Monthly Means and Standard Deviations of Cross-Shelf Velocity $\left(\mathrm{cm}^{-1} \mathrm{~s}^{-1}\right)$ for Site BlB $(21 \mathrm{~m})$

\begin{tabular}{lrrr} 
Date & Mean $^{(a)}$ & Standard Deviation & Days \\
\cline { 3 - 4 } Apri1 & 2.86 & 7.60 & 3 \\
May & -1.04 & 10.11 & 31 \\
June & 0.68 & 8.84 & 7 \\
& & 10.31 & 21 \\
June & -0.06 & 7.28 & 31 \\
Ju1y & 1.61 & 7.71 & 31 \\
August & 3.21 & 10.82 & 12 \\
September & -1.64 & 9.47 & 15 \\
September & 1.45 & 9.45 & 31 \\
October & 3.15 & 8.82 & 30 \\
November & 0.75 & 9.49 & 31 \\
December & 2.45 & 8.10 & 19 \\
January & -1.17 & 7.54 & 1 \\
January & & 7.22 & 28 \\
February & 2.21 & 9.13 & 31 \\
March & -1.12 & 9.70 & 30 \\
April & 1.66 & 10.38 & 1 \\
May & 1.96 & 4.87 & \\
June & 0.96 & &
\end{tabular}

(a) Positive toward $58^{\circ} \mathrm{T}$. 


\section{TABLE B.13. Monthly Means and Standard Deviations of Alongshore Velocity $\left(\mathrm{cm} \cdot \mathrm{s}^{-1}\right)$ for Site BlB $(46 \mathrm{~m})$}

\begin{tabular}{|c|c|c|c|}
\hline Date & Mean $(a)$ & Standard Deviation & Days \\
\hline $\begin{array}{l}\text { Apri] } 1988 \\
\text { May } \\
\text { June }\end{array}$ & $\begin{array}{r}1.63 \\
-6.55 \\
-4.01\end{array}$ & $\begin{array}{r}7.30 \\
10.05 \\
10.38\end{array}$ & $\begin{array}{r}3 \\
31 \\
7\end{array}$ \\
\hline $\begin{array}{l}\text { June } \\
\text { July } \\
\text { August } \\
\text { September }\end{array}$ & $\begin{array}{r}-0.75 \\
1.36 \\
-0.28 \\
-2.36\end{array}$ & $\begin{array}{r}10.03 \\
10.14 \\
9.01 \\
7.37\end{array}$ & $\begin{array}{l}21 \\
31 \\
31 \\
12\end{array}$ \\
\hline $\begin{array}{l}\text { September } \\
\text { October } \\
\text { November } \\
\text { December } \\
\text { January }\end{array}$ & $\begin{array}{r}-2.27 \\
1.24 \\
-5.61 \\
0.54 \\
-6.46\end{array}$ & $\begin{array}{r}8.29 \\
8.89 \\
9.05 \\
10.00 \\
8.53\end{array}$ & $\begin{array}{l}15 \\
31 \\
30 \\
31 \\
19\end{array}$ \\
\hline $\begin{array}{l}\text { January } 1989 \\
\text { February } \\
\text { March } \\
\text { Apri1 } \\
\text { May } \\
\text { June }\end{array}$ & $\begin{array}{r}7.54 \\
-1.55 \\
1.01 \\
-9.08 \\
-9.19 \\
-5.10\end{array}$ & $\begin{array}{l}4.34 \\
8.49 \\
9.78 \\
9.58 \\
9.89 \\
7.66\end{array}$ & $\begin{array}{r}1 \\
28 \\
31 \\
30 \\
31 \\
1\end{array}$ \\
\hline
\end{tabular}

(a) Positive toward $328^{\circ} \mathrm{T}$. 
TABLE B.14. Monthly Means and Standard Deviations of Cross-Shelf Velocity $\left(\mathrm{cm} \cdot \mathrm{s}^{-1}\right)$ for Site B1B $(46 \mathrm{~m})$

\begin{tabular}{|c|c|c|c|}
\hline Date & $\operatorname{Mean}(a)$ & Standard Deviation & Days \\
\hline $\begin{array}{l}\text { April } 1988 \\
\text { May } \\
\text { June }\end{array}$ & $\begin{array}{l}1.63 \\
1.16 \\
1.93\end{array}$ & $\begin{array}{l}3.90 \\
7.02 \\
7.77\end{array}$ & $\begin{array}{r}3 \\
31 \\
7\end{array}$ \\
\hline $\begin{array}{l}\text { June } \\
\text { July } \\
\text { August } \\
\text { September }\end{array}$ & $\begin{array}{r}0.26 \\
1.58 \\
0.59 \\
-1.68\end{array}$ & $\begin{array}{l}7.41 \\
7.74 \\
5.98 \\
7.76\end{array}$ & $\begin{array}{l}21 \\
31 \\
31 \\
12\end{array}$ \\
\hline $\begin{array}{l}\text { September } \\
\text { October } \\
\text { November } \\
\text { December } \\
\text { January }\end{array}$ & $\begin{array}{l}1.15 \\
2.04 \\
1.11 \\
3.87 \\
0.45\end{array}$ & $\begin{array}{l}6.63 \\
6.92 \\
7.81 \\
8.80 \\
7.04\end{array}$ & $\begin{array}{l}15 \\
31 \\
30 \\
31 \\
19\end{array}$ \\
\hline $\begin{array}{l}\text { January } 1989 \\
\text { February } \\
\text { March } \\
\text { April } \\
\text { May } \\
\text { June }\end{array}$ & $\begin{array}{r}5.75 \\
0.32 \\
1.94 \\
0.92 \\
1.96 \\
-0.47\end{array}$ & $\begin{array}{l}4.57 \\
6.65 \\
7.58 \\
8.07 \\
7.79 \\
6.36\end{array}$ & $\begin{array}{r}1 \\
28 \\
31 \\
30 \\
31 \\
1\end{array}$ \\
\hline
\end{tabular}

(a) Positive toward $58^{\circ} \mathrm{T}$. 
TABLE B.15. Monthly Means and Standard Deviations of Alongshore Velocity $\left(\mathrm{cm} \cdot \mathrm{s}^{-1}\right)$ for Site BlB $(85 \mathrm{~m})$

$\begin{array}{lccr}\text { Date } & \text { Mean } & \text { Standard Deviation } & \text { Days } \\ \text { Apri1 1988 } & -0.30 & 5.25 & 3 \\ \text { May } & -3.87 & 8.66 & 31 \\ \text { June } & -1.37 & 7.92 & 7 \\ \text { June } & -1.50 & 6.94 & 21 \\ \text { July } & 1.79 & 6.54 & 31 \\ \text { August } & -1.37 & 6.85 & 31 \\ \text { September } & -1.68 & 6.87 & 12 \\ & & & \\ \text { September } & -0.11 & 7.76 & 15 \\ \text { October } & 3.11 & 7.01 & 31 \\ \text { November } & -2.10 & 6.96 & 30 \\ \text { December } & 2.17 & 7.93 & 31 \\ \text { January } 1989 & -2.77 & 7.31 & 19\end{array}$

(a) Positive toward $328^{\circ} \mathrm{T}$.

TABLE B.16. Monthly Means and Standard Deviations of Cross-Shelf Velocity $\left(\mathrm{cm} \cdot \mathrm{s}^{-1}\right)$ for Site BlB $(85 \mathrm{~m})$

\begin{tabular}{lccr} 
Date & Mean $(a)$ & Standard Deviation & Days \\
Apri1 1988 & -1.12 & 4.33 & 3 \\
May & 0.39 & 5.99 & 31 \\
June & -0.74 & 5.04 & 7 \\
June & -0.39 & 4.27 & 21 \\
July & -0.66 & 4.05 & 31 \\
August & -0.23 & 4.36 & 31 \\
September & -0.47 & 4.96 & 12 \\
September & -1.40 & & 15 \\
October & -1.02 & 5.50 & 31 \\
November & -0.78 & 6.38 & 30 \\
December & -1.52 & 7.11 & 31 \\
January 1989 & -1.29 & 8.04 & 19 \\
\hline
\end{tabular}

(a) Positive toward $58^{\circ} \mathrm{T}$. 
TABLE B.17. Monthly Means and Standard Deviations of Alongshore Velocity $\left(\mathrm{cm}^{\circ} \mathrm{s}^{-1}\right)$ for Site IM $(21 \mathrm{~m})$

$\begin{array}{lccc}\text { Date } & \text { Mean }(a) & \text { Standard Deviation } & \text { Days } \\ \text { May } 1988 & -1.86 & 9.61 & 23 \\ \text { June } & -1.41 & 10.13 & 6 \\ & & 10.86 & 21 \\ \text { June } & 1.76 & 11.44 & 31 \\ \text { July } & 5.62 & 9.41 & 31 \\ \text { August } & 3.59 & 8.35 & 27 \\ \text { September } & 3.50 & 8.71 & 31 \\ \text { October } & 4.17 & 9.35 & 30 \\ \text { November } & 1.37 & 10.74 & 31 \\ \text { December } & -1.26 & 10.13 & \\ \text { January 1989 } & -2.31 & 9.60 & 28 \\ \text { February } & & 10.03 & 31 \\ \text { March } & 0.10 & 9.54 & 30 \\ \text { Apri1 } & -2.38 & 10.47 & 27 \\ \text { May } & -2.20 & & \end{array}$

(a) Positive toward $328^{\circ} \mathrm{T}$. 
TABLE B.18. Monthly Means and Standard Deviations of Cross-Shelf Velocity $\left(\mathrm{cm}^{\circ} \mathrm{s}^{-1}\right)$ for Site IM $(21 \mathrm{~m})$

$\begin{array}{lccr}\text { Date } & \text { Mean } & \text { Sa) } & \text { Days } \\ \text { May } 1988 & 0.52 & 8.68 & 23 \\ \text { June } & 3.26 & 7.23 & 6 \\ \text { June } & 0.90 & 7.90 & 21 \\ \text { July } & 0.50 & 7.23 & 31 \\ \text { August } & 1.84 & 7.47 & 31 \\ \text { September } & 2.54 & 7.21 & 27 \\ \text { October } & 3.55 & 7.69 & 31 \\ \text { November } & 3.14 & 8.37 & 30 \\ \text { December } & 0.40 & 9.75 & 31 \\ \text { January 1989 } & -0.16 & 8.28 & 16 \\ & & 7.86 & 28 \\ \text { February } & 0.47 & 7.86 & 31 \\ \text { March } & 0.24 & 8.20 & 30 \\ \text { Aprit } & -0.16 & 7.78 & 27 \\ \text { May } & -0.64 & & \end{array}$

(a) Positive toward $58^{\circ} \mathrm{T}$. 
IABLE B.19. Monthly Means and Standard Deviations of A]ongshore Velocity $\left(\mathrm{cm} \cdot \mathrm{s}^{-1}\right)$ for Site IM $(40 \mathrm{~m})$

$\begin{array}{lccr}\text { Date } & \text { Mean } & \text { Sa } & \text { Standard Deviation } \\ \text { May 1988 } & -2.22 & 6.48 & 23 \\ \text { June } & -4.18 & 6.47 & 3 \\ \text { June } & -11.58 & 8.08 & 21 \\ \text { July } & -2.72 & 6.62 & 31 \\ \text { August } & -1.54 & 5.17 & 31 \\ \text { September } & 0.71 & 5.81 & 28 \\ \text { October } & 2.00 & 5.65 & 31 \\ \text { November } & 1.22 & 7.17 & 30 \\ \text { December } & 1.31 & 6.71 & 31 \\ \text { January 1989 } & -0.48 & 7.01 & 15 \\ \text { February } & -0.22 & 6.39 & 28 \\ \text { March } & -1.41 & 6.63 & 31 \\ \text { April } & -0.75 & 5.60 & 30 \\ \text { May } & -0.84 & 6.77 & 27\end{array}$

(a) Positive toward $328^{\circ} \mathrm{T}$. 
TABLE B.20. Monthly Means and Standard Deviations of Cross-She $1 f$ Velocity $\left(\mathrm{cm} \cdot \mathrm{s}^{-1}\right)$ for Site $1 M(40 \mathrm{~m})$

\begin{tabular}{lccr} 
Date & Mean & Da & Days \\
\cline { 2 - 4 } May 1988 & 0.91 & 5.41 & 23 \\
June & 3.17 & 5.94 & 3 \\
& & 7.75 & 21 \\
June & 8.52 & 4.82 & 31 \\
July & 1.54 & 5.20 & 31 \\
August & 0.97 & 5.57 & 28 \\
September & -1.98 & 5.26 & 31 \\
October & -2.15 & 6.60 & 30 \\
November & -1.51 & 5.47 & 31 \\
December & -0.59 & 5.68 & 15 \\
January 1989 & 0.29 & 5.06 & 28 \\
February & -0.44 & 6.09 & 31 \\
March & -0.74 & 5.64 & 30 \\
Apri7 & 1.27 & 5.31 & 27 \\
May & 1.63 & &
\end{tabular}

(a) Positive toward $58^{\circ} \mathrm{T}$. 
TABLE B.21. Monthly Means and Standard Deviations of Temperature $\left({ }^{\circ} \mathrm{C}\right)$ for Site B1B $(21 \mathrm{~m})$

$\begin{array}{lrcr}\text { Date } & \text { Mean } & \text { Standard Deviation } & \text { Days } \\ \text { Apri] 1988 } & 11.36 & 0.48 & 3 \\ \text { May } & 10.05 & 0.50 & 31 \\ \text { June } & 9.95 & 0.25 & 7 \\ & & & 21 \\ \text { June } & 9.96 & 0.61 & 31 \\ \text { Ju1y } & 10.72 & 0.77 & 31 \\ \text { August } & 11.74 & 0.81 & 12 \\ \text { September } & 13.32 & 0.79 & 15 \\ \text { September } & 11.90 & 0.67 & 31 \\ \text { October } & 12.14 & 0.67 & 30 \\ \text { November } & 12.36 & 0.53 & 31 \\ \text { December } & 11.40 & 0.51 & \\ \text { January } & 10.39 & 0.24 & 1 \\ \text { January } & 10.19 & 0.10 & 31 \\ \text { February } & 10.39 & 0.21 & 30 \\ \text { March } & 10.75 & 0.43 & 31 \\ \text { Apri1 } & 10.89 & 0.61 & 1 \\ \text { May } & 10.30 & 0.74 & \end{array}$


IABLE B.22. Monthly Means and Standard Deviations of Temperature $\left({ }^{\circ} \mathrm{C}\right)$ for Site B1B $(46 \mathrm{~m})$

\begin{tabular}{|c|c|c|c|}
\hline Date & Mean & Standard Deviation & Days \\
\hline $\begin{array}{l}\text { Aprit } 1988 \\
\text { May } \\
\text { June }\end{array}$ & $\begin{array}{l}9.96 \\
9.33 \\
9.10\end{array}$ & $\begin{array}{l}0.23 \\
0.45 \\
0.32\end{array}$ & $\begin{array}{r}3 \\
31 \\
7\end{array}$ \\
\hline $\begin{array}{l}\text { June } \\
\text { Juły } \\
\text { August } \\
\text { September }\end{array}$ & $\begin{array}{r}8.81 \\
9.11 \\
10.03 \\
12.80\end{array}$ & $\begin{array}{l}0.24 \\
0.48 \\
0.20 \\
1.08\end{array}$ & $\begin{array}{l}21 \\
31 \\
31 \\
12\end{array}$ \\
\hline $\begin{array}{l}\text { September } \\
\text { October } \\
\text { November } \\
\text { December } \\
\text { January } 1989\end{array}$ & $\begin{array}{l}10.41 \\
10.44 \\
10.76 \\
10.69 \\
10.33\end{array}$ & $\begin{array}{l}0.41 \\
0.46 \\
0.50 \\
0.48 \\
0.29\end{array}$ & $\begin{array}{l}15 \\
31 \\
30 \\
31 \\
19\end{array}$ \\
\hline \multirow[t]{2}{*}{$\begin{array}{l}\text { February } \\
\text { March } \\
\text { Apri1 } \\
\text { May } \\
\text { June }\end{array}$} & $\begin{array}{r}10.18 \\
10.14 \\
9.70 \\
9.43 \\
9.23\end{array}$ & $\begin{array}{l}0.17 \\
0.32 \\
0.34 \\
0.34 \\
0.23\end{array}$ & $\begin{array}{r}28 \\
31 \\
30 \\
31 \\
1\end{array}$ \\
\hline & 23. & $\begin{array}{l}\text { Monthly Means and Standard Deviations of } \\
\text { Temperature }\left({ }^{\circ} \mathrm{C}\right) \text { for Site } \mathrm{B} 1 \mathrm{~B}(85 \mathrm{~m})\end{array}$ & \\
\hline Date & Mean & Standard Deviation & Days \\
\hline $\begin{array}{l}\text { Apri1 } 1988 \\
\text { May } \\
\text { June }\end{array}$ & $\begin{array}{l}9.49 \\
8.35 \\
8.37\end{array}$ & $\begin{array}{l}0.02 \\
0.25 \\
0.12\end{array}$ & $\begin{array}{r}3 \\
31 \\
7\end{array}$ \\
\hline $\begin{array}{l}\text { June } \\
\text { July } \\
\text { August } \\
\text { September }\end{array}$ & $\begin{array}{l}8.48 \\
8.58 \\
9.36 \\
9.45\end{array}$ & $\begin{array}{l}0.07 \\
0.28 \\
0.11 \\
0.15\end{array}$ & $\begin{array}{l}21 \\
31 \\
31 \\
12\end{array}$ \\
\hline $\begin{array}{l}\text { September } \\
\text { October } \\
\text { November } \\
\text { December } \\
\text { January } 1989\end{array}$ & $\begin{array}{l}9.65 \\
9.87 \\
9.70 \\
9.83 \\
9.55\end{array}$ & $\begin{array}{l}0.06 \\
0.15 \\
0.23 \\
0.29 \\
0.43\end{array}$ & $\begin{array}{l}15 \\
31 \\
30 \\
31 \\
19\end{array}$ \\
\hline
\end{tabular}


TABLE B.24. Monthly Means and Standard Deviations of Temperature $\left({ }^{\circ} \mathrm{C}\right)$ for Site $1 M(21 \mathrm{~m})$

$\begin{array}{lccr}\text { Date } & \text { Mean } & \text { Standard Deviation } & \text { Days } \\ \text { May 1988 } & 9.62 & 0.35 & 23 \\ \text { June } & 9.09 & 0.11 & 6 \\ \text { June } & 8.99 & 0.30 & 21 \\ \text { July } & 9.32 & 0.79 & 31 \\ \text { August } & 11.07 & 0.56 & 31 \\ \text { September } & 10.89 & 0.66 & 27 \\ \text { October } & 11.74 & 0.64 & 31 \\ \text { November } & 12.00 & 0.39 & 30 \\ \text { December } & 10.85 & 0.37 & 31 \\ \text { January 1989 } & 10.38 & 0.24 & 16 \\ \text { February } & 10.02 & & \\ \text { March } & 10.55 & 0.16 & 28 \\ \text { Apri1 } & 9.74 & 0.39 & 31 \\ \text { May } & 9.71 & 0.27 & 30 \\ \text { May } & & 0.34 & 27\end{array}$

TABLE B.25. Monthly Means and Standard Deviations of Temperature $\left({ }^{\circ} \mathrm{C}\right)$ for Site $1 M(40 \mathrm{~m})$

$\begin{array}{lrcr}\text { Date } & \text { Mean } & \text { Standard Deviation } & \text { Days } \\ \text { May 1988 } & 9.07 & 0.33 & 23 \\ \text { June } & 7.41 & 3.27 & 3 \\ \text { June } & 8.65 & 0.10 & 21 \\ \text { July } & 9.04 & 0.66 & 31 \\ \text { August } & 10.34 & 0.35 & 31 \\ \text { September } & 10.16 & 0.17 & 28 \\ \text { October } & 10.83 & 0.30 & 31 \\ \text { November } & 10.87 & 0.33 & 30 \\ \text { December } & 10.39 & 0.19 & 31 \\ \text { January } 1989 & 10.47 & 0.15 & 15 \\ \text { February } & 9.97 & 0.14 & 28 \\ \text { March } & 10.30 & 0.25 & 31 \\ \text { Apri1 } & 9.43 & 0.18 & 30 \\ \text { May } & 9.23 & 0.23 & 31 \\ \text { June } & 9.02 & 0.04 & 1\end{array}$


TABLE B.26. Seasonal Means and Standard Deviations of Alongshore Velocity $\left(\mathrm{cm} \cdot \mathrm{s}^{-1}\right)$

\begin{tabular}{|c|c|c|c|c|c|c|c|c|}
\hline \multirow[b]{3}{*}{ Station } & \multirow[b]{3}{*}{ Depth } & \multirow[b]{3}{*}{ Year } & \multicolumn{3}{|c|}{ Spring/Summer } & \multicolumn{3}{|c|}{ Fall/Winter } \\
\hline & & & & Standard & & & Standard & \\
\hline & & & Mean & Deviation & Days & Mean & Deviation & Days \\
\hline $\begin{array}{l}\text { B1BTOP } \\
\text { B1BMID } \\
\text { B1BBOT }\end{array}$ & $\begin{array}{l}21 \\
43 \\
85\end{array}$ & $\begin{array}{l}88 \\
88 \\
88\end{array}$ & $\begin{array}{l}-4.76 \\
-1.21 \\
-0.71\end{array}$ & $\begin{array}{l}9.65 \\
9.53 \\
7.23\end{array}$ & $\begin{array}{l}130 \\
130 \\
130\end{array}$ & $\begin{array}{l}-4.34 \\
-2.17 \\
-0.61\end{array}$ & $\begin{array}{r}10.31 \\
9.74 \\
7.75\end{array}$ & $\begin{array}{r}123 \\
123 \\
80\end{array}$ \\
\hline $\begin{array}{l}\text { 1MTOP } \\
\text { 1MBOT }\end{array}$ & $\begin{array}{l}21 \\
40\end{array}$ & $\begin{array}{l}88 \\
88\end{array}$ & $\begin{array}{r}2.70 \\
-3.10\end{array}$ & $\begin{array}{r}10.43 \\
7.52\end{array}$ & $\begin{array}{l}130 \\
127\end{array}$ & $\begin{array}{r}-0.38 \\
0.49\end{array}$ & $\begin{array}{r}10.09 \\
6.81\end{array}$ & $\begin{array}{l}120 \\
119\end{array}$ \\
\hline $\begin{array}{l}\text { M3S1 } \\
\text { M3S2 } \\
\text { M3S1 } \\
\text { M3S2 }\end{array}$ & $\begin{array}{l}35 \\
65 \\
35 \\
65\end{array}$ & $\begin{array}{l}81 \\
81 \\
82 \\
82\end{array}$ & $\begin{array}{r}0.74 \\
1.32 \\
-2.20 \\
0.92\end{array}$ & $\begin{array}{l}6.54 \\
3.67 \\
6.07 \\
3.46\end{array}$ & $\begin{array}{l}119 \\
119 \\
109 \\
109\end{array}$ & $\begin{array}{l}4.47 \\
3.09\end{array}$ & $\begin{array}{l}7.52 \\
4.67\end{array}$ & $\begin{array}{l}117 \\
117\end{array}$ \\
\hline & 63 & 84 & 3.02 & 7.91 & 117 & 1.61 & 8.87 & 9 \\
\hline
\end{tabular}

IABLE B.27. Mean and Standard Deviations of A11 Stations and Variables for the Complete Record. Positive alongshore is northward, positive cross-shelf is onshore.

\begin{tabular}{|c|c|c|c|c|c|}
\hline Station & Variable & Start & Stop & Mean. & $\begin{array}{l}\text { Standard } \\
\text { Deviation }\end{array}$ \\
\hline 898, $21 \mathrm{~m}$ & Alongshore ${ }^{(a)}$ & April i, 1988 & June 1, 1989 & -6.07 & 10.72 \\
\hline $\mathrm{B1B}, 46 \mathrm{~m}$ & Alongshore ${ }^{(a)}$ & April 1, 1988 & June 1, 1999 & -2.80 & 10.14 \\
\hline B1B, $85 \mathrm{~m}$ & Alongshore ${ }^{(a)}$ & April 1, 1988 & Jenuary 1, 1989 & -0.47 & 7.67 \\
\hline $1 \mathrm{M}, 21 \mathrm{~m}$ & Alongshore $\mathrm{e}^{(a)}$ & May 1, 1988 & May 1, 1989 & 0.64 & 10.28 \\
\hline $1 \mathrm{M}, 40 \mathrm{~m}$ & Alongshore ${ }^{(a)}$ & May 1, 1988 & May 1, 1989 & -1.05 & 7.09 \\
\hline 818, $21 \mathrm{~m}$ & Cross-5helf ${ }^{(b)}$ & April 1, 1988 & June 1, 1989 & 1.08 & 9.22 \\
\hline $818,46 \mathrm{~m}$ & Cross-shelf(b) & April 1, 1988 & June 1, 1989 & 1.33 & 7.49 \\
\hline 818, $85 \mathrm{~m}$ & Cross-Shelf ${ }^{(b)}$ & April 1, 1988 & Jenwery 1, 1989 & -0.71 & 5.91 \\
\hline $1 \mathrm{~m}, 21 \mathrm{~m}$ & Cross-Shelf (b) & May 1,1988 & May 1, 1989 & 1.12 & 8.13 \\
\hline $111,40 \mathrm{~m}$ & Cross-Shelf ${ }^{(b)}$ & May 1, 1988 & May 1,1989 & 0.41 & 6.16 \\
\hline B18, $21 \mathrm{~m}$ & Temperature $^{(c)}$ & April 1, 1988 & June 1, 1989 & 11.06 & 1.06 \\
\hline B1B, $46 \mathrm{~m}$ & Temperature ${ }^{(c)}$ & April 1, 1988 & June 1, 1989 & 10.02 & 0.88 \\
\hline B1B, $85 \mathrm{~m}$ & Temperature ${ }^{(c)}$ & April 1, 1988 & January 1,1989 & 9.24 & 0.63 \\
\hline $1 \mathrm{M}, 21 \mathrm{~m}$ & Temperature $e^{(c)}$ & May 1,1988 & May 1, 1989 & 10.41 & 1.01 \\
\hline $1 \mathrm{H}, 40 \mathrm{~m}$ & Tenperature ${ }^{(c)}$ & May 1, 1988 & June 1, 1989 & 9.91 & 0.83 \\
\hline
\end{tabular}

(a) Alongshore and cross-shelf variables in units of $\mathrm{cm}^{-1} \mathrm{~s}^{-1}$.

(b) Temperature in ${ }^{\circ} \mathrm{C}$. 
IABLE B.28. Joint Probability Distribution of Site BIB (21 m) for Spring/Summer. Sample interval is $15 \mathrm{~min}$, May 15 to October 1, 1988.

\begin{tabular}{|c|c|c|c|c|c|c|c|c|c|c|c|c|c|c|}
\hline \multirow{3}{*}{$\begin{array}{l}\text { Direction, } \\
\qquad \mathrm{T} \\
\end{array}$} & \multicolumn{14}{|c|}{ Speed, an॰s ${ }^{-1}$} \\
\hline & 0.00 & 5.00 & 10.00 & 15.00 & 20.00 & 25.00 & 30.00 & 35.00 & 40.00 & 45.00 & 50.00 & 55.00 & $>$ & \\
\hline & $\underline{5.00}$ & 10.00 & 15.00 & 20.00 & 25.00 & 30.00 & $\underline{35.00}$ & 40.00 & 45.00 & 50.00 & 55.00 & 60.00 & 60.00 & Iotal \\
\hline $0-30$ & $16 i$ & 280 & 196 & 109 & 57 & 26 & 3 & 0 & 2 & 0 & 0 & 0 & 0 & 834 \\
\hline $30 \cdot 60$ & 177 & 331 & 258 & 150 & 91 & 23 & $\$ 1$ & 4 & 0 & 0 & 0 & 0 & 0 & 1045 \\
\hline $60 \cdot 90$ & 165 & 356 & 359 & 202 & 123 & 40 & 21 & 3 & 0 & 0 & 0 & 0 & 0 & 1269 \\
\hline $90-120$ & 223 & 535 & 456 & 338 & $12 B$ & 51 & 26 & 3 & 0 & 0 & 0 & 0 & 0 & 1760 \\
\hline $120-150$ & 256 & 499 & 415 & 318 & 177 & 54 & 21 & 1 & 0 & 0 & 0 & 0 & 0 & 1741 \\
\hline $150-180$ & 187 & 426 & 462 & 351 & 218 & 121 & 55 & 30 & 5 & 1 & 0 & 0 & 0 & 1856 \\
\hline $180-210$ & 198 & 289 & 331 & 306 & 212 & 130 & 108 & 28 & 11 & 3 & 0 & 0 & 0 & 1616 \\
\hline $210-240$ & 128 & 192 & 212 & 123 & 70 & 31 & 8 & 2 & 0 & 0 & 0 & 0 & 0 & 766 \\
\hline $240-270$ & 94 & 143 & 102 & 45 & 25 & 11 & 0 & 0 & 0 & 0 & 0 & 0 & 0 & 420 \\
\hline $270 \cdot 300$ & 89 & 134 & $\pi$ & 42 & 23 & 3 & 0 & 0 & 0 & 0 & 0 & 0 & 0 & 366 \\
\hline $300-330$ & 109 & 170 & 112 & 53 & 40 & 8 & 1 & 0 & 0 & 0 & 0 & 0 & 0 & 493 \\
\hline $330-360$ & 148 & 214 & 197 & 130 & $\pi$ & 28 & 1 & 1 & 0 & 0 & 0 & 0 & 0 & 798 \\
\hline Total & 1935 & 3569 & 3173 & $2: 67$ & 1243 & 526 & 255 & 72 & 18 & 4 & 0 & 0 & 0 & 12964 \\
\hline \multicolumn{15}{|l|}{ Percentages } \\
\hline Direction, & 0.00 & 5.00 & 10.00 & $\$ 5.00$ & 20.00 & 25.00 & 30.00 & 35.00 & 40.00 & 45.00 & 50.00 & 55.00 & $>$ & \\
\hline${ }^{\top} T$ & 5.00 & 10.00 & 15.00 & 20.00 & $\underline{25.00}$ & 30.00 & 35.00 & 40.00 & 45.00 & $\underline{50.00}$ & $\underline{55.00}$ & 60.00 & $\underline{60.00}$ & Total \\
\hline $0-30$ & 1.2 & 2.2 & 1.5 & 0.8 & 0.4 & 0.2 & 0.0 & & 0.0 & & & & & 6.4 \\
\hline $30-60$ & 1.4 & 2.6 & 2.0 & 1.2 & 0.7 & 0.2 & 0.1 & 0.0 & & & & & & 8.1 \\
\hline $60-90$ & 1.3 & 2.7 & 2.8 & 1.6 & 0.9 & 0.3 & 0.2 & 0.0 & & & & & & 9.8 \\
\hline $90-120$ & 9.7 & 4.1 & 3.5 & 2.6 & 1.0 & 0.4 & 0.2 & 0.0 & & & & & & 13.6 \\
\hline $120-150$ & 2.0 & 3.8 & 3.2 & 2.5 & 1.4 & 0.4 & 0.2 & 0.0 & & & & & & 13.4 \\
\hline $150-180$ & 1.4 & 3.3 & 3.6 & 2.7 & 1.7 & 0.9 & 0.4 & 0.2 & 0.0 & 0.0 & & & & 14.3 \\
\hline $180-210$ & 1.5 & 2.2 & 2.6 & 2.4 & 1.6 & 1.0 & 0.8 & 0.2 & 0.1 & 0.0 & & & & 12.5 \\
\hline $210-240$ & 1.0 & 1.5 & 1.6 & 0.9 & 0.5 & 0.2 & 0.1 & 0.0 & & & & & & 5.9 \\
\hline $240-270$ & 0.7 & 1.1 & 0.8 & 0.3 & 0.2 & 0.1 & & & & & & & & 3.2 \\
\hline $270-300$ & 0.7 & 1.0 & 0.6 & 0.3 & 0.2 & 0.0 & & & & & & & & 2.8 \\
\hline $300-330$ & 0.8 & 1.3 & 0.9 & 0.4 & 0.3 & 0.1 & 0.0 & - & & & & & & 3.8 \\
\hline $330-360$ & 1.1 & 1.7 & 1.5 & 1.0 & 0.6 & 0.2 & 0.0 & 0.0 & & & & & & 6.2 \\
\hline Total & 14.9 & 27.5 & 24.5 & 16.7 & 9.6 & 4.1 & 2.0 & 0.6 & 0.1 & 0.0 & & & & 100.0 \\
\hline
\end{tabular}


IABLE B.29. Joint Probability Distribution of Site B1B $(21 \mathrm{~m})$ for Fall/Winter. Sample interval is $15 \mathrm{~min}$, November 1 , 1988, to March 15, 1989.

\begin{tabular}{|c|c|c|c|c|c|c|c|c|c|c|c|c|c|c|}
\hline \multirow{3}{*}{$\begin{array}{l}\text { Direction, } \\
\text { or } \\
\end{array}$} & \multicolumn{14}{|c|}{ Speed, $c m * s^{-1}$} \\
\hline & $0: 00$ & 5.00 & 10.00 & 15.00 & 20.00 & 25.003 & 30.00 & 35.004 & 40.00 & 45.00 & 50.00 & 55.00 & $>$ & \\
\hline & 5.00 & 10.00 & 15.00 & 20.00 & 25.00 & 30.00 & 35.00 & 40,00 & $\quad 45.00$ & 50.00 & 55.00 & 60.00 & 60.00 & Total \\
\hline $0-30$ & 120 & 192 & 202 & 133 & 47 & 8 & 1 & 2 & 0 & 0 & 0 & 0 & 0 & 695 \\
\hline $30-60$ & 164 & 214 & 185 & 107 & 35 & 15 & 1 & 0 & 0 & 0 & 0 & 0 & 0 & 721 \\
\hline $60-90$ & 172 & 289 & 272 & 143. & 65 & 19 & 1 & 0 & 0 & 0 & 0 & 0 & 0 & $\$ 01$ \\
\hline $90-120$ & 203 & 412 & 476 & 295 & 154 & 64 & 4 & 2 & 1 & 0 & 0 & 0 & 0 & 1611 \\
\hline $120-150$ & 190 & 453 & 493 & 380 & 186 & 51 & 15 & 10 & 3 & 0 & 0 & 0 & 0 & 1781 \\
\hline $150-180$ & 150 & 401 & 512 & 366 & 214 & 101 & 18 & 7 & 2 & 0 & 0 & 0 & 0 & 1771 \\
\hline $180-210$ & 135 & 277 & 286 & 216 & 154 & 123 & 56 & 16 & 10 & 0 & 0 & 0 & 0 & 1273 \\
\hline $210-240$ & 151 & 275 & 221 & 146 & 92 & 17 & 11 & 8 & 0 & 0 & 0 & 0 & 0 & 861 \\
\hline $240-270$ & 96 & $\$ 53$ & 95 & 58 & 28 & 7 & 1 & 0 & 0 & 0 & 0 & 0 & 0 & 438 \\
\hline $270-300$ & 109 & 126 & 100 & 34 & 20 & 1 & 0 & 0 & 0 & 0 & 0 & 0 & 0 & 390 \\
\hline $300-330$ & $10 t$ & 161 & 163 & 88 & 86 & 31 & 3 & 0 & 0 & 0 & 0 & 0 & 0 & 633 \\
\hline $330-360$ & 86 & 157 & 178 & 225 & 92 & 31 & 6 & 6 & 2 & 1 & 0 & 0 & 0 & 784 \\
\hline Total & 1677 & 3050 & 3183 & 2181 & 1173 & 468 & 117 & 51 & 18 & 1 & 0 & 0 & 0 & 11,819 \\
\hline \multicolumn{15}{|l|}{ Percentages } \\
\hline Direction, & 0.00 & 5.00 & 10.00 & 15.00 & 20.00 & 25.00 & 30.003 & 35.00 & 40.00 & 45.00 & $50.00=$ & 55.00 & $>$ & \\
\hline${ }^{\circ} \mathrm{T}$ & $\underline{5.00}:$ & 10.00 & $\underline{15.00}=$ & $\underline{20.00}$ & 25.00 & $30.00=$ & 35.00 & 40.00 & 45.00 & $\underline{50.00}$ & $\underline{55.00}$ & 60.00 & 60.00 & Total \\
\hline 0.30 & 1.0 & 1.6 & 1.7 & 1.0 & 0.4 & 0.1 & 0.0 & 0.0 & & & & & & 5.8 \\
\hline $30-60$ & 1.4 & 1.8 & 1.6 & 0.9 & 0.3 & 0.1 & 0.0 & & & & & & & 6.0 \\
\hline $60-90$ & 1.4 & 2.4 & 2.3 & 1.2 & 0.5 & 0.2 & 0.0 & & & & & & & 8.1 \\
\hline $90-120$ & 1.7 & 3.5 & 4.0 & 2.5 & 1.3 & 0.5 & 0.0 & 0.0 & 0.0 & & & & & 13.5 \\
\hline $120-150$ & 9.6 & 3.8 & 4.1 & 3.2 & 1.6 & 0.4 & 0.1 & 0.1 & 0.0 & & & & & 14.9 \\
\hline $150-180$ & 1.3 & 3.4 & 4.3 & 3.1 & 9.8 & 0.8 & 0.2 & 0.1 & 0.0 & & & & & 14.9 \\
\hline $180-210$ & 1.1 & 2.3 & 2.4 & 1.8 & 1.3 & 1.0 & 0.5 & 0.1 & 0.1 & & & & & 10.7 \\
\hline $210-240$ & 1.3 & 1.8 & 1.8 & 1.2 & 0.8 & 0.1 & 0.1 & 0.1 & & & & & & 7.2 \\
\hline $240-270$ & 0.8 & 1.3 & 0.8 & 0.5 & 0.2 & 0.1 & 0.0 & & & & & & & 3.7 \\
\hline $270-300$ & 0.9 & 1.1 & 0.8 & 0.3 & 0.2 & 0.0 & & & & & & & & 3.3 \\
\hline $300-330$ & 0.8 & 1.4 & 1.4 & 0.7 & 0.7 & 0.3 & 0.0 & & & & & & & 5.3 \\
\hline $330-360$ & 0.7 & 1.3 & $\uparrow .5$ & 1.9 & 0.8 & 0.3 & 0.1 & 0.1 & 0.0 & 0.0 & & & & 6.6 \\
\hline Total & 14.1 & 25.6 & 26.7 & 18.3 & 9.8 & 3.9 & 1.0 & 0.4 & 0.2 & 0.0 & & & & 100.0 \\
\hline
\end{tabular}


TABLE B.30. Joint Probability Distribution of Complete Record for Site BlB $(21 \mathrm{~m})$. Sample interval is $15 \mathrm{~min}$.

Occurrences

speed, $\cos ^{-1}$

$\begin{array}{llllllllllllll}\text { Direction, } & 0.00 & 5.00 & 10.00 & 15.00 & 20.00 & 25.00 & 30.00 & 35.00 & 40.00 & 45.00 & 50.00 & 55.00 & >\end{array}$

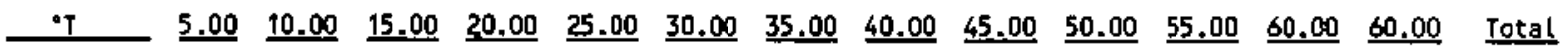

\begin{tabular}{|c|c|c|c|c|c|c|c|c|c|c|c|c|c|c|}
\hline $0=30$ & 398 & 682 & 558 & 336 & 157 & 44 & 7 & 2 & 2 & 0 & 0 & 0 & 0 & 2186 \\
\hline $30-60$ & 476 & 793 & 667 & 362 & 183 & 47 & 18 & 4 & 0 & 0 & 0 & 0 & 0 & 2550 \\
\hline $60-90$ & 468 & 926 & 888 & 525 & 278 & 104 & 41 & 6 & 2 & 0 & 1 & 0 & 0 & 3239 \\
\hline $90-120$ & 545 & 1277 & 1345 & 971 & 569 & 331 & 142 & 86 & 40 & 12 & 5 & 4 & 1 & 5328 \\
\hline $120-150$ & 600 & 1319 & 1440 & 1135 & 744 & 354 & 182 & 80 & 40 & 5 & 1 & 0 & 0 & 5900 \\
\hline $150-180$ & 463 & 1144 & 1428 & 1258 & 838 & 504 & 213 & 86 & 31 & 6 & 0 & 0 & 0 & 5971 \\
\hline $180-210$ & 444 & 792 & $\$ 10$ & 832 & 557 & 358 & 248 & 103 & 38 & 4 & 0 & 0 & 0 & 4286 \\
\hline $210-240$ & 348 & 539 & 538 & 343 & 199 & 58 & 22 & 10 & 0 & 0 & 0 & 0 & 0 & 2057 \\
\hline $240-270$ & 247 & 405 & 262 & 140 & 57 & 23 & 1 & 0 & 0 & 0 & 0 & 0 & 0 & 1135 \\
\hline $270-300$ & 267 & 359 & 280 & 113 & 46 & 4 & 0 & 0 & 0 & 0 & 0 & 0 & 0 & 1069 \\
\hline $300-330$ & 286 & 451 & 348 & 182 & 145 & 44 & 4 & 0 & 0 & 0 & 0 & 0 & 0 & 1460 \\
\hline $330-360$ & 309 & 531 & 492 & 431 & 201 & 63 & 8 & 7 & 2 & 1 & 0 & 0 & 0 & 2045 \\
\hline Total & 4851 & 9218 & 9156 & 6628 & 3974 & 1934 & 886 & 384 & 155 & 28 & 7 & 4 & 1 & 37,226 \\
\hline
\end{tabular}

Percentages

Speed, $c m-\mathrm{s}^{-1}$

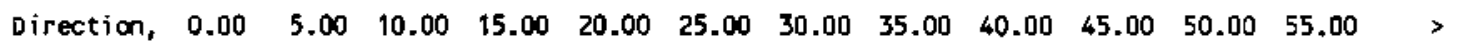

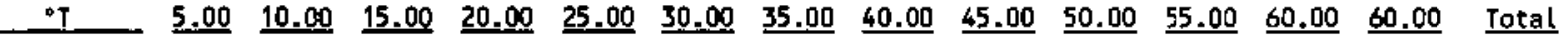

\begin{tabular}{|c|c|c|c|c|c|c|c|c|c|c|c|c|c|c|}
\hline 0.30 & 1.1 & 1.8 & 1.5 & 0.9 & 0.4 & 0.1 & 0.0 & 0.0 & 0.0 & & & & & 5.9 \\
\hline $30-60$ & 1.3 & 2.1 & 1.8 & 1.0 & 0.5 & 0.1 & 0.0 & 0.0 & & & & & & 6.9 \\
\hline $60-90$ & 1.3 & 2.5 & 2.4 & 1.4 & 0.7 & 0.3 & 0.1 & 0.0 & 0.0 & 0.0 & 0.0 & 0.0 & & 8.7 \\
\hline $90-120$ & 1.5 & 3.4 & 3.6 & 2.6 & 1.5 & 0.9 & 0.4 & 0.2 & 0.1 & 0.0 & 0.0 & & 0.0 & 14.3 \\
\hline $120 \cdot 150$ & 1.6 & 3.5 & 3.9 & 3.0 & 2.0 & 1.0 & 0.5 & 0.2 & 0.1 & 0.0 & & & & 15.8 \\
\hline $150-180$ & 1.2 & 3.1 & 3.8 & 3.4 & 2.3 & 1.4 & 0.6 & 0.2 & 0.1 & 0.0 & & & & 16.0 \\
\hline $180-210$ & 1.2 & 2.1 & 2.4 & 2.2 & 1.5 & 1.0 & 0.7 & 0.3 & & & & & & 11.5 \\
\hline $210-240$ & 0.9 & 1.4 & 1.6 & 0.9 & 0.5 & 0.2 & 0.1 & & & & & & & 5.5 \\
\hline $240 \cdot 270$ & 0.7 & 1.1 & 0.7 & 0.4 & 0.2 & 0.1 & & & & & & & & 3.0 \\
\hline $270-300$ & 0.7 & 1.0 & 0.8 & 0.3 & 0.1 & 0.0 & 0.0 & & & & & & & 2.9 \\
\hline $300-330$ & 0.8 & 1.2 & 0.9 & 0.5 & 0.4 & 0.1 & 0.0 & 0.0 & 0.0 & 0.0 & & & & 3.9 \\
\hline $330-360$ & 0.8 & 1.4 & 1.3 & 1.2 & 0.5 & 0.2 & 0.0 & 0.0 & 0.0 & 0.0 & 0.0 & 0.0 & 0.0 & 5.5 \\
\hline Totsi & 13.0 & 24.8 & 26.6 & 17.8 & 10.7 & 5.2 & 2.4 & 1.0 & 0.4 & 0.1 & 0.0 & 0.0 & 0.0 & 100.0 \\
\hline
\end{tabular}


IABLE B.31. Joint Probability Distribution of Site B1B (46 m) for Spring/Summer. Sample interval is $15 \mathrm{~min}$, May 15 to October 1, 1988.

Occurrences

\begin{tabular}{|c|c|c|c|c|c|c|c|c|c|c|c|c|c|c|}
\hline \multirow[b]{2}{*}{$\begin{array}{l}\text { Direction, } \\
\quad \mathrm{T} \\
\end{array}$} & \multicolumn{14}{|c|}{ Speed, $\mathrm{cm} \cdot \mathrm{s}^{-1}$} \\
\hline & $\begin{array}{l}0.00 \\
5.00\end{array}$ & $\begin{array}{r}5.00 \\
10.00 \\
\end{array}$ & $\begin{array}{l}10.00 \\
15.00 \\
\end{array}$ & $\begin{array}{l}15.00 \\
20.00 \\
\end{array}$ & $\begin{array}{l}20.00 \\
25.00\end{array}$ & $\begin{array}{l}25.00 \\
30.00 \\
\end{array}$ & $\begin{array}{l}30.00 \\
35.00 \\
\end{array}$ & $\begin{array}{l}35.00 \\
40.00\end{array}$ & $\begin{array}{l}40.00 \\
45.00 \\
\end{array}$ & $\begin{array}{l}45.00 \\
50.00 \\
\end{array}$ & $\begin{array}{l}50.00 \\
55.00\end{array}$ & $\begin{array}{l}55.00 \\
60.00\end{array}$ & $\begin{array}{c}> \\
60.00\end{array}$ & Total \\
\hline $0-30$ & 222 & 403 & 320 & 177 & 79 & 17 & 5 & 0 & 0 & 0 & 0 & 0 & 0 & 1223 \\
\hline $30-60$ & 218 & 348 & 234 & 73 & 25 & 2 & 0 & 0 & 0 & 0 & 0 & 0 & 0 & 900 \\
\hline $60 \cdot 90$ & 223 & 379 & 240 & 79 & 38 & 10 & 0 & .0 & 0 & 0 & 0 & 0 & 0 & 967 \\
\hline $90-120$ & 238 & 426 & 350 & 153 & 76 & 36 & 0 & 0 & 0 & 0 & 0 & 0 & 0 & 1279 \\
\hline $120-150$ & 217 & 422 & 358 & 181 & 112 & 22 & 3 & 0 & 0 & 0 & 0 & 0 & 0 & 1315 \\
\hline $150-180$ & 218 & 466 & 339 & 234 & 133 & 59 & 26 & 13 & 0 & 0 & 0 & 0 & 0 & 1488 \\
\hline $180-210$ & 219 & 385 & 396 & 213 & 129 & 31 & 10 & 8 & 0 & 0 & 0 & 0 & 0 & $\$ 391$ \\
\hline $210-240$ & 201 & 279 & 223 & 97 & 35 & 2 & 0 & 0 & 0 & 0 & 0 & 0 & 0 & 837 \\
\hline $240-270$ & 184 & 258 & 123 & 44 & 4 & 2 & 0 & 0 & 0 & 0 & 0 & 0 & 0 & 615 \\
\hline $270-300$ & 175 & 223 & 186 & 18 & 9 & 0 & 0 & 0 & 0 & 0 & 0 & 0 & 0 & 611 \\
\hline $300-330$ & 169 & 278 & 244 & 126 & 27 & 4 & 0 & 0 & 0 & 0 & 0 & 0 & 0 & 848 \\
\hline $330-360$ & 185 & 408 & 362 & 296 & 157 & 56 & 18 & 0 & 0 & 0 & 0 & 0 & 0 & 1482 \\
\hline Total & 2467 & 4273 & $33 \pi$ & 1691 & 824 & 241 & 62 & 21 & 0 & 0 & 0 & 0 & 0 & 12,956 \\
\hline
\end{tabular}

Percentages

Speed, $\mathrm{cm} \cdot \mathrm{s}^{-1}$

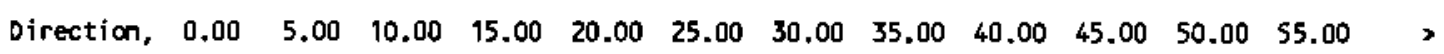

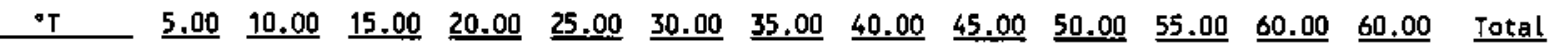

$\begin{array}{rrrrrrrrrrr}0-30 & 1.7 & 3.1 & 2.5 & 1.4 & 0.6 & 0.1 & 0.0 & & 9.4 \\ 30-60 & 1.7 & 2.7 & 1.8 & 0.6 & 0.2 & 0.0 & & & 6.9 \\ 60-90 & 1.7 & 2.9 & 1.9 & 0.6 & 0.3 & 0.1 & & & 7.5 \\ 90-120 & 1.8 & 3.3 & 2.7 & 1.2 & 0.6 & 0.3 & & & 9.9 \\ 120-150 & 1.7 & 3.3 & 2.8 & 1.4 & 0.9 & 0.2 & 0.0 & & 10.1 \\ 150-180 & 1.7 & 3.6 & 2.6 & 1.8 & 1.0 & 0.5 & 0.2 & 0.1 & 11.5 \\ 180-210 & 1.7 & 3.0 & 3.1 & 1.6 & 1.0 & 0.2 & 0.1 & 0.1 & 10.7 \\ 210-240 & 1.6 & 2.2 & 1.7 & 0.7 & 0.3 & 0.0 & & & 6.5 \\ 240-270 & 1.4 & 2.0 & 0.9 & 0.3 & 0.0 & 0.0 & & & 4.7 \\ 270-300 & 1.4 & 1.7 & 1.4 & 0.1 & 0.1 & & & & 4.7 \\ 300-330 & 1.3 & 2.1 & 1.9 & 1.0 & 0.2 & 0.0 & & & 6.5 \\ 330-360 & 1.4 & 3.1 & 2.8 & 2.3 & 1.2 & 0.4 & 0.1 & & 11.4 \\ \text { Total } & 19.0 & 33.0 & 26.0 & 13.1 & 0.4 & 1.9 & 0.5 & 0.2 & 100.0\end{array}$


IABLE B.32. Joint Probability Distribution of Site BIB $(46 \mathrm{~m})$ for Fall/Winter. Sample interval is $15 \mathrm{~min}$, November 1 , 1988, to March 15, 1989.

occurrences

Speed, $c m \cdot \mathrm{s}^{-1}$

\begin{tabular}{|c|c|c|c|c|c|c|c|c|c|c|c|c|c|c|}
\hline $\begin{array}{l}\text { Direction, } \\
\qquad .\end{array}$ & $\begin{array}{l}0.00 \\
\underline{5.00}\end{array}$ & $\begin{array}{r}5.00 \\
10.00\end{array}$ & $\begin{array}{l}10.00 \\
15.00 \\
\end{array}$ & $\begin{array}{l}15.00 \\
20.00\end{array}$ & $\begin{array}{l}20.00 \\
25.00\end{array}$ & $\begin{array}{l}25.00 \\
30.00\end{array}$ & $\begin{array}{l}30.00 \\
35.00\end{array}$ & $\begin{array}{l}35.00 \\
40.00\end{array}$ & $\begin{array}{l}40.00 \\
65.00\end{array}$ & $\begin{array}{l}65.00 \\
50.00\end{array}$ & $\begin{array}{l}50.00 \\
55.00\end{array}$ & $\begin{array}{l}55.00 \\
60.00\end{array}$ & $\begin{array}{c}> \\
60.00\end{array}$ & Iotal \\
\hline 0.30 & 164 & 328 & 270 & 194 & 95 & 45 & 20 & 1 & 0 & 0 & 0 & 0 & 0 & 1117 \\
\hline $30-60$ & 175 & 322 & 30 & 130 & 69 & 14 & 8 & 2 & 0 & 0 & 0 & 0 & 0 & 950 \\
\hline$\infty 0-\infty 0$ & 167 & 298 & 36 & 132 & 72 & 8 & 3 & 0 & 0 & 0 & 0 & 0 & 0 & 916 \\
\hline $90-120$ & 188 & 356 & 358 & 183 & 86 & 25 & 12 & 1 & 0 & 0 & 0 & 0 & 0 & 1219 \\
\hline $120-150$ & 210 & 475 & 498 & 338 & 141 & 57 & 8 & 0 & 0 & 0 & 0 & 0 & 0 & 1727 \\
\hline $150-180$ & t51 & 395 & 480 & 307 & 81 & 25 & 8 & 6 & 6 & 0 & 0 & 0 & 0 & 1469 \\
\hline $180-210$ & 184 & 362 & 375 & 187 & 59 & 13 & 2 & 0 & 0 & 0 & 0 & 0 & 0 & 1182 \\
\hline $210-240$ & 153 & 293 & 202 & 76 & 25 & 6 & 1 & 0 & 0 & 0 & 0 & 0 & 0 & 756 \\
\hline $240-270$ & 122 & 183 & 79 & 22 & 6 & 4 & 0 & 0 & 0 & 0 & 0 & 0 & 0 & 416 \\
\hline $270-300$ & 125 & 171 & 68 & 32 & 18 & 10 & 0 & 0 & 0 & 0 & 0 & 0 & 0 & 424 \\
\hline $300-330$ & 103 & 200 & 187 & 93 & 58 & 4 & 9 & 0 & 0 & 0 & 0 & 0 & 0 & 654 \\
\hline $330-360$ & 120 & 280 & 261 & 251 & 132 & 38 & 6 & 0 & 0 & 0 & 0 & 0 & 0 & 1089 \\
\hline Total & 1882 & 3663 & 3244 & 1945 & 862 & 250 & $\pi$ & 10 & 6 & 0 & 0 & 0 & 0 & 1919 \\
\hline
\end{tabular}

Percentages

Speed, $c \mathrm{~m} \cdot \mathrm{s}^{-1}$

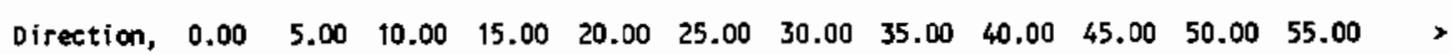

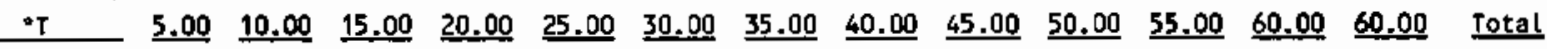

$\begin{array}{rrrrrrrrrrr}0-30 & 1.4 & 2.8 & 2.3 & 1.6 & 0.8 & 0.4 & 0.2 & 0.0 & & 9.4 \\ 30-60 & 1.5 & 2.7 & 1.9 & 1.1 & 0.6 & 0.1 & 0.1 & 0.0 & \\ 60-90 & 1.4 & 2.5 & 2.0 & 1.1 & 0.6 & 0.1 & 0.0 & & \\ 90-120 & 1.6 & 3.0 & 3.0 & 1.5 & 0.8 & 0.2 & 0.1 & 0.0 & 7.7 \\ 120-150 & 1.8 & 4.0 & 4.2 & 2.8 & 1.2 & 0.5 & 0.1 & & & 10.2 \\ 150-180 & 1.3 & 3.3 & 4.0 & 2.6 & 0.8 & 0.2 & 0.1 & 0.1 & 0.1 & 14.5 \\ 180-210 & 1.5 & 3.0 & 3.1 & 1.6 & 0.5 & 0.1 & 0.0 & & & 12.3 \\ 230-240 & 1.3 & 2.5 & 1.7 & 0.6 & 0.2 & 0.1 & 0.0 & & & 9.8 \\ 240-270 & 1.0 & 1.5 & 0.7 & 0.2 & 0.1 & 0.0 & & & & 6.3 \\ 270-300 & 1.0 & 1.4 & 0.6 & 0.3 & 0.2 & 0.1 & & & & 3.5 \\ 300-330 & 0.9 & 1.7 & 1.6 & 0.8 & 0.5 & 0.0 & 0.1 & & & 3.6 \\ 330-360 & 1.0 & 2.3 & 2.2 & 2.1 & 1.1 & 0.3 & 0.1 & & & 5.5 \\ \text { Totai } & 15.6 & 30.7 & 27.2 & 16.3 & 7.2 & 2.1 & 0.6 & 0.1 & 0.1 & 9.1 \\ \end{array}$


TABLE B.33. Joint Probability Distribution of Complete Record for Site B1B $(46 \mathrm{~m})$. Sample interval is $15 \mathrm{~min}$.

\begin{tabular}{|c|c|c|c|c|c|c|c|c|c|c|c|c|c|c|}
\hline \multicolumn{15}{|c|}{ Occur rences } \\
\hline \multirow{2}{*}{$\begin{array}{l}\text { Direction, } \\
\\
\end{array}$} & 0.00 & 5.00 & 10.00 & 15.00 & 20.00 & 25.00 & 30.00 & 35.00 & 40.00 & 45.00 & 50.00 & 55.00 & $>$ & \\
\hline & $\underline{5.00}$ & $\underline{10.00}$ & 15.00 & 20.00 & 25.00 & $\underline{30.00}$ & $\underline{35.00}$ & $\underline{40.00}$ & $\underline{45.00}$ & 50.00 & $\underline{55.00}$ & 60.00 & $\underline{60.00}$ & Iotal \\
\hline 0.30 & 548 & 1027 & 915 & 518 & 248 & 72 & 25 & 1 & 0 & 0 & 0 & 0 & 0 & 3356 \\
\hline $30-60$ & 573 & 969 & 719 & 338 & 137 & 17 & 8 & 2 & 0 & 0 & 0 & 0 & 0 & 2763 \\
\hline $60-90$ & 553 & 1040 & 752 & 352 & 162 & 25 & 4 & 0 & 0 & 0 & 0 & 0 & 0 & 2888 \\
\hline $90-120$ & 623 & 1137 & 1076 & 604 & 340 & 158 & 47 & 10 & 2 & 0 & 0 & 0 & 0 & 3997 \\
\hline $120-150$ & 604 & 1343 & 1295 & 915 & 515 & 217 & 70 & 14 & 5 & 2 & 0 & 0 & 0 & 4980 \\
\hline $150-180$ & 534 & 1299 & 1271 & 1019 & 63 & 252 & 92 & 39 & 15 & 3 & 7 & 0 & 0 & 5094 \\
\hline $380-210$ & 580 & 997 & 1064 & 627 & 311 & 100 & 28 & 9 & 0 & 0 & 0 & 0 & 0 & 3716 \\
\hline $210-240$ & 499 & 755 & 544 & 223 & 82 & 21 & 3 & 2 & 0 & 0 & 0 & 0 & 0 & 2129 \\
\hline $240-270$ & 423 & 584 & 277 & $\pi$ & 10 & 6 & 0 & 0 & 0 & 0 & 0 & 0 & 0 & 1377 \\
\hline $2 \pi 0-300$ & 395 & 532 & 328 & 56 & 27 & 10 & 0 & 0 & 0 & 0 & 0 & 0 & 0 & 1348 \\
\hline $300-330$ & 399 & $6 \pi$ & 629 & 304 & 95. & 8 & 9 & 0 & 0 & 0 & 0 & 0 & 0 & 2119 \\
\hline $330-360$ & 431 & 937 & 903 & 704 & 351 & 104 & 24 & 0 & 0 & 0 & 0 & 0 & 0 & 3454 \\
\hline Total & 6962 & 11295 & 9773 & 5737 & 2841 & 990 & 310 & $\pi$ & 22 & 5 & 7 & 0 & 0 & 37,219 \\
\hline \multicolumn{15}{|l|}{ Percentoges } \\
\hline Direction, & 0.00 & 5.00 & 10.00 & 15.00 & 20.00 & 25.00 & 30.00 & 35.00 & 40.00 & 45.00 & 50.00 & 55.00 & $>$ & \\
\hline 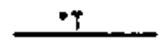 & 5.00 & $\underline{10.00}$ & $\underline{15.00}$ & $\underline{20.00}$ & 25.00 & 30.00 & 35.00 & 40.00 & 45.00 & $\underline{50.00}$ & $\underline{55.00}$ & $\underline{60.00}$ & $\underline{60.00}$ & Total \\
\hline $0-30$ & 1.5 & 2.8 & 2.5 & 1.4 & 0.7 & 0.2 & 0.1 & 0.0 & & & & & & 9.0 \\
\hline $30-60$ & 1.5 & 2.6 & 1.9 & 0.9 & 0.4 & 0.0 & 0.0 & 0.0 & & & & & & 7.4 \\
\hline $60 \cdot 90$ & 1.5 & 2.8 & 2.0 & 0.9 & 0.4 & 0.1 & 0.0 & & & & & & & 7.8 \\
\hline 90.120 & 1.7 & 3.1 & 2.9 & 1.6 & 0.9 & 0.4 & 0.1 & 0.0 & 0.0 & & & & & 10.7 \\
\hline $120-150$ & 1.6 & 3.6 & 3.5 & 2.5 & 1.4 & 0.6 & 0.2 & 0.0 & 0.0 & 0.0 & & & & 13.4 \\
\hline $150-180$ & 1.4 & 3.5 & 3.4 & 2.7 & 1.5 & 0.7 & 0.2 & 0.1 & 0.0 & 0.0 & 0.0 & & & 13.7 \\
\hline $180-210$ & 1.6 & 2.7 & 2.9 & 1.7 & 0.8 & 0.3 & 0.1 & 0.0 & & & & & & 10.0 \\
\hline $210 \cdot 240$ & 1.3 & 2.0 & 1.5 & 0.6 & 0.2 & 0.1 & 0.0 & 0.0 & & & & & & 5.7 \\
\hline $240-270$ & 1.1 & 1.6 & 0.7 & 0.2 & 0.0 & 0.0 & & & & & & & & 3.7 \\
\hline $270-300$ & 1.1 & 1.4 & 0.9 & 0.2 & 0.1 & 0.0 & & & & & & & & 3.6 \\
\hline $300-330$ & 1.1 & 1.8 & 1.7 & 0.8 & 0.3 & 0.0 & 0.0 & & & & & & & 5.7 \\
\hline $330-360$ & 1.2 & 2.5 & 2.4 & 1.9 & 0.9 & 0.3 & 0.1 & & & & & & & 9.3 \\
\hline Totat & 16.6 & 30.3 & 26.3 & 15.4 & 7.6 & 2.7 & 0.8 & 0.2 & 0.1 & 0.0 & 0.0 & & & 100.0 \\
\hline
\end{tabular}


IABLE B.34. Joint Probability Distribution of Site BIB (85 m) for Spring/Sunmer. Sample interval is $15 \mathrm{~min}$, May 15 to October $1,1988$.

\begin{tabular}{|c|c|c|c|c|c|c|c|c|c|c|c|c|c|c|}
\hline \multicolumn{15}{|c|}{ Occurrences } \\
\hline \multirow{2}{*}{$\begin{array}{l}\text { Direction, } \\
\begin{array}{c}{ }^{\circ} \boldsymbol{T} \\
\end{array}\end{array}$} & \multirow{2}{*}{$\begin{array}{l}0.00 \\
5.00 \\
\end{array}$} & \multirow{2}{*}{$\begin{array}{r}5.00 \\
10.00 \\
\end{array}$} & \multirow{2}{*}{$\begin{array}{l}10.00 \\
15.00 \\
\end{array}$} & \multirow{2}{*}{$\begin{array}{l}15.00 \\
20.00 \\
\end{array}$} & \multirow{2}{*}{$\begin{array}{l}20.00 \\
25.00 \\
\end{array}$} & \multirow{2}{*}{$\begin{array}{l}25.00 \\
30.00 \\
\end{array}$} & \multirow{2}{*}{$\begin{array}{l}30.00 \\
35.00 \\
\end{array}$} & 35.00 & \multirow{2}{*}{$\begin{array}{r}40.00 \\
45.00 \\
\end{array}$} & \multirow{2}{*}{$\begin{array}{l}45.00 \\
50.00 \\
\end{array}$} & \multirow{2}{*}{$\begin{array}{l}50.00 \\
55.00 \\
\end{array}$} & \multirow{2}{*}{$\begin{array}{l}55.00 \\
60.00 \\
\end{array}$} & \multirow{2}{*}{$\begin{array}{c}> \\
60.00 \\
\end{array}$} & \multirow[b]{2}{*}{ Iotal } \\
\hline & & & & & & & & 40.00 & & & & & & \\
\hline $0-30$ & 361 & 357 & 79 & 8 & 0 & 1 & 1 & 0 & 0 & 0 & 0 & 0 & 0 & 807 \\
\hline $30-60$ & 247 & 309 & 72 & 4 & 1 & 0 & 0 & 0 & 0 & 0 & 0 & 0 & 0 & 633 \\
\hline 60.90 & 228 & 293 & 105 & 26 & 3 & 0 & 0 & 0 & 0 & 0 & 0 & 0 & 0 & 655 \\
\hline $90-120$ & 197 & 376 & 260 & 103 & 19 & 3 & $t$ & 0 & 0 & 0 & 0 & 0 & 0 & 959 \\
\hline $120-150$ & 283 & 565 & 471 & 206 & 65 & 11 & 1 & 0 & 0 & 0 & 0 & 0 & 0 & 1602 \\
\hline $150-180$ & 318 & 567 & 409 & 138 & 19 & 3 & 2 & 0 & 0 & 0 & 0 & 0 & 0 & 1456 \\
\hline $180-210$ & 283 & 458 & 197 & 49 & 9 & 2 & 1 & 0 & 0 & 0 & 0 & 0 & 0 & 999 \\
\hline $210-240$ & 275 & 403 & 145 & 44 & 7 & 5 & 1 & 0 & 0 & 0 & 0 & 0 & 0 & 880 \\
\hline $240-270$ & 259 & 340 & 136 & 33 & 12 & 1 & 0 & 0 & 0 & 0 & 0 & 0 & 0 & 781 \\
\hline $270-300$ & 257 & 428 & 219 & 80 & 18 & 3 & 0 & 0 & 0 & 0 & 0 & 0 & 0 & 1005 \\
\hline $300-330$ & 530 & 751 & 428 & 85 & 9 & 1 & 0 & 0 & 0 & 0 & 0 & 0 & 0 & 1804 \\
\hline $330-360$ & 527 & 586 & 228 & 43 & 4 & 0 & 0 & 0 & 0 & 0 & 0 & 0 & 0 & 1398 \\
\hline Totel & 3765 & 5433 & 2749 & 819 & 166 & 30 & 7 & 0 & 0 & 0 & 0 & 0 & 0 & 12,969 \\
\hline \multicolumn{15}{|l|}{ Percentages } \\
\hline Direction, & 0.00 & 5.00 & 10.00 & 15.00 & 20.00 & 25.00 & 30.00 & 35.00 & 40.00 & 45.00 & 50.00 & 55.00 & $>$ & \\
\hline${ }^{\circ} \mathrm{T}$ & $\underline{5.00}$ & $\underline{10.00}$ & 15.00 & 20.00 & 5.5.00 & 30.00 & $\underline{35.00}$ & $\underline{60.00}$ & $\underline{45.00}$ & $\underline{50.00}$ & $\underline{55.00}$ & 60.00 & 60.00 & Iotal \\
\hline $0-30$ & 2.8 & 2.8 & 0.6 & 0.1 & & 0.0 & 0.0 & & & & & & & 6.2 \\
\hline $30 \cdot 60$ & 1.9 & 2.4 & 0.6 & 0.0 & 0.0 & & & & & & & & & 4.9 \\
\hline $60-90$ & 1.8 & 2.3 & 0.8 & 0.2 & 0.0 & & & & & & & & & 5.1 \\
\hline $90-120$ & 1.5 & 2.9 & 2.0 & 0.8 & 0.1 & 0.0 & 0.0 & & & & & & & 7.4 \\
\hline $120-150$ & 2.2 & 4,4 & 3.6 & 1.6 & 0.5 & 0.1 & 0.0 & & & & & & & 12.4 \\
\hline $150-180$ & 2.5 & 4.4 & 3.2 & 1.1 & 0.1 & 0.0 & 0.0 & & & & & & & 11.2 \\
\hline $180-210$ & 2.2 & 3.5 & 1.5 & 0.4 & 0.1 & 0.0 & 0.0 & & & & & & & 7.7 \\
\hline $210-240$ & 2.1 & 3.1 & 1.1 & 0.3 & 0.1 & 0.0 & 0.0 & & & & & & & 6.8 \\
\hline $240-270$ & 2.0 & 2.6 & 1.0 & 0.3 & 0.1 & 0.0 & & & & & & & & 6.0 \\
\hline $270-300$ & 2.0 & 3.3 & 1.7 & 0.6 & 0.1 & 0.0 & & & & & & & & 7.7 \\
\hline $300-330$ & 4.1 & 5.8 & 3.3 & 0.7 & 0.1 & 0.0 & & & & & & & & 13.9 \\
\hline $330-360$ & 4.1 & 4.5 & 1.8 & 0.3 & 0.0 & & & & & & & & & 10.7 \\
\hline Total & 29.0 & 47.9 & 21.2 & 6.3 & 1.3 & 0.2 & 0.1 & & & & & & & 100.0 \\
\hline
\end{tabular}


IABLE B.35. Joint Probability Distribution of Site B1B $(85 \mathrm{~m})$ for Fall/Winter. Sample interval is $15 \mathrm{~min}$, November 1 , 1988, to March 15, 1989.

\begin{tabular}{|c|c|c|c|c|c|c|c|c|c|c|c|c|c|c|}
\hline \multirow{3}{*}{$\begin{array}{l}\text { 0ccurrences } \\
\text { Direction, } \\
{ }^{\circ} \mathrm{T} \\
\end{array}$} & \multicolumn{14}{|c|}{ Speed, $c m B^{-1}$} \\
\hline & 0.00 & 5.00 & 10.00 & 15.00 & 20.00 & 25.00 & 30.00 & 35.00 & 40.00 & 45.00 & 50.00 & 55.00 & $>$ & \\
\hline & $\underline{5.00}$ & 10.00 & 15.00 & 20.00 & 25.00 & 30.00 & 35,00 & 40.00 & $\underline{45.00}$ & 50.00 & $\underline{55.00}$ & 60.00 & $\underline{60.00}$ & Total \\
\hline $0-30$ & 109 & 193 & 140 & 25 & 7 & 0 & 0 & 0 & 0 & 0 & 0 & 0 & 0 & 474 \\
\hline $30-60$ & 119 & 203 & 110 & 25 & 3 & 0 & 0 & 0 & 0 & 0 & 0 & 0 & 0 & 460 \\
\hline $60-90$ & 139 & 293 & 148 & 36 & 10 & 1 & 0 & 0 & 0 & 0 & 0 & 0 & 0 & 627 \\
\hline $90-120$ & 127 & 281 & 164 & 75 & 20 & 0 & 0 & 0 & 0 & 0 & 0 & 0 & 0 & 667 \\
\hline $120-150$ & 123 & 309 & 233 & 93 & 22 & 0. & 0 & 0 & 0 & 0 & 0 & 0 & 0 & 780 \\
\hline $150-180$ & 134 & 272 & 203 & 89 & 21 & 4 & 0 & 0 & 0 & 0 & 0 & 0 & 0 & 723 \\
\hline $180-210$ & 97 & 242 & 187 & 97 & 68 & 9 & 1 & 0 & 0 & 0 & 0 & 0 & 0 & 701 \\
\hline $210-240$ & 123 & 238 & 184 & 89 & 56 & 31 & 5 & 0 & 0 & 0 & 0 & 0 & 0 & 726 \\
\hline $240-270$ & 106 & 208 & 197 & $\pi$ & 40 & 21 & 2 & 0 & 0 & 0 & 0 & 0 & 0 & 647 \\
\hline $270-300$ & 118 & 209 & 204 & 71 & 24 & 1 & 0 & 0 & 0 & 0 & 0 & 0 & 0 & 627 \\
\hline $300-330$ & 106 & 262 & 220 & 82 & 13 & 0 & 0 & 0 & 0 & 0 & 0 & 0 & 0 & 683 \\
\hline $330-360$ & 85 & 271 & 211 & 67 & 10 & 2 & 0 & 0 & 0 & 0 & 0 & 0 & 0 & 646 \\
\hline Total & 1386 & 2981 & 2201 & 822 & 294 & 69 & 8 & 0 & 0 & 0 & 0 & 0 & 0 & 7761 \\
\hline \multicolumn{15}{|l|}{ Percentages } \\
\hline Direction, & 0.00 & 5.00 & 10.00 & 15.00 & 20.00 & 25.00 & 30.00 & 35.00 & 40.00 & 45.00 & 50.00 & 55.00 & $>$ & \\
\hline${ }^{\circ} \mathrm{T}$ & $\underline{5.00}$ & $\underline{10.00}$ & 15.00 & $\underline{20.00}$ & $\underline{25.00}$ & 30.00 & 35.00 & 40.00 & $\underline{65.00}$ & $\underline{50.00}$ & $\underline{55.00}$ & $\underline{60.00}$ & 60.00 & Total \\
\hline $0-30$ & 1.4 & 2.5 & 1.8 & 0.3 & 0.1 & & & & & & & & & 6.1 \\
\hline $30-60$ & 1.5 & 2.6 & 1.4 & 0.3 & 0.0 & & & & & & & & & 5.9 \\
\hline $60-90$ & 1.8 & 3.8 & 1.9 & 0.5 & 0.1 & 0.0 & & & & & & & & 8.1 \\
\hline $90-120$ & 1.6 & 3.6 & 2.1 & 1.0 & 0.3 & & & & & & & & & 8.6 \\
\hline $120-150$ & 1.6 & 4.0 & 3.0 & 1.2 & 0.3 & & & & & & & & & 10.1 \\
\hline $150-180$ & 1.7 & 3.5 & 2.6 & 1.1 & 0.3 & 0.1 & & & & & & & & 9.3 \\
\hline $180-210$ & 1.2 & 3.1 & 2.4 & 1.2 & 0.9 & 0.1 & 0.0 & & & & & & & 9.0 \\
\hline $210-240$ & 1.6 & 3.1 & 2.4 & 1.1 & 0.7 & 0.4 & 0.1 & & & & & & & 9.4 \\
\hline $240-270$ & 1.4 & 2.7 & 2.5 & 0.9 & 0.5 & 0.3 & 0.0 & & & & & & & 8.3 \\
\hline $2 \pi 0-300$ & 1.5 & 2.7 & 2.6 & 0.9 & 0.3 & 0.0 & & & & & & & & 8.1 \\
\hline $300-330$ & 1.4 & 3.4 & 2.8 & 1.1 & 0.2 & & & & & & & & & 8.8 \\
\hline $330-360$ & 1.1 & 3.5 & 2.7 & 0.9 & 0.1 & 0.0 & & & & & & & & 8.3 \\
\hline Totel & 17.9 & 38.4 & 28.4 & 10.6 & 3.8 & 0.9 & 0.7 & 0.0 & & & & & & 100.0 \\
\hline
\end{tabular}


IABLE B.36. Joint Probability Distribution of Site BlB (B5 m) for Winter Storm Season. Sample interva1 is $15 \mathrm{~min}$, December 1, 1988, to March 1, 1989.

Decurrences

Speed, $\mathrm{cmes}^{-1}$

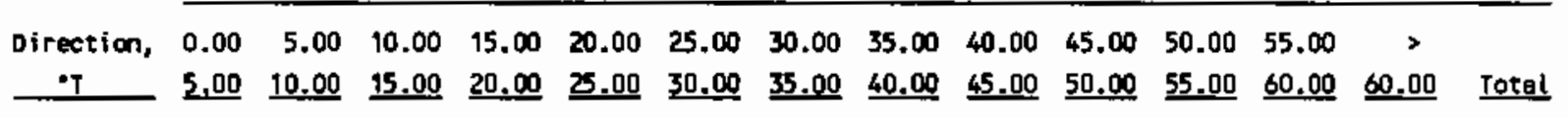

\begin{tabular}{|c|c|c|c|c|c|c|c|c|c|c|c|c|c|c|}
\hline 0.30 & 61 & 132 & 106 & 24 & 7 & 0 & 0 & 0 & 0 & 0 & 0 & 0 & 0 & 330 \\
\hline $30 \cdot \Delta 0$ & 82 & 140 & $\pi$ & 16 & 2 & 0 & 0 & 0 & 0 & 0 & 0 & 0 & 0 & 317 \\
\hline$\Delta-90$ & 92 & 156 & 71 & 20 & 7 & 1 & 0 & 0 & 0 & 0 & 0 & 0 & 0 & 347 \\
\hline $90-120$ & 73 & 126 & 64 & 40 & 14 & 0 & 0 & 0 & 0 & 0 & 0 & 0 & 0 & 317 \\
\hline $120-150$ & 70 & 155 & 119 & 52 & 15 & 0 & 0 & 0 & 0 & 0 & 0 & 0 & 0 & 411 \\
\hline $150-180$ & $\pi$ & 140 & 131 & 65 & 18 & 4 & 0 & 0 & 0 & 0 & 0 & 0 & 0 & 437 \\
\hline $180-2 \% 0$ & 59 & 133 & 102 & 57 & 47 & 8 & 1 & 0 & 0 & 0 & 0 & 0 & 0 & 407 \\
\hline $210-240$ & 90 & 155 & 95 & 47 & 31 & 23 & 4 & 0 & 0 & 0 & 0 & 0 & 0 & 445 \\
\hline $240-270$ & $\pi$ & 137 & 132 & 43 & 33 & 21 & 2 & 0 & 0 & 0 & 0 & 0 & 0 & 447 \\
\hline $270-300$ & 86 & 143 & 142 & 45 & 23 & 1 & 0 & 0 & 0 & 0 & 0 & 0 & 0 & 440 \\
\hline $300-330$ & 78 & 191 & 174 & 65 & 8 & 0 & 0 & 0 & 0 & 0 & 0 & 0 & 0 & 516 \\
\hline $330 \cdot 360$ & 53 & 185 & 154 & 63 & 10 & 2 & 0 & 0 & 0 & 0 & 0 & 0 & 0 & 667 \\
\hline Total & 902 & 1793 & 1367 & 537 & 215 & 60 & 7. & 0 & 0 & 0 & 0 & 0 & 0 & 4881 \\
\hline
\end{tabular}

Percentages

speed, $\mathrm{cm}_{\mathrm{s}}^{-1}$

$\begin{array}{lllllllllllll}\text { Direction, } & 0.00 & 5.00 & 10.00 & 15.00 & 20.00 & 25.00 & 30.00 & 35.00 & 40.00 & 45.00 & 50.00 & 55.00\end{array}$

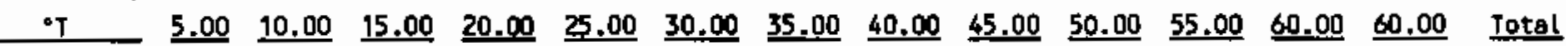

$\begin{array}{rrrrrrrrr}0-30 & 1.2 & 2.7 & 2.2 & 0.5 & 0.1 & & & 6.8 \\ 30-60 & 1.7 & 2.9 & 1.6 & 0.3 & 0.0 & & & 6.5 \\ 60-90 & 1.9 & 3.2 & 1.5 & 0.4 & 0.1 & 0.0 & & 7.1 \\ 90-120 & 1.5 & 2.6 & 1.3 & 0.8 & 0.3 & & & 6.5 \\ 120-150 & 1.4 & 3.2 & 2.4 & 1.1 & 0.3 & & & 8.4 \\ 150-180 & 1.6 & 2.9 & 2.7 & 1.3 & 0.4 & 0.1 & & 9.0 \\ 180-210 & 1.2 & 2.7 & 2.1 & 1.2 & 1.0 & 0.2 & 0.0 & 8.3 \\ 210-240 & 1.8 & 3.2 & 1.9 & 1.0 & 0.6 & 0.5 & 0.1 & 9.1 \\ 240-270 & 1.6 & 2.8 & 2.7 & 0.9 & 0.7 & 0.4 & 0.0 & 9.2 \\ 270-300 & 1.8 & 2.9 & 2.9 & 0.9 & 0.5 & 0.0 & & 9.0 \\ 300-330 & 1.6 & 3.9 & 3.6 & 1.3 & 0.2 & & & 10.6 \\ 330-360 & 1.1 & 3.8 & 3.2 & 1.3 & 0.2 & 0.0 & & 9.6 \\ 10 t a t & 18.5 & 36.7 & 28.0 & 11.0 & 4.4 & 1.2 & 0.1 & 700.0\end{array}$


IABLE B.37. Joint Probability Distribution of Complete Record for Site BlB $(85 \mathrm{~m})$. Sample interval is $15 \mathrm{~min}$.

\begin{tabular}{|c|c|c|c|c|c|c|c|c|c|c|c|c|c|c|}
\hline \multirow[b]{2}{*}{$\begin{array}{l}\text { Direction, } \\
\qquad .{ }^{\top}\end{array}$} & \multicolumn{14}{|c|}{ Speed, cm: s ${ }^{-1}$} \\
\hline & $\begin{array}{l}0.00 \\
5.00\end{array}$ & $\begin{array}{r}5.00 \\
10.00\end{array}$ & $\begin{array}{l}10.00 \\
15.00\end{array}$ & $\begin{array}{l}15.00 \\
20.00\end{array}$ & $\begin{array}{l}20.00 \\
25.00\end{array}$ & $\begin{array}{l}25.00 \\
30.00\end{array}$ & $\begin{array}{l}30.00 \\
35.00\end{array}$ & $\begin{array}{l}35.00 \\
40.00\end{array}$ & $\begin{array}{l}40.00 \\
45.00\end{array}$ & $\begin{array}{l}45.00 \\
50.00\end{array}$ & $\begin{array}{l}50.00 \\
55.00\end{array}$ & $\begin{array}{l}55.00 \\
60.00\end{array}$ & $\begin{array}{c}> \\
60.00\end{array}$ & Total \\
\hline $0-30$ & 558 & 710 & 318 & 61 & 11 & 1 & 1 & 0 & 0 & 0 & 0 & 0 & 0 & 1660 \\
\hline $30-60$ & 459 & 631 & 236 & 39 & 5 & 0 & 0 & 0 & 0 & 0 & 0 & 0 & 0 & 1370 \\
\hline $60-90$ & 443 & 670 & 282 & 70 & 18 & 1 & 0 & 0 & 0 & 0 & 0 & 0 & 0 & 1484 \\
\hline $90-120$ & 400 & 786 & 505 & 210 & 69 & 17 & 8 & 0 & 0 & 0 & 0 & 0 & 0 & 1993 \\
\hline $120-450$ & 482 & 1004 & 812 & 349 & 133 & 43 & 5 & 1 & 0 & 0 & 0 & 0 & 0 & 2829 \\
\hline $150-180$ & 530 & 989 & 699 & 255 & 57 & 12 & 3 & 0 & 0 & 0 & 0 & 0 & 0 & 2545 \\
\hline $180-210$ & 439 & 883 & 481 & 165 & 83 & 15 & 2 & 0 & 0 & 0 & 0 & 0 & 0 & 2068 \\
\hline $210-240$ & 509 & $\pi 7$ & 427 & 173 & 79 & 39 & 8 & 0 & 0 & 0 & 0 & 0 & 0 & 2010 \\
\hline $240-270$ & 465 & 707 & 631 & 161 & 67 & 26 & 2 & 0 & 0 & 0 & 0 & 0 & 0 & 1859 \\
\hline $270-300$ & 446 & 764 & 528 & 196 & 50 & 4 & 0 & 0 & 0 & 0 & 0 & 0 & 0 & 1988 \\
\hline $300-330$ & 732 & 1171 & 816 & 242 & 32 & 1 & 0 & 0 & 0 & 0 & 0 & 0 & 0 & 2994 \\
\hline $330-360$ & 695 & 1032 & 689 & 174 & 25 & 2 & 0 & 0 & 0 & 0 & 0 & 0 & 0 & 2617 \\
\hline Total & 6158 & 10,120 & 6224 & 2095 & 629 & 161 & 29 & 1 & 0 & 0 & 0 & 0 & 0 & 25,417 \\
\hline
\end{tabular}

Percentages

\begin{tabular}{|c|c|c|c|c|c|c|c|c|c|c|c|c|c|c|}
\hline \multirow[b]{2}{*}{$\begin{array}{c}\text { Direction, } \\
-\mathrm{T} \\
\end{array}$} & \multicolumn{14}{|c|}{ Speed, cm-s $s^{-1}$} \\
\hline & $\begin{array}{l}0.00 \\
5.00\end{array}$ & $\begin{array}{r}5.00 \\
10.00 \\
\end{array}$ & $\begin{array}{l}10.00 \\
15.00 \\
\end{array}$ & $\begin{array}{l}15.00 \\
20.00 \\
\end{array}$ & $\begin{array}{l}20.00 \\
\underline{25.00} \\
\end{array}$ & $\begin{array}{l}25.00 \\
30.00 \\
\end{array}$ & $\begin{array}{l}30.00 \\
35.00 \\
\end{array}$ & $\begin{array}{l}35.00 \\
40.00 \\
\end{array}$ & $\begin{array}{r}40.00 \\
45.00 \\
\end{array}$ & $\begin{array}{l}45.00 \\
\underline{50.00}\end{array}$ & $\begin{array}{l}50.00 \\
\underline{55.00} \\
\end{array}$ & $\begin{array}{l}55.00 \\
60.00 \\
\end{array}$ & $\begin{array}{c}> \\
60.00 \\
\end{array}$ & Iotal \\
\hline $0-30$ & 2.2 & 2.8 & 1.3 & 0.2 & 0.0 & 0.0 & 0.0 & & & & & & & 6.5 \\
\hline $30-60$ & 1.8 & 2.5 & 0.9 & 0.2 & 0.0 & & & & & & & & & 5.4 \\
\hline $60-90$ & 1.7 & 2.6 & 1.1 & 0.3 & 0.1 & 0.0 & & & & & & & & 5.8 \\
\hline $90-120$ & 1.6 & 3.1 & 2.0 & 0.8 & 0.3 & 0.1 & 0.0 & & & & & & & 7.8 \\
\hline $120-150$ & 1.9 & 4.0 & 3.2 & 1.4 & 0.5 & 0.2 & 0.0 & 0.0 & & & & & & 11.1 \\
\hline $150-180$ & 2.1 & 3.9 & 2.8 & 1.0 & 0.2 & 0.0 & 0.0 & & & & & & & 10.0 \\
\hline $180-210$ & 1.7 & 3.5 & 1.9 & 0.6 & 0.3 & 0.7 & 0.0 & & & & & & & 8.1 \\
\hline $210-240$ & 2.0 & 3.0 & 1.7 & 0.7 & 0.3 & 0.2 & 0.0 & & & & & & & 7.9 \\
\hline $240-270$ & 1.8 & 2.8 & 1.7 & 0.6 & 0.3 & 0.1 & 0.0 & & & & & & & 7.3 \\
\hline $270-300$ & 1.8 & 3.0 & 2.1 & 0.8 & 0.2 & 0.0 & & & & & & & & 7.8 \\
\hline $300-330$ & 2.9 & 4.6 & 3.2 & 1.0 & 0.1 & 0.0 & & & & & & & & 11.8 \\
\hline $330-360$ & 2.7 & 4.1 & 2.7 & 0.7 & 0.1 & 0.0 & & & & & & & & 10.3 \\
\hline Totel & 24.2 & 39.8 & 24.5 & 8.2 & 2.5 & 0.6 & 0.1 & 0.0 & & & & & & $\uparrow 00.0$ \\
\hline
\end{tabular}


TABLE B.38. Joint Probability Distribution of Site $1 M(21 \mathrm{~m})$ for Spring/Summer. Sample interval is $15 \mathrm{~min}$, May 15 to October $1,1988$.

Occurrences

Speed, $\mathrm{cm} \mathrm{s}^{-1}$

\begin{tabular}{|c|c|c|c|c|c|c|c|c|c|c|c|c|c|c|}
\hline $\begin{array}{c}\text { Direction, } \\
* T \\
\end{array}$ & $\begin{array}{l}0.00 \\
5.00\end{array}$ & $\begin{array}{r}5.00 \\
10.00 \\
\end{array}$ & $\begin{array}{l}10.00 \\
15.00 \\
\end{array}$ & $\begin{array}{l}15.00 \\
20.00 \\
\end{array}$ & $\begin{array}{l}20.00 \\
25.00 \\
\end{array}$ & $\begin{array}{l}25.00 \\
30.00 \\
\end{array}$ & $\begin{array}{l}30.00 \\
35.00 \\
\end{array}$ & $\begin{array}{l}35.00 \\
40.00 \\
\end{array}$ & $\begin{array}{r}40.00 \\
65.00 \\
\end{array}$ & $\begin{array}{l}45.00 \\
50.00 \\
\end{array}$ & $\begin{array}{l}50.00 \\
55.00 \\
\end{array}$ & $\begin{array}{l}55.00 \\
60.00 \\
\end{array}$ & $\begin{array}{c}2 \\
60,00 \\
\end{array}$ & Total \\
\hline $0-30$ & 194 & $4 \pi$ & 715 & 431 & 179 & 34 & 10 & 1 & 0 & 0 & 0 & 0 & 0 & 2036 \\
\hline $30-60$ & 166 & 406 & 417 & 107 & 7 & 1 & 0 & 0 & 0 & 0 & 0 & 0 & 0 & 1104 \\
\hline $60-90$ & 162 & 294 & 201 & 47 & $\uparrow$ & 0 & 0 & 0 & 0 & 0 & 0 & 0 & 0 & 705 \\
\hline $90-120$ & 155 & 212 & 161 & 34 & 2 & 0 & 0 & 0 & 0 & 0 & 0 & 0 & 0 & 544 \\
\hline $120-150$ & 177 & 218 & 162 & 52 & 8 & 0 & 0 & 0 & 0 & 0 & 0 & 0 & 0 & 617 \\
\hline $150-180$ & 144 & 283 & 270 & 172 & 110 & 51 & 15 & 4 & 0 & 0 & 0 & 0 & 0 & 1049 \\
\hline $180-210$ & 172 & 344 & 378 & 310 & 142 & 60 & 13 & 17 & 12 & 5 & 0 & 0 & 0 & 1453 \\
\hline $210-240$ & 173 & 326 & 217 & 80 & 23 & 2 & 0 & 0 & 0 & 0 & 0 & 0 & 0 & 821 \\
\hline $240-270$ & 139 & 262 & 78 & 30 & 4 & 0 & 0 & 0 & 0 & 0 & 0 & 0 & 0 & 513 \\
\hline $270-300$ & 177 & 238 & 76 & 6 & 0 & 0 & 0 & 0 & 0 & 0 & 0 & 0 & 0 & 495 \\
\hline $300-330$ & 180 & 346 & 286 & 108 & 26 & 12 & 0 & 0 & 0 & 0 & 0 & 0 & 0 & 958 \\
\hline $330-360$ & 180 & 496 & 722 & 637 & 329 & 135 & 66 & 54 & 21 & 3 & 0 & 0 & 0 & 2643 \\
\hline Total & 2019 & 3897 & 3663 & 2012 & 831 & 295 & 104 & 76 & 33 & 8 & 0 & 0 & 0 & 12,938 \\
\hline
\end{tabular}

Percentages

speed, $\mathrm{cm} \cdot \mathrm{s}^{-1}$

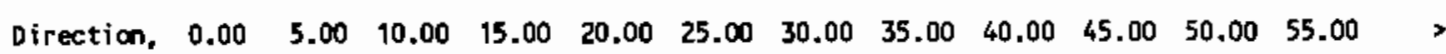

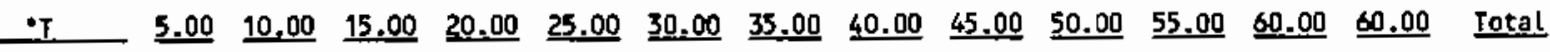

\begin{tabular}{|c|c|c|c|c|c|c|c|c|c|c|c|}
\hline $0-30$ & 1.5 & 3.6 & 5.5 & 3.3 & 1.4 & 0.3 & 0.1 & 0.0 & & & 15.7 \\
\hline $30-60$ & 1.3 & 3.1 & 3.2 & 0.8 & 0.1 & 0.0 & & & & & 8.5 \\
\hline $60-90$ & 1.3 & 2.3 & 1.6 & 0.4 & 0.0 & & & & & & 5.4 \\
\hline $90-120$ & 1.2 & 1.6 & 1.1 & 0.3 & 0.0 & & & & & & 4.2 \\
\hline $120-150$ & 1.4 & 1.7 & 1.3 & 0.4 & 0.1 & & & & & & 4.8 \\
\hline $150-180$ & 1.1 & 2.2 & 2.1 & 1.3 & 0.9 & 0.4 & 0.1 & 0.0 & & & 8.1 \\
\hline $180-210$ & 1.3 & 2.7 & 2.9 & 2.4 & 1.1 & 0.5 & 0.1 & 0.1 & 0.1 & 0.0 & 11.2 \\
\hline $210-240$ & 1.3 & 2.5 & 1.7 & 0.6 & 0.2 & 0.0 & & & & & 6.3 \\
\hline $240-270$ & 1.1 & 2.0 & 0.6 & 0.2 & 0.0 & & & & & & 4.0 \\
\hline $270-300$ & 1.4 & 1.8 & 0.6 & 0.0 & & & & & & & 3.8 \\
\hline $300 \cdot 330$ & 1.4 & 2.7 & 2.2 & 0.8 & 0.2 & 0.1 & & & & & 7.4 \\
\hline $330-360$ & 1.4 & 3.8 & 5.6 & 4.9 & 2.5 & 1.0 & 0.5 & 0.4 & 0.2 & 0.0 & 20.4 \\
\hline Total & 15.6 & 30.1 & 28.3 & 15.6 & 6.4 & 2.3 & 0.8 & 0.6 & 0.3 & 0.1 & 100.0 \\
\hline
\end{tabular}


TABLE B.39. Joint Probability Distribution of Site 1M (21 m) for Fal1/Winter. Sample interval is 15 min, November 1 , 1988, to March 15, 1989.

accurrences

\begin{tabular}{|c|c|c|c|c|c|c|c|c|c|c|c|c|c|c|}
\hline \multirow[b]{2}{*}{$\begin{array}{l}\text { Oirection, } \\
. \\
\end{array}$} & \multicolumn{14}{|c|}{ Speed, cmis $\mathrm{s}^{-1}$} \\
\hline & $\begin{array}{l}0.00 \\
5.00 \\
\end{array}$ & $\begin{array}{r}5.00 \\
10.00 \\
\end{array}$ & $\begin{array}{l}10.00 \\
15.00 \\
\end{array}$ & $\begin{array}{l}15.00 \\
\underline{20.00} \\
\end{array}$ & $\begin{array}{l}20.00 \\
25.00\end{array}$ & $\begin{array}{l}25.00 \\
30,00\end{array}$ & $\begin{array}{l}30.00 \\
\$ 5,00\end{array}$ & $\begin{array}{r}35.00 \\
40.00 \\
\end{array}$ & $\begin{array}{l}40.00 \\
45.00 \\
\end{array}$ & $\begin{array}{l}45.00 \\
50.00 \\
\end{array}$ & $\begin{array}{l}50.00 \\
55,00 \\
\end{array}$ & $\begin{array}{l}55.00 \\
60.00 \\
\end{array}$ & $\begin{array}{c}> \\
60.00 \\
\end{array}$ & Total \\
\hline $0-30$ & 191 & 484 & 386 & 327 & 240 & 126 & 21 & 10 & 0 & 0 & 0 & 0 & 0 & 1785 \\
\hline $30-60$ & 194 & 390 & 243 & 100 & 41 & 2 & 0 & 0 & 0 & 0 & 0 & 0 & 0 & 970 \\
\hline $60-90$ & 188 & 373 & 195 & $\infty$ & 5 & 0 & 0 & 0 & 0 & 0 & 0 & 0 & 0 & 827 \\
\hline $90-120$ & 198 & 311 & 210 & 61 & 2 & 0 & 0 & 0 & 0 & 0 & 0 & 0 & 0 & 782 \\
\hline $120-150$ & 196 & 375 & 34 & 80 & 25 & 3 & 0 & 0 & 0 & 0 & 0 & 0 & 0 & 913 \\
\hline $150-180$ & 173 & 390 & 329 & 203 & 90 & 65 & 26 & 4 & 0 & 0 & 0 & 0 & 0 & 1280 \\
\hline $180-210$ & 160 & 357 & 377 & 370 & 238 & 119 & 38 & 10 & 6 & 0 & 0 & 0 & 0 & 1675 \\
\hline $210-240$ & 134 & 171 & 197 & 123 & 60 & 14 & 2 & 2 & 0 & 0 & 0 & 0 & 0 & 703 \\
\hline $240-270$ & 97 & 117 & 72 & 31 & 1 & 0 & 0 & 0 & 0 & 0 & 0 & 0 & 0 & 318 \\
\hline $270-300$ & 119 & 131 & 42 & 2 & 0 & 0 & 0 & 0 & 0 & 0 & 0 & 0 & 0 & 294 \\
\hline $300-330$ & 160 & 207 & 109 & 34 & 6 & 0 & 0 & 0 & 0 & 0 & 0 & 0 & 0 & 516 \\
\hline $330-360$ & 161 & 410 & 340 & 310 & 145 & 93 & 20 & 14 & 0 & 0 & 0 & 0 & 0 & 1493 \\
\hline Total & t971 & 3716 & 2734 & 1707 & 853 & 422 & 107 & 40 & 6 & 0 & 0 & 0 & 0 & 11,556 \\
\hline
\end{tabular}

Percentages

Speed, $\mathrm{cm} \cdot \mathrm{s}^{-1}$

oirection, $\begin{array}{lllllllllllll}0.00 & 5.00 & 10.00 & 15.00 & 20.00 & 25.00 & 30.00 & 35.00 & 40.00 & 45.00 & 50.00 & 55.00 & >\end{array}$

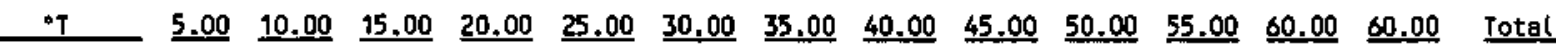

$\begin{array}{rrrrrrrrrrr}0-30 & 1.7 & 4.2 & 3.3 & 2.8 & 2.1 & 1.1 & 0.2 & 0.1 & & 15.4 \\ 30-60 & 1.7 & 3.4 & 2.1 & 0.9 & 0.4 & 0.0 & & & & 8.4 \\ 60-90 & 1.6 & 3.2 & 1.7 & 0.6 & 0.0 & & & & & 7.2 \\ 90-120 & 1.7 & 2.7 & 1.8 & 0.5 & 0.0 & & & & & 6.8 \\ 120-150 & 1.7 & 3.2 & 2.0 & 0.7 & 0.2 & 0.0 & & & & 7.8 \\ 150-180 & 1.5 & 3.4 & 2.8 & 1.8 & 0.8 & 0.6 & 0.2 & 0.0 & & 11.1 \\ 180-210 & 1.4 & 3.1 & 3.3 & 3.2 & 2.1 & 1.0 & 0.3 & 0.1 & 0.1 & 14.5 \\ 210-240 & 1.2 & 1.5 & 1.7 & 1.1 & 0.5 & 0.1 & 0.0 & 0.0 & & 6.1 \\ 240-270 & 0.8 & 1.0 & 0.6 & 0.3 & 0.0 & & & & & 2.8 \\ 270-300 & 1.0 & 1.1 & 0.4 & 0.0 & & & & & & 4.5 \\ 300-330 & 1.4 & 1.8 & 0.9 & 0.3 & 0.1 & & & & & 4.5 \\ 330-360 & 1.4 & 3.5 & 2.9 & 2.7 & 1.3 & 0.8 & 0.2 & 0.1 & & 12.9 \\ \text { Totsl } & 17.1 & 32.2 & 23.7 & 14.8 & 7.4 & 3.7 & 0.9 & 0.3 & 0.1 & \end{array}$


IABLE B.40. Joint Probability Distribution of Complete Record for Site $1 M(21 \mathrm{~m})$. Sample interval is $15 \mathrm{~min}$.

\begin{tabular}{|c|c|c|c|c|c|c|c|c|c|c|c|c|c|c|}
\hline \multirow[b]{2}{*}{$\begin{array}{l}\text { Direction, } \\
\text { 'T } \\
\end{array}$} & \multicolumn{14}{|c|}{ Speed, $\mathrm{cm}^{-1} \mathrm{~s}^{-1}$} \\
\hline & $\begin{array}{l}0.00 \\
5.00 \\
\end{array}$ & $\begin{array}{r}5.00 \\
10.00 \\
\end{array}$ & $\begin{array}{l}10.00 \\
15.00 \\
\end{array}$ & $\begin{array}{l}15.00 \\
20.00 \\
\end{array}$ & $\begin{array}{l}20.00 \\
25.00 \\
\end{array}$ & $\begin{array}{l}25.00 \\
30.00\end{array}$ & $\begin{array}{l}30.00 \\
35.00 \\
\end{array}$ & $\begin{array}{l}35.00 \\
40.00 \\
\end{array}$ & $\begin{array}{l}40.00 \\
45.00 \\
\end{array}$ & $\begin{array}{l}45.00 \\
50.00 \\
\end{array}$ & $\begin{array}{l}50.00 \\
55.00 \\
\end{array}$ & $\begin{array}{l}55.00 \\
60.00 \\
\end{array}$ & $\begin{array}{c}> \\
60.00 \\
\end{array}$ & Iotal \\
\hline $0-30$ & 540 & 1379 & 1597 & 1075 & $5 \pi$ & 241 & 52 & 11 & 0 & 0 & 0 & 0 & 0 & 5470 \\
\hline $30-60$ & 541 & 1163 & 927 & 288 & 62 & 9 & 0 & 0 & 0 & 0 & 0 & 0 & 0 & 2990 \\
\hline $60=90$ & 504 & 1025 & 574 & 146 & 6 & 0 & 0 & 0 & 0 & 0 & 0 & $D$ & 0 & 2255 \\
\hline $90-120$ & 535 & 906 & 562 & 136 & 12 & 0 & 0 & 0 & 0 & 0 & 0 & 0 & 0 & 2149 \\
\hline $120-150$ & 538 & 970 & 633 & 203 & 51 & 6 & 2 & 0 & 0 & 0 & 0 & 0 & 0 & 2403 \\
\hline $150-180$ & 497 & 1016 & 962 & 690 & 343 & 155 & 55 & 8 & 0 & 0 & 0 & 0 & 0 & 3726 \\
\hline $180-210$ & 476 & 1010 & 1113 & 945 & 595 & 277 & $\pi$ & 27 & 18 & 5 & 0 & 0 & 0 & 4543 \\
\hline $210-240$ & 444 & 709 & 562 & 286 & 121 & 22 & 2 & 2 & 0 & 0 & 0 & 0 & 0 & 2148 \\
\hline $240-270$ & 326 & 49 & 214 & 80 & 5 & 0 & 0 & 0 & 0 & 0 & 0 & 0 & 0 & 1121 \\
\hline $270-300$ & 394 & 482 & 175 & 14 & 0 & 0 & 0 & 0 & 0 & 0 & 0 & 0 & 0 & 1065 \\
\hline $300-330$ & 446 & 714 & 510 & 212 & 49 & 12 & 0 & 0 & 0 & 0 & 0 & 0 & 0 & 1943 \\
\hline $330-360$ & $\pi$ & 1237 & 1398 & 1207 & 615 & 304 & 100 & 68 & 21 & 3 & 0 & 0 & 0 & 5432 \\
\hline Total & 5720 & 11,107 & 9227 & 5280 & 2434 & 1026 & 288 & 116 & 39 & 8 & 0 & 0 & 0 & 35,245 \\
\hline
\end{tabular}

Percentages

Speed, $c m \cdot s^{-1}$

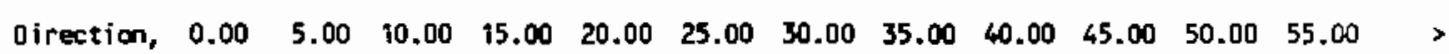

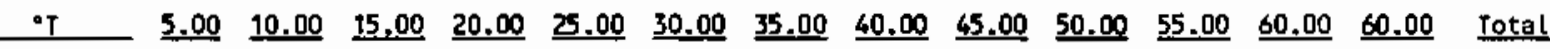

$\begin{array}{rrrrrrrrrrrr}0-30 & 1.5 & 3.9 & 4.5 & 3.1 & 1.6 & 0.7 & 0.1 & 0.0 & & & 15.5 \\ 30-60 & 1.5 & 3.3 & 2.6 & 0.8 & 0.2 & 0.0 & & & & & 8.5 \\ 60-90 & 1.4 & 2.9 & 1.6 & 0.4 & 0.0 & & & & & & 6.4 \\ 90-120 & 1.5 & 2.6 & 1.6 & 0.4 & 0.0 & & & & & & 6.1 \\ 120-150 & 1.5 & 2.8 & 1.8 & 0.6 & 0.1 & 0.0 & 0.0 & & & & 6.8 \\ 150-180 & 1.4 & 2.9 & 2.7 & 2.0 & 1.0 & 0.4 & 0.2 & 0.0 & & & 10.6 \\ 180-210 & 1.4 & 2.9 & 3.2 & 2.7 & 1.7 & 0.8 & 0.2 & 0.1 & 0.1 & 0.0 & 12.9 \\ 210-240 & 1.3 & 2.0 & 1.6 & 0.8 & 0.3 & 0.1 & 0.0 & 0.0 & & & 6.1 \\ 240-270 & 0.9 & 1.4 & 0.6 & 0.2 & 0.0 & & & & & & 3.2 \\ 270-300 & 1.1 & 1.4 & 0.5 & 0.0 & & & & & & & 3.0 \\ 300-330 & 1.3 & 2.0 & 1.4 & 0.6 & 0.1 & 0.0 & & & & & 5.5 \\ 330-360 & 1.4 & 3.5 & 4.0 & 3.4 & 1.7 & 0.9 & 0.3 & 0.2 & 0.1 & 0.0 & 15.4 \\ \text { Tot81 } & 16.2 & 31.5 & 26.2 & 15.0 & 6.9 & 2.9 & 0.8 & 0.3 & 0.1 & 0.0 & 100.0\end{array}$


TABLE B.41. Joint Probability Distribution of Site 1M (40 m) for Spring/Summer. Sample interval is 15 min, May 15 to October 1, 1988.

\begin{tabular}{|c|c|c|c|c|c|c|c|c|c|c|c|c|c|c|}
\hline \multirow{3}{*}{$\begin{array}{l}\text { Occurrences } \\
\text { Direction, } \\
. T \\
\end{array}$} & \multicolumn{14}{|c|}{ Speed, $c m+s^{-1}$} \\
\hline & 0.00 & 5.00 & 10.00 & 15.00 & 20.00 & 25.00 & 30.00 & 35.00 & 40.00 & 45.00 & 50.00 & 55.00 & $>$ & \\
\hline & $\underline{5.00}$ & $\underline{10,00}$ & $\underline{15.00}$ & $\underline{20.00}$ & $\underline{\underline{25.00}}$ & $\underline{30.00}$ & $\underline{35.00}$ & $\underline{40.00}$ & 45.00 & $\underline{50.000}$ & 55.00 & 60.00 & 60.00 & Total \\
\hline 0.30 & 325 & 557 & 157 & 3 & 0 & 0 & 0 & 0 & 0 & 0 & 0 & 0 & 0 & 1042 \\
\hline $30-60$ & 292 & 553 & 191 & 26 & 29 & 20 & 0 & 0 & 0 & 0 & 0 & 0 & 0 & 1111 \\
\hline $60-90$ & 288 & 581 & 347 & 113 & $\pi$ & 28 & 11 & 7 & 0 & 0 & 0 & 0 & 0 & 1454 \\
\hline $90-120$ & 226 & 483 & 352 & 211 & 61 & 56 & 49 & 19 & 0 & 0 & 0 & 0 & 0 & 1457 \\
\hline $120-150$ & 277 & 450 & 358 & 238 & 173 & 86 & 32 & 1 & 0 & 0 & 0 & 0 & 0 & 1615 \\
\hline $150-180$ & 259 & 604 & 499 & 206 & 43 & 9 & 11 & 1 & 0 & 0 & 0 & 0 & 0 & 1552 \\
\hline $180-210$ & 251 & 407 & 301 & 90 & 11 & 2 & 0 & 0 & 0 & 0 & 0 & 0 & 0 & 1062 \\
\hline $210-240$ & 220 & 296 & 142 & 34 & 7 & 3 & 1 & 0 & 0 & 0 & 0 & 0 & 0 & 703 \\
\hline $240-270$ & 217 & 244 & $\pi$ & 21 & 3 & 0 & 0 & 0 & 0 & 0 & 0 & 0 & 0 & 584 \\
\hline $270-300$ & 254 & 239 & 84 & 19 & 0 & 0 & 0 & 0 & 0 & 0 & 0 & 0 & 0 & 596 \\
\hline $300-330$ & 250 & 257 & 84 & 5 & 0 & 0 & 0 & 0 & 0 & 1 & 0 & 0 & 0 & 597 \\
\hline $330-360$ & 261 & 423 & 150 & 6 & 0 & 0 & 0 & 0 & 0 & 0 & 0 & 0 & 0 & 840 \\
\hline Total & 3120 & $50 \%$ & 2664 & 972 & 406 & 204 & 106 & 28 & 0 & 1 & 0 & 0 & 0 & 12,593 \\
\hline \multicolumn{15}{|l|}{ Percentages } \\
\hline oirection, & 0.00 & 5.00 & 10.00 & 15.00 & 20.00 & 25.00 & 30.00 & 35.00 & 40.00 & 45.00 & 50.00 & 55.00 & $>$ & \\
\hline ז & 5.00 & 10.00 & $\underline{15.00}$ & $\underline{20.00}$ & $\underline{\underline{25,00}}$ & 30.00 & 35.00 & $\underline{40.00}$ & $\underline{45.00}$ & 50.00 & $\underline{55.00}$ & 60.00 & 60.00 & Total \\
\hline $0-30$ & 2.6 & 4.4 & 9.2 & 0.0 & & & & & & & & & & 8.3 \\
\hline $30-60$ & 2.3 & 4.4 & 1.5 & 0.2 & 0.2 & 0.2 & & & & & & & & 8.8 \\
\hline $60-90$ & 2.3 & 4.6 & 2.8 & 0.9 & 0.6 & 0.2 & 0.1 & 0.1 & & & & & & 11.5 \\
\hline $90-120$ & 1.8 & 3.8 & 2.8 & 1.7 & 0.5 & 0.4 & 0.4 & 0.2 & & & & & & 11.6 \\
\hline $120-150$ & 2.2 & 3.6 & 2.8 & 1.9 & 1.4 & 0.7 & 0.3 & 0.0 & & & & & & 12.8 \\
\hline $150-180$ & 2.1 & 4.8 & 3.3 & 1.6 & 0.3 & 0.8 & 0.1 & 0.0 & & & & & & 12.3 \\
\hline $180-210$ & 2.0 & 3.2 & 2.4 & 0.7 & 0.1 & 0.0 & & & & & & & & 8.4 \\
\hline $210-240$ & 1.7 & 2.4 & 1.1 & 0.3 & 0.1 & 0.0 & 0.0 & & & & & & & 5.6 \\
\hline $240-270$ & 1.7 & 1.9 & 0.6 & 0.2 & 0.0 & & & & & & & & & 4.5 \\
\hline $270-300$ & 2.0 & 1.9 & 0.7 & 0.2 & & & & & & & & & & 4.7 \\
\hline $300-330$ & 2.0 & 2.0 & 0.7 & 0.0 & & & & & & & & & & 4.7 \\
\hline $330-360$ & 2.1 & 3.4 & 1.2 & 0.0 & & & & & & & & & & 6.7 \\
\hline Total & 24.8 & 40.5 & 21.2 & 7.7 & 3.2 & 1.6 & 0.8 & 0.2 & & 0.0 & & & & 100.0 \\
\hline
\end{tabular}


TABLE B.42. Joint Probability Distribution of Site $1 M(40 \mathrm{~m})$ for Fall/Winter. Sample interval is $15 \mathrm{~min}$, November 1 , 1988, to March 15, 1989.

Occurrences

Speed, $\operatorname{com}^{-1}$

\begin{tabular}{|c|c|c|c|c|c|c|c|c|c|c|c|c|c|c|}
\hline $\begin{array}{c}\text { Direction, } \\
\qquad \mathrm{T} \\
\end{array}$ & $\begin{array}{l}0.00 \\
5.00 \\
\end{array}$ & $\begin{array}{r}5.00 \\
10.00 \\
\end{array}$ & $\begin{array}{l}10.00 \\
15.00 \\
\end{array}$ & $\begin{array}{l}15.00 \\
20.00 \\
\end{array}$ & $\begin{array}{l}20.00 \\
25.00 \\
\end{array}$ & $\begin{array}{l}25.00 \\
30.00 \\
\end{array}$ & $\begin{array}{l}30.00 \\
35.00 \\
\end{array}$ & $\begin{array}{l}35.00 \\
40.00 \\
\end{array}$ & $\begin{array}{l}40.00 \\
45.00 \\
\end{array}$ & $\begin{array}{l}45.00 \\
50.00 \\
\end{array}$ & $\begin{array}{l}50.00 \\
55.00 \\
\end{array}$ & $\begin{array}{l}55.00 \\
60.00 \\
\end{array}$ & $\begin{array}{c}> \\
60.00 \\
\end{array}$ & Total \\
\hline $0-30$ & 273 & 569 & 227 & 48 & 4 & 0 & 0 & 0 & 0 & 0 & 0 & 0 & 0 & 1121 \\
\hline $30-60$ & 292 & 455 & 138 & 5 & 3 & 0 & 0 & 0 & 0 & 0 & 0 & 0 & 0 & 893 \\
\hline 60.90 & 243 & 293 & 104 & 25 & 2 & 0 & 3 & 0 & 0 & 0 & 0 & 0 & 0 & 670 \\
\hline $90-120$ & 196 & 237 & 72 & 21 & 1 & 1 & 1 & 0 & 0 & 0 & 0 & 0 & 0 & 529 \\
\hline $120-150$ & 220 & 294 & 136 & 24 & 0 & 0 & 0 & 0 & 0 & 0 & 0 & 0 & 0 & 674 \\
\hline $150-180$ & 178 & 436 & 339 & 107 & $i \uparrow$ & 0 & 0 & 0 & 0 & 0 & 0 & 0 & 0 & 1071 \\
\hline $180-210$ & 259 & 454 & 448 & 146 & 25 & 12 & 0 & 0 & 0 & 0 & 0 & 0 & 0 & 9364 \\
\hline $210-240$ & 274 & 450 & 205 & 70 & 3 & 0 & 0 & 0 & 0 & 0 & 0 & 0 & 0 & 1002 \\
\hline 240.270 & 297 & 360 & 160 & 64 & 1 & 0 & 0 & 0 & 0 & 0 & 0 & 0 & 0 & 882 \\
\hline $270-300$ & 245 & 423 & $\uparrow 37$ & 57 & 4 & 0 & 0 & 0 & 0 & 0 & 0 & 0 & 0 & 866 \\
\hline $300-330$ & 253 & 544 & 263 & 55 & 28 & 0 & 0 & 0 & 0 & 0 & 0 & 0 & 0 & 1143 \\
\hline $330-360$ & 244 & 553 & 442 & 113 & 8 & 0 & 0 & 0 & 0 & 0 & 0 & 0 & 0 & 1360 \\
\hline Total & 2974 & 5068 & 2671 & 735 & 90 & 13 & 4 & 0 & 0 & 0 & 0 & 0 & 0 & 11,555 \\
\hline
\end{tabular}

Percentages

Speed, $c m \cdot s^{-1}$

Direction, $\begin{array}{lllllllllllll}0.00 & 5.00 & 10.00 & 15.00 & 20.00 & 25.00 & 30.00 & 35.00 & 40.00 & 45.00 & 50.00 & 55.00 & >\end{array}$

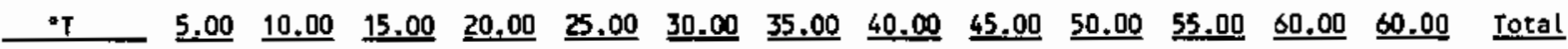

$\begin{array}{rrrrrrrrr}0-30 & 2.4 & 4.9 & 2.0 & 0.4 & 0.0 & & & 9.7 \\ 30-60 & 2.5 & 3.9 & 1.2 & 0.0 & 0.0 & & & 7.7 \\ 60-90 & 2.1 & 2.5 & 0.9 & 0.2 & 0.0 & & 0.0 & 5.8 \\ 90-120 & 1.7 & 2.1 & 0.6 & 0.2 & 0.0 & 0.0 & 0.0 & 4.6 \\ 120-150 & 1.9 & 2.5 & 1.2 & 0.2 & & & & 5.8 \\ 150-180 & 1.5 & 3.8 & 2.9 & 0.9 & 0.1 & & & 9.3 \\ 180-210 & 2.2 & 3.9 & 3.9 & 1.3 & 0.2 & 0.1 & & 11.6 \\ 230-240 & 2.4 & 3.9 & 1.8 & 0.6 & 0.0 & & & 8.7 \\ 240-270 & 2.6 & 3.1 & 1.4 & 0.6 & 0.0 & & & 7.6 \\ 270-300 & 2.1 & 3.7 & 1.2 & 0.5 & 0.0 & & & 7.5 \\ 300-330 & 2.2 & 4.7 & 2.3 & 0.5 & 0.2 & & & 9.9 \\ 330-360 & 2.1 & 4.8 & 3.8 & 1.0 & 0.1 & & & 11.8 \\ \text { Total } & 25.7 & 43.9 & 23.1 & 6.4 & 0.8 & 0.1 & 0.0 & 100.0\end{array}$


TABLE B.43. Joint Probability Distribution of Site $1 M(40 \mathrm{~m})$ for Winter Storm Season. Sample interval is $15 \mathrm{~min}$, December 1, 1988, to March 1, 1989.

Occurrences

Speed, $\mathrm{cm} \cdot \mathrm{s}^{-1}$

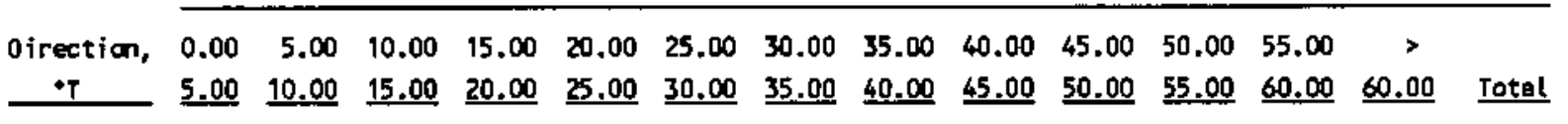

\begin{tabular}{|c|c|c|c|c|c|c|c|c|c|c|c|c|c|c|}
\hline $0-30$ & 179 & 386 & 132 & 31 & 3 & 0 & 0 & 0 & 0 & 0 & 0 & 0 & 0 & 731 \\
\hline $30-60$ & $20 t$ & 285 & 51 & 2 & 2 & 0 & 0 & 0 & 0 & 0 & 0 & 0 & 0 & 541 \\
\hline $60-90$ & 185 & 197 & 57 & 18 & 1 & 0 & 1 & 0 & 0 & 0 & 0 & 0 & 0 & 459 \\
\hline $90-120$ & 145 & $\$ 51$ & 39 & 18 & 1 & 0 & 0 & 0 & 0 & 0 & 0 & 0 & 0 & 354 \\
\hline $120-150$ & 155 & 183 & 100 & 23 & 0 & 0 & 0 & 0 & 0 & 0 & 0 & 0 & 0 & 461 \\
\hline $150-180$ & 118 & 305 & 180 & 82 & 3 & 0 & 0 & 0 & 0 & 0 & 0 & 0 & 0 & 688 \\
\hline $180-210$ & 176 & 314 & 300 & 73 & 4 & 0 & 0 & 0 & 0 & 0 & 0 & 0 & 0 & 867 \\
\hline $210-240$ & 180 & 269 & 110 & 20 & 1 & 0 & 0 & 0 & 0 & 0 & 0 & 0 & 0 & 580 \\
\hline $240-270$ & 218 & 206 & 56 & 19 & 0 & 0 & 0 & 0 & 0 & 0 & 0 & 0 & 0 & 490 \\
\hline $270-300$ & 176 & 260 & 47 & 14 & 0 & 0 & 0 & 0 & 0 & 0 & 0 & 0 & 0 & 497 \\
\hline $300-330$ & 168 & 354 & 110 & 21 & 6 & 0 & 0 & 0 & 0 & 0 & 0 & 0 & 0 & 659 \\
\hline $330-360$ & 166 & 410 & 326 & 91 & 2 & 0 & 0 & 0 & 0 & 0 & 0 & 0 & 0 & $\cos$ \\
\hline Total & 2067 & 3320 & 1508 & 412 & 23 & 0 & 1 & 0 & 0 & 0 & 0 & 0 & 0 & 7331 \\
\hline
\end{tabular}

Percentages

Speed, $\mathrm{cm}^{*} \mathrm{~s}^{-1}$

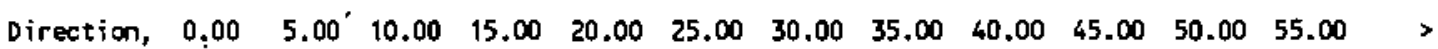

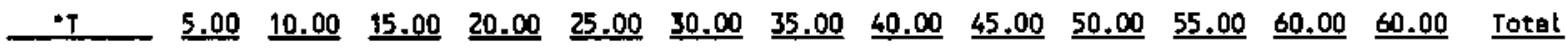

$\begin{array}{rrrrrrrr}0-30 & 2.4 & 5.3 & 1.8 & 0.4 & 0.0 & 10.0 \\ 30-60 & 2.7 & 3.9 & 0.7 & 0.0 & 0.0 & 7.4 \\ 60-90 & 2.5 & 2.7 & 0.8 & 0.2 & 0.0 & 6.3 \\ 90-120 & 2.0 & 2.1 & 0.5 & 0.2 & 0.0 & 4.8 \\ 120-450 & 2.1 & 2.5 & 1.4 & 0.3 & & 6.3 \\ 150-180 & 1.6 & 4.2 & 2.5 & 1.1 & 0.0 & 9.4 \\ 180-210 & 2.4 & 4.3 & 4.1 & 1.0 & 0.1 & 11.8 \\ 210-240 & 2.5 & 3.7 & 1.5 & 0.3 & 0.0 & 7.9 \\ 240-270 & 3.0 & 2.8 & 0.8 & 0.3 & & 6.8 \\ 270-300 & 2.4 & 3.5 & 0.6 & 0.2 & & & 6.8 \\ 300-330 & 2.3 & 4.8 & 1.5 & 0.3 & 0.1 & & 9.0 \\ 330-360 & 2.3 & 5.6 & 4.4 & 1.2 & 0.0 & & 13.6 \\ \text { Total } & 28.2 & 45.3 & 20.6 & 5.6 & 0.3 & 0.0 & 100.0\end{array}$


IABLE B.44. Joint Probability Distribution of Complete Record for Site $1 \mathrm{M}(40 \mathrm{~m})$. Sample interval is $15 \mathrm{~min}$.

\begin{tabular}{|c|c|c|c|c|c|c|c|c|c|c|c|c|c|c|}
\hline \multirow{3}{*}{$\begin{array}{l}\text { Direction, } \\
{ }^{\circ} \mathrm{T} \\
\end{array}$} & \multicolumn{14}{|c|}{ Speed, cmos s-1 } \\
\hline & 0.00 & 5.00 & 10.00 & 15.00 & 20.00 & 25.00 & 30.00 & 35.00 & 40.00 & 45.00 & 50.00 & 55.00 & $>$ & \\
\hline & 5.00 & 10.00 & $\$ 5.00$ & $\underline{20.00}$ & 3.00 & 30,00 & 35.00 & 40.00 & 45.00 & 50.00 & 55.00 & 60.00 & 60.00 & Total \\
\hline $0-30$ & 862 & 1899 & 604 & 93 & 6 & 0 & 0 & 0 & 0 & 0 & 0 & 0 & 0 & 3464 \\
\hline $30-60$ & 891 & 1679 & 618 & 36 & 33 & 20 & 0 & 0 & 0 & 0 & 0 & 0 & 0 & 327 \\
\hline $60-90$ & $m$ & 1296 & 595 & $15 \uparrow$ & 84 & 29 & 14 & 7 & 0 & 0 & 0 & 0 & 0 & 2953 \\
\hline $90-120$ & 642 & 1028 & 503 & 238 & 63 & 57 & 50 & 19 & 0 & 0 & 0. & 0 & 0 & 2600 \\
\hline $120-150$ & 713 & 1172 & 649 & 278 & 180 & 87 & 32 & 1 & 0 & 1 & 2 & 2 & 5 & 3122 \\
\hline $150-180$ & 622 & 1614 & 1159 & 413 & 59 & 14 & 15 & 9 & 3 & 2 & 0 & 3 & 5 & 3918 \\
\hline $180-210$ & 731 & 1347 & 991 & 311 & 46 & 16 & 1 & 0 & 0 & 0 & 1 & 3 & 7 & 3454 \\
\hline $210-240$ & 304 & 1142 & 536 & 156 & 16 & 4 & 1 & 1 & 1 & 1 & 1 & 0 & 0 & 2563 \\
\hline $240-270$ & roo & $\$ 94$ & 381 & 106 & 10 & 0 & 0 & 0 & 0 & 0 & 0 & 0 & 0 & 2191 \\
\hline $270-300$ & 723 & 1018 & 332 & 97 & 5 & 0 & 0 & 0 & 1 & 0 & 0 & 0 & 0 & 2176 \\
\hline $300-330$ & 743 & 1161 & 498 & 77 & 28 & 0 & 0 & 0 & 0 & 1 & 0 & 1 & 0 & 2509 \\
\hline $330-360$ & 745 & 1534 & 786 & 157 & 9 & 0 & 0 & 0 & 0 & 0 & 0 & 0 & 0 & 3231 \\
\hline Total & 8853 & 15,886 & 7652 & 2113 & 539 & 227 & 113 & 37 & 5 & 5 & 4 & 9 & 17 & 35,458 \\
\hline \multicolumn{15}{|l|}{ Percentages } \\
\hline Direction, & 0.00 & 5.00 & 10.00 & 15.00 & 20.00 & 25.00 & 30.00 & 35.00 & 40.00 & 45.00 & 50.00 & 55.00 & $>$ & \\
\hline 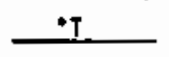 & $\underline{5.00}$ & 10.00 & $\underline{15.00}$ & 20.00 & $\underline{3.00}$ & 30,00 & 35.00 & 40.00 & $\underline{45.00}$ & 50.00 & $\underline{55.00}$ & 60.00 & 60.00 & Total \\
\hline 0.30 & 2.6 & 5.4 & 1.7 & 0.3 & 0.0 & & & & & & & & & 9.8 \\
\hline $30-60$ & 2.5 & 4.7 & 1.7 & 0.1 & 0.1 & 0.1 & & & & & & & & 9.2 \\
\hline $60-90$ & 2.2 & 3.7 & 1.7 & 0.4 & 0.2 & 0.1 & 0.0 & 0.0 & & & & & & B.3 \\
\hline $90-120$ & 1.8 & 2.9 & 1.4 & 0.7 & 0.2 & 0.2 & 0.1 & 0.1 & & & & & & 7.3 \\
\hline $120-150$ & 2.0 & 3.3 & 1.8 & 0.8 & 0.5 & 0.2 & 0.1 & 0.0 & & 0.0 & 0.0 & 0.0 & 0.0 & 8.8 \\
\hline $150-180$ & 1.8 & 4.6 & 3.3 & 1.2 & 0.2 & 0.0 & 0.0 & 0.0 & 0.0 & 0.0 & & 0.0 & 0.0 & 11.0 \\
\hline $480-210$ & 2.1 & 3.8 & 2.8 & 0.9 & 0.1 & 0.0 & 0.0 & & & & 0.0 & 0.0 & 0.0 & 9.7 \\
\hline $210-240$ & 2.0 & 3.2 & 1.5 & 0.4 & 0.0 & 0.0 & 0.0 & 0.0 & 0.0 & 0.0 & 0.0 & & & 7.2 \\
\hline $240-270$ & 2.0 & 2.8 & 1.1 & 0.3 & 0.0 & & & & & & & & & 6.2 \\
\hline $270 \cdot 300$ & 2.0 & 2.9 & 0.9 & 0.3 & 0.0 & & & & 0.0 & & & & & 6.1 \\
\hline $300-330$ & 2.1 & 3.3 & 9.4 & 0.2 & 0.1 & & & & & 0.0 & & 0.0 & & 7.1 \\
\hline $330-360$ & 2.1 & 4.3 & 2.2 & 0.4 & 0.0 & & & & & & & & & 9.1 \\
\hline Total & 25.0 & 44.8 & 21.6 & 6.0 & 1.5 & 0.6 & 0.3 & 0.1 & 0.0 & 0.0 & 0.0 & 0.0 & 0.0 & 100.0 \\
\hline
\end{tabular}


TABLE B.45. Principal Components of Current Meters for Complete Record

Station

$B 1 B, 21 \mathrm{~m}$

$B 1 B, 46 \mathrm{~m}$

$B 1 B, 85 \mathrm{~m}$

$1 M, 21 \mathrm{~m}$

$1 \mathrm{M}, 40 \mathrm{~m}$

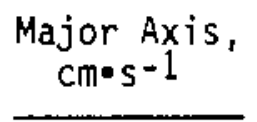

7.47

6.20

4.26

5.56

4.65
Minor Axis, $\mathrm{cm} \bullet \mathrm{s}^{-1}$

4.40

2.60

1.51

2.62

2.37
Orientation, ${ }^{\circ} \mathrm{T}$

337

332

311

347

298

TABLE B.46. Principal Components of Current Meters for Spring/Summer and Fall/winter Seasons

Spring/Summer

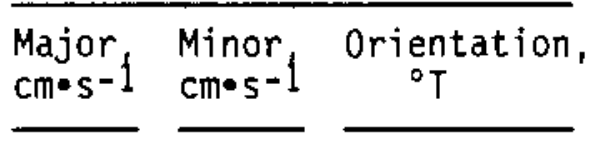

$\mathrm{B} 1 \mathrm{~B}, 21 \mathrm{~m}$

B1B, $46 \mathrm{~m}$

B1B， $85 \mathrm{~m}$

1M. $21 \mathrm{~m}$

$1 \mathrm{M}, 40 \mathrm{~m}$
5.07

5.02

3.83

4.92

5.65
3.93

2.49

1.22

2.57

2.17
355

333

310
349

Fall/winter

TABLE B.47. Average Percentage of Alongshore Variance by Frequency Band

Station

B1B, $21 \mathrm{~m}$

B1B, $46 \mathrm{~m}$

$B 1 B, 85 \mathrm{~m}$

$1 \mathrm{M}, 21 \mathrm{~m}$

$1 \mathrm{M}, 40 \mathrm{~m}$

\section{Frequency Band}

\begin{tabular}{llc}
\hline Low & Diurnal & $\begin{array}{c}\text { Semidiurnal } \\
0.6 \mathrm{~d}-1\end{array} \quad \underline{0.91<\mathrm{f}<1.3 \mathrm{~d}-1} \quad \underline{1.9<\mathrm{f}<2.1 \mathrm{~d}-1} \quad$ Total \\
\hline
\end{tabular}

41.7

31.1

26.6
31.2

38.7

27.1

10.3

16.7

25.9

19.9

22.5

83.2

86.5

79.6

51.4

44.8

93.1

92.1 
APPENDIX C

SEDIMENT TRANSPORT CALCULATIONS 


\section{APPENDIX C}

\section{SEDIMENT TRANSPORT CALCULATIONS}

This appendix describes sediment transport calculations made using current velocity data measured at candidate dredged-material disposal Sites $B 1 B$ and IM offshore San Francisco. Wave data recorded at the nearby Montara pressure-gage array and provided by the Coastal Data Information Program (CDIP) were also used in the calculations. The objective in making these sediment transport calculations was to assess relative suitability of the two candidate sites and to determine the likely fate of dredged material placed at either site.

Because both waves and currents are important in the resuspension of bottom material, the calculations include a wave-current boundary layer model, which estimates the total bottom shear stress $\tau_{C w}$ resulting from the combined effects of waves and currents. The critical shear stress is a shear stress at which sediment (or dredged material) begins to move. The critical shear stress is a property of the bottom material and varies according to the size distribution, shear strength, water content, and density of the material. For noncohesive natural coarse silt or sand of uniform size, empirical values for critical shear stresses have been determined to within a reasonable range. For finer material, cohesive material, and mixed size distributions, it is very difficult to estimate (or directly measure) the critical shear stress. Nonetheless, all material will move in the direction of the current whenever the critical shear stress is exceeded. Sediment transport may occur as either bedload or suspended sediment. Coarse material moves as bedload at low shear stresses (greater than the critical shear stress) and is suspended at sufficiently high shear stresses. Fine material with low settling velocities may go immediately into suspension when the critical shear stress is exceeded. Transport rates for a given silt-or sand-sized material under suspended sediment conditions are much higher than bedload transport rates for the same material, and most shelf transport occurs during relatively infrequent high-energy events associated with large, long-period 
waves and strong currents. Therefore, the calculations made here consider only suspended-sediment transport and disregard bedload transport.

The calculations were made using the characteristics of natural sediment at the candidate disposal sites. Movement of dredged material is discussed but not specifically estimated because of the wide range of material dredged in San Francisco Bay projects and because specific in situ characteristics of dredged material, including critical shear stress and settling velocity, have not been determined. The behavior of naturai material, however, provides significant insight into the likely fate of dredged material at both sites and allows comparison of the two sites.

Details of the boundary layer model calculations and the suspended sediment transport calculations are provided here in Sections C.1 and C.2. Input for the calculations is discussed in Section C.3, and the results are presented in Section C.3 and discussed in Section C.4. References cited are listed in Section C.5.

\section{C.1 WAVE-CURRENT BOUNDARY LAYER MODEL}

The sediment transport calculations were made using a model of the wavecurrent boundary layer developed by Grant and Madsen (1979). The model provides a semi-analytical solution for the near-bottom velocity field resulting from a combination of oscillatory wave motion and steady current. The model assumes that the combined bottom shear stress $\tau_{\mathrm{CW}}$ at the bed is a sum of the mean shear stress $\tau_{\mathrm{C}}$ exerted by the steady current, and the instantaneous shear stress $\tau_{w}$ exerted by wave-induced oscillations. In the absence of ripples, or other large-scale roughness elements, the combined shear stress is the best measure of the tangential force available for sediment resuspension and near-bottom transport.

The Grant-Madsen model assumes that a thin wave-boundary layer is embedded within a thicker mean-flow boundary layer and that turbulent diffusion of momentum within the boundary layers can be parameterized using an eddy viscosity that increases linearly with height above the bed. The model further assumes that wave-induced oscillations can be described with a single orbital velocity amplitude $u_{b}$ and period $T$, that the mean current $u_{r}$ 
measured at height $\mathrm{z}_{r}$ is steady and smaller than the oscillatory orbital velocities, and that the bottom roughness can be characterized using a single length scale $z_{0}$. Larsen et al. (1981) made use of several assumptions to provide a solution to the momentum equations that is easier to implement and computationally more efficient than the Grant and Madsen (1979) solution. Solution of the momentum equations using the approach described in Larsen et al. (1981) results in a two-part logarithmic mean velocity profile $u(z)$ :

$$
\begin{aligned}
& u(z)=\frac{u_{*_{C}}}{k} \ln \frac{z}{z_{o C}} \quad z \geq \delta_{w} \\
& u(z)=\frac{u_{\star c}}{k} \frac{u_{\star c}}{u_{\star c} w} \text { in } \frac{z}{z_{0}} \quad z \leq \delta_{w}
\end{aligned}
$$

where $u_{\star_{c}}=\tau_{c} / \rho=\begin{aligned} & \text { shear velocity for the mean flow above } \\ & \text { the wave-boundary layer }\end{aligned}$

$$
\begin{aligned}
& \text { * }=0.4=\text { von Karman's (dimensionless) constant } \\
& z=\text { height above the bed } \\
& z_{O C}=\quad \text { apparent roughness length for the mean flow } \\
& \text { above the wave-boundary layer } \\
& \delta_{w}=u_{\star_{C W}} / w=\text { thickness of the wave-boundary layer, } \\
& \text { where the wave angular frequency } \\
& \omega=2 \pi / \mathrm{T} \\
& u_{* C W}=\tau_{C W} / \rho=\begin{array}{l}
\text { shear velocity for the maximum } \\
\text { instantaneous combined flow in the wave- }
\end{array} \\
& \text { boundary layer } \\
& z_{0}=\quad \text { roughness length inside the wave-boundary } \\
& \text { layer. }
\end{aligned}
$$

A representative velocity profile, calculated using Equations (C.1) and (C.2), is shown in Figure C.1a. In the limiting case when waves are absent, the solution is replaced by a single logarithmic profile: 


$$
u(z)=\frac{{ }^{u_{\star} C}}{\pi} \ln \frac{z}{z_{0}}
$$

Model predictions of bottom shear stress for a range of orbital velocities and several mean current speeds using the Larsen et al. (1981) solution have been compared with the solution of Grant and Madsen (1979) as computed by Glenn (1983; Glenn and Grant 1987) for the case of neutral stratification, fixed bottom roughness, and coincident current and wave directions (Figure C.2). The importance of enhanced bottom shear stress when waves are present is evident in both solution methods. The Larsen et al. method results in slightly higher shear stress predictions (Figure C.2), but both values are within the range of uncertainty in field measurements made to test wave-current boundary layer flow calculations (Dyer and Soulsby 1988; Grant, Willians, and Glen 1984).

Several researchers, including Glenn and Grant (1987), Kachel and Sinith (1989), and Lyne, Butman, and Grant (in press) have presented more complex wave-current boundary layer formulations. Glenn and Grant (1987) include a correction for stratification effects caused by suspended sediment and a formulation for movable bed roughness originally presented by Grant and Madsen (1982). Many of the refinements produce only small changes in predicted shear stresses, and some have not been verified with field measurements. Inclusion of bedform (e.g., ripple) roughness typically results in higher predicted bottom shear stresses for specified current and wave conditions. However, when bedforms are present, only a fraction (one-half to two-thirds) of the higher shear stress is the skin-friction component responsible for causing sediment transport. The larger portion of the higher bottom shear stress is associated with form drag on the bedforms. Therefore, if bedform effects are included in the calculation of bottom shear stress, a second calculation is required to extract the relevant skin friction component before making sediment transport calculations. Smith and McLean (1977b), among others, have suggested methods for partitioning the total 
bottom shear stress into skin friction and form drag components, but none of these formulations have been confirmed with laboratory or field measurements.

In the calculations presented here, a flat bed has been assumed, and bed roughness $z_{0}$ is characterized as a sum of the Nikuradse roughness $z_{0 N}$ and the effective roughness caused by sediment transport $z_{0}$. The sediment transport roughness is calculated according to the Wiberg-Smith formulation (Wiberg and Rubin 1989):

$$
z_{o S}=a \frac{a_{1} \cdot 0 \cdot \tau_{\star}}{\left(1+a_{2} \cdot \tau_{\star}\right)}
$$

where $\boldsymbol{\alpha}=0.056$

$a_{1}=0.68$

$\tau_{\star}=\frac{\rho u_{\star}^{2} \mathrm{CW}}{\tau_{\text {crit }}}$

$0=$ grain diameter

$a_{2}=0.0204(\ln 0)^{2}+0.220(\ln 0)+0.0709$.

The Nikuradse roughness $Z_{\text {oN }}$ depends only on grain height $k_{s}$ (usually taken as the grain diameter, D) in fully turbulent flow, but has a functional dependence on the roughness Reynold's Number Re* $=u^{*} \mathrm{Cw}^{*} \cdot \mathrm{k}_{\mathrm{s}} / v$ (where $v$ is the kinematic viscosity of the fluid), in hydraulically smooth or transitional flow (Figure C.3). The grain diameter of the coarsest-size class was used for $k_{s}$ in the $Z_{O N} c a l c u l a t i o n s$, and a kinematic viscosity of $0.0126 \mathrm{~cm} \cdot \mathrm{s}-1$ was used in all calculations.

When several size classes are in transport, the sediment transport roughness is a weighted sum of the individual contribution from each class:

$$
z_{0 S}=\sum_{i=1}^{9} z_{0 S_{i}} f r_{i}
$$


where $n$ is the number of size fractions in transport, and $f r i$ is the $i$ th fractional total of bed sediments.

\section{C.2 SUSPENDED-SEDIMENT CALCULATIONS}

Suspended-sediment calculations were made using the combined bottomshear velocities $\left(u{ }^{*} \mathrm{Cw}\right)$ determined from the wave-current boundary layer modeT. The suspended-sediment equation for steady flow is based on the balance between downward particle settling velocity and upward diffusion:

$$
\frac{\partial C_{s}}{\partial t}=\frac{\partial}{\partial z}\left[\left(w_{s} c_{s}\left(1-c_{s}\right)\right)+k_{s} \frac{\partial C_{s}}{\partial z}\right]
$$

where $C_{S}$ is the volume concentration of sediment in the water, $K_{S}$ is the eddy diffusivity for sediment (assumed equal to the eddy viscosity for diffusion of momentum), and $w_{s}$ is the settling velocity of the sediment.

When the sediment concentration is sma11 and steady, Equation (C.6) is simplified to the Rouse (1937) equation:

$$
-w_{s} C_{s}=k_{s} \frac{\partial C_{s}}{\partial z}
$$

and sediment concentration at any level $z$ above the reference level, assumed to equal the roughness length $z_{0}$, can be determined by integration of Equation (C.7) over $z$. When $w_{s}$ is constant, and a two-part linear eddy viscosity profile consistent with the Grant-Madsen model is used, concentration $C(z)$ at elevation $z$ above the bottom is given in terms of a reference concentration $c_{0}$ as:

$$
c(z)_{i}=c_{o_{j}}\left(\frac{z}{z_{0}}\right)^{-w_{s} / \kappa u_{\star} C w} \quad z \leq \delta_{w}
$$




$$
c(z)_{i}=c_{w_{i}} \cdot\left(\frac{z}{\delta_{w}}\right)^{-w_{s} / k u_{\star} c} \quad z \geq \delta_{w}
$$

where $C_{O_{i}}$ is the a reference concentration of size class $i$ at $z=z_{0}$, and $c_{\delta} \delta_{w}$. the concentration of sediment size class $i$ at the top of the waveboundary layer.

The reference concentration for the $i$ th $c l a s s$ is determined according to the formulation of Smith and McLean (1977a):

$$
c_{o_{i}}=\frac{C_{b_{i}} \gamma_{0} S_{i}}{1-\gamma_{0} S_{i}}
$$

where $\quad S_{i}=\frac{\tau_{\mathrm{CW}}-\tau_{\text {crit }_{i}}}{\tau_{\text {crit }}}$

In Equations (C.IO) and (C.11), $S_{i}$ is the shear stress in excess of the critical shear stress $\tau_{\text {crit }}$ required to initiate movement of the sediment in size class $i$. The value of the coefficient $\gamma_{0}$ is determined empiricaliy, and a large range of vaiues has been proposed (Hill et al. 1988; Drake and Cacchione 1989). Estimates of suspended-sediment concentration vary directly with $\gamma_{0}$ whenever the critical shear stress is exceeded. The selection of $\gamma_{0}$ in this study is discussed below in Section C.4.

In these calculations, four sediment sizes were considered; the total suspended-sediment concentration profile is the sum of the individual profiles:

$$
c(z)=\sum_{i=1}^{n} c(z)_{i}
$$


where $C(z)_{i}$ is the concentration of the $i^{\text {th }}$ sediment size, and $n$ is 4 or the number of size classes.

The relative proportion of each size class in the bed material is specified in terms of the bed concentration $\mathrm{Cb}_{b}$, and the relative proportions in the suspended sediment profile are controlled by values of bed concentration and excess shear stress for each size class. A suspended-sediment profile for conditions of large excess shear stress is shown in Figure C.2b.

The suspended-sediment flux profile $I(z)$ is the product of the concentration and the current velocity at each elevation $z$. Total sediment flux is found by integration from the level of zero velocity $z_{0}$ to the top of the suspended-sediment profile:

$$
I=\int_{0}^{z} \max c(z) u(z) d z
$$

The upper limit for integration of Equation (C.13) ( $z_{\max }$ ) was set at $10 \mathrm{~m}$ because 1) sediment was seldom suspended above this level, 2) extrapolation of the near-bed current profile above this level is probably unjustified, and 3) it is reasonable to suspect that salinity- or temperature-induced stratification frequently reduces mixing at some elevation above the bed. A sediment flux profile during high-concentration conditions is shown in Figure C.2c.

\section{C.3 INPUT FOR SEDIMENT-TRANSPORT CALCULATIONS}

The sediment-transport calculations are driven by values for current velocity $u_{r}$ at reference level $\mathrm{zr}_{r}$, near-bottom wave-orbital velocity amplitude $u b$, and wave period $T$.

\section{C.3.1 Currents}

Current velocities were obtained from the near-bottom instrument at both sites. The $15-m i n$ measurements were rotated into alongshore $\left(328^{\circ} \mathrm{T}\right)$ and cross-sheif components, smoothed with a 3-h low-pass filter (described in 
Section B.3.2 of Appendix B, Volume 2), and decimated to obtain hourly values. Time series of the current alongshore $(v)$ and cross-shelf $(u)$ components used as model input at Sites $B 1 B$ and $1 M$ are shown in Figures $C .4 a$ and $\mathrm{C} .4 \mathrm{~b}$, respectively. No current velocity data were recorded at Site B1B during the fourth deployment, so model runs were not performed for Site B1B for this period.

\section{C.3.2 Waves}

Near-bottom wave-orbital velocities were not measured during the first three deployments and, because of the instrument failure at Site B1B during the fourth deployment, no direct measurements are available. Wave-orbital velocities were instead estimated from surface-wave spectra recorded by the CDIP at the Montara pressure-gage array. The Montara array is located inshore and southeast of both sites on the 15-m depth contour. The CDIP distributes digital surface-wave spectra detemined from the pressure data (Seymour, Sessions, and Castel 1985). Wave data for the period April 1, 1988, to May 30, 1989, were obtained for the model calculations. The surface-wave spectra are reported as wave energy densities ( $\mathrm{a}^{2}$, units of $\mathrm{cm}^{2}$ ) in nine frequency bands every 3 to $6 \mathrm{~h}$. The sum over all nine bands is equal to the variance of the sea surface elevation $\sigma^{2}$ :

$$
\sigma^{2}=\sum_{i=1}^{9} a_{i}^{2}
$$

and the significant wave height $H_{S}$ is determined as:

$$
H_{S}=2 a_{S}=4 \sigma
$$

The period $T$ associated with the significant wave height is determined from the mid-point of the frequency band containing the highest energy density.

Sediment-transport calculations require an estimate of the characteristic, near-bottom wave-orbital velocity amplitude from the surface wave spectrum. Near-bottom wave-orbital velocities associated with a monochromatic surface wave of period $T$ and amplitude a can be accurately calculated using linear wave theory. However, when a broad surface-wave spectrum 
exists, use of the significant wave height $H_{5}$ and surface-wave period $T$ can underestimate the near-bottom wave-orbital velocity because wave motions are attenuated with depth. For example, virtually no surface-wave motions with periods less than $8 \mathrm{~s}$ will affect the bottom at Site B1B (86 m). When the surface-wave spectrum is the result of combined swell (e.g., period of $12 \mathrm{~s}$ ) and higher local wind-waves (period of $6 \mathrm{~s}$ ), use of the 6 -s surface-wave period will neglect the orbital velocities associated with the swell. To provide more meaningful estimates of the near-bottom wave-orbital velocities for sediment-transport calculations at both sites, the surface wave spectrum was used to calculate a spectrum of near-bottom orbital-velocity amplitudes, as shown schematically in Figure C.5. Linear wave theory was used to convert the surface-elevation amplitude $a_{j}$ in each of the $j$ frequency bands to orbital-velocity amplitudes ub:

$$
u_{b_{i}}=\frac{2 \pi}{T} \frac{a_{i}}{\sinh (k h)}
$$

where $k=2 \pi / \lambda$ is the wavenumber, $\lambda$ is the wavelength, and $h$ is the water depth, and the wavenumber is related to water depth by the dispersion relationship:

$$
\omega^{2}=k h \tanh (k h)
$$

A "significant orbital-velocity amplitude" was determined as $2 \sigma_{u}$, where $\sigma_{u}$ is the variance of the orbital-velocity spectrum:

$$
\sigma \underbrace{2}=\sum_{i=1}^{9} u_{b_{i}} 2
$$

Period $T_{d}$ was determined from the dominant frequency band in the orbitalvelocity spectrum. The resulting orbital velocities are slightly higher and show less variation than those based on significant wave height. The 
corresponding periods are, however, longer and probably more representative of motions near the bottom. The distributions of orbital velocities and periods calculated using both approaches are compared in Table C.1.

A time series of hourly, near-bottom orbital velocities and periods was determined from the COIP spectra. The time series of near-bottom orbital velocities and associated periods are shown in Figures $c .4 c$ and $c .4 d$, and joint probability distributions for orbital-velocity amplitude and period are shown in Tables C.2 and C.3.

\section{C.3.3 Bottom-Sediment Parameters}

Bottom-sediment parameters used in the calculations assumed natural, noncohesive sediments with density of quartz $\left(2.65 \mathrm{~g} \cdot \mathrm{cm}^{-3}\right)$ and bed volume concentration $C_{b}$ of $0.65 \mathrm{~cm}^{3} \cdot \mathrm{cm}^{-3}$. The grain-size distributions of bottom sediment were determined from grab samples taken at both sites. Standard sieve and hydrometer methods were used in the size analysis, and the average results from several replicates are presented in Figure C.6. Settling velocities were estimated for each size class from empirical curves and formulae presented by Madsen and Grant (1976) and Dietrich (1982). The critical shear stress $\tau_{\text {crit }}$ for erosion of each size class was detemined using the nondimensional Shields curve presented by Smith (1977). Greater errors are likely in values for settling velocity and critical shear stress in finer grain-size classes. The sensitivity of calculations and subsequent interpretations to these errors is discussed below in Section C.4. Values for bottom-sediment parameters used in the sediment-transport calculations are summarized in Table C.4.

\section{4 RESULTS AND DISCUSSION \\ C. 4.1 Sensitivity}

Sensitivity analysis was conducted empirically by adjusting values of individual parameters and noting changes in the calculated results. Parameters that were systematically altered include

- bottom roughness coefficient $z_{0}$

- sediment transport coefficient $\gamma_{0}$ 
- critical shear stress $T_{\text {crit }}$

- wave-orbital velocity calculation scheme.

Parameters tested are listed Table C.5. The following discussion of sensitivity combines results from these calculation runs, analytical relationships inherent in the formulae, and field observations of researchers to provide insight regarding the factors that influence the calculated results.

\section{Wave-Current Combined Shear Stress}

Combined shear stress $\tau_{\mathrm{CW}}$ is the most important single quantity derived in the sediment-transport calculations. Combined shear stress is controlled by input values for mean currents, wave-orbital velocity amplitude, wave period, and bottom roughness. In general, combined shear stress increases with increased mean current, increased orbital velocity, and increased bottom roughness. Of these, bottom roughness is the most difficult to precisely determine. The influence of mean current velocity and orbital velocity is shown in Figure C.1; these physical quantities dominate $\tau_{\mathrm{CW}}$, confirming the combined importance of waves and currents in sediment resuspension.

The influence of bottom roughness on $\tau_{C W}$ is important because of the uncertainty in the value of $z_{0}$. The wave-current boundary layer model indicates that, for given current and wave-orbital velocities, increases in the bottom roughness will result in higher estimates of $\tau_{\mathrm{CW}}$. This tends to shift all of the curves plotted in Figure C.1 upward. Calculations made with a range of prescribed bottom roughnesses confirmed this tendency: mean $\tau_{C W}$ increased by a factor of two to three as $z_{0}$ was increased by four orders of magnitude. The effect of varying $z_{0}$ is shown in curves (1) and (2) in Figures C.7 and C.8.

Current velocities at both sites are seldom high enough to cause resuspension in the absence of wave activity. At Site B1B, currents exceeded $20 \mathrm{~cm} \cdot \mathrm{s}^{-1}$ less than $6 \%$ of the time in the winter storm season (Figure C.4), and velocities at Site $1 M$ are comparable. Very low correlation exists between current speed and calculated (or measured) sediment concentrations. In contrast, measures of wave energy (such as orbital-velocity amplitude) are well correlated with calculated sediment concentrations and, to a lesser 
degree, are correlated with sediment concentrations measured with the optical backscatter (OBS) sensors. This correlation indicates that most resuspension at Sites $B 1 B$ and $I M$ is caused by wave activity.

\section{Frequency of Resuspension and Transport}

Sediment is resuspended whenever the combined bottom shear stress $\tau_{\mathrm{CW}}$ exceeds the critical value $\tau_{c r i t}$ for each size class. (This relationship can also be expressed in more convenient units using shear velocity $4 * \mathrm{CW}$ and critical shear velocity $u^{\star}$ crit). The frequency of resuspension can be estimated from cumulative distributions of $u^{*} \mathrm{cw}$, such as those shown in Figures C.7 and C.8, using an appropriate value of $u * c r i t$ for the material in question. If $u \star c r i t$ exceeds the maximum value of $u \star c w$, the material will not move. The curves in Figures $C .7$ indicate that material with $u \star_{c r i t}=$ $1.0 \mathrm{~cm} \cdot \mathrm{s}^{-1}$ (e.g., mobile, very fine sand) will move less than $15 \%$ of the time at Site B1B.

Accurate determination of $\tau_{\text {crit }}$ is difficult, and uncertainty in $\tau_{\mathrm{crit}}$ is an important source of error in determining the excess shear stress $\left[\left(\tau_{\mathrm{CW}^{-}}\right.\right.$ $\left.\left.\tau_{\text {crit }}\right) / \tau_{\text {crit }}\right]$. Estimates of $\tau_{\text {crit }}$ derived from the Shields curve presented by Smith (1977) are applicable only for noncohesive sediment with sizes ranging from coarse silt to coarse sand, and even in this size range, there is significant scatter in the empirical data used to generate the curve. It is much more difficult to estimate $\tau_{c r i t}$ for cohesive or very fine material. The calculations of $u^{*} \mathrm{CW}$ are not particularly sensitive to errors in $\tau_{\mathrm{crit}}$ and enter only through the sediment transport roughness term, zoS. Errors in estimates of $\tau_{\text {crit }}$ will, however, directly affect calculations of excess shear stress and reference concentrations, and will have an effect on the predicted suspended sediment concentration, as discussed below.

Suspended Sediment Concentration

The concentration profile for suspended sediment [Equations (C.8) and (C.9)] primarily depends on the reference concentration and on the ratio of settling velocity to friction velocity $-w s / \kappa u \star_{c}$ (or $-w s / \kappa u{ }^{*} \mathrm{cw}$ in the waveboundary layer). This ratio determines the concentration gradient in the water column: when it is low, concentrations vary only slightly with height above the bed; when it is high, there is a sharp concentration gradient.

$$
\text { C. } 13
$$


Examples of these profile shapes are shown in Figure C.1b, where they are caused by differences in settling velocity among the various size classes. Concentrations in the entire profile are scaled by the reference concentration, which is controlled by excess shear stress and a coefficient ro [Equations (C.10) and (C.11)]. Uncertainty in excess shear stress arises from uncertainty in $\tau_{\mathrm{CW}}$ and $\tau_{\mathrm{crit}}$, discussed above. Variations in bed concentration $C_{b}$ also affect reference concentration, but the range of $C_{b}$ is small compared to the large range of $\gamma_{0}$ values that have been suggested in the literature. A value of $\gamma_{0}=0.002$ used by Glenn (1983; Glenn and Grant 1987) provided fair agreement with the sediment concentrations estimated using the OBS sensors, and because calculated concentrations and fluxes vary linearly with $\gamma_{0}$, no further adjustments were made. Because of uncertainty in both the OBS estimates and the value of $\gamma_{0}$, a large uncertainty (at least a factor of five) exists in the sediment concentration estimates.

\section{Sediment-Transport Rate}

The transport rate depends on the velocity profile and the suspended sediment profile. Roughness length $z_{0}$ has a small influence on both profiles, but the measured current velocities at the reference height largely determine the velocity profile. Because the errors in current measurements are small (see specifications in Volume 2, Appendix B), the uncertainty in flux rates is due to uncertainty in calculated suspended sediment concentrations, assumptions in the boundary layer model, and the timing of resuspension events. The magnitude of transport is the least dependable value calculated because it depends on virtually all of the forcing functions and parameters, and may be in error by a factor of 10 .

\section{Oirection of Sediment Transport}

In the wave-current boundary layer calculation, no correction for angle between currents and waves was made because the wave data were not directional, and the direction of sediment transport was determined from the hourly current direction. Neglecting the angle between wave-orbital velocities and the current can result in a slight over-prediction of the combined bottom shear stress and errors of up to $15^{\circ}$ in direction of the wave-averaged mean stress (Grant and Madsen 1979). The direction of botton stress is most 
important for bedload transport and, because bedload transport is not included in these calculations, the assumption of coincident waves and currents effectively results in a conservatively high calculation of bottom shear stress. It is unlikely that significant error is introduced through this assumption.

A more important influence on the direction of transport is the timing of resuspension events with respect to current direction or, equivalently, the timing of excess shear stresses $\left(\tau_{\mathrm{CW}}>\tau_{\mathrm{Crit}}\right)$. The uncertainty in predicting this timing arises from uncertainty in $\tau_{\mathrm{CW}}$ and, mostly, $\tau_{\mathrm{crit}}$, as discussed above. To determine the influence of various $\tau_{c r i t}$ values on the predicted direction of transport, progressive vector diagrams were made for current velocities when $\tau_{\mathrm{CW}}$ was greater than $\tau_{\mathrm{Crit}}$. Examples are shown in Figures C.9 and C.10. These plots indicate the cumulative movement of water during the periods when material with critical shear stresses of $0.8,1.2$, and 1.7 dynes $\cdot \mathrm{cm}^{-2}$ is in suspension. They indicate that sediment that is difficult to erode (higher $\tau_{\text {crit }}$ ) moves in generally the same direction as sediment that is easy to erode (lower $\tau_{c r i t}$ ). These diagrams should not be interpreted as the particle transport paths, because currents more than a short distance from the mooring locations will be different. They do confirm that the timing of resuspension for materials (over a moderate range of $\tau_{\mathrm{crit}}$ values) does not differ sufficiently to cause large changes in net transport direction.

The bottom roughness parameter $z_{0}$ can also influence direction of sediment transport. The value $z_{0}$ has a direct, but small, influence on the amount of sediment in suspension when $\tau_{\mathrm{CW}}$ exceeds $\tau_{\mathrm{crit}}$ [through Equations (C.8) and (C.9)] but, more importantly, the value of $z_{0}$ influences $\tau_{C W}$ and, therefore, the estimated frequency with which $\tau_{\mathrm{CW}}$ exceeds $\tau_{\mathrm{Crit}}$. Increasing $z_{0}$ tends to increase the estimated time (measured in hours) that sediment is in transport. Because the currents continually shift direction, the direction of net transport may be changed by changing the timing of resuspension events. For this reason, the direction of net transport can be influenced by the choice of $z_{0}$. However, test calculations made using several fixed- and variable-roughness formulations resulted in similar net 
transport directions, implying that bottom roughness does not have an important influence on direction of sediment transport.

\section{C.4.2 Calculated Sediment Transport}

The spectral estimation procedure for calculating wave-orbital velocities, discussed in Section C.3.2, was used in the final calculations. Values selected for the coefficients are $z_{0}=z_{O N}+z_{O} S$, as discussed in Section C.1; $\gamma_{0}=0.002 ;$ and sediment parameters (including $\tau_{c r i t}$ ) as listed in Table C.4.

\section{Bottom Shear Velocity}

The most important calculated result is a time series of bottom shear velocity $u{ }^{\star} \mathrm{CW}=\left(\tau_{\mathrm{CW}} / \rho\right) \frac{1}{1}$. As discussed above (Section $\left.\mathrm{C.4.1}\right)$, combined bot tom shear stress $\tau_{\mathrm{CW}}$, produced by waves and currents, is the primary agent in sediment resuspension. Plots of calculated shear velocity (Figures C.11a and $c$ ) essentially summarize the forces controlling sediment resuspension. Whenever the shear velocity exceeds the critical value for the bottom sediment, avajlable sediment will be resuspended. 0ccurrence of resuspension events can be identified as points in the time series when the calculated shear velocity is greater than the critical shear velocity. For example, the calculations suggest that sediment with a critical shear velocity of $2.0 \mathrm{~cm} \cdot \mathrm{s}^{-1}$ moved only during two events in December at Site B1B, and reference to curve (3) in Figure $C .7$ confirms that $u^{\star} \mathrm{Cw}$ less than $2.0 \mathrm{~cm} \cdot \mathrm{s}^{-1}$ for more than $99 \%$ of the time.

There is a good visual correlation between the calculated time series of $u{ }^{*} \mathrm{CW}$ values (Figures $\mathrm{C.11}$ and $\mathrm{C.12}$ ) and time series of wave-orbital velocities used as input for the calculations (Figures $c .4 \mathrm{c}$ and $d$ ). Much less correlation is observed between $u^{\star} \mathrm{CW}$ and the time series of near-bottom current speed used as input (Figures $C .4$ and C.5). This confirms that waves were responsible for most of the bottom shear stress during the study period. Calculated $u^{\star} \mathrm{Cw}$ varies seasonally and is generally lower during the summer months and higher in the winter. Calculated $u \star c w$ values are significantly higher at Site $1 M$ (compare Figures C.11a and $C$ and Figures C.7 and C.8). Mean shear velocity at Site $1 M$ was $1.2 \mathrm{~cm} \cdot \mathrm{s}^{-1}$ and at $S$ ite $B 1 B$ was $0.7 \mathrm{~cm} \cdot \mathrm{s}^{-1}$. The higher shear velocities at Site $1 \mathrm{M}$ are caused by the shallower depth,

$$
\text { C.16 }
$$


which allows shorter period waves to reach the bottom and results in higher wave-orbital velocity amplitudes at all wave periods.

\section{Suspended Sediment Concentrations}

Time series of suspended sediment concentrations calculated for Sites $B 1 B$ and $1 M$ are shown in Figures $C .11 b$ and $C$. Sediment concentration is estimated at $36 \mathrm{~cm}$ above the bed, corresponding to the elevation of the OBS sensors. Sediment concentrations are closely correlated with the shear velocity in excess of $1 \mathrm{~cm} \cdot \mathrm{s}^{-1}$ because the calculations assumed critical shear velocities near $1 \mathrm{~cm} \cdot \mathrm{s}^{-1}$ for most of the sediment size classes at both sites (Table C.4). Calculated sediment concentrations, therefore, also are well correlated with the time series of wave-orbital velocities used as input in the calculations, re-emphasizing the importance of waves in causing sediment resuspension. The suspended sediment concentration time series is composed of numerous short-duration events. The events have time scales equal to those of the shortest meteorological time scales; virtually all resuspension events last less than 4 days, and many occur over a few hours when waves and, for example, peak tidal currents combine to produce sufficient shear velocities for resuspension.

There were several resuspension events associated with high-current events when wave-orbital velocities were Iow. For example, at Site 1M, large current speeds were recorded near the beginning of the second deployment (days 162 to 180, Figure C.4b) at the end of the study (days 134 and 151; Figure C.4b). Examination of Figure C.11d, however, shows that the suspended sediment concentrations calculated during these events were small compared to wave-induced resuspension in November and 0ecember.

Suspended sediment concentrations are, overall, about 20 times higher at Site $1 M$ than at Site BIB. This is primarily a result of the higher shear velocities calculated for Site $1 M$, but the finer sediment size distribution at Site $1 \mathrm{M}$ also produces a slight increase in calculated concentrations. The cumulative amounts of material suspended during the calculated period are shown for the two sites in Figure C.12. These cumulative amounts have been converted into sediment depth using the bed concentration $C_{b}$. While these 
plots are valuable for comparison among the candidate sites, they do provide a misleading indication of net erosion depth because the calculations neglect deposition.

\section{Suspended Sediment Flux}

Suspended sediment flux was calculated up to $10 \mathrm{~m}$ above the bottom. The direction of calculated sediment flux, therefore, corresponds exactly with the direction of the hourly current, but the rate of sediment flux depends on current speed and the sediment concentration. Thus, the mean transport direction can differ markedly from the mean current direction, depending on the timing of resuspension events relative to the currents.

The calculated alongshore and cross-shelf components of sediment flux at Sites $B 1 B$ and $1 M$ are plotted in Figures C.13 and C.14. Cumulative fluxes, also shown in Figures $\mathrm{C} .13$ and $\mathrm{C} .14$, provide an indication of the net transport over the calculation period. Most resuspension events are oscillatory and a preferred flux direction is often difficult to ascertain from the flux plots, indicating that sediment is resuspended for several tidal cycles and is advected with tidal currents during the period of resuspension. For example, calculated fluxes during a winter transport event at Site B1B are apparent in Figure C.13 beginning on about day 330. The alongshore direction varied from northward (positive) to southward (negative) at rates up to \pm $2 \mathrm{~g} \cdot \mathrm{cm}^{-1} \cdot \mathrm{s}^{-1}$. Net alongshore transport during the event can be determined by the cumulative fluxes shown in Figures $C .13 \mathrm{c}$ and $d_{i}$ in this case, net transport was southward and amounted to about $1 \mathrm{~kg} \cdot \mathrm{m}^{-1}$ over the course of the event.

Calculated flux rates assocjated with individual events were 10 to 20 times higher at Site $1 M$ than rates during the same events at Site B1B. The current speed at Site $1 M$ is not significantly greater; the higher flux rates are associated with generally higher suspended sediment concentrations.

Calculated net sediment transport at Site B1B was southward at $2.5 \mathrm{~kg} \mathrm{~m}-1$ and offshore at nearly $3.0 \mathrm{~kg} \mathrm{~m}^{-1}$, but virtually all of the alongshore transport can be accounted for by one event in Aprit 1988 (near day 110). Although calculated flux rates were highest during the winter resuspension events, they resulted in very little net alongshore transport. 
Net alongshore transport to the north would have resulted if any of the larger southward-transport events had not occurred, but southward alongshore transport might have been higher if a longer current-meter record allowed calculations during late winter and spring 1989. Because the calculated net alongshore transport depends so heavily on individual events, it could easily change in a different year. In contrast, however, offshore transport occurred consistently during each resuspension event and probably represents a long-term trend with greater certainty.

The cumulative transport curve calculated for Site $1 M$ has a shape similar to that of Site B1B. A spring resuspension event associated with a strong southward current (Figure C.14) caused initial southward and onshore transport. Winter events through early January produced little net alongshore transport and caused additional offshore transport. A calculated resuspension event in late March 1989 (beginning about day 452) caused additional southward transport, but only slight alongshore transport. Two final events associated with anomalous current speeds produced additional southward, offshore transport. Calculated net sediment transport at Site 1M was southward at $76 \mathrm{~kg} \mathrm{~m}^{-1}$ and offshore at about $30 \mathrm{~kg} \mathrm{~m}^{-1}$. The strong currents measured at the beginning of the second deployment (day 162, Figure $c: 14)$ and near the end of the study period are anomalous, but their effect on the calculated net transports is smali.

\section{C.4.3 Comparison With Optical Backscatterance Oata}

Suspended sediment concentrations were estimated using OBS sensors mounted $36 \mathrm{~cm}$ above the bottom. Previous experiments with these instruments deployed in San Francisco Bay (Sternberg et al. 1986), on the California continental shelf (Sherwood and Sternberg 1989), and in the nearshore zone (Downing 1983) have successfully measured wave-induced resuspension of silt and sand. Processing of the OBS data is described in Volume 2, Appendix B (Section B.4.5). Several key assumptions were made during the processing of the OBS records that may affect data interpretation. The assumptions are listed below.

- The offset of the OBS voltage response drifts slowly over periods longer than 5 days because of changes in background water clarity and biofouling of the optical sensor. 
- The gain of the sensor response to rapid changes (periods less than 5 days) in water clarity does not vary over the deployment period.

- The gain and the offset are uncorrelated and the gain can be used to detemine changes in sediment concentration after background drift of the offset is removed.

These assumptions were required to justify extensive "massaging" of the OBS data. Fairly arbitrary procedures were used to remove spikes and offsets in the data, and confidence in resultant suspended sediment estimates is low.

Time series of the sediment concentrations estimated from the OBS data are shown in Figure C.15. At Site B1B, the general trends in OBS estimates of suspended sediment show reasonable visual correlation with wave-orbital velocity and calculated values (although the calculated suspended sediment estimates are a factor of 5 lower). At Site $1 M$, there is very little correlation between $0 B S$ estimates and calculated sediment concentrations.

The apparently noisy OBS signal does not appear to be the result of instrument or data logger problems. Kinetics Laboratories, Inc. (KLI) has deployed identical systems in other environments with satisfactory results, and the instruments performed well in laboratory calibrations. (a) Some corroborative evidence exists to suggest that the sensor at Site B1B was measuring suspended sediment: when the primary mooring was released but not immediately recovered on September 1, 1988 (day 245), OBS estimates of suspended sediment immediately jumped and remained high until recovery. The primary mooring was, during that period, anchored by the secondary anchor with the OBS mount, and the added buoyancy probably caused that anchor to drag and resuspend sediment.

A number of physical phenomena can be invoked to explain the OBS signals observed in other parts of the record. They include 1) locally enhanced resuspension caused by scour at the base of the bottom mount, 2) intermittent resuspension of sediment by movement of the polypropelene groundline, 3) aliasing of cyclical wave-induced resuspension caused by short-period measurements (20-s average) of longer-period (80 to $200 \mathrm{~s}$ ) wave-group

(a) D. Beard, KLI, Santa Cruz, California, personal communication with C. R. Sherwood, PNL, February 1, 1990. 
phenomena, 4) intermittent passage of clouds of material resuspended by bottom-trawlers operating nearby, or finally 5) biological activity, including growth and predation of biofouling organisms and backscatterance from organisms in the water column near the sensor. None of these explanations is wholly satisfactory, and because the data are not well understood, discussions of sediment transport at Sites $1 M$ and $B 1 B$ will not be based on estimates of suspended sediment obtained with the OBS sensors.

\section{C.5 CONCLUSIONS}

Trends in long-term sediment fluxes calculated for Sites B1B and $1 M$ are summarized in Figure C.16, which shows the principal axes of variation (principal components) in calculated sediment fluxes after filtering with a 40-h low-pass filter (described in Volume 2, Appendix B, Section B.3.2). The vector of the long-term mean is also plotted as an arrow. Note that the scale changes among sites. Also plotted for each site in Figure C.16 are the long-term mean current vectors and the principal axis of the M2 tidal ellipse; these are discussed in Volume 2, Appendix $B$. Note that, because of the malfunction of the current meter near the bottom at Site B1B during the last deployment, data and sediment transport calculations at Site B1B are based on a shorter period.

The principal axis of variation for sediment flux at Site B1B is rotated slightly clockwise $\left(346^{\circ} \mathrm{T}\right)$ relative to the alongshore axis defined in this report $\left(328^{\circ} \mathrm{T}\right)$, and the principal axes are closely aligned with the principal axes of the 40-h low-pass filtered currents from Site B1B. Likewise, the mean sediment flux is closely aligned with the mean current vector: mean sediment flux is southward and slightly offshore $\left(197^{\circ} \mathrm{T}\right)$ at $0.016 \mathrm{~g} \cdot \mathrm{cm}^{-1} \cdot \mathrm{s}^{-1}$. Mean currents for the study period were also southward and offshore $\left(204^{\circ} \mathrm{T}\right)$ at $0.85 \mathrm{~cm} \cdot \mathrm{s}^{-1}$. At Site BlB, calculated direction and variance in sediment transport direction correlates well with direction and variance in the long-term mean flow and low-frequency current variation.

At Site $1 M$, calculated mean sediment flux is southward $\left(170^{\circ}\right)$ with a very slight offshore component. The mean rate is $0.26 \mathrm{~g} \cdot \mathrm{cm}^{-1} \cdot \mathrm{s}-1$, about 15 times higher than the mean rate at Site B1B. The direction of sediment flux 
contrasts with the mean current direction, which was southward with a substantial onshore component $\left(1.12 \mathrm{~cm} \cdot \mathrm{s}^{-1}\right.$ toward $\left.126^{\circ} \mathrm{T}\right)$. The principal axes of variation for the calculated sediment fluxes $\left(341^{\circ} \mathrm{T}\right)$ are rotated clockwise about $43^{\circ}$ degrees relative to those for currents $\left(298^{\circ} \mathrm{T}\right)$. The differences in low-pass filtered currents and sediment fluxes at Site $1 M$ suggest that higher-frequency variations in current speed during times of sediment suspension are responsible for the mean sediment flux. In other words, tidal variations in currents make a larger contribution to the fate of material transported from Site $1 M$ than they do at Site B1B. This is consistent with the larger diurnal tides observed at Site 1M (Volume 2, Appendix B).

The sediment transport calculations performed at Sites B1B and IM are quite detafled and include many of the physical processes known to affect sediment transport.

In summary, the important conclusions from these sediment transport calculations are as follows:

- Resuspension of bottom material is caused primarily by wave action. Currents alone are seldom sufficient to cause resuspension and transport, but isolated incidents of strong currents, which caused sediment transport, were recorded. Strong, near-bottom currents occur more often in the winter storm season, probably because 1) stronger winds are present and 2) the water column is well mixed and wind-driven surface currents are coupled more closely with near-bottom currents.

- Resuspension of sediment occurs much more frequently in fall/winter, when long-period swell from distant storms and shorter-period wind waves from intense local storms both cause higher wave-orbital velocities near the bottom.

- Resuspension occurs more frequently at the shallower Site $1 M$ because 1) energy from shorter-period waves can reach the bottom and 2) more energy from waves of all periods can reach the bottom.

- Because resuspension occurs more frequently, and because more sediment is suspended, transport rates at Site $1 M$ are approximately 15 times higher than transport rates at Site B1B. In addition, because more energy reaches the bottom at Site $1 M$, material will be transported there that would remain immobile at Site BlB.

- Calculated net transport at both sites is southward and offshore. At Site B1B, the mean transport direction corresponds closely with the mean current direction. At Site 1M, calculated mean sediment transport diverges from the mean current direction, which has a substantial 
onshore component. Because the transport calculations at Site 1M are based on a longer record and depend less on individual events, reasonable confidence is associated with the calculated southward direction for net transport. In contrast, less confidence is placed on the calculations made at Site B1B because 1) the period of data for calculations is shorter, 2) the sign of the calculated alongshore component of sediment transport can be changed by omitting key individual transport events, and 3 ) the estimated sediment fluxes (which are not considered highly reliable) derived from the OBS data indicate slight northward alongshore transport. On the other hand, mean southward flow probably occurred during the spring of 1989, and calculations for that period would have probably have increased the estimate of southward sediment flux.

- Finally, there are uncertainties inherent in these sediment transport calculations. Greatest uncertainty is associated with the magnitude of the flux, which may be in error by a factor of 10 . The direction of transport is more certain for the period with current-meter data, especially at Site 1M. Flux directions might differ in another year and only long-term current-meter data can provide an indication of interannual variability. The frequency of resuspension depends strongly on the critical shear stress assumed for bottom material, but can be estimated for other values using the cumulative frequency curves presented in Figures $C .7$ and $C .8$. Frequency of resuspension also depends on the wave climate and again might vary from year to year. Some wave data from other years suggest that wave energy was somewhat lower than normal during the study period and that resuspension would occur more frequently in other years. The greatest confidence is placed in comparisons between the two sites. Unless the Montara wave data provide a very poor representation of conditions at one of the two sites, it is apparent from these calculations that material will disperse more rapidly from Site $1 M$ than from Site BlB.

\section{C.6 REFERENCES}

Dietrich, W. E. 1982. "Settling Velocity of Natural Particles." Water Resources Research 18:1615-1626.

Downing, J. P. 1983. "An Optical Instrument for Monitoring Suspended Particles in Ocean and Laboratory." In Proceedings of OCEANS ' 83 , pp. 199-202, Institute of Electronic and Electrical Engineers and Marine Technology Society, San Francisco.

Drake, D. E., and D. A. Cacchione. 1989. "Estimates of the Suspended Sediment Reference Concentration $\left(C_{a}\right)$ and Resuspension Coefficient $\left(\gamma_{0}\right)$ from Near-Bottom Observations on the California Shelf." Continental Shelf Research 9(1):51-64.

Dyer, K. R., and R. L. Soulsby. 1988. "Sand Transport on the Continental Shelf." Annual Review of Fluid Mechanics 20:295-324. 
Glenn, S. M. 1983. A Continental Shelf Bottom Boundary Layer Model: The Effects of Waves, Currents, and a Moveable Bed. ScD. Thes is, WHOI-83-6, Massachusetts Institute of Technology/Woods Hole Oceanographic Institution, Cambridge, Massachusetts.

Glenn, S. M., and W. D. Grant. 1987. "A Suspended Sediment Stratification Correction for Combined Wave and Current Flows." Journal of Geophysical Research 92(C8):8244-8264.

Grant, W. D., and 0. S. Madsen. 1979. "Combined Wave and Current Interaction With a Rough Bottom." Journal of Geophysical Research 84(C4):1797-1808.

Grant, W. D., and 0. S. Madsen. 1982. "Movable Bed Roughness in Unsteady Oscillatory Flow." Journal of Geophysical Research $87(\mathrm{Cl}): 469-481$.

Grant, W. D., A. J. Williams III, and S. M. Glenn. 1984. "Bottom Stress Estimates and Their Prediction on the Northern California Continental Shelf During CODE-1: The Importance of Wave-Current Interaction." Journal of Physical Oceanography 14(3):506-527.

Hill, P. S., A. R. M. Nowel1, and P. A. Jumars. 1988. "Flume Evaluation of the Relationship Between Suspended Sediment Concentration and Excess Boundary Shear Stress." Journal of Geophysical Research 93(C10):12,499-12,509.

Kache I, N. B., and J. D. Smith. 1989. "Sediment Transport and Deposition on the Washington Continental Shelf." In Coastal Oceanography of Washington and Oregon, p. 287-348. Landry, M. R. and B. M. Hickey, eds., Elsevier, Amsterdam.

Larsen, L. H., R. W. Sternberg, N. C. Shi, M. A. H. Marsden, and L. Thomas. 1981. "Field Investigations of the Threshold of Grain Motion by Ocean Waves and Currents." Marine Geology $42: 105-132$.

Lyne, V. D., B. Butman, and W. D. Grant. (in press) "Sediment Movement Along the U.S. East Coast Continental Shelf, Part 2: Modelling Suspended Sediment Concentration and Transport During Storms." Continental Shelf Research.

Madsen, 0. S., and W. D. Grant. 1976. Sediment Transport in the Coastal Environment. Report No. 209, Ralph M. Parsons Laboratory, Massachusetts Institute of Technology, Cambridge, Massachusetts.

Rouse, H. 1937. "Modern Conceptions of the Mechanics of Fluid Turbulence." Iransactions of the American Society of Civil Engineering 102:463-543.

Seymour, R. J., M. H. Sessions, and D. Castel. 1985. "Automated Remote Recording and Analys is of Coastal Data." Journal of Waterway, Port, Coastal, and Ocean Engineering $111(2): 388-400$. 
Sherwood, C. R., and R. W. Sternberg. 1989. "Near-Bottom Suspended Sediment Measurements on the Northern California Continental Shelf - STRESS-1." EOS $70(43): 1144$.

Smith, J. D. 1977. "Modeling of Sediment Transport on Continental Shelves." In The Sea: Ideas and Observations on Progress in the Study of the Seas. Vol. 6, pp 539-576. E. G. Goldberg, ed., Wiley, New York.

Smith, J. D., and S. R. McLean. 1977a. "Boundary Layer Adjustments to Bottom Topography and Suspended Sediment." In Bottom Turbulence, J. C. J. Nihoul, ed. Elsevier, New York.

Simith, J. 0., and S. R. McLean. 1977b. "Spatially Averaged Flow Over a Wavy Surface." Journal of Geophysical Research 82:1735-1746.

Sternberg, R. W., R. V. Johnson II, D. A. Cacchione, and D. E. Orake. 1986. "An Instrument System for Monitoring and Sampling Suspended Sediment in the Benthic Boundary Layer." Marine Geology 71:187-199.

Wiberg, P., and D. M. Rubin. 1989. "Bed Roughness Produced by Saltating Sediment." Journal of Geophysical Research 94(C4):5011-5016. 
a) Current Velocity

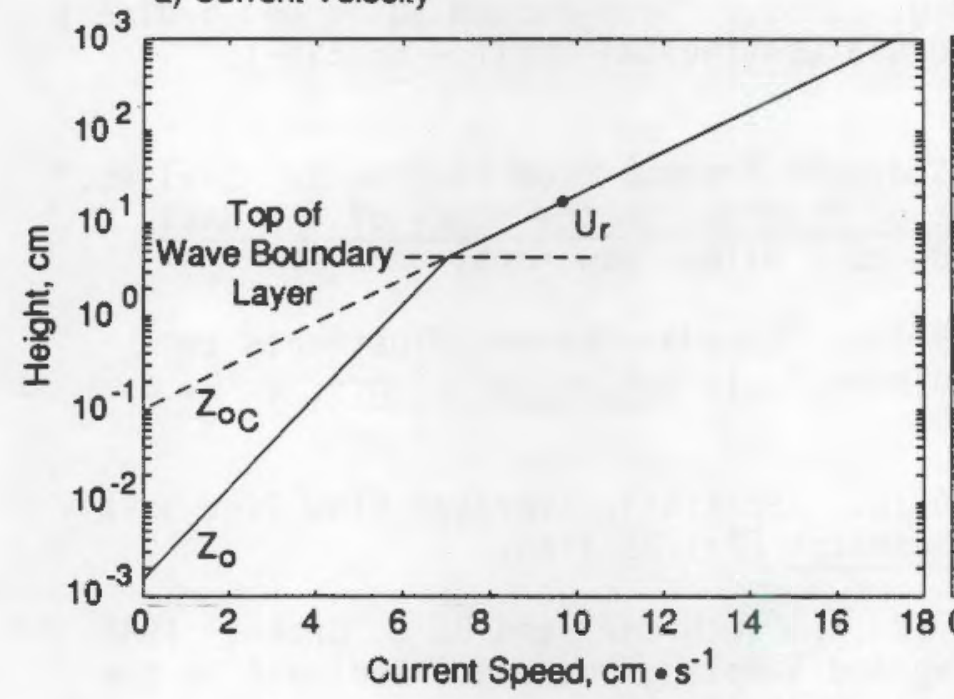

b) Sediment Concentration

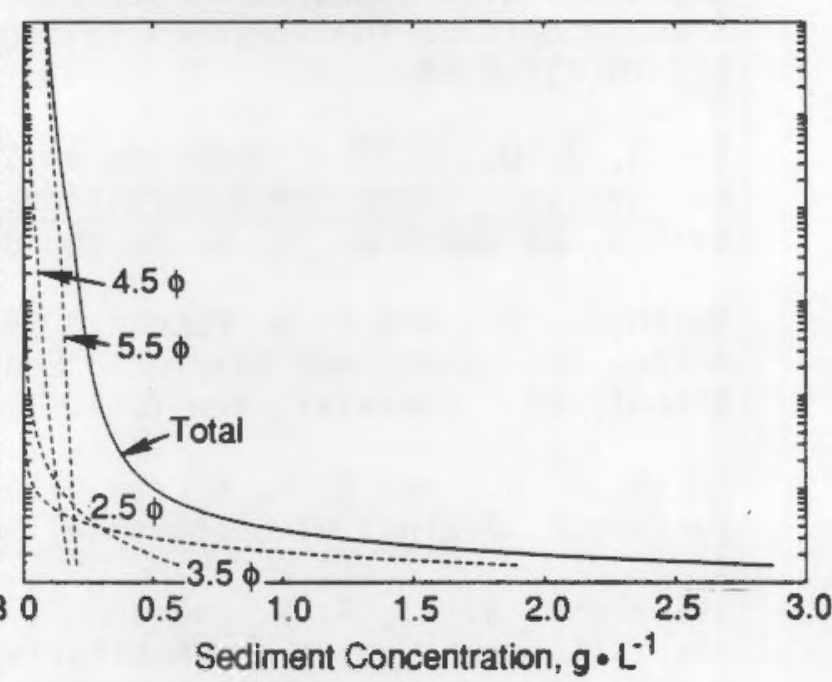

c) Sediment Flux

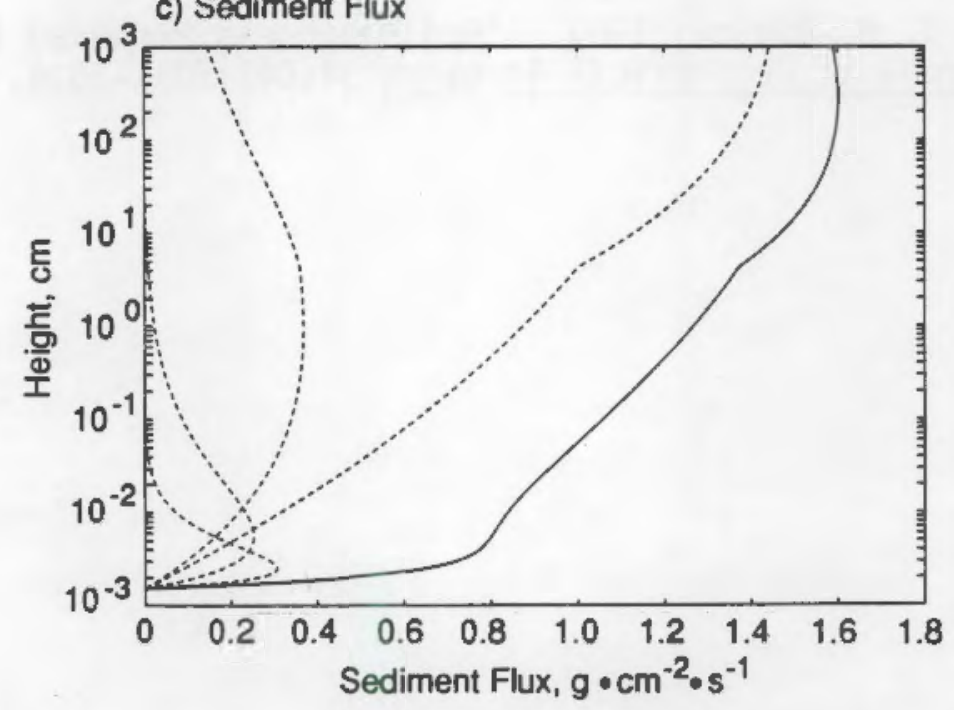

FIGURE C.1. a) Representative Velocity Profile, b) Suspended-Sediment Profile, and c) Flux Profile Calculated for High ShearStress Conditions at Site B1B. Input values for the calculation are: water depth $h=86 \mathrm{~m}$; current velocity $u_{r}=13.7 \mathrm{~cm} \cdot \mathrm{s}^{-1}$ at $\mathrm{z}_{r}=142 \mathrm{~cm}$; wave orbital velocity amplitude $u_{b}=19.3 \mathrm{~cm} \cdot \mathrm{s}^{-1}$; and wave period $\mathrm{T}_{d}=16.7 \mathrm{~s}$. Calculated parameters are: combined shear velocity $u \star C w=$ $1.62 \mathrm{~cm} \cdot \mathrm{s}^{-1}$, bottom roughness $\mathrm{z}_{0}=0.0015 \mathrm{~cm}$; current shear velocity $=0.76 \mathrm{~cm} \cdot \mathrm{s}^{-1} ;$ and apparent bottom roughness $z_{O C}=$ $0.10 \mathrm{~cm}$. 


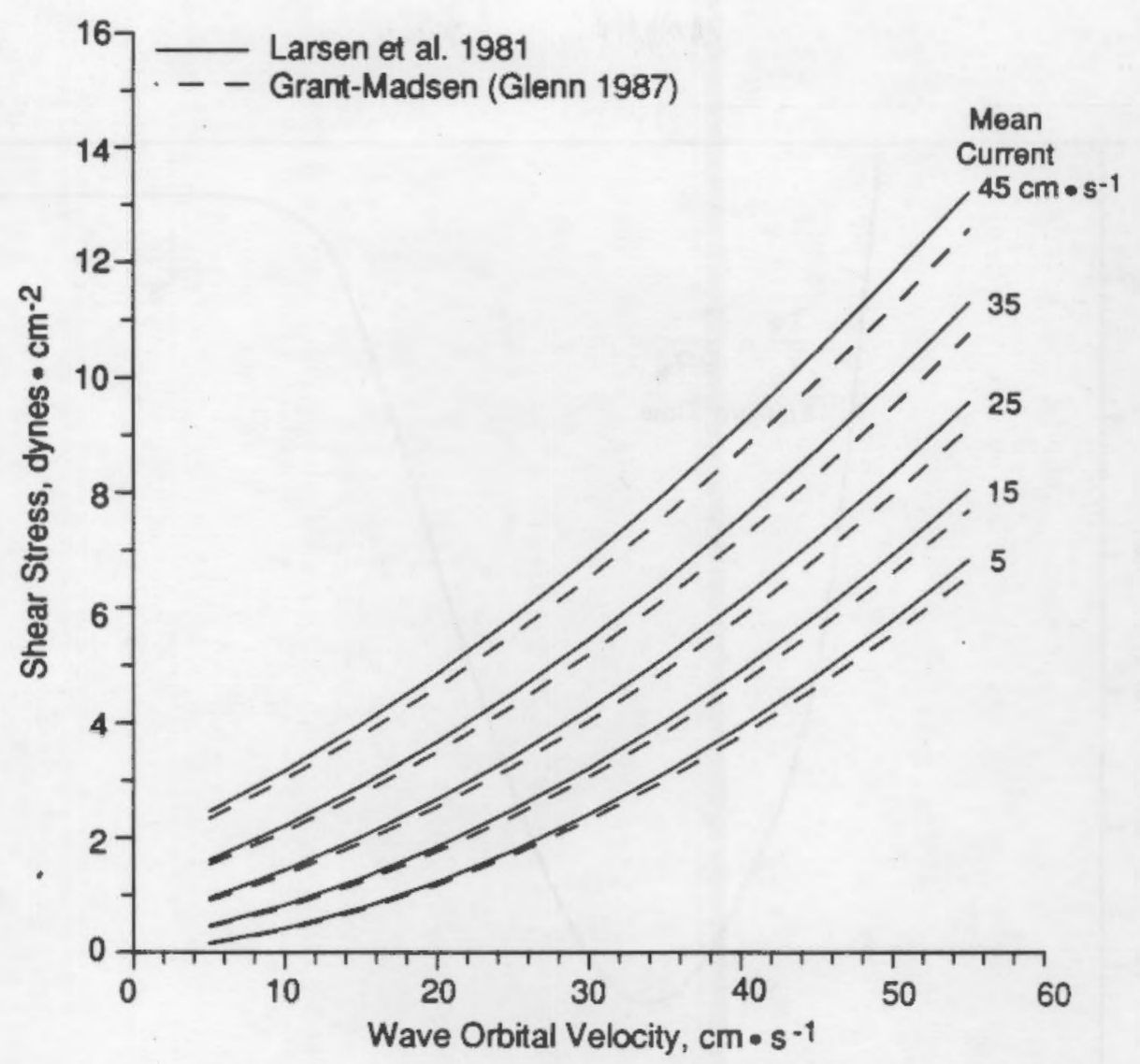

FIGURE C.2. Bottom Shear Stresses Computed Using the Grant and Madsen (1979) Model and the Solution Methods of Larsen et al. (1981) and Glenn (1983; Glenn and Grant 1987). Constant bottom roughness parameter $z_{0}=0.0001$. 


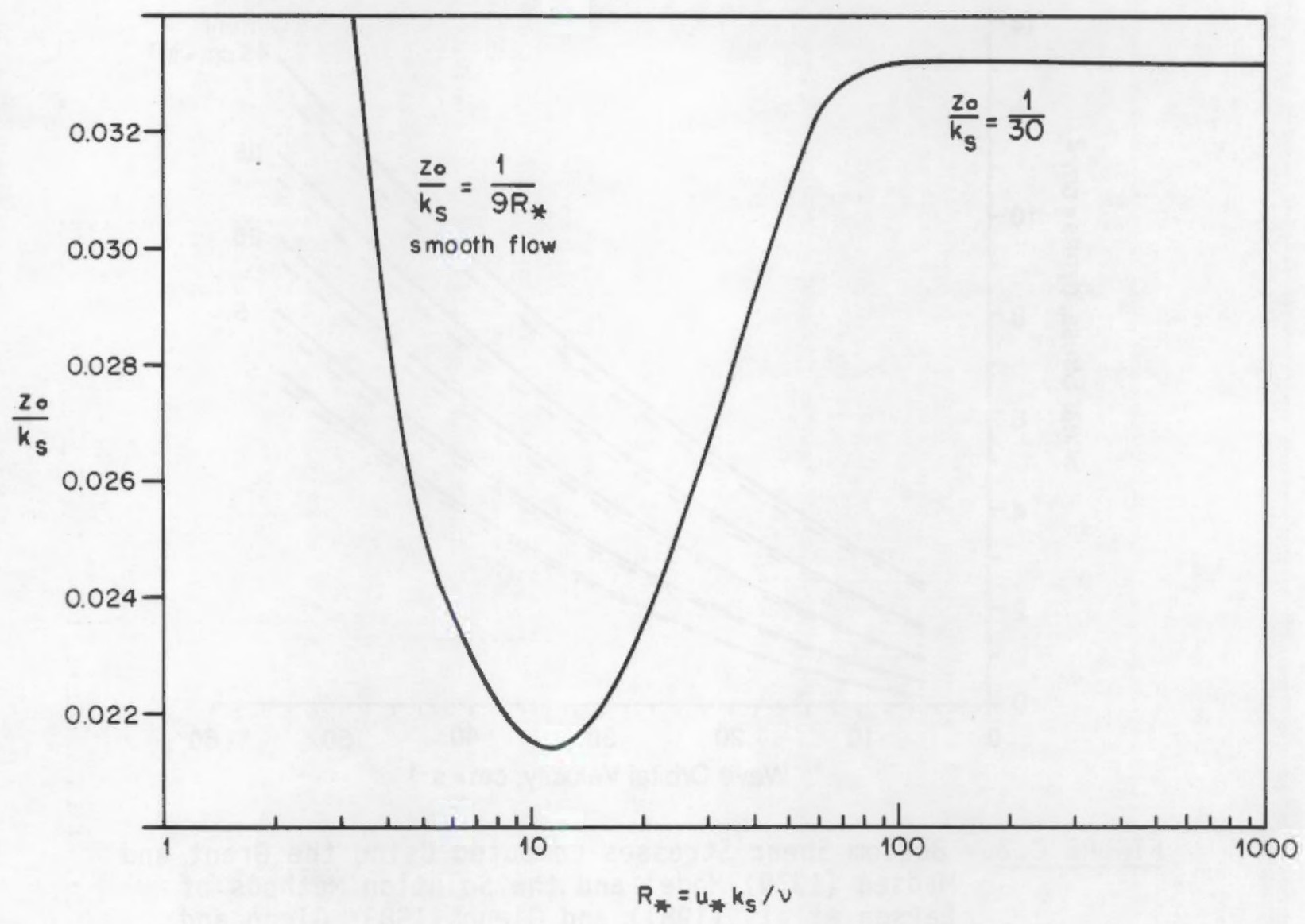

FIGURE C.3. Plot of the Nikuradse Bottom Roughness ( $z_{O N}$ ) Function 

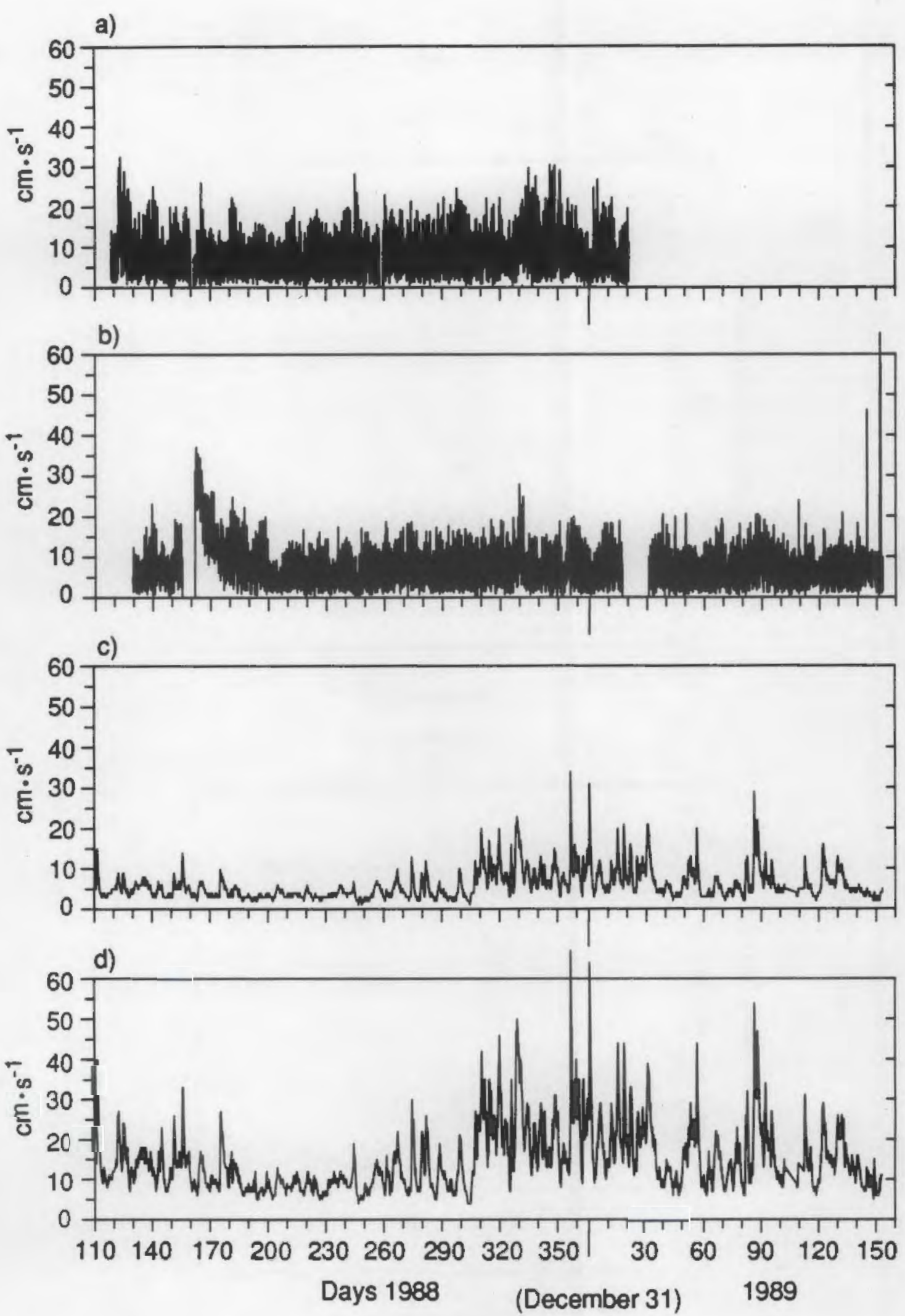

FIGURE C.4. Input Time Series for Sediment Transport Calculations:

a) Hourly Current Speed at Site B1B and b) Site $1 M$ and c) Near-Bottom Wave-Orbital Velocity at Site B1B and d) Site $1 M$ 

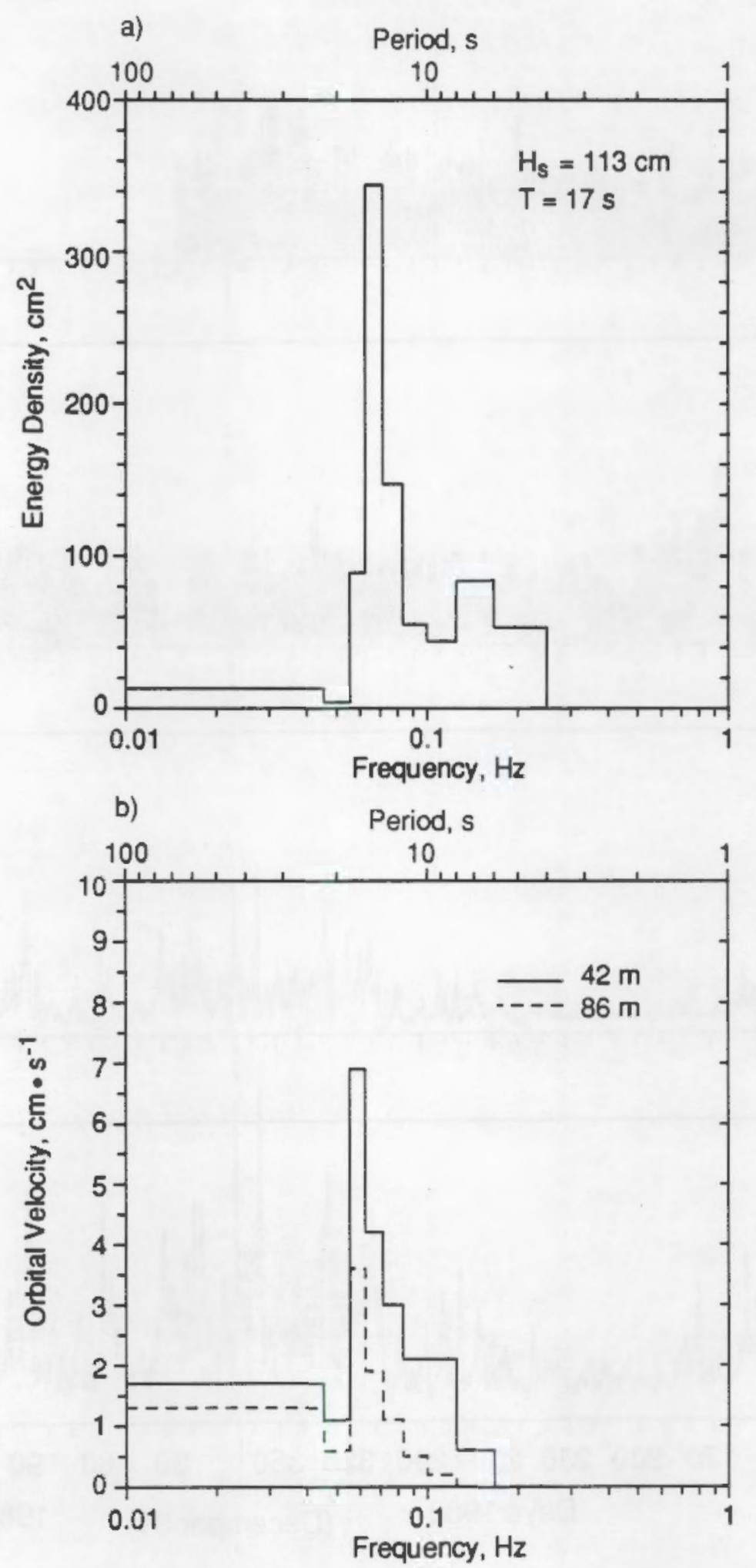

FIGURE C.5. Schematic Illustration of Signifcant Orbital-Velocity Amplitude Calculation From Surface Wave Spectrum: a) Wave Spectrum and b) Wave-Orbital Velocity Amplitude Spectra for 42 and $86 \mathrm{~m}$ 


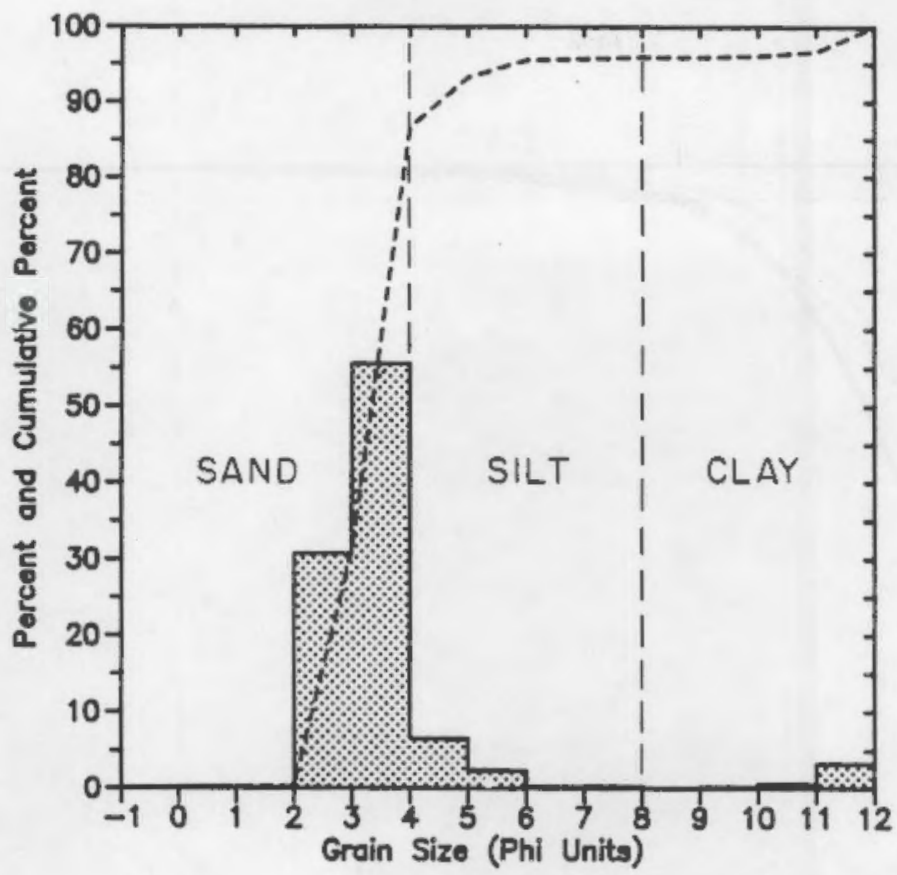

SITE $1 M$

$42 \mathrm{~m}$

$87 \%$ Sand

$9 \%$ Silt

$4 \%$ Clay

Graphic Mean:

$3.2 \mathrm{phi}$

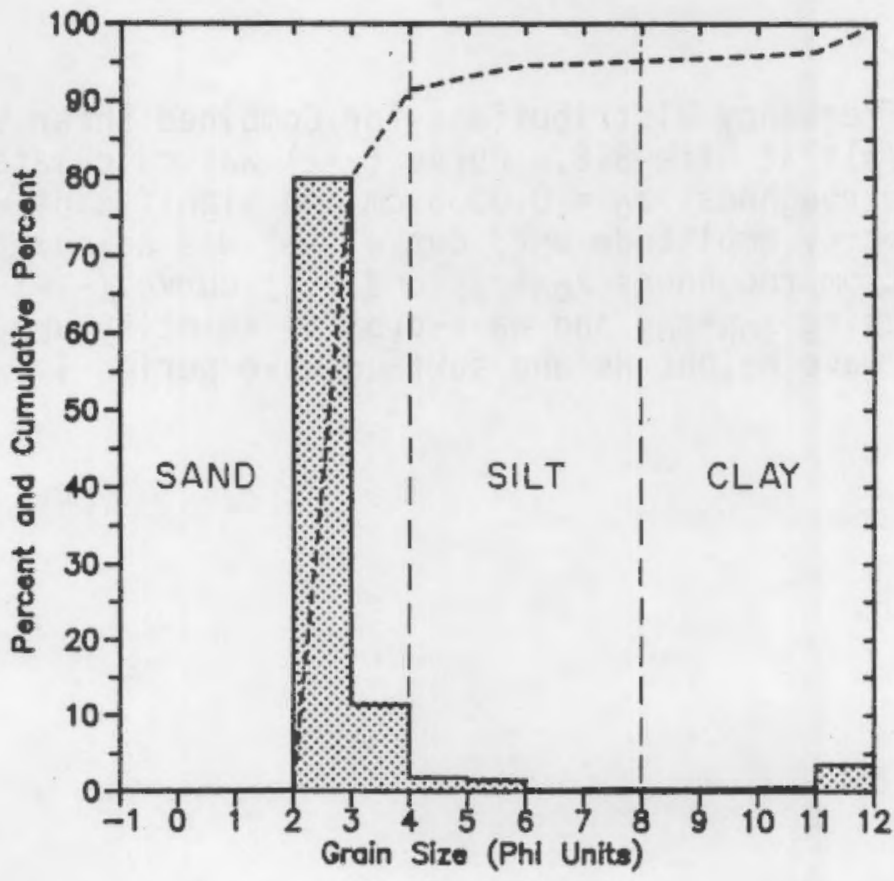

SITE BAB $86 \mathrm{~m}$

$91 \%$ Sand

$4 \%$ Silt

$5 \%$ Clay

Graphic Mean:

2.7 phi

FIGURE C.6. Sediment Grain-Size Distribution Histograms and Cumulative Frequency Plots for Bottom-Grab Samples From a) Site $B 1 B$ and b) Site $I M$ 


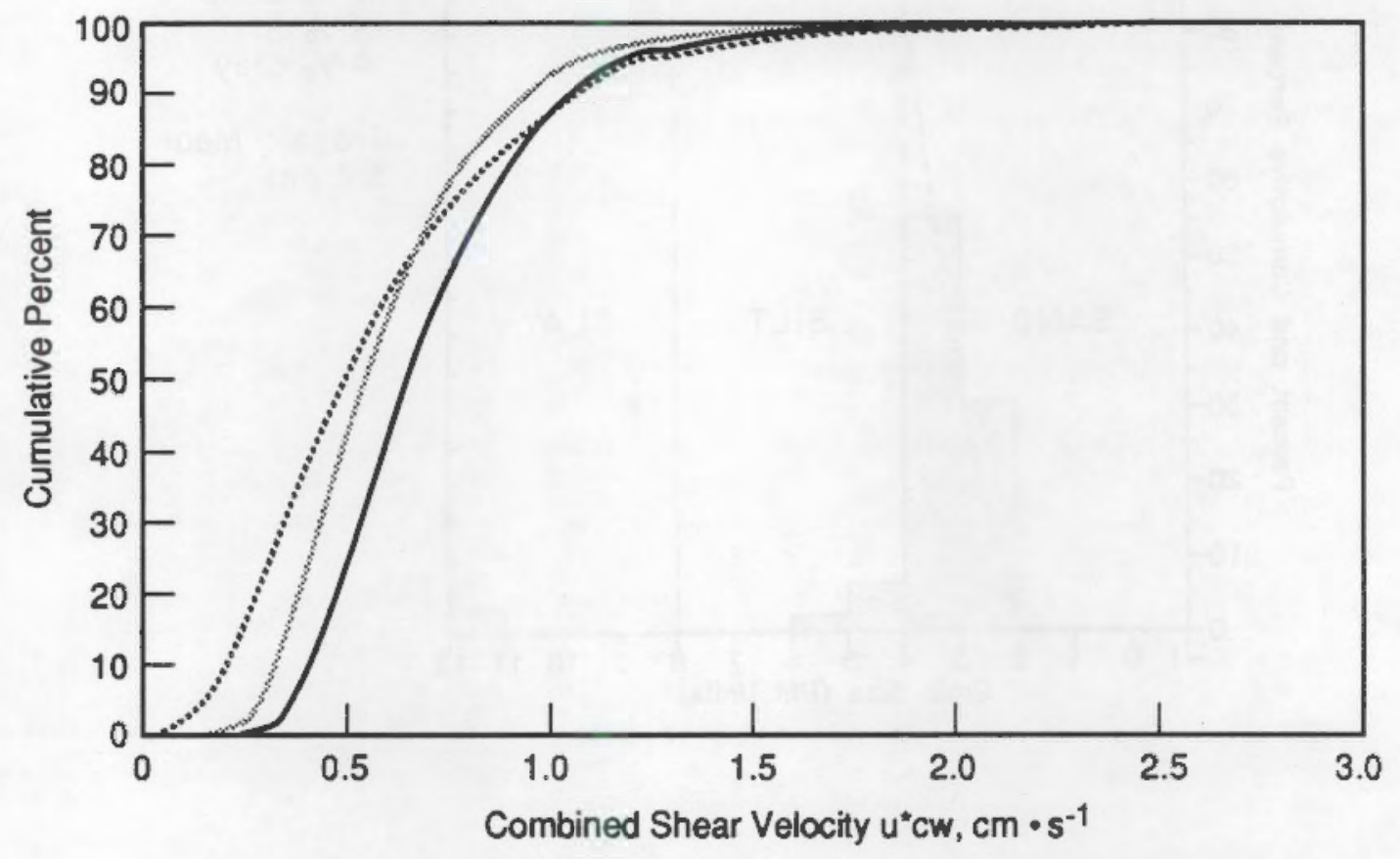

FIGURE C.7. Cumulative Frequency Distributions for Combined Shear Velocity $\mathrm{u} * \mathrm{CW}=\left(\tau_{\mathrm{CW}} / \rho\right)^{\frac{1}{2}}$ at Site B1B. Curve $(\cdots)$ was calculated using fixed bottom roughness $z_{0}=0.0005 \mathrm{~cm}$ and significant waveorbital velocity amplitude ubs; curve $(-)$ was calculated using variable bottom roughness $\mathrm{z}_{\mathrm{O}} \mathrm{N}+\mathrm{Z}_{\mathrm{O}} \mathrm{S}$ and ubsi curve (---) was calculated using $\mathrm{Z}_{\mathrm{ON}}+\mathrm{Z}_{\mathrm{OS}}$ and wave-orbital velocity ubHs based on significant wave height $\mathrm{Hs}$ and surface wave period T. 


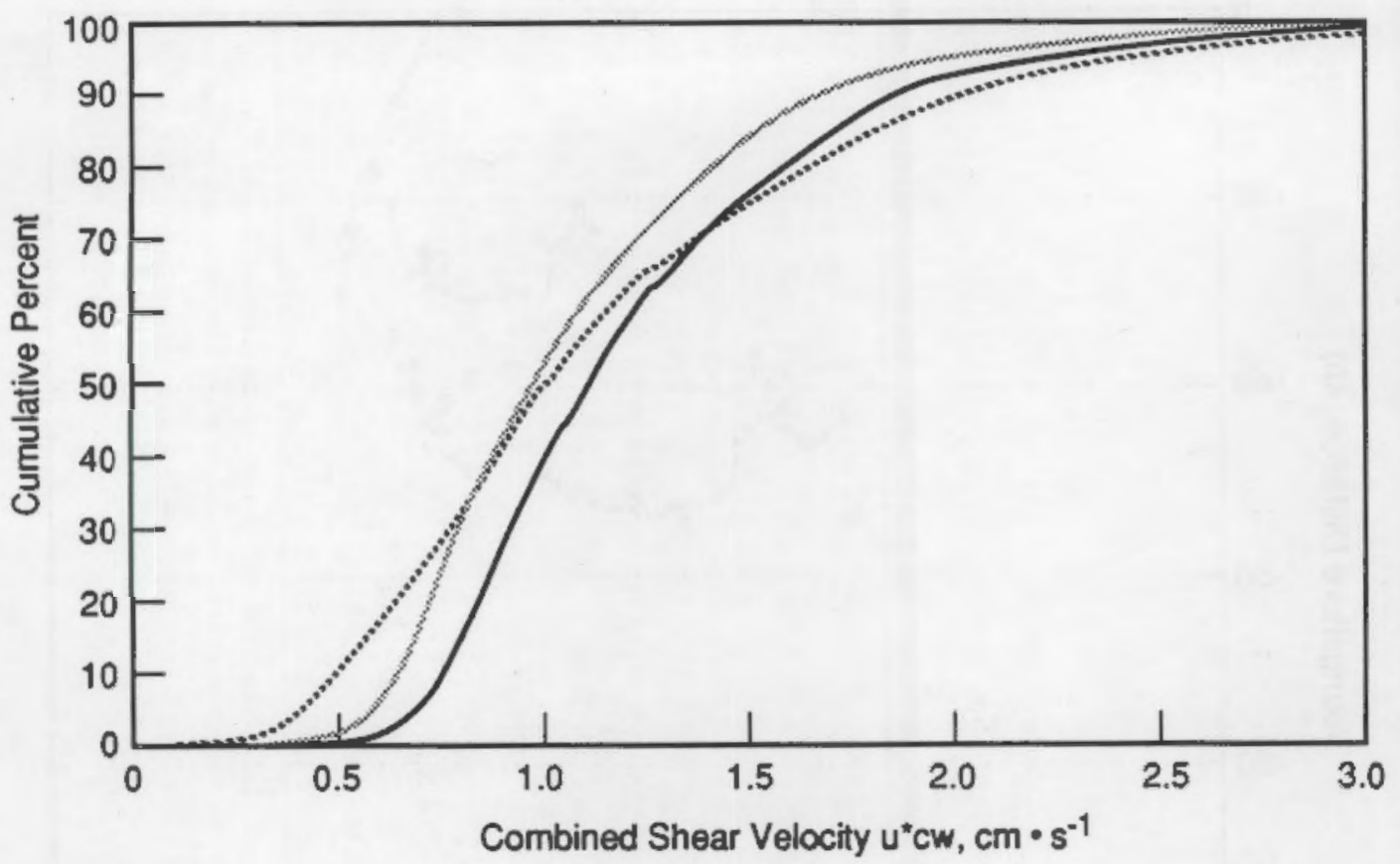

FIGURE C.8. Cumulative Frequency Distributions for Combined Shear Velocity $u * C W=(\tau \mathrm{CW} / \rho)$ at Site $1 \mathrm{M}$. Curve $(\cdots)$ was calculated using fixed bottom roughness $z_{0}=0.0005 \mathrm{~cm}$ and significant waveorbital velocity amplitude ubsi curve $(-)$ was calculated using variable bottom roughness $Z_{O N}+Z_{O S}$ and ubsi curve (---) was calculated using $Z_{0 N}+Z_{O S}$ and wave-orbital velocity ubHs based on significant wave height Hs and surface wave period $T$. 


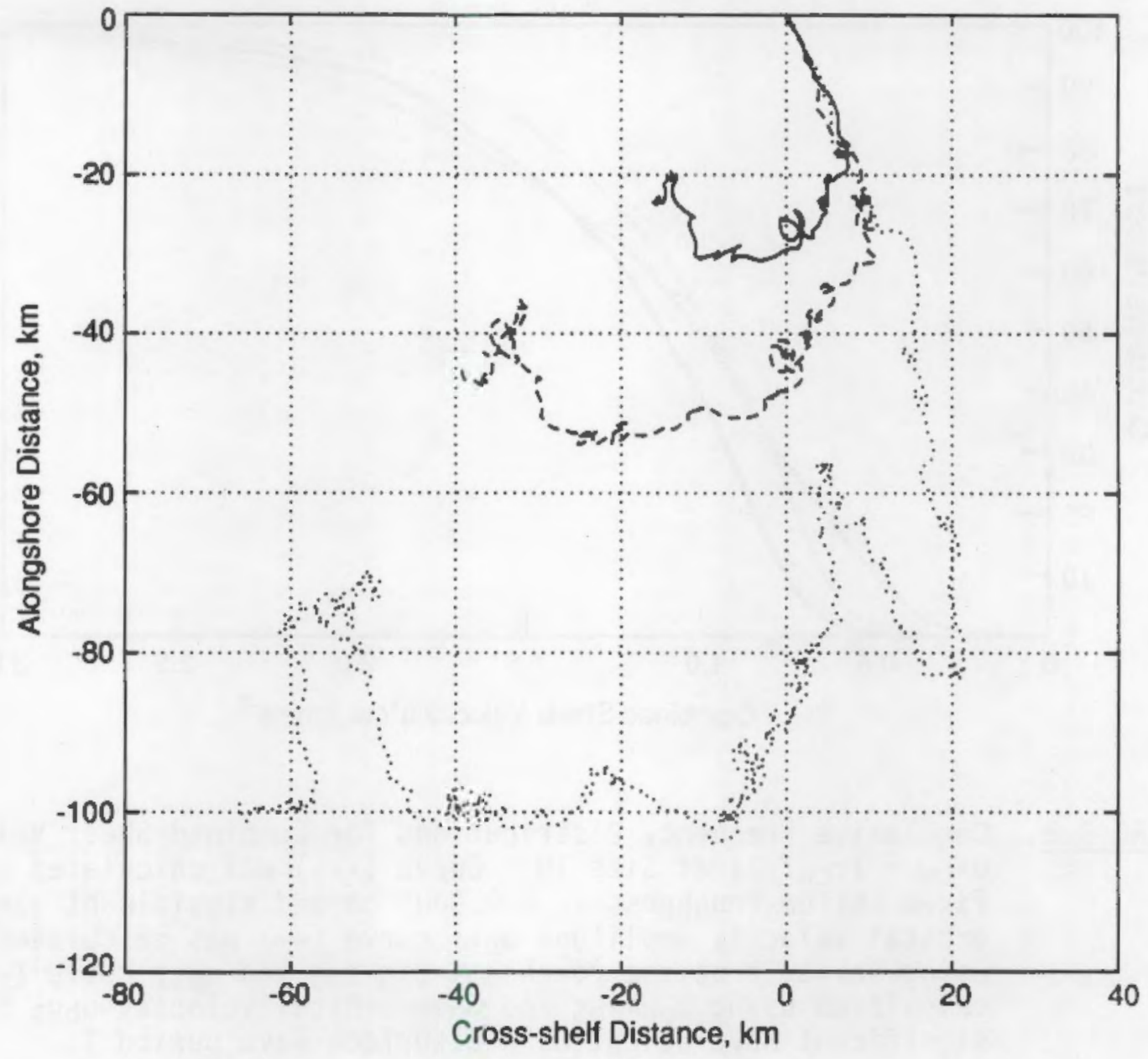

FIGURE C.9. Progressive Vector Diagrams for Currents at Site B1B when Combined Bottom Shear Stress $\tau_{\mathrm{CW}}$ Exceeded 0.8 dynes. $\mathrm{cm}-2(\cdots)$, 1.2 dynes $\cdot \mathrm{cm}^{-2}(-\ldots-)$, and 1.7 dynes $\cdot \mathrm{cm}^{-2}(-)$. The traces represent the cumulative movement of water particles (and suspended sediment) whenever combined wave and current energy is sufficient to cause resuspension, and assume no spatial variation in currents. These diagrams indicate that the mean transport direction is relatively insensitive to choice of $\mathrm{T}_{\mathrm{CW}}$ in this range of values. 


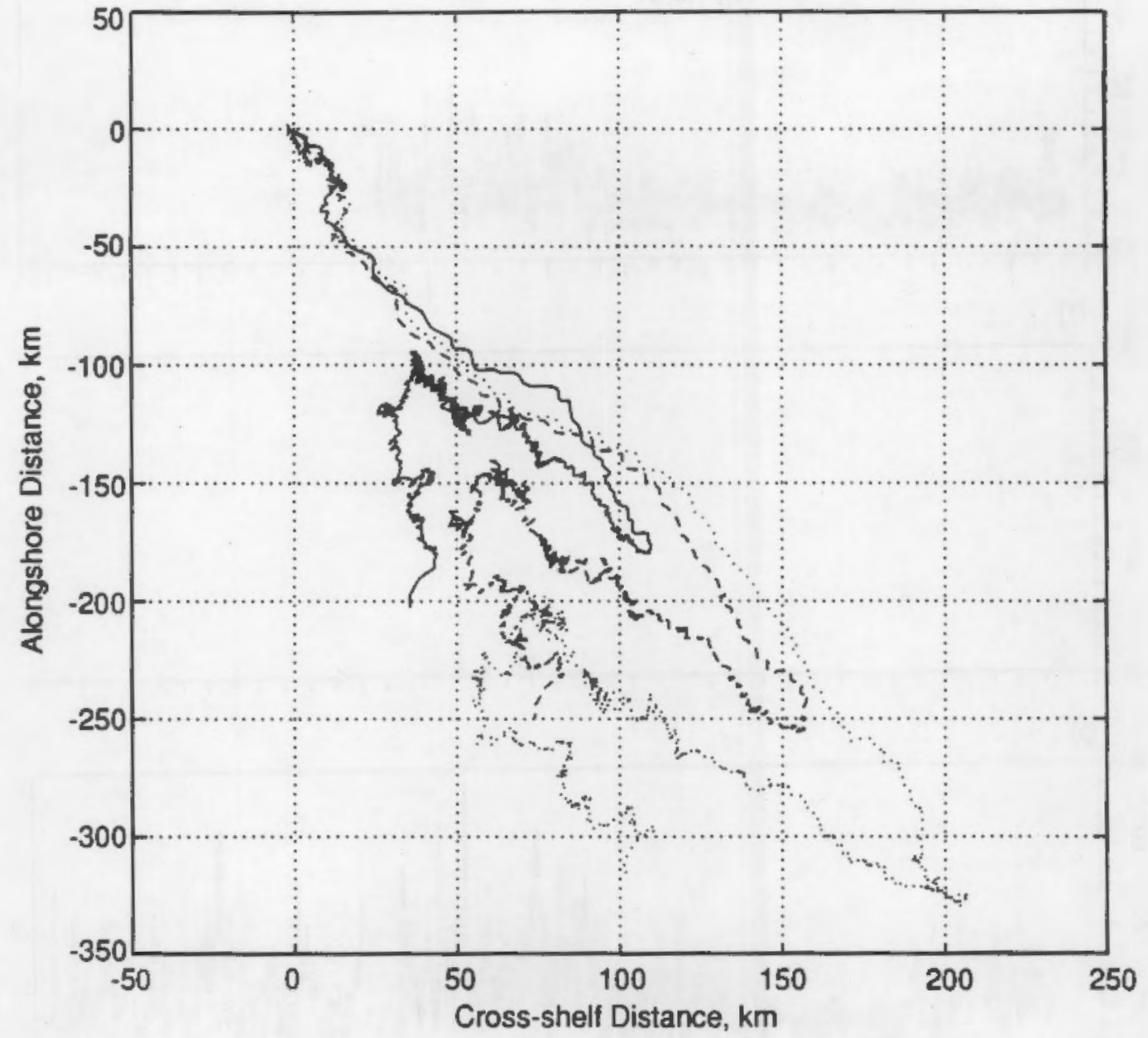

FIGURE C.10. Progressive Vector Diagrams for Currents at Site $1 M$ When Combined Bottom Shear Stress $\tau_{\mathrm{CW}}$ Exceeded 0.8 dynes. $\mathrm{cm}^{-2}$ $(\cdots), 1.2$ dynes $\cdot \mathrm{cm}^{-2}(--$,$) and 1.7$ dynes $\cdot \mathrm{cm}^{-2}(-)$. (See discussion for Figure C.9.) 

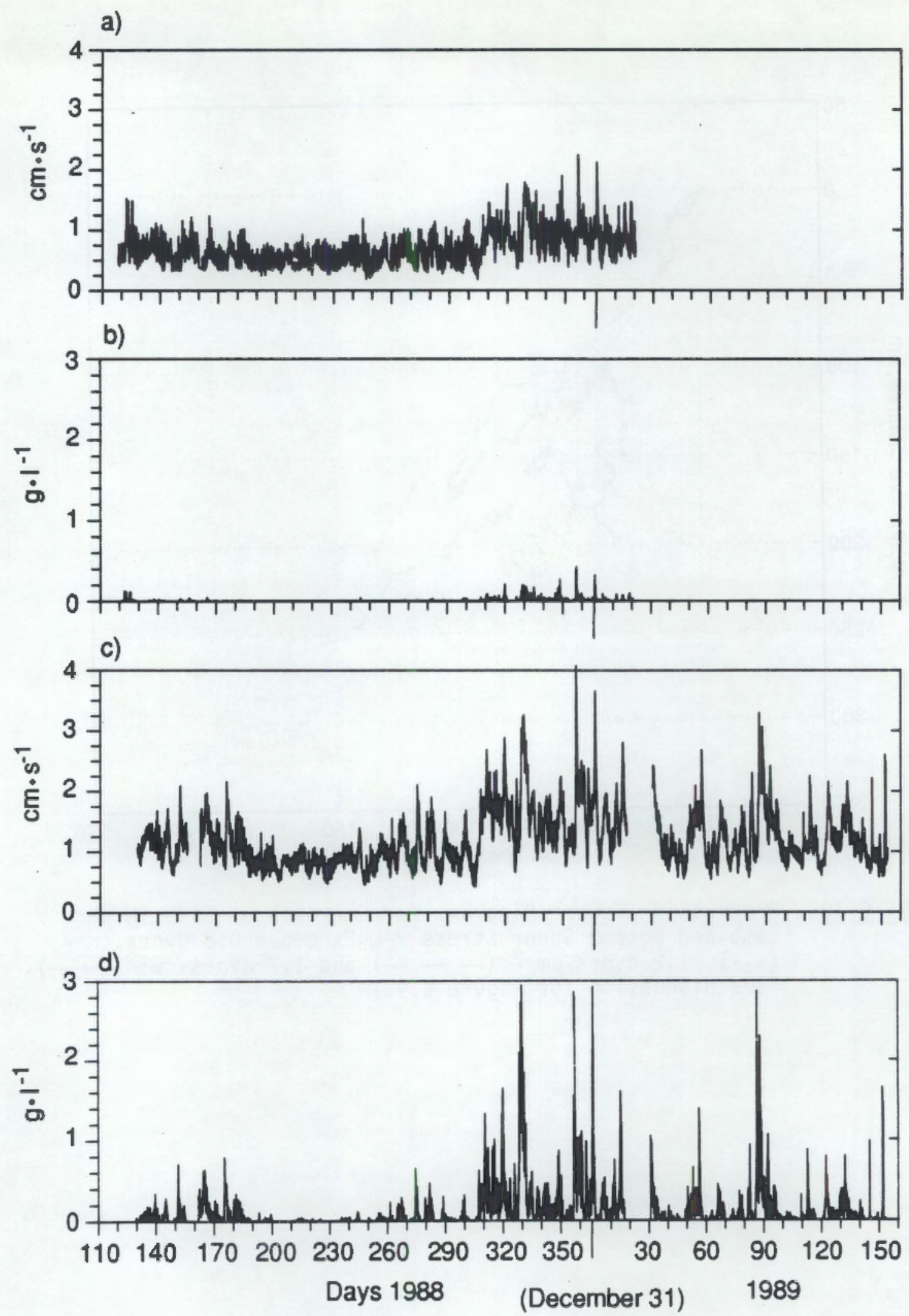

FIGURE C.11. Time Series of Calculated Combined Shear Velocity $4{ }^{*} \mathrm{CW}$, and Calculated Suspended Sediment Concentrations ( $36 \mathrm{~cm}$ Above the Bottom) at a) and b) Site B1B and at c) and d) Site 1M 


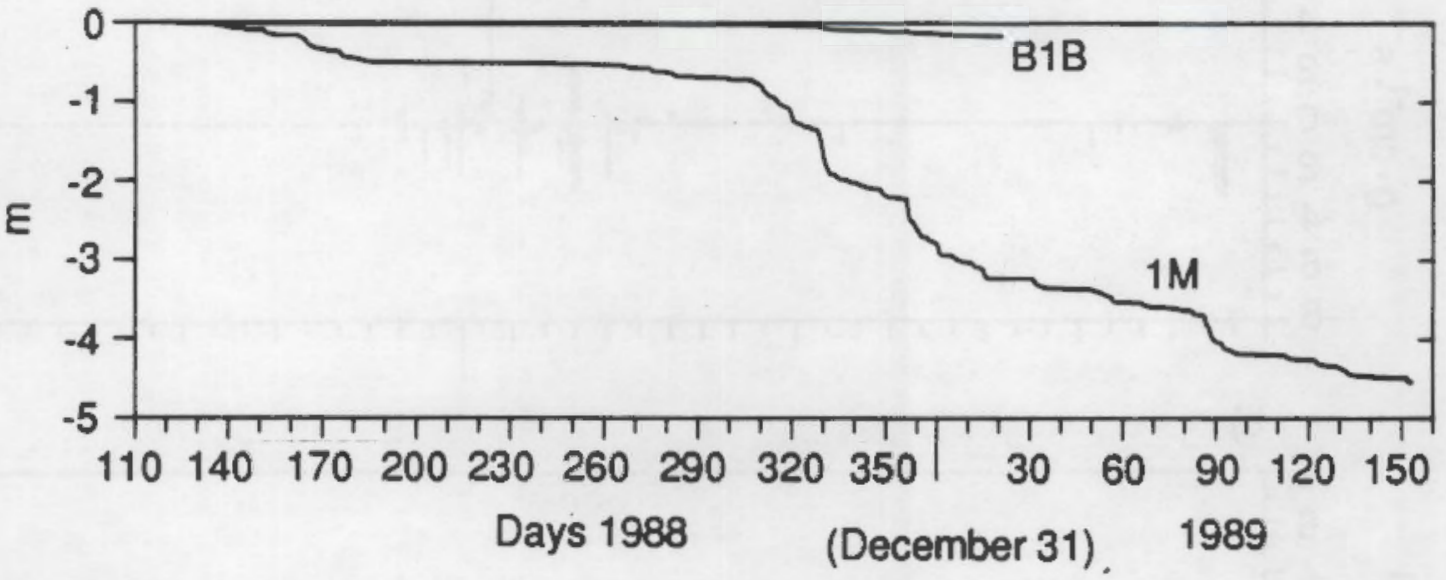

FIGURE C.12. Calculated Cumulative Erosion Depths at Sites B1B and IM 
a)

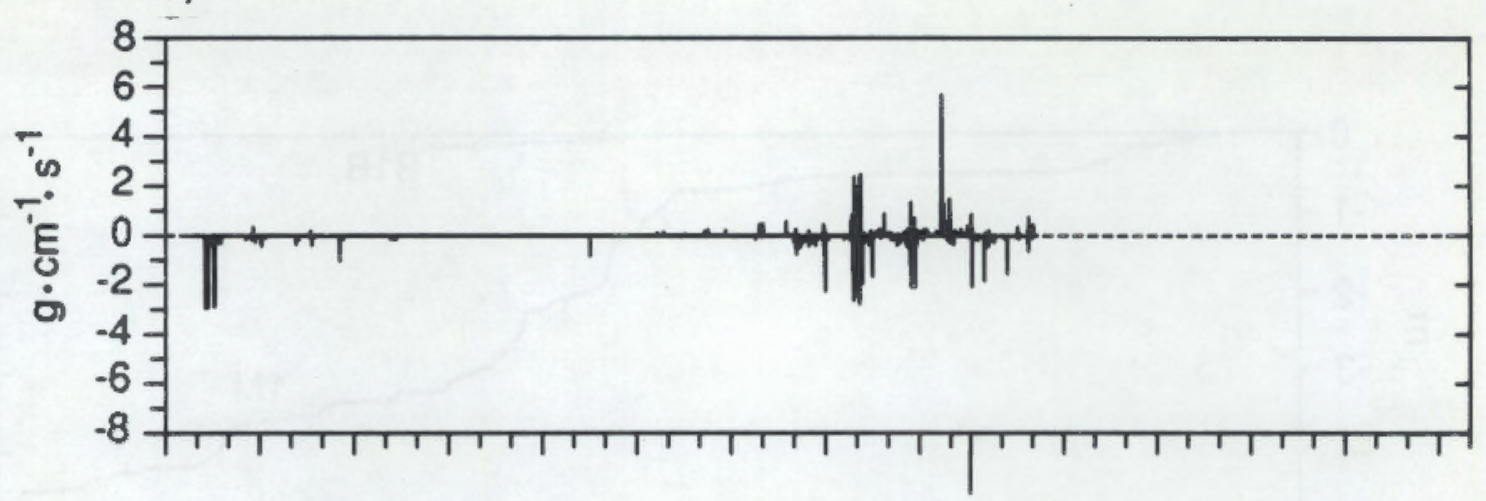

b)
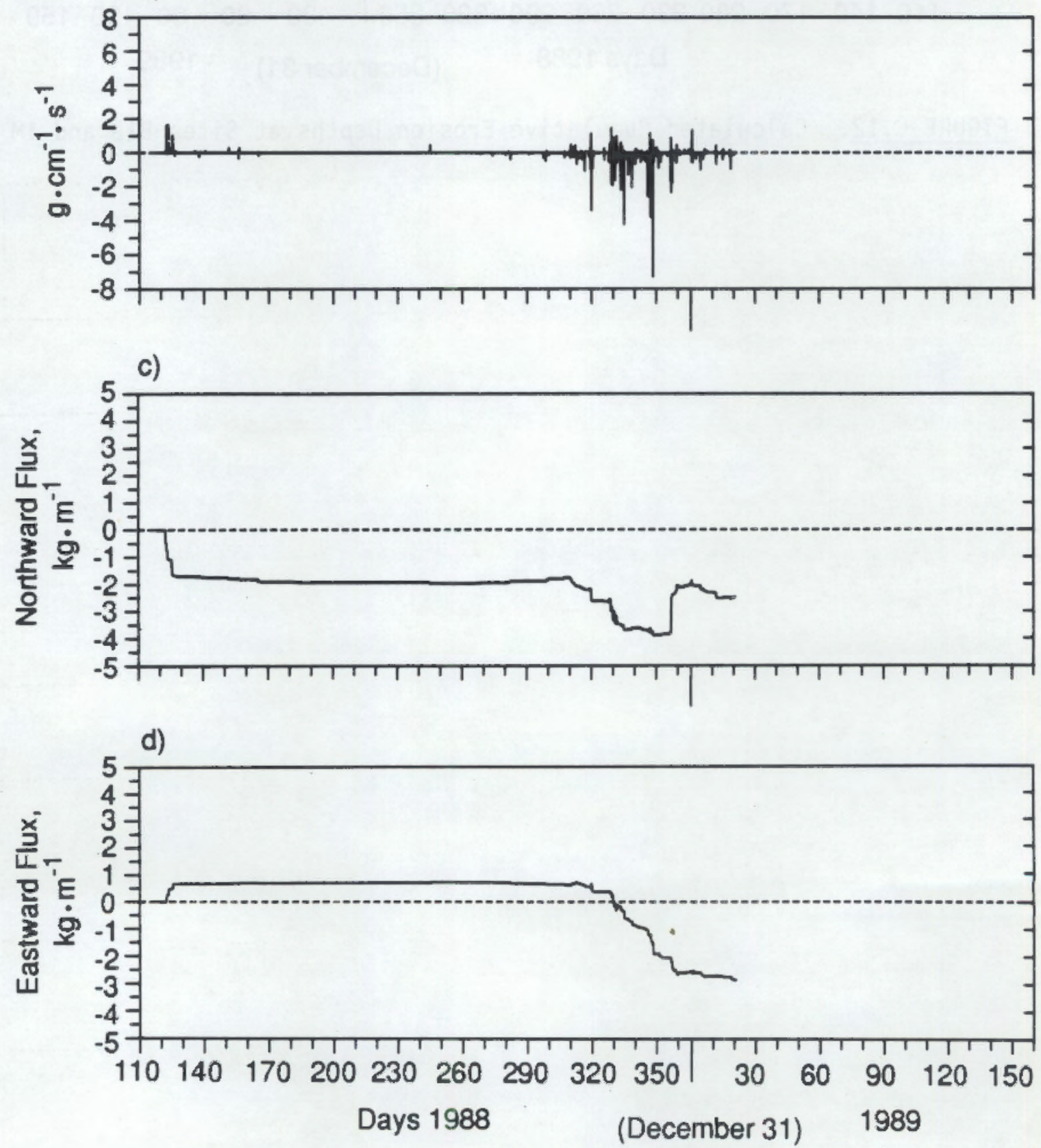

FIGURE C.13. Time Series of a) and b) Calculated Alongshore and Cross-Shelf Sediment Flux, and C) and d) Cumulative Alongshore and CrossShelf Sediment Flux at Site B1B 

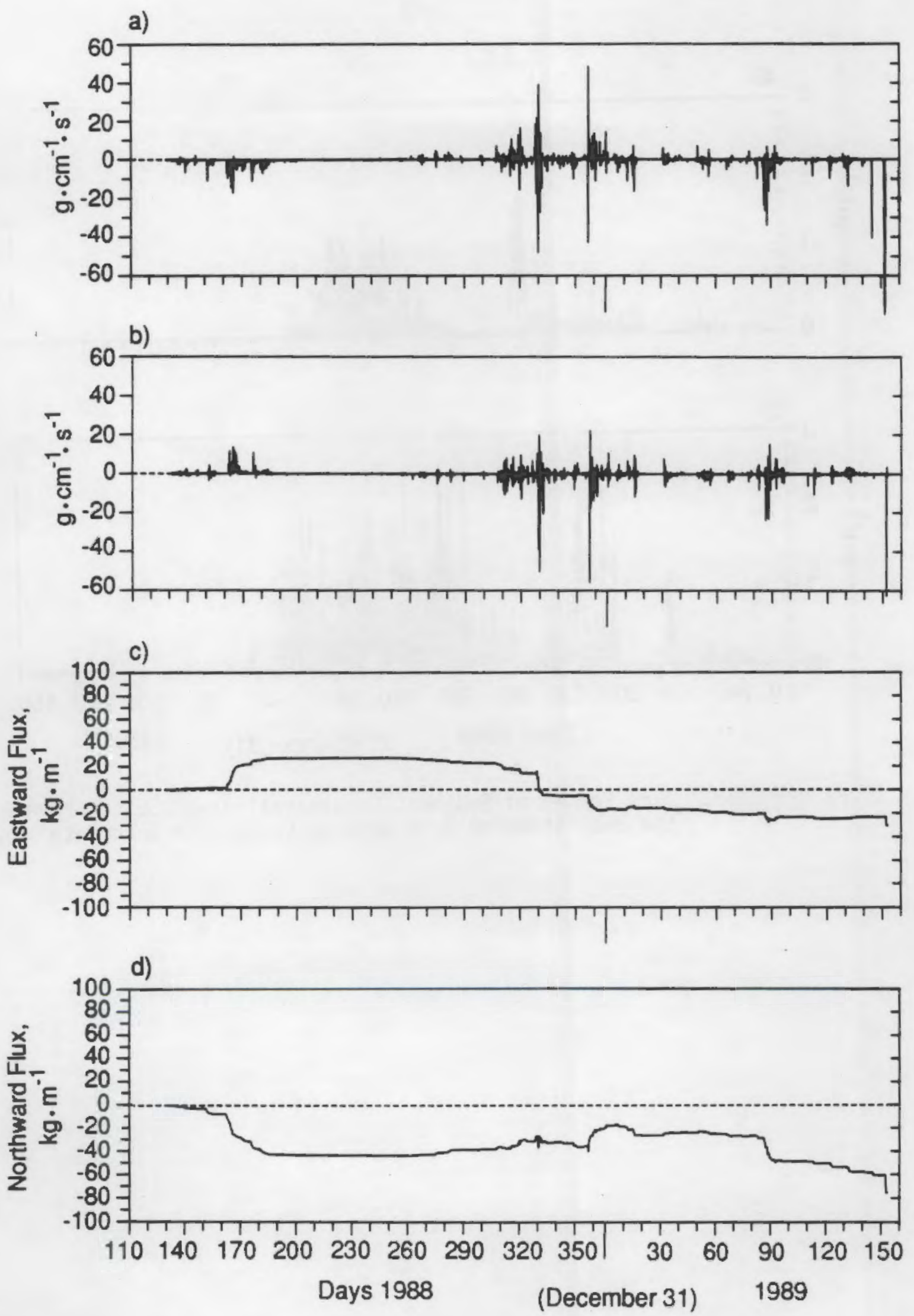

FIGURE C.14. Time Series of a) and b) Calculated Alongshore and Cross-Shelf Sediment Flux, and c) and d) Cumulative Alongshore and CrossShelf Sediment Flux at Site 1M 

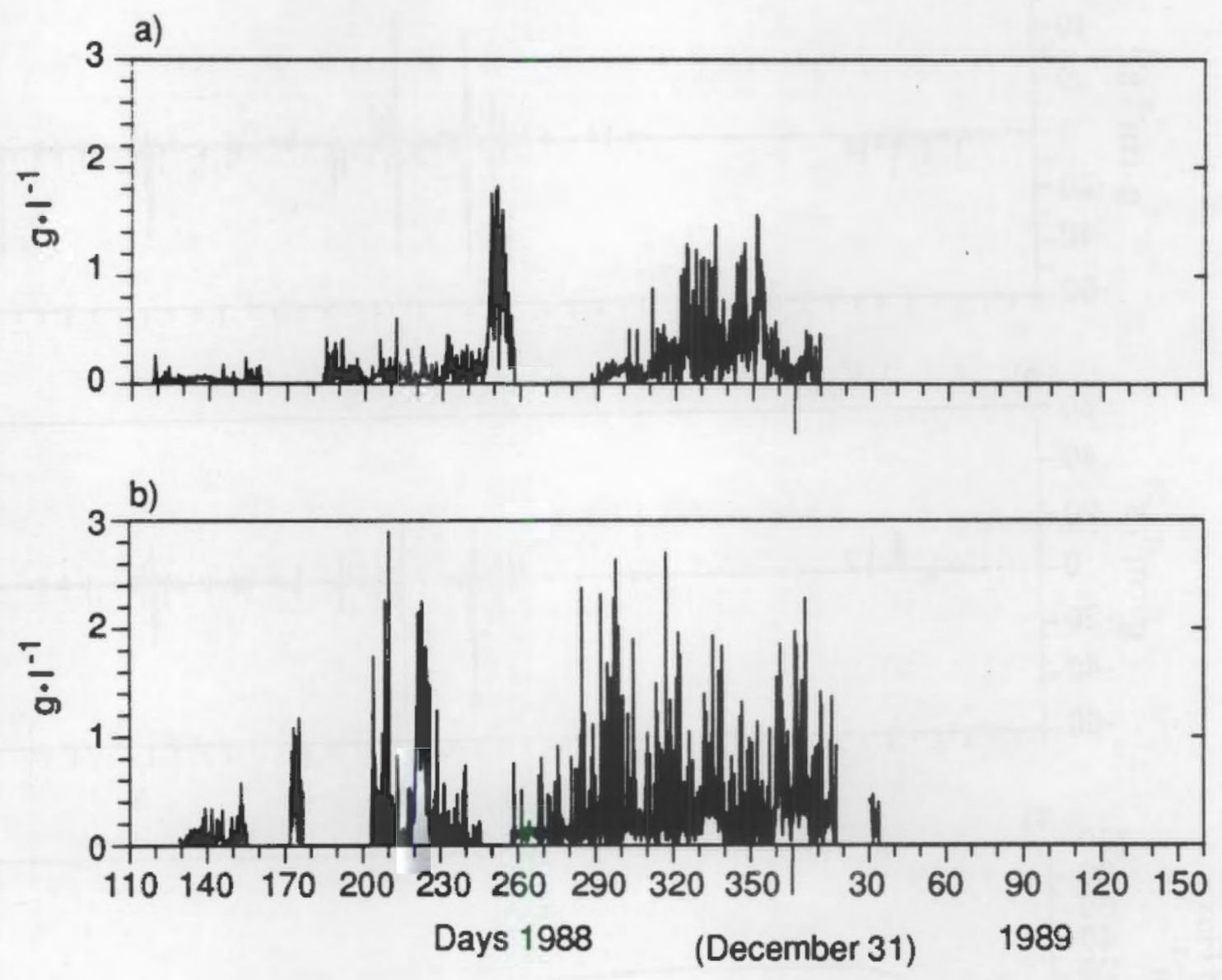

FIGURE C.15. Time Series of Sediment Concentrations at $36 \mathrm{~cm}$ Above the Bed Estimated from Optical Backscatterance Data 


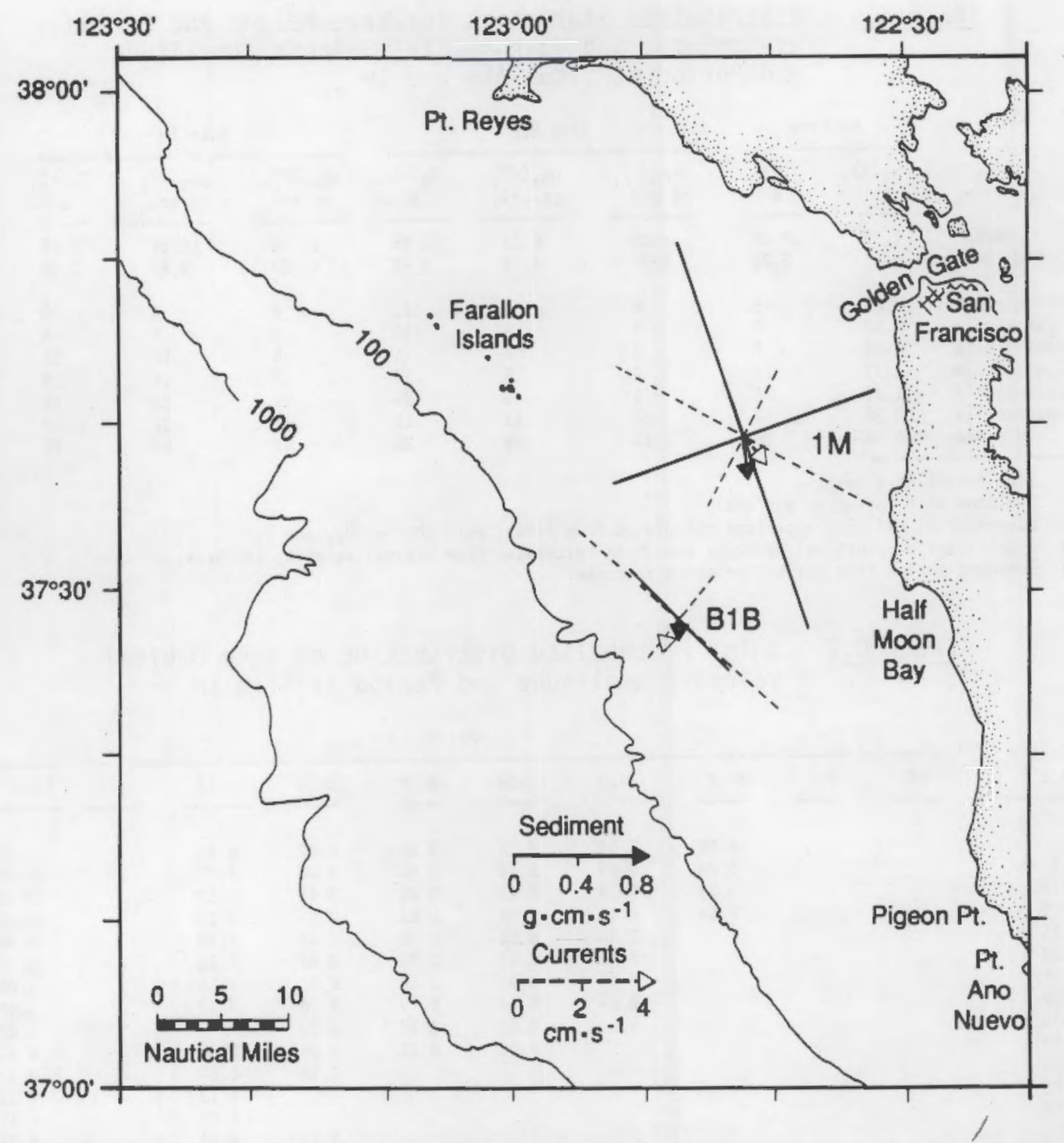

FIGURE C.16. Principal Axes and Means of Sediment Flux (-) and NearBottom Currents (--) at Sites B1B and 1M. Upper bar scale is for sediment flux of Site $1 M$; flux at site $B 1 B$ is exaggerated $40 x$. Lower bar scale is for currents. 
TABLE C.1. Distribution Statistics for Wave Height and Period at Montara, and Wave-Orbital Velocity Amplitude, and Period at Sites $\mathrm{B} 1 \mathrm{~B}$ and $1 \mathrm{M}$

\begin{tabular}{|c|c|c|c|c|c|c|c|c|}
\hline & \multicolumn{2}{|c|}{ Uontara } & \multicolumn{3}{|c|}{ Site $\mathrm{B1B}$} & \multicolumn{3}{|c|}{ Site 1II } \\
\hline & $\mathrm{H}_{\mathrm{s}}(\mathrm{a})$, & $\begin{array}{c}T(b), \\
s\end{array}$ & $\begin{array}{l}\text { UbHs (c), } \\
\mathrm{cn} \cdot \mathrm{s}^{-1}\end{array}$ & $\begin{array}{l}\text { Ubs (d), } \\
\mathrm{ca} \cdot \mathrm{s}^{-1}\end{array}$ & $\begin{array}{c}\mathrm{Td}_{\mathrm{d}}(\mathrm{e}) \\
\text {, }\end{array}$ & $\begin{array}{l}\mathrm{UbHs}_{\mathrm{s}}(\mathrm{c}) \text {, } \\
\mathrm{cas} \cdot \mathrm{s}^{-1}\end{array}$ & $\begin{array}{l}u_{b s}(d) \\
c s \cdot s^{-1}\end{array}$ & $\mathrm{~T}_{\mathrm{d}}(\mathrm{e})$ \\
\hline $\begin{array}{l}\text { Mean } \\
\text { Std. Dev. }\end{array}$ & $\begin{array}{l}1.35 \\
6.54\end{array}$ & $\begin{array}{r}16.60 \\
3.20\end{array}$ & $\begin{array}{l}4.86 \\
6.60\end{array}$ & $\begin{array}{l}6.56 \\
4.10\end{array}$ & $\begin{array}{r}18.80 \\
3.40\end{array}$ & $\begin{array}{l}15.20 \\
11.80\end{array}$ & $\begin{array}{r}16.10 \\
9.80\end{array}$ & $\begin{array}{r}13.10 \\
2.90\end{array}$ \\
\hline Minimum & 9.30 & 5 & 0 & 1 & 11 & 6 & 4 & 9 \\
\hline 5-percentile & 6.62 & 7 & (1) & 3 & 13 & 2 & 7 & 9 \\
\hline 25-percentile & 8.95 &, 7 & - & 4 & 15 & 5 & 10 & 11 \\
\hline 50-percentile & 1.27 & 11 & 2 & 5 & 29 & 12 & 14 & 13 \\
\hline 75-percentile & 1.86 & 13 & 8 & 8 & 22 & 22 & 21 & 15 \\
\hline 95-percentile & 2.36 & 17 & 17 & 15 & 22 & 37 & 32 & 17 \\
\hline Maxinum & 4.18 & 29 & 43 & 39 & 22 & 81 & 67 & 22 \\
\hline
\end{tabular}

(a) Significant wave hoight.

(b) Doninant wave period at surface.

(c) Wave-orbital velocity anplitude calculated fron linear wave theory, $\mathrm{H}_{\boldsymbol{s}}$, and $\mathrm{T}$.

(d) Significant wave-orbital velocity anplitude calculated from orbital volocity spectrum.

(a) Doninant period from orbital velocity spectrun.

TABLE C.2. Joint Probability Distribution of Wave Orbital Velocity Amplitude and Period at Site 1M

Period, s

\begin{tabular}{|c|c|c|c|c|c|c|c|c|c|c|}
\hline \multirow{2}{*}{$\begin{array}{l}\text { Volocity, } \\
\text { cu-s-1 }\end{array}$} & & & & & & & & & & \\
\hline & $<6$ & $6-8$ & $8-10$ & $10-12$ & $12-14$ & $14-16$ & $16-18$ & $18-22$ & $>22$ & Total \\
\hline$<5$ & & & 0.20 & 9.68 & פ.12 & 6. 36 & б. 32 & ฮ. 32 & & 1.38 \\
\hline $5-10$ & & & 8.06 & 5.45 & 5.10 & 6.65 & 3.20 & 1.82 & & 29.49 \\
\hline $10-15$ & & & 5.30 & 9.13 & B. 21 & 2.92 & 3.40 & 6.63 & & 27.59 \\
\hline $15-20$ & & & 0.59 & 4.98 & 6.44 & 2.61 & 0.75 & 0.38 & & 15.85 \\
\hline $26-25$ & & & & 2.65 & 6.69 & 2.92 & 1.38 & 0.46 & & 13.36 \\
\hline $25-38$ & & & & 0.46 & 2.41 & 2.86 & 9.67 & 9.55 & & 6.09 \\
\hline $30-35$ & & & & 9.04 & 0.91 & 1.54 & פ. 36 & פ. 16 & & 3.60 \\
\hline $35-40$ & & & & 8.84 & 0.24 & 6.79 & ต. 28 & 6.12 & & 1.48 \\
\hline $46-45$ & & & & & 0.98 & 0.67 & 0.32 & & & 1.07 \\
\hline $45-50$ & & & & & 0.04 & 0.32 & 0.84 & б. 68 & & 0.47 \\
\hline $50-55$ & & & & & & & 6.08 & 0.04 & & 0.12 \\
\hline $55-66$ & & & & & & & & 0.12 & & 0.12 \\
\hline $89-65$ & & & & & . & & & 0.12 & & 0.12 \\
\hline$>65$ & & & & & & & 0.04 & 0.04 & & 6.68 \\
\hline Total & 6.60 & 0.00 & 14.15 & 22.69 & 27.63 & 20.24 & 10.99 & 4.31 & $\varnothing .00$ & 100.00 \\
\hline
\end{tabular}


IABLE C.3. Joint Probability Distribution of Wave-Orbital Velocity Amplitude and Period at Site BlB

\begin{tabular}{|c|c|c|c|c|c|c|c|c|c|c|}
\hline \multirow{2}{*}{$\begin{array}{l}\text { Velocity, } \\
\mathrm{cm} \cdot \mathrm{s}^{-1}\end{array}$} & \multicolumn{10}{|c|}{ Period, s } \\
\hline & $<6$ & $3-8$ & $8-16$ & $10-12$ & $12-14$ & $14-16$ & $18-18$ & $18-22$ & $>22$ & Total \\
\hline$<5$ & & & & 2.21 & 8.85 & 9.76 & 8.68 & 22.85 & & 52.33 \\
\hline $5-10$ & & & & 0.71 & 14.18 & 9.88 & 5.89 & 3.87 & & 34.35 \\
\hline $10-15$ & & & & & 1.54 & 4.76 & 2.21 & 0.87 & & 9.33 \\
\hline $15-20$ & & & & & & 1.48 & 0.95 & 0.43 & & 2.85 \\
\hline $20-25$ & & . & & & & 9.32 & 0.28 & 6.08 & & 0.67 \\
\hline $25-38$ & & & & & & & 0.16 & 6.12 & & 0.28 \\
\hline $39-35$ & & & & & & & 0.16 & & & 0.16 \\
\hline $35-46$ & & & & & & & & 0.04 & & 6.64 \\
\hline $40-45$ & & & · & & & & & & & 0.60 \\
\hline $45-56$ & & & & & & & & & & 0.60 \\
\hline $50-55$ & & & & & & & & & & 0.00 \\
\hline $55-60$ & & & & & & & & & & 1. 09 \\
\hline $60-65$ & & & & & & & & & & 1. .09 \\
\hline$>65$ & & & & & & & & & & 0.00 \\
\hline Total & 0.60 & 0.00 & 0.80 & 2.92 & 24.58 & 25.93 & 18.36 & 28.28 & 0.60 & 160.60 \\
\hline
\end{tabular}

TABLE C.4. Bottom Sediment Characteristics Used in Transport Calculations
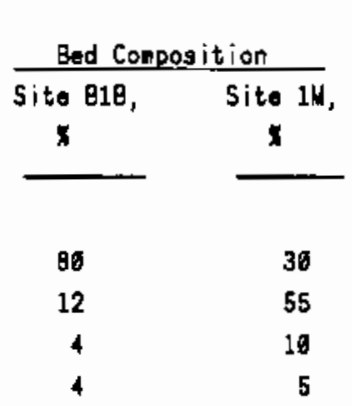

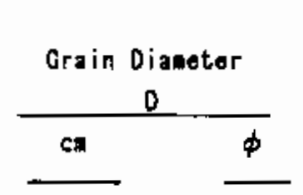

$\begin{array}{ll}0.0177 & 2.5 \\ 0.6088 & 3.5 \\ 6.6044 & 4.5 \\ 6.6022 & 5.5\end{array}$

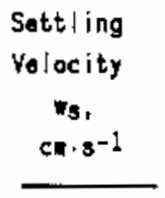

1.36
0.50
0.19
0.63

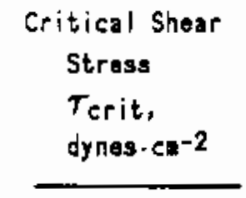

1.6

1.1

1.6

0.9

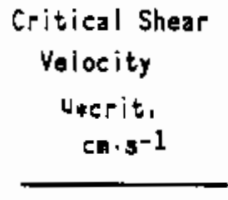

1.25

1.84

9.89

0.94

TABLEC.5. Summary of Parameters Varied in Transport Calculations

\section{Orbital Amplitude Period Bottom Roughness}

ubs, Td

ubHs, T
Fixed $z_{0}=0.5 \cdot 10^{-4}$

Fixed $z_{0}=0.0067$

Variable ZoN

Variable $\mathrm{z}_{\mathrm{ON}}+\mathrm{z}_{\mathrm{OS}}$
Resuspension Coefficient

$\gamma_{0}=0.002$

$\gamma_{0}=1.4 \cdot 10^{-4}$ 

APPENDIX D

CURRENT-METER DATA FILE FORMAT 
APPENDIX D

\section{CURRENT-METER DATA FILE FORMAT}

This appendix describes the contents of data disks prepared for submission to the National Oceanographic Data Center (NOOC). The disks contain data recorded by current meters moored in the Gulf of the Farallones as part of an oceanographic study conducted by the Pacific Northwest Laboratory (PNL) for the U.S. Army Corps of Engineers (USACE), San Francisco District. A complete description of the study and an analysis of the results is presented elsewhere in this report.

The current-meter moorings were maintained by Kinnetics Laboratories, Inc. (KLI), and resulted in 19 data files from four deployments from two locations, Sites $B 1 B$ and $1 M$. At Site B1B, data were collected at the top, middle, and bottom of the water column (11 files; no data were obtained from the near-bottom meter during the fourth deployment). At Site 1M, data were collected at the top and bottom ( 8 files). Temperature, cross-shelf, and alongshore components of current velocity were collected at all sites during a11 deployments.

The original 19 data files were received from $\mathrm{KLI}$ and subsequently edited at PNL. The final data files differ from the original data in five ways: 1) the header information has been standardized in all files, 2) the location (latitude and longitude) have been corrected in all files, 3) temperature data were despiked (outliers were replaced by averaging the adjacent four points) in all but two files (1385 records were changed in total), 4) missing velocity components were replaced by interpolation in one file (10 records were changed), and 5) the first data record was deleted in two files.

These data are publicly available through NODC:

\section{U.S. Department of Commerce}

National Oceanic and Atmospheric Administration National Oceanographic Data Center Records Section Washington, D.C. 20235 


\section{D.1 FORMAT}

\section{D.1.1 Disk Format}

The distribution disks are 3.5-in. double-sided, high-density floppy disks formatted for 1.44 Mb using IBM DOS 3.30. Data are contained in 19 American Standard Code for Information Interchange (ASCII) files on 9 disks. File names and contents are summarized in Table D.1.

\section{D.1.2 File Format}

File format conforms to NODC Format F015 (NODC 1984, Table D.2). The NODC file structure uses four types of 60-character records: 1) Text Record containing descriptive header information, 2) Master Record containing specific header information, and either 3) Detail Record 1 containing currentmeter data, or 4) Detail Record 2 containing current-meter data. All of the files contained on these distribution disks use the following structure:

1) the first record in the file is a Text Record, 2) the second record is a Master Record, and 3) remaining records are data records of type Detail Record 2. The number of Detail Records varies with the length of the data file and can be determined by subtracting two from the number of records listed in Table D.1. Record format for each record type is specified in Table D.2. Note that the current meters used did not have pressure or conductivity sensors; thus, no data appear in those columns. A listing of the first 30 records in file BTITON (Table D.3) provides an example of the file and record formats.

\section{D.2 REFERENCE}

NODC (National Oceanographic Data Center). 1984. National Oceanographic Data Center Users Guide Key to Oceanographic Records Documentation No. 14. U.S. Department of Commerce, National Oceanic and Atmospheric Administration, National Environmental Satellite, Data, and Information Service, Washington, D.C. 
IABLE D.1. Sumnary of Current-Meter Data Files in NODC Format

\begin{tabular}{|c|c|c|c|c|c|c|c|c|c|}
\hline \multirow{2}{*}{$\begin{array}{c}\begin{array}{c}\text { Disk } \\
\text { Number }\end{array} \\
\end{array}$} & \multirow{2}{*}{$\begin{array}{l}\text { File } \\
\text { Name }\end{array}$} & \multirow{2}{*}{$\begin{array}{l}\text { Station } \\
\text { Name } \\
\end{array}$} & \multirow{2}{*}{$\begin{array}{l}\text { Number } \\
\text { Rec }\end{array}$} & \multirow{2}{*}{$\begin{array}{l}\text { Water } \\
\text { Depth, } \\
\text { m }\end{array}$} & \multirow[t]{2}{*}{$\begin{array}{l}\text { Instr. } \\
\text { Depth, } \\
\text { m }\end{array}$} & \multicolumn{2}{|c|}{ Location } & \multirow{2}{*}{$\begin{array}{l}\text { Start } \\
\text { Date }\end{array}$} & \multirow{2}{*}{$\begin{array}{l}\text { Stop } \\
\text { Date }\end{array}$} \\
\hline & & & & & & Latitude & Longltude & & \\
\hline 1 & btiton. & B1BTA8 & 4008 & 86 & 21 & $37^{\circ} 28^{\prime} 06^{\prime \prime N}$ & $122^{\circ} 47^{\circ} 09^{\prime H}$ & $4 / 27 / 88$ & $6 / 7 / 88$ \\
\hline 1 & bt2ton. & B1886T & 9214 & 86 & 21 & $37^{\circ} 28^{\prime} 13^{\prime \prime} \mathrm{N}$ & $122^{\circ} 47^{\prime} 03^{\prime \prime W}$ & $6 / 9 / 88$ & $9 / 13 / 88$ \\
\hline 2 & bt3ton. & $\mathrm{B} 1889 \mathrm{~T}$ & 12197 & 86 & 21 & $37^{\circ} 28^{\prime} 15^{\prime \prime} \mathrm{N}$ & $122^{\circ} 46^{\prime} 43^{\prime \prime} \mathrm{H}$ & $9 / 15 / 88$ & $1 / 20 / 89$ \\
\hline 3 & bt 4 ton. & $\mathrm{B} 1891 \mathrm{~T}$ & 11815 & 86 & 21 & $37^{\circ} 28^{\prime} 13^{\prime \prime N}$ & $122^{\circ} 47^{\prime} 03^{\prime \prime W}$ & $1 / 30 / 89$ & $6 / 2 / 89$ \\
\hline 3 & bm1ton. & B1BMA8 & 4009 & 86 & 46 & $37^{\circ} 28^{\prime} 06^{\prime \prime} \mathrm{N}$ & $122^{\circ} 47^{\prime} 09^{\prime \prime} \mathrm{K}$ & $4 / 27 / 88$ & $6 / 7 / 88$ \\
\hline 1 & bm2ton. & $\mathrm{B} 1886 \mathrm{M}$ & 9205 & 86 & 46 & $37^{\circ} 28^{\prime} 13^{\prime \prime N}$ & $122^{\circ} 47^{\prime} 03^{\prime \prime W}$ & $6 / 9 / 88$ & $9 / 13 / 88$ \\
\hline 4 & bm3ton. & B1889M & 12197 & 86 & 46 & $37^{\circ} 28^{\prime} 15^{\prime \prime N}$ & $122^{\circ} 46^{\prime} 43^{\prime \prime W}$ & $9 / 15 / 88$ & $1 / 20 / 89$ \\
\hline 5 & bm4ton. & B1891M & 11816 & 86 & 46 & $37^{\circ} 28^{\prime} 13^{\prime \prime} \mathrm{N}$ & $122^{\circ} 47^{\prime} 03^{\prime \prime} \mathrm{W}$ & $1 / 30 / 89$ & $6 / 2 / 89$ \\
\hline 3 & bb1ton. & B1BBA8 & 4011 & 86 & 85 & $37^{\circ} 28^{\prime} 06^{\prime \prime} \mathrm{N}$ & $122^{\circ} 47^{\prime} 09^{\prime \prime W}$ & $4 / 27 / 88$ & $6 / 7 / 88$ \\
\hline 5 & bb2ton. & B1886B & 9215 & 86 & 85 & $37^{\circ} 28^{\prime} 13^{\prime \prime N}$ & $122^{\circ} 47^{\prime} 03^{\prime \prime} \mathrm{W}$ & $6 / 9 / 88$ & $9 / 13 / 88$ \\
\hline 6 & bb3ton. & $\mathrm{B} 1889 \mathrm{~B}$ & 12197 & 86 & 85 & $37^{\circ} 28^{\prime} 15^{\prime \prime} \mathrm{N}$ & $122^{\circ} 46^{\prime} 43^{\prime \prime W}$ & $9 / 15 / 88$ & $1 / 20 / 89$ \\
\hline 6 & mt1ton. & 1 MTA8 & 2953 & 42 & 21 & $37^{\circ} 38^{\prime} 50^{\prime \prime N}$ & $122^{\circ} 42^{\prime} 01^{\prime \prime W}$ & $5 / 8 / 88$ & $6 / 7 / 88$ \\
\hline 6 & mt2ton. & $1 M 886 \mathrm{~T}$ & 8051 & 42 & 21 & $37^{\circ} 38^{\prime} 43^{\prime \prime N}$ & $122^{\circ} 42^{\prime} 16^{\prime \prime} \mathrm{W}$ & $6 / 9 / 88$ & $9 / 1 / 88$ \\
\hline 7 & mt3ton. & $1 M 889 T$ & 12997 & 42 & 21 & $37^{\circ} 38^{\prime} 39^{\prime \prime} \mathrm{N}$ & $122^{\circ} 42^{\prime} 19^{\prime \prime W}$ & $9 / 3 / 88$ & $1 / 17 / 89$ \\
\hline 2 & mt $4 t 0 n$ & $1 M 891 \mathrm{~T}$ & 11252 & 42 & 21 & $37^{\circ} 38^{\prime} 43^{\prime \prime N}$ & $122^{\circ} 42^{\prime} 16^{\prime \prime W}$ & $1 / 30 / 89$ & $5 / 28 / 89$ \\
\hline 3 & mb1ton. & $1 M B A 8$ & 2509 & 42 & 40 & $37^{\circ} 38^{\prime} 50^{\prime \prime} \mathrm{N}$ & $122^{\circ} 42^{\prime} 01^{\prime \prime W}$ & $5 / 8 / 88$ & $6 / 3 / 88$ \\
\hline 4 & mb2ton. & $1 M 886 B$ & 8052 & 42 & 40 & $37^{\circ} 38^{\prime} 43^{\prime \prime} \mathrm{N}$ & $122^{\circ} 42^{\prime} 16^{\prime \prime} \mathrm{W}$ & $6 / 9 / 88$ & $9 / 1 / 88$ \\
\hline 8 & mb3ton. & $1 M 889 B$ & 13094 & 42 & 40 & $37^{\circ} 38^{\prime} 39^{\prime \prime} \mathrm{N}$ & $122^{\circ} 42^{\prime} 19^{\prime \prime W}$ & $9 / 2 / 88$ & $1 / 17 / 89$ \\
\hline 9 & mb4ton. & $1 M 891 B$ & 11811 & 42 & 40 & $37^{\circ} 38^{\prime} 43^{\prime \prime} \mathrm{N}$ & $122^{\circ} 42^{\prime} 16^{\mathrm{WW}}$ & $1 / 30 / 89$ & $6 / 2 / 89$ \\
\hline
\end{tabular}


TABLE 0.2. NODC File Format (after NODC 1984)

\section{Current Meter Data (Components) (F015)}

Parameter

\section{Text Record}

Meter Number

Text

Blank

Sequence Number

Master Record
Meter Number
Latitude
Longitude
Depth of Bottom
Depth of Current Meter
Meter Usage Sequence
Number
(NODC Use)
Axis Rotation

Location Name

Number of Detail

North-South Current Component (V)

Description

Column

Always ' 1 '

Five-Character Field Assigned by the originator - also included on record types 2 and 3

Thirty-eight character field for comments or pertinent information

$x x x x x x$ - used for sorting text information

10

11

16

54

55

A]ways ' 2 '

See Record ' 1 '

DDMMXX plus hemisphere ' $N$ ' or ' $S$ ' minutes in hundredths

DDDMMXX plus hemisphere ' $E$ ' or ' $W$ ' minutes in hundredths

$X X X X X$ (Whole Meters)

$X X X X X$ (Meters in Tenths)

$X X X$ - Used for indicating number of times meter has been used

Two characters for NODC internal use

$X X X$ - Degrees clockwise from true north of $V$ axis - values should be 0 when final processed to provide true direction information

Six-character name determined by originator

$X X X X X X$ - used to indicate number of detail records (3) to follow the master record (2)

Always ' 3 '
See Record ' 1 '
$Y Y M M D D$
$X X X X X X$ (Hours, Minutes in hundredths)
$X X X X X X$ - CM/SEC in hundredths with
positive directions (east and north)
indicated without plus sign - negative
directions (west and south) preceded
by minus sign - direction toward
$X X X X X X$ - CM/SEC in hundredths with
positive directions (east and north)
indicated without plus sign - negative
directions (west and south) preceded
by minus sign - direction toward

10

11

16

22

28 
TABLE 0.2. (contd)

Current Meter Data (Components) (F015)

Parameter

Temperature

Pressure

Conductivity

Blank

Sequence Number

\section{Detail Record 2 \\ Meter Number \\ Date (GMT) \\ Time (GMT) \\ East-West Current \\ Component (U)}

North-South Current Component (V)

Temperature

Pressure

Salinity

Sequence Number
Description

Column

$X X X X X$ with negative temperatures preceded by minus sign ( $\operatorname{deg} C$ to thousandths)

$X X X X X$ (decjbars in tenths)

$X X X X$ - MMHOS/CM in hundredths

$X X X X X X$ - Used for sorting data records originator

Always ' 4 '

See Record ' 1 '

YYMMDD

$X X X X X X$ (hours, minutes in hundredths)

$X X X X X X-C M / S E C$ in hundredths with

22

positive directions (east and

north) indicated without plus

sign - negative directions (west

and south) preceded by minus

sign - direction toward

$X X X X X X-C M / S E C$ in hundredths with positive directions (east and north) indicated without plus sign - negative directions (west and south) preceded by minus sign

$X X X X X$ with negative temperatures preceded by minus sign (deg $C$ thousandths)

$X X X X X$ (decibars in tenths)

45

$X X X X X$ parts per thousand in thousandths $\quad 50$

$X X X X X X$ - used for sorting data records $\quad 55$ 
TABLE D.3. NOOC File Sample (First 30 records from File BT1TON)

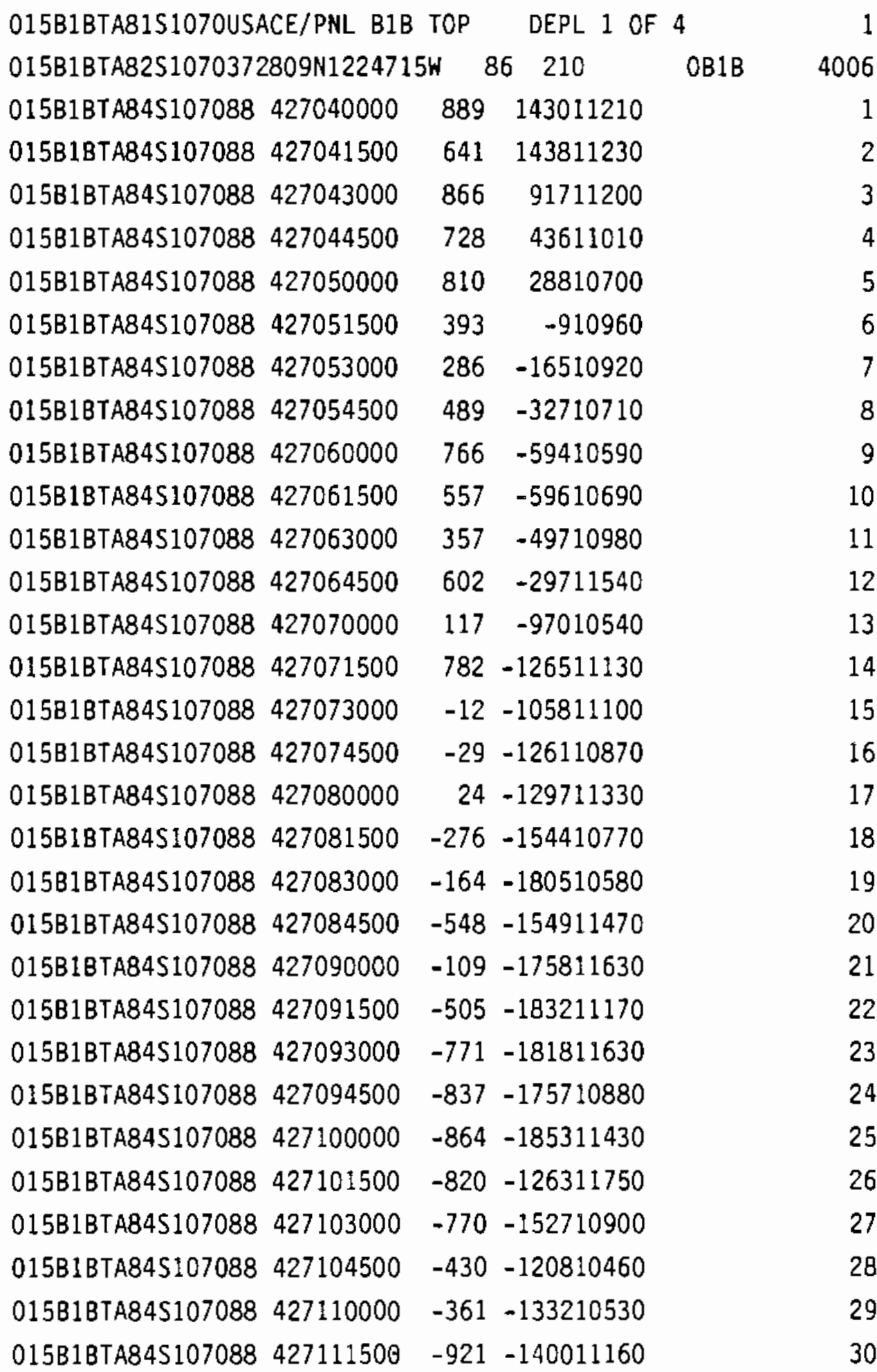


DISTRIBUTION

No. of

Copies

OFFSITE

2 DOE/Office of Scientific and Technical Information

R. Chisolm

U.S. Army Corps of Engineers

San Francisco District

211 Main St.

San Francisco, CA 94105

2 D. Coats

Marine Research Specialists

3639 E. Harber BIvd.

Ventura, CA 93001

P. Dragos

Battelle Ocean Sciences

397 Washington St.

Duxbury, MA 02332-0601

G. Gelfenbaum

U.S. Geological Survey

600 4th St. South

St. Petersburg, FL 33701

J. Harari

U.S. Army Corps of Engineers

San Francisco District

211 Main St.

San Francisco, CA 94105

C. Hunt

Battelle Ocean Sciences

397 Washington St.

Duxbury, MA 02332-0601

S. McDowel]

Battelle Ocean Sciences

397 Washington St.

Duxbury, MA 02332-0601
No. of

Copies

M. Noble

U.S. Geological Survey

345 Middlefield Rd.

Menlo Park, CA 94025

5 D. Roberts

U.S. Army Corps of Engineers

San Francisco District

211 Main St.

San Francisco, CA 941D5

R. Sternberg

Oceanography WB-10

University of Washington

Seattle, WA 98195

B. Walls

Battelle Ocean Sciences

397 Washington St.

Duxbury, MA 02332-0601

ONSITE

DOE Richland Operations Office

P. W. Kruger

31 Pacific Northwest Laboratory

D. W. Denbo (2)

J. P. Downing (2)

R. M. Ecker

J. W. Falco

W. R. Gorst

J. M. Hales

P. C. Hays

W. H. Pearson

W. T. Pennel1

C. R. Sherwood (10)

R. L. Skaggs

J. A. Trelstad (2)

J. Q. Word

Publishing Coordination

Technical Report Files (5) 
